\title{
Agronomic performance, nutritional yields and sensory properties of different tomato cultivars under organic low-input production
}

\author{
Doctoral Dissertation
}

Submitted to Obtain the Doctoral Degree in the Faculty of Agricultural Sciences Georg-August-University Göttingen, Germany

Presented by

Cut Erika

born in Desa Mesjid, Indonesia

Göttingen, June 2021 
D7

Referee: Prof. Dr. Elke Pawelzik

Co-referee: Prof. Dr. Heiko Becker

Date of examination: 26.06.2019 


\section{Acknowledgments}

I owe my deepest gratitude to Prof. Elke Pawelzik for her kind support and continuous encouragement in numerous aspects not only related to study but also to my daily life in Germany. I acknowledge Prof. Heiko Becker and Prof. Susanne Neugart as members of my thesis committee, for providing a lot of insightful comments. Many thanks go to Dr. Bernd Horneburg for his supervision and guidance during my study, especially during the field experiment. I also express the warmest gratitude to Dr. Detlef Ulrich (formerly at the Institute for Ecological Chemistry, Julius Kühn-Institute, Quedlinburg) for being a collaborative partner of this project. He was also conducting spectroscopy analysis for the samples, data processing as well as reviewing the manuscript for this related chapter. Thanks to Dr. Marcel Naumann for various helps and the feedbacks given for the thesis. I am thankful to Dr. Inga Smit (currently at Max Rubner-Institut, Detmold, Germany), who supported me especially in laboratory analysis during her stay in the Division Quality of Plant Products from the first phase of my PhD journey until her leave. Thanks for all various assistances and valuable input for the project.

I thank Barbara Wedemeyer-Kremer and Ulrike Hill at the Division of Plant breeding for their technical assistance in the greenhouses and field; Evelyn Krueger, Bettina Egger, Gunda Jansen, Reinhard Hilmer from technical assistance at the Division Quality of Plant Products; Susanne Koch (Division Plant Nutrition) and Kirsten Fladung (IAPN) for technical assistance. Special thanks go to Dr. Janna Groeneveld, Srun, Usman, Jonas, for spending time and doing hard effort for taking care of the plants and collecting numerous data in the field. I have to thank also to Laura and Natalia who helped a lot in laboratory.

I would like to thank all my family, especially my parents, brothers and sister for motivating me spiritually from there. My appreciation goes to my husband for his unfailing support during my study. Huge loves go to my kids: Azzam, Azima and Adzkia, who not only make my life more colorful but also keeping me always motivated and optimistic.

Importantly, I would like to gratitude the Directorate General for Higher Education (DIKTI), Indonesia for providing the scholarship through BLN-DIKTI 2014. Thanks to my colleagues: Adnan, Mirjam, Frederike, Bashar, Marcel, Daniela, Larissa, Lisanne, Jacob and Amina. Lastly, I would like to thank all friends in ATW student apartment and Indonesian community in Göttingen whom I could not name them one by one for sharing all the life lessons during my stay in Germany.

Göttingen, June 2021

Cut Erika 


\section{Table of Content}

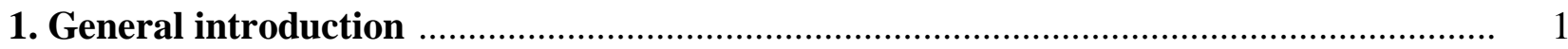

1.1 A brief description of the cultivated tomato........................................................................ 1

1.2 Composition and quality of tomato and its contribution to human nutrition .......................... 2

1.2.1 Nutrient contents ....................................................................................................... 2

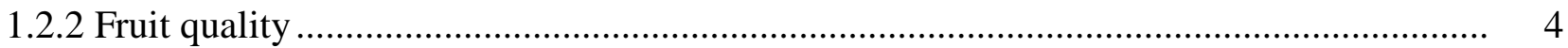

1.2.3 Contribution of tomato to nutrient intakes ……................................................................ 6

1.3 Farming systems for tomato production...........................................................................

1.4 Tomato breeding in organic low-input agriculture.............................................................. 9

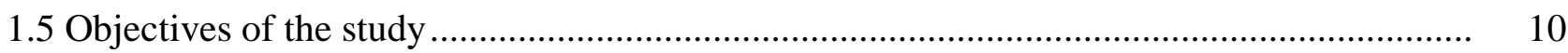

\section{Morphological, leaf nutrient, and fruit quality characteristics of diverse tomato} cultivars in organic low-input management .................................................................................. 12

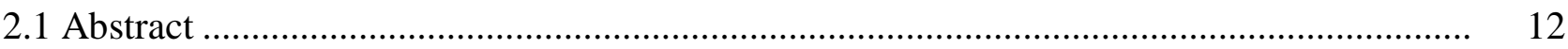

2.2 Introduction ................................................................................................................ 12

2.3 Materials and Methods .......................................................................................... 15

2.3.1 Site and climatic description ......................................................................................... $\quad 15$

2.3.2 Cultivars ............................................................................................................. 15

2.3.3 Experimental layout and crop cultivation ....................................................................... 16

2.3.4 Sample collection, mineral nutrient, and quality determination ....................................... 17

2.3.5 Statistical analysis .......................................................................................................... 19

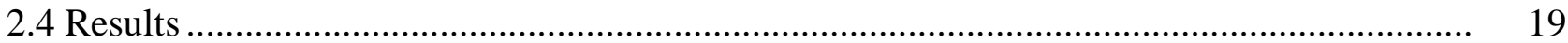

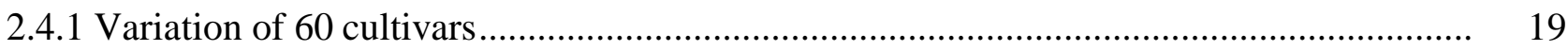

2.4.2 Morphological and fruit quality characteristics of the selected 20 cultivars....................... 22

2.4.3 Plant morphological characteristics.............................................................................. 24

2.4.4 Leaf macronutrient concentration .............................................................................. 25

2.4.5 Fruit minerals .......................................................................................................... 25

2.4.6 Fruit quality characteristics and fruit color ..................................................................... $\quad 26$

2.4.7 Correlations between fruit yield and fruit quality ............................................................ 27

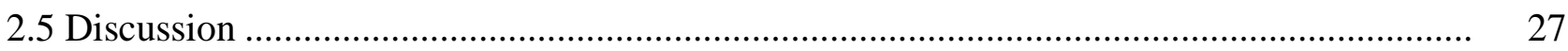

2.5.1 Genotypic variability of 60 tomato cultivars.................................................................. 28 
2.5.2 Morphological and fruit quality characterization of the selected 20 cultivars

2.5.3 Tradeoffs between yield and fruit quality ............................................................. 31

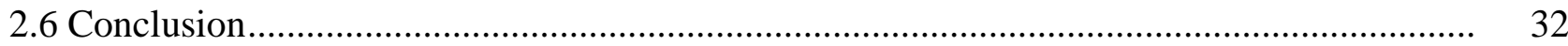

\section{Biodiversity in tomatoes: is it reflected in nutrient density and nutritional yields}

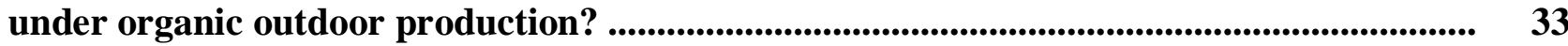

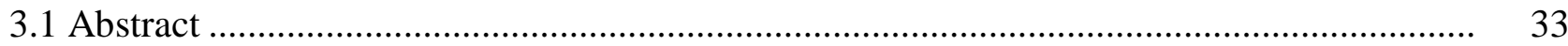

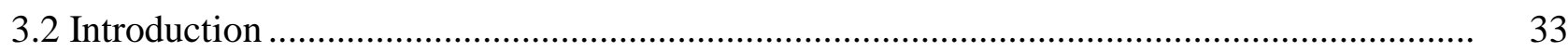

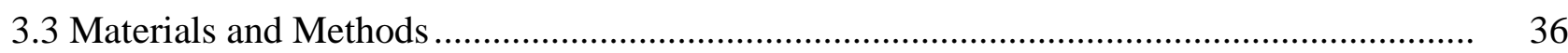

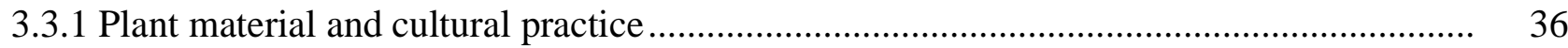

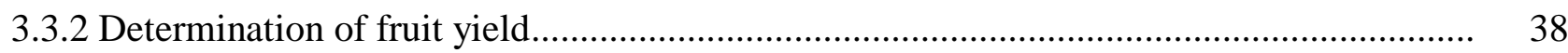

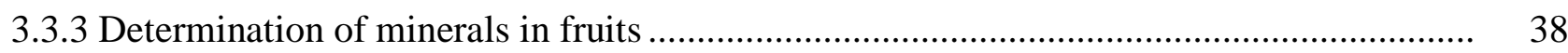

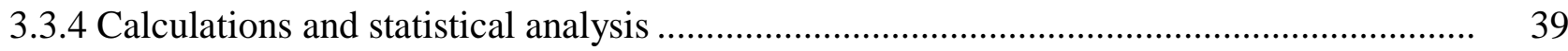

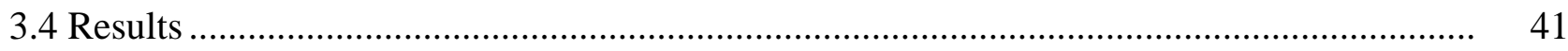

3.4.1 Fruit mineral concentrations and their contribution to the dietary reference .................... 41

3.4.2 Fruit yield and its variation in nutritional yield across years ....................................... 43

3.4.3 Heritabilities of traits and genotypic values of cultivars and their stability across years ... 45

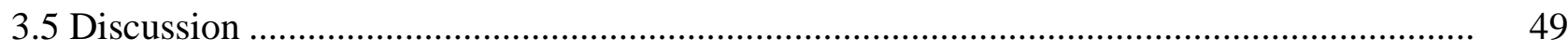

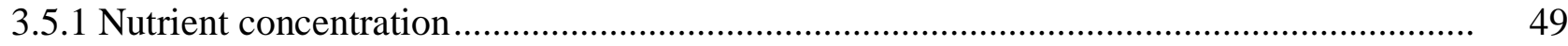

3.5.2 Contribution of tomatoes to the DRI of mineral nutrients .......................................... 52

3.5.3 Fruit yield and its variation in the nutritional yields of the cultivars ............................. 52

\section{Characterization of different tomato cultivars from organic low-input production} with respect to their sensory properties .......................................................................... 58

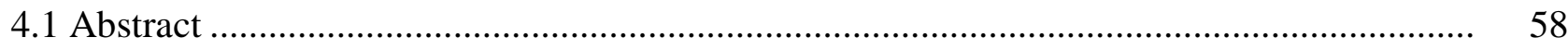

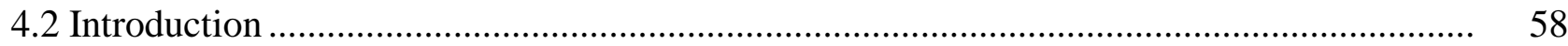

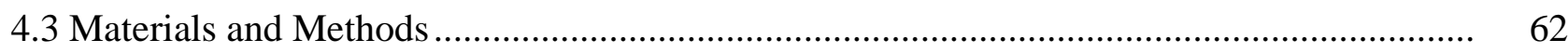

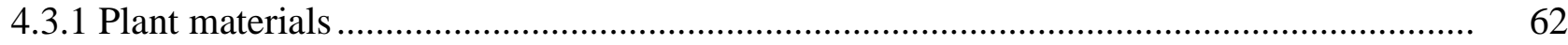

4.3.2 Preliminary treatment of the samples prior to analysis .............................................. 62

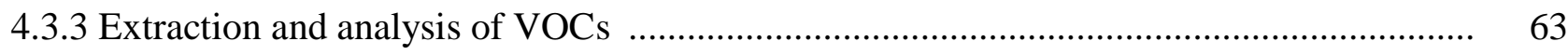

4.3.3.1 Headspace solid-phase micro-extraction (HS-SPME) procedure ................................ 63

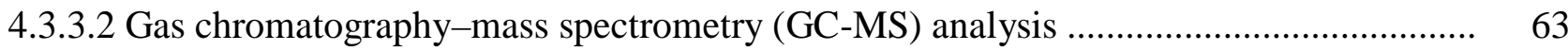




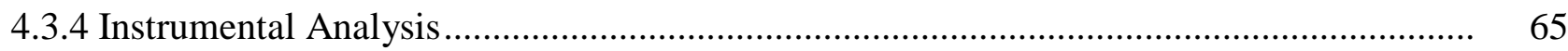

4.3.5 Descriptive sensory evaluation..................................................................................... 65

4.3.6 Statistical analysis ..................................................................................................... 67

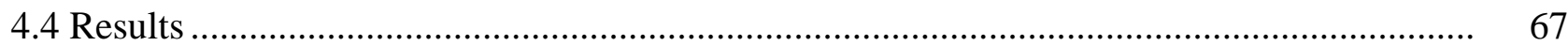

4.4.1 Identification and classification of the VOCs .................................................................... 67

4.4.2 Correlations between VOCs.......................................................................................... $\quad 74$

4.4.3 Variation within instrumental and sensory traits.............................................................. $\quad 74$

4.4.4 Correlations between instrumental and human sensory data ............................................. $\quad 75$

4.4.5 Principal component analysis (PCA) ............................................................................... 76

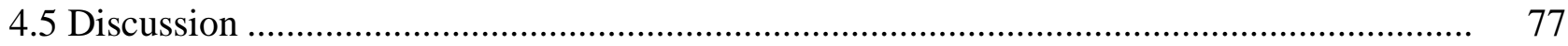

4.5.1 VOCs profile of the tomato cultivars ........................................................................

4.5.2 Influence of cultivar, harvest date and year on instrumental traits of the fruits................... $\quad 79$

4.5.3 Sensory characteristics among the cultivars......................................................................... 82

4.5.4 Correlation between the traits........................................................................................... 83

4.5.5 PCA of instrumental and sensory data .......................................................................... 85

4.6 Conclusion ................................................................................................................ 86

5. General discussion and conclusion .................................................................................. 8

5.1 Agronomic, morphological and fruit quality performance of the cultivars ........................... 88

5.2 Nutrient density and nutritional yield of the cultivars.............................................................. 89

5.3 VOCs and sensory profiles of the cultivars....................................................................... 91

5.4 Conclusion ................................................................................................................ 92

6. Summary …................................................................................................................................... 94

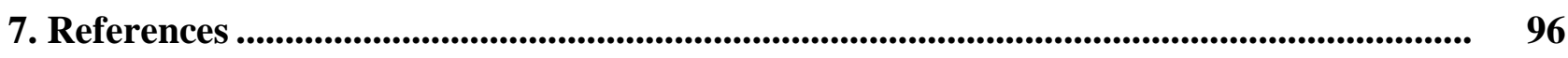

8. Supplementary Materials ........................................................................................................... 108 


\section{List of Tables}

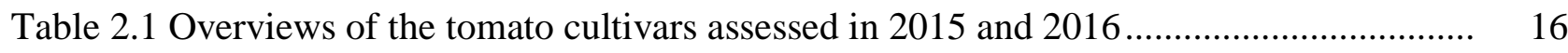

Table 2.2 Summary statistics for 28 traits of 60 tomato cultivars........................................... 20

Table 2.3 Plant morphological and agronomic characteristics of eight salad and twelve cocktail tomato cultivars grown in 2015 and 2016

Table 2.4 Fruit minerals, dry matter, total soluble solid, titratable acidity, total phenolic concentration, and color of 8 salad and 12 cocktail cultivars grown in 2015 and 2016 23

Table 3.1 Overview of the tested cultivars. 37

Table 3.2 Information about field location and cultural practices in 2015 and 2016................. 38

Table 3.3 Fruit concentrations of K, Ca, Mg, P, Fe and Zn (mg 100 g-1 FW) by cultivar.....

Table 3.4 Contribution of cultivars to the dietary reference intake (DRI) for K, Ca, Mg, P,

Fe and Zn

Table 3.5 Variation of fruit yield and nutritional yield (adults year $\mathrm{ha}^{-1}$ ) for K, Ca, Mg, P,

Fe and Zn by cultivar

Table 3.6 Genetic parameters [(heritability as broad sense heritability $\left(\mathrm{H}^{2}\right)$ and genotypic values (BLUPS) of fruit yield and micronutrient densities (Fe, Zn, Ca) created from a linear fully randomized model on a year basis.....

Table 3.7 Genetic parameters [(heritability as broad sense heritability $\left(\mathrm{H}^{2}\right)$ and genotypic values (BLUPS)] of macronutrient densities (K, Mg, P) created from a linear fully randomized model on a year basis

Table 3.8 Nutritional yield (adults ha $^{-1}$ year $^{-1}$ ) of macro and micronutrients from different vegetables (organically cultivated) in comparison with data of the present study.....

Table 4.1 List of VOCs identified across all samples and abbreviation used for the statistical analysis

Table 4.2 ANOVA of relative concentration of VOCs (\%) in the 20 tomato cultivars over two harvest dates and two years as well as comparison between its fruit type with the student t-test for significance

Table 4.3 Variation of relative concentration of VOCs (\%) in the 12 cocktail tomato cultivars over two harvests and two years with the Tukey's HSD test for significance. 72 Table 4.4 Variation of relative concentration of VOCs (\%) of 8 salad tomato cultivars over two harvests and two years with the Tukey's HSD test for significance. 


\section{List of Figures}

Fig. 2.1 (A) Leaf and stem biomass, fruit yield, and fruit weight and (B) fruit total soluble solid and titratable acidity of 60 tomato cultivars grown in 2015.

Fig. 2.2 Fruit phenotypes of 20 tomato cultivars consisting of eight salad and twelve cocktail cultivars selected in 2015 for further evaluation in 2016

Fig. 2.3 Relationship between fruit Mg with (A) leaf Mg, (B) fruit titratable acidity (TA), and (C) fruit total phenolic concentration (TPC) of salad $(n=8)$ and cocktail $(n=12)$ cultivars grown in 2015 and 2016

Fig. 2.4 Correlations among fruit quality traits of salad $(A, n=8)$ and cocktail $(B, n=12)$ tomato cultivars in 2015 and 2016

Fig. 4.1 Percentage of relative abundance of VOCs accumulated in five different functional groups in the 20 tomato cultivars across two harvests and two years, by group across all cultivars

Fig. 4.2 PC1 vs. PC2 scatter plot of the main sources of variability between cocktail and salad cultivars. 


\section{General introduction}

\subsection{A brief description of the cultivated tomato}

Tomatoes (Solanum lycopersicum L.) are the most consumed vegetable in the world and in economic terms they are the important vegetable in Germany. The major productions areas are in 2017 are China, India, Turkey and USA, contributing 67.6\% of worldwide tomato production. Tomato production in Germany in 2016 was 85.287 tons with an import quantity of 738.548 tons. Consumption per capita varies greatly between countries and regions, but a major trend seems to be that consumption of fresh and processed tomato is increasing (Slimestad and Verheul, 2009), e.g., consumption per capita in Germany gradually increased from 14.96 to $19.01 \mathrm{~kg} /$ year from 2006 to 2013 (FAOSTAT, 2019). The cultivated tomato belongs to the family Solanaceae, which covers also potato, chili pepper, eggplant and petunia (Slimestad and Verheul, 2009).

Originated from the Andean region and most likely imported to Europe during the first half of the $16^{\text {th }}$ century (Cortés-Olmos et al., 2015), today tomatoes are widespread globally and shows increasing production and consumption with population growth. They are grown on all temperate and tropical regions and are incredible for their morphological and ecological diversity (Bergougnoux, 2014). Like for other crops, domestication has remarkably increased tomato fruit size up to 500-fold in cultivated varieties compared to their wild ancestor (Causse et al., 2011). However, due to the domestication occurred in prehistoric times, the evolutionary pathway associated with fruit size transformation is unknown (Bai and Lindhout, 2007). Most likely, the explanation is that mutations associated with larger fruit were selected by early humans and, over time the accumulated "large-fruited" mutations contributed to the increasing fruit size in the present cultivars (Tanksley, 2004).

Tomato is characterized by a large diversity of fruit shapes, sizes, colors and flavors (Acquaah, 2012) while the plants are characterized with different growing habits, i.e. determinate (bush type) and indeterminate (single stem) and different fruiting habits, i.e. beefsteak (large in size but few in number), round (medium in both size and number) and cherry 
beefsteak (large in size but few in number), round (medium in both size and number) and cherry with small in size but numerous in number (Ho, 1996). Cherry tomatoes are characterized by small fruits with fruit weight less than $20 \mathrm{~g}$ for standard cherry and $20-50 \mathrm{~g}$ for cocktail (Causse et al., 2011). Cocktail tomatoes usually consumed raw, they have sensory attributes such as sweetness, juiciness and a fruitlike appearance (Zörb et al., 2020), while salad tomatoes are mostly used as an ingredient for cooking. Cherry tomatoes were reported to have a different textural profile compared to larger fruit varieties, being less mealy and firm, despite these traits are probably not perceived due to the small size of the fruit (Casals et al., 2018). Modern cultivated tomatoes exist in a wide range of shapes and fruit sizes, from the small cherry tomato $(<20 \mathrm{~g})$ to very large beef tomatoes with fruit weight up to $500 \mathrm{~g}$ (Bai and Lindhout, 2007; Bergougnoux, 2014).

Yield of tomato which takes into account both fruit number and fruit weight was apparently not an isolated trait, as it is highly correlated with factors influencing plant growth such as temperature (Bergougnoux, 2014). Reganold and Wachter (2016) reported that organic systems produce lower yields compared to conventional agriculture. A recent study from Japan focusing on organic tomato production reported that the yields of tomato varied from 12.9 to 59.6 ton/ha (Adhikari et al., 2018). According to utilization, cultivated tomato can be divided into two commercial market groups, fresh or processed tomato, which also form the basis of breeding programs for the crop (Acquaah, 2012). The universal target of tomato breeding for both fresh market and processing purposes has been to increase fruit yield per unit area, though this increase may be achieved by selecting essential desirable characteristics including earliness in maturity and improved fruit sugar contents (Foolad, 2007).

\subsection{Composition and quality of tomato and its contribution to human nutrition}

\subsubsection{Nutrient contents}

Tomato is considered the most valuable fruit crop in the world (Tieman et al., 2017) and is an important component of a healthy diet, providing ready sources of essential nutrients such as vitamins $\mathrm{A}, \mathrm{C}, \mathrm{E}$, and $\mathrm{K}$, minerals including $\mathrm{K}$ and $\mathrm{Fe}$, and lycopene as an antioxidant 
(Dufera, 2013; Ilić et al., 2014; Wang and Seymour, 2017). Eating one medium fresh tomato fruit (135 g) per day provides for example $47 \%$ daily recommended dietary allowance (RDA) of vitamin $\mathrm{C}$, it contributes significantly to the dietary intake of vitamins $\mathrm{C}$, minerals and other essential nutrients (Foolad, 2007). Tomato is usually freshly served as salad with other leafy vegetables, consumed as stewed, fried or as ingredient in pizza, pasta, hamburger and other foods (Sainju et al., 2003).

Micronutrients density, defined as the amount of a nutrient per unit weight in a food, is important to achieve an optimal micronutrient status in the human diet (Miller and Welch, 2013). As a result of increasing world population, many global food systems are not providing enough micronutrients to insure adequate micronutrient intakes for all people (Welch, 2002). It is estimated that 2 billion people of world's population were experienced with micronutrient deficiencies (Beal et al., 2017). Iron (Fe) and zinc ( $\mathrm{Zn})$ were among the most common widespread micronutrient deficiencies worldwide (Bailey et al., 2015), with the highest estimated prevalence of inadequate intake (Beal et al., 2017). Deficiencies of iron, with or without anemia, commonly caused by poor dietary iron intake, can lead to physical impairment and decrease intellectual performance (Aspuru et al., 2011). Similarly, thought to be one of the most prevalent micronutrient deficiencies worldwide (Wieringa et al., 2015), zinc deficiency can affect the immune response and the endocrine system (Sauer et al., 2016).

Potassium is the most abundant element among minerals in fresh tomatoes (Labate et al., 2018; Sager, 2017). Fresh tomato has also a very low content of sodium, despite some processed tomato products contain higher levels (Willcox et al., 2003). Mineral content in tomato is significantly affected by cultivars (Ilic et al., 2013). The average tomato fruit weight presented significant negative correlations with $\mathrm{Ca}, \mathrm{Mg}, \mathrm{Fe}$ and $\mathrm{P}$, and a positive correlation of the same fruit traits with Na (Chávez-Servia et al., 2018). Davis (2009) revealed inverse relationships between crop yield and mineral concentration consistent with the so-called "dilution effect" that commonly occurs when selective breeding successfully increases crop yields. However, the 
management to increase the amounts of beneficial phytochemicals can lead to decreased marketable yield (Bumgarner et al., 2012).

\subsubsection{Fruit quality}

From the consumer's point of view, quality is defines i.e., by fruit size or fresh mass, color, flavor and health value (Bertin and Génard, 2018). Among these, flavor quality is of great interest to both the fresh market and the processing tomato industry (Foolad, 2007). However, consumer dissatisfaction with the lack of flavor in commercial products, especially in tomatoes, has been increased in last decades (Bruhn et al., 1991; Fernqvist and Hunter, 2012). The lack of breeder focus on flavor improvement may be due to the genetic complexity of the flavor and the growers, as the customer of the breeder, do not care about or asked about the flavor quality (Klee and Tieman, 2018). Flavor is the sum of inputs from multiple senses that inform the brain about what we eat, which mainly includes overall perception, not only taste and aroma (smell) but also texture and appearance (Klee and Tieman, 2018; Vilgis, 2013). However, in this study we focus on taste-and aroma-associated compounds present in the tomato fruit. The flavor of fresh commercial grown tomatoes is usually accepted as poor by consumers (Vogel et al., 2010), likely due to low concentration of sugars, organic acids, and reduced levels of the VOCs, particularly of $\beta$-ionone, (E)-2-hexenal, 6-methyl-5-hepten-2-one, and phenylacetaldehyde (Wang and Seymour, 2017). For taste, at most important are sugars, organic acids and, in some fruits, bitter compounds (Klee and Tieman, 2018). Total soluble solids (TSS), consisting of fructose and glucose, with fructose as main sugar (Selli et al., 2014), is a good measurement of sugar content (Georgelis et al., 2004). Citrate, malate, ascorbate and glutamate are organic acids primarily contribute to sourness in tomato fruits (Vogel et al., 2010).

While sugar and organic acids are important for a good taste, the unique aroma of tomato is mainly determined by the VOCs (Baldwin et al., 2000). From more than 400 VOCs has been identified, only 16-17 are of primary importance for the aroma notes (Yilmaz, 2001). These important VOCs are derived from a diverse set of precursors such as amino acids, fatty acids, 
and carotenoids (Klee and Giovannoni, 2011). For example, reduction of the major apocarotenoids (e.g., $\beta$-cyclocitral and $\beta$-ionone) had a negative impact on aroma and sweetness acceptability of tomato fruits (Vogel et al., 2010). A major challenge is to determine not only which VOCs contribute to flavor acceptance, but also, and more importantly, which ones contribute to consumer liking. The most common way to determine which chemicals have an impact on liking is empirically, by providing consumers with a sample set with as much chemically diversity as possible, quantifying potential flavor-associated compounds (e.g., sugars, acids and VOCs) with gas chromatography and high-performance liquid chromatography, and statistically correlating each compound with sensory scores (Klee and Tieman, 2018). In fruits, the VOCs are mainly comprised of different classes of chemicals, including esters, alcohols, aldehydes, ketones, lactones, terpenoides and sulfur compounds (El Hadi et al., 2013). Their production in tomato fruits are obviously influenced by genetic, and pre-and postharvest external factors such as growth conditions and cultivation practices (Libin Wang et al., 2016).

Tomato has been ranked as the leading phenol-providing vegetable in the human diet (Vinson et al., 1998). The presence of various antioxidants related to the observed health effects of tomato (George et al., 2004) includes quercetin and chlorogenic acid as the most abundant phenolic compounds (Martínez-Valverde et al., 2002). Total phenolic content (TPC), showing a strong connection with antioxidant activity, was observed at significant higher level in cocktail cultivars, and in greenhouse tomatoes, where all of the cherry cultivars had higher TPC than large fruit tomato cultivars (Bhandari and Lee, 2016). TPC is an indicator of the antioxidants content in tomato fruit. Skin and seed are fractions contributing the most to TPC and, therefore, is important contributor to the overall antioxidant activity of tomatoes (Toor and Savage, 2005). The gain in TPC in cocktail cultivars might be attributed to a higher content of total phenols and flavonoid (Bhandari and Lee, 2016), e.g., flavonol and quercetin are primarily more concentrated in the skin than in the fruit flesh, in which; cocktail tomatoes have a higher skin - volume ratio than that of large fruit cultivars (Dorais, 2007). The accumulation of TPC in tomatoes was 
cultivar-dependent (Bhandari and Lee, 2016), and therefore cultivar was reported as the main factor contributing to the TPC content in tomatoes when grown under similar environmental conditions (Stewart et al., 2000).

Sensory properties are important to evaluate the quality of vegetable products and are also determinant factors in purchasing decision of vegetables (Sinesio et al., 2010). Improving the sensory quality of tomato is a complex goal for breeders (Folta and Klee, 2016). Besides affecting fruit size and shape, domestication and breeding processes have resulted in a wide diversity of tomato fruit color (Causse et al., 2011). Fruit color is an important sensory trait of interest to fresh market (Foolad, 2007). The red color of tomato is determined by the color of the skin and flesh; while the skin color varies from yellow to colorless, the flesh color varies from green to red (Bai and Lindhout, 2007). Color is the most important external characteristic to assess ripeness and postharvest behavior of tomato (López Camelo and Gómez, 2004). During ripening, there is a remarkable increase in lycopene concentration in the tomato fruit up to 500fold (Bai and Lindhout, 2007). Yellow-colored tomatoes contain higher vitamin A content than red-colored fruits, but the red-colored ones contain lycopene, an antioxidant that may help protect against carcinogenic substances (Naika et al., 2005).

\subsubsection{Contribution of tomato to nutrient intakes}

Introduced by the Food and Nutrition Board of the Institute of Medicine (IOM) in 1994, Dietary Reference Intake values (DRIs) have been used in recommending quantitative estimates of nutrient intakes for the US and Canadian populations (Institute of Medicine, 2006). These values provide guidance to develop the nutrition policy in the US and Canada and are used to evaluate the nutrient status of the population (Chung et al., 2010).

Besides WHO/FAO (World Health Organization/Food and Agriculture Organization) and the EC (European Commission), the majority of European countries have also set their own reference values for different nutrients, for example, the nutrition societies of the so-called DACH consisting of Germany, Austria and Switzerland (Doets et al., 2008; Ströhle et al., 2019). 
The DRI accommodated four nutrient-based reference values including EAR (estimated average requirement), RDA (recommended dietary allowance), AI (adequate intake), and UL (tolerable upper intake level) (Murphy and Poos, 2002). Each estimated average requirement of DRI refers to daily nutrient intake for adults which reflects maintenance needs only (Atkinson and Koletzko, 2007).

The recommended daily intakes of micronutrients vary depending on the compound, e.g. the average recommended daily intake for the most commonly deficient micronutrients are for iron $13 \mathrm{mg}$ /day and $9.5 \mathrm{mg}$ /day for zinc (Institute of Medicine, 2006). However, the values would not necessarily sufficient for people who either suffers from malnutrition or those in certain disease status demanding higher nutrient (Institute of Medicine, 2006). To date, DRI values of the US and Canada exists for most minerals and vitamins. Due to lack of adequate data, reference values for polyphenols are currently not available yet, regardless of the importance of some selected plant-based polyphenols as essential dietary components (Williamson and Holst, 2008).

\subsection{Farming systems for tomato production}

Despite organic agriculture has been growing in many part of world during the past two decades (de Ponti et al., 2012), only a small share of $1.2 \%$ of the total world agricultural land is used for organic production (Willer and Lernoud, 2019). In 2017, Germany was one of the second world largest markets for organic products after the USA with retail sales of 10 billion euros and per capita consumption of 122 Euros. Being one of the largest world's markets, Germany is also one of the biggest importers of organic products (Willer and Lernoud, 2019). Rising interest in organic agriculture around the world is primarily due to the assumption that consumption of organically produced food is advantageous to public health (Johansson et al., 2014). To date, very limited data about organically produced tomatoes in the world (e.g., cultivation area, production quantity) is available. 
With a lower productivity of yield, organic system is claimed to be more sustainable, and deliver equally or more nutritious foods that contain less or no pesticide residues, compared with conventional practices (Reganold and Wachter, 2016). A low-input farming system is generally associated to organic production systems but it is not necessarily organic in practice (Fess et al., 2011). Agronomic practice used in low-input systems tend to less chemical fertilizer and/or crop protection inputs as well as apply more diverse crop rotation systems (Lehesranta et al., 2007).

While organic farming relies at most on self-sustainability (Schrama et al., 2018), conventionally managed systems are characterized by high-input practices with strong dependence on off-farm resources and high capital investment (Fess and Benedito, 2018). Conventional system may provide high yields (Fess et al., 2011) while organic low-input systems generally are less productive (Lehesranta et al., 2007). However, the yield gap between organic and conventional agriculture decreased over time (Schrama et al., 2018). Yield of organically grown tomatoes represented $36.5 \%$ of the yield in the conventional system (Bettiol et al., 2004), nevertheless, tomatoes from organic system were economically viable in comparison with the conventional system because they need less external inputs and have higher selling price (Santos Neto et al., 2017).

Comparing organic and conventional tomato production systems, Bettiol et al. (2004) reported lower incidence of early blight (caused by $A$. solani) but higher severity of tomato leaf spot (caused by $X$. vesicatoria) in the organic production system. While the global population will continue to grow, at the same time, food production was experiencing greater competition for land, water, and energy which leads to increasing environmental impact (Godfray et al., 2010). Providing nutrients for human consumption with efficient use of land is an important goal of sustainable agriculture (DeFries et al., 2016).

Continuing concerns about global food security, food quality particularly for increased nutrient content need to be improved with reduced inputs (Tester and Langridge, 2010). While the biodiversity on and around agricultural land may be higher, organic agriculture may require 
more land than conventional systems to produce the same yield (Schrama et al., 2018). Nutritional yield (NY) specifically defined as the number of adults able to obtain their full dietary requirements of each nutrient for one year from one hectare of land, has been proposed as an indicator to evaluate the production of healthy and highly nutritious food with efficient use of land (DeFries et al., 2015). The NY was considered a powerful metric in depicting the actual nutritional value of crop production (Graham et al., 2018).

\subsection{Tomato breeding in organic low-input agriculture}

Tomato is a well-studied crop specie in terms of genetics, genomics, and breeding (Foolad, 2007). Besides modification of the fruit size, appearance, firmness and shelf-life that have been intensively achieved by breeding, tomato flavor is recently become a major target for breeders (Causse et al., 2011). To date, only few varieties were particularly bred for organic low-input systems, whereas more than $95 \%$ of organic production in developed countries relied on crop varieties that were bred for the conventional high-input system (Lammerts van Bueren et al., 2011). Nutrient contents and taste-associated components (TSS and TA) - are important to consumer, thus these traits are becoming important breeding targets for developing new tomato cultivars (Kimbara et al., 2018).

High yielding varieties were normally bred for high-input farming system, which mostly do not exhibit well under low-input conditions (Fess et al., 2011). With no exception of tomato as the most popular varieties among organic growers, breeding in open pollinated vegetables varieties for organic production systems has been limited since most seed companies were unwilling to invest in such varieties because their seeds can be easily saved (Boyhan et al., 2014). Organic agriculture was increased in order to meet the demand from a growing number of consumers who are willing to pay premium price for food produced under environmentally friendly conditions (Didier and Lucie, 2008) and also due to growing concerns about the impact of agriculture on the environment (Fess and Benedito, 2018). Therefore, it is necessary to develop cultivars adapted to low-input farming systems (Dawson et al., 2008) not only targeting 
for high crop yield but also improved nutritional and sensory quality. However, the final quality of tomato depends not only on genotype or bred seeds but it is the result of interactions of genotype, environmental factors, agricultural practices, after-harvest processing and storage conditions (Ghorbani et al., 2012).

\subsection{Objectives of the study}

Developments in breeding and cultivation systems can lead to significant changes in plant growth, yield, and overall fruit quality. To date, not much is known about the performance of cocktail and salad tomatoes under organic low-input management, especially with respect to plant growth performance, fruit yield and quality formation. Therefore, in view of the above concern, the following new aspects are presented in this thesis:

1. Morphological, leaf nutrient, and fruit quality characteristics of diverse tomato cultivars in organic low-input management are investigated. Experiments were performed on 60 and a subset of 20 tomato cultivars differing in their fruit type, color, year of cultivar release and suitability to different growing environments in 2015 and 2016. Thus, the main objectives of this work are:

1a). to characterize the plant morphology, leaf nutrients, and fruit quality of diverse tomato cultivars in organic low-input production

1b). to identify suitable cultivars with superior fruit yield and quality traits for production under low-input management and as resources for future breeding programs

2. It is a challenge to meet demands for food crops to feed growing population and to produce nutrient-dense cultivars of high quality at the same time; the adoption of agricultural production systems must have the potential to contribute to environmental sustainability. Therefore, the biodiversity in tomatoes was investigated with a focus on nutrient density and nutritional yields under organic outdoor production, with the following objectives: 
2a). to estimate the production potential and contribution of the cultivars differing in their fruit type to meet human dietary needs for mineral nutrients

2b). to assess the NY of the cultivars grown in a 2-year field experiment for selected macro- and micronutrients

2c). to evaluate the heritability of traits and the genotypic value and stability of the cultivars

3. An important prerequisite to improve overall acceptability of fresh tomato is an understanding of VOCs that significant contributes to the flavor. Hence, characterization of different tomato cultivars from organic low-input production with respect to their sensory properties is performed. The goals of this study were:

3a). to characterize different cocktail and salad tomato cultivars with respect to their sensory properties with the focus on instrumentally determined traits and on human-sensory perception

3b). to investigate possible relationships among VOCs, taste-related traits (TSS and TA) and sensory attributes of these cultivars 


\section{Morphological, leaf nutrient, and fruit quality characteristics of diverse tomato cultivars in organic low-input management}

Submitted: Journal Scientia Horticulturae (under review)

By: Leangsrun Chea, Cut Erika, Marcel Naumann, Inga Smit, Bernd Horneburg, and Elke Pawelzik

\subsection{Abstract}

Increasing fruit yield and fruit quality of tomato under organic low-input conditions remains a challenge for producers and breeders. We assessed variations of tomato cultivars in plant morphology and fruit quality characteristics in order to reveal the traits associated with improved yield and fruit quality and to identify tomato cultivars suitable for production and use as resources for breeding programs. Sixty diverse tomato cultivars were screened in 2015 and a subset of 20 cultivars was selected for further evaluation in 2016. The results showed a high variability among cultivars in all the 28 traits that were observed. Comparisons between salad and cocktail cultivars revealed that salad cultivars had lower plant height, leaf number, fruit number, fruit minerals $(\mathrm{P}, \mathrm{S}, \mathrm{Mg}$, and $\mathrm{K})$, and fruit quality characteristics (dry matter, total soluble solids, and total phenolic concentration) by $10-70 \%$, but they displayed $10-60 \%$ higher fruit yield, fruit weight, and leaf mineral concentration $(\mathrm{S}, \mathrm{Mg}$, and $\mathrm{Ca}$ ). Considering genotypic differences in each group of salad and cocktail cultivars, we found a trade-off between fruit yield and fruit quality, which implied a challenge for the improvement of yield and quality at the same time. The importance of $\mathrm{Mg}$ is highlighted because of its contribution to fruit mineral concentration and fruit quality. Superior cultivars with one, or a combination of, traits associated with growth, fruit yield, and fruit quality are also identified. Salad tomato cultivars with superior yield and harvest index were mainly derived from breeding for intensive indoor production. Cocktail cultivars with superior yield were mainly derived from organic and outdoor breeding programs. This information is valuable for producers to select cultivars suitable for their production targets and for future breeding programs aimed at improving fruit yield and quality.

Keywords: cultivar, fruit yield, fruit quality, magnesium, organic low-input management, tomato

\subsection{Introduction}

Tomato production and consumption have grown rapidly worldwide over the last 25 years (FAOSTAT, 2020). The tomato fruit is a valuable source of minerals and vitamins necessary for human dietary intake (Aldrich et al., 2010). At the same time, the demand for organically grown tomato has also increased (Rosa et al., 2019), driven by consumer perception that organic food is more sustainable and is of better quality than food derived from conventional farming (Stolz et al., 2011). However, organic tomato production presents a unique set of challenges, among which cultivar choice is important because it is one of the main determinants of fruit yield and quality (Aldrich et al., 2010). Tomato cultivars suitable for organic production 
require an adaptation strategy of being more efficient in nutrient uptake and utilization under limited nutrient availability in the soils (Horneburg and Myers, 2012).

The diversity of cultivated tomato has increased as a result of domestication and breeding (Schouten et al., 2019). Consequently, fruit weight varies strongly among cultivars, ranging from a few grams to one kilogram per fruit (Tanksley, 2004). Plant morphological characteristics and fruit quality of these cultivars also differ because cultivars bred for high yield often have poor flavor and nutritional quality (Scott et al., 2013). Tomato flavor is derived mainly from sugars, acids, and aromatic volatiles (Kanski et al., 2020). Small fruited tomatoes may have better quality attributes, but a lower yield than large-fruited tomatoes (DeVerma and Paterson, 1991). There is no universal classification of tomato as regards fruit weight; however, Scott et al. (2013) referred to tomatoes with high sugar concentration and weighing less than $50 \mathrm{~g}$ as cocktail tomatoes. Based on this differentiation and the fruit weights recorded in the present study, we classified tomato cultivars with a fruit weight exceeding $52 \mathrm{~g}$ as salad tomato. Costa and Heuvelink (2018) considered tomato fruits weighing more than $180 \mathrm{~g}$ as beefsteak tomato. The consumers' preference for cocktail tomato has increased in the last decade. For example, the production of cocktail tomatoes rapidly increased from $7 \%$ in 2012 to $30 \%$ in 2019 of the total tomato production in the Netherlands. In Belgium, cocktail tomato consumption was at $40 \%$ compared to the total number of purchased tomatoes per household (Behr, 2018). The evaluation of salad and cocktail cultivars in organic low-input management is important to select superior cultivars from each fruit type for production and for future breeding programs.

The main focus of tomato production, especially in Germany and the Netherlands, is on the fresh market, with farmers using indeterminate cultivars that continuously produce fruits for an extended period of time (van Heusden and Lindhout, 2018). This requires relatively high nutrient availability in the soil to sustain growth and yield. Recently, there has been increasing consumer demand for high quality fruits in terms of visual appearance and flavor (Rocha et al., 2013; van Heusden and Lindhout, 2018). Calcium, magnesium, potassium, and phosphorus are 
the major minerals that make up about $8 \%$ of the dry matter in tomato fruits (Davies and Hobson, 1981). The concentration of these fruit minerals influences fruit color, sweetness, and sourness (Dorais et al., 2001). Sweetness and sourness are the main determinants of tomato fruit quality (Causse et al., 2010; Dorais et al., 2001), which make the fruit mineral concentration a key factor for consumer acceptance. Therefore, the ability of tomato cultivars to uptake and allocate these nutrients efficiently to leaves and fruits is essential. Till date, the effect of tomato cultivars on fruit mineral concentration, especially their relationship with fruit yield and leaf mineral nutrients, has not been extensively studied.

In Germany, commercial tomato production covered an area of 398 hectares in 2018 (FAOSTAT, 2020); about 17\% of this area was used for organic cultivation (Federal Statistical Office, 2020). The high demand for organic tomato relies heavily on imports from other countries (FAO, 2001; FiBL, 2012). Therefore, it is necessary to identify superior cultivars suitable for organic low-input production and for future breeding and selection programs to genetically improve tomato fruit yield and quality. In the present study, we assessed 60 tomato cultivars released between 1880 and 2015 with a large range of fruit weight in 2015, and a subset of 20 cultivars in 2016 under organic low in-input conditions. These cultivars were used in the past, or are still grown, in present tomato production systems. Two very small fruited cultivars"Rote Murmel" and "Golden Currant" (Table 2.1) — are usually grown as currant tomatoes, with multiple shoots; they were included in the study because of their relevance in amateur outdoor production. The objectives were i) to characterize the plant morphology, leaf nutrients, and fruit quality of diverse tomato cultivars in organic low-input production, and ii) to identify suitable cultivars with superior fruit yield and quality traits for production under low-input management and as resources for future breeding programs. 


\subsection{Materials and Methods}

\subsubsection{Site and climatic description}

To assess the tomato cultivars, they were grown under low-input conditions in a temperate climate in accordance with certified organic standards (European Council, 2008). Low-input was defined as a condition with no fertilizer applications and with moderate irrigation. The experiments were carried out at Reinshof Experimental Station, University of Goettingen, at 152 meters above sea level on an organic field of Fluventic Eutrochrept soil (Rauber et al., 2001) from May to October in 2015 and 2016. Temperature, relative humidity, and soil properties during the experiments were previously described in Erika et al. (2020) Additionally, soil nitrogen concentrations during the growing period are shown in Table S1.

\subsubsection{Cultivars}

In 2015, we used 60 indeterminate tomato cultivars (Table 2.1; additional information in Table S2). They were chosen in close cooperation with extension services, research stations, breeders, seed companies, and the Genebank of the Leibniz Institute of Plant Genetics and Crop Plant Research (IPK) Gatersleben (www.ipk-gatersleben.de/en/genebank/). The cultivars covered the entire range from old cultivars released in the 1880 s to the most recently developed cultivars. For the traditional cultivars "Goldene Königin", "Haubners Vollendung", and "Rheinlands Ruhm" limited knowledge could be gathered from old books and personal communication with Arche Noah, Austria (www.arche-noah.at) and the Genebank Gatersleben. These cultivars may have been released earlier than stated in Table 2.1. The year of release of "Golden Currant", "Rote Murmel", "Sliwowidnij", "Zuckertraube", "Yellow Submarine", "Black Cherry", and "Black Plum" is not known with certainty because - to the best of our knowledge - they were not derived from formal breeding programs and may have existed long before the year given in Table 2.1. In the case of "Goldita", an inbred on-farm selection derived from the original hybrid cultivar was used. "Aroma" is an advanced breeding line from organic 
breeder S. Wedemeyer (Kultursaat e.V., Germany). A subset of 20 potential cultivars was selected for further evaluation in 2016.

\subsubsection{Experimental layout and crop cultivation}

In 2015, the 60 cultivars were assessed in a randomized complete block design with eight blocks and one plant per plot. Tomato seeds were sown in multi-pot trays QP 96 (Hermann Meyer, Germany) filled with the substrate "Anzuchtsubstrat Organisch" (Kleeschulte, Germany). Each seedling was potted (pot dimension $11 \times 11 \times 11 \mathrm{~cm}$ ) 20 days later in the substrate "Fruhstorfer Bio-Aussaat- und Kräutererde" (Hawita, Germany) and maintained in the greenhouse with a temperature of $20^{\circ} \mathrm{C}$ during the day and $18{ }^{\circ} \mathrm{C}$ during the night. During the first 20 days, the photoperiod was adjusted to 16 hours. Seven weeks after germination, the seedlings were transplanted to the field spaced $50 \mathrm{~cm}$ apart within rows and $100 \mathrm{~cm}$ between rows. The growing system was designed to exclude major pathogens to allow the assessment of cultivars without up-to-date field resistance. These pathogens included Phytophthora infestans (Mont.) de Bary and Cladosporium fulvum (Pers.) Link. Therefore, a well-ventilated rainout shelter with sides open to $1.8 \mathrm{~m}$ was used (Fig. S1). Border effects were avoided by planting three border plants at either end of each row. The space between rows was covered with fleece (Plantex Gold Unkrautvlies, Meyer, Germany) for weed control. The tomato plants were trellised to strings to vertically support the vine and the plants were fixed each week. The main shoot was pruned on a weekly basis. Drip irrigation was provided through lateral polytube drip lines (John Deere, Germany) with $20 \mathrm{~cm}$ emitter spacing. Irrigation was moderate, based on ambient temperature, with a total amount of $1501 \mathrm{~m}^{-2}$ applied during the growing season. In 2016, the 20 selected cultivars were further assessed with two plants per plot. The crop cultivation procedures, experimental design, and management practices remained the same as in 2015 .

Table 2.1 Overviews of the tomato cultivars assessed in 2015 and 2016

\begin{tabular}{|c|c|c|c|}
\hline Cultivar name & Fruit color & Cultivar name & Fruit color \\
\hline \multicolumn{2}{|c|}{ Salad cultivars (>52g fruit $\left.^{-1}\right)$} & \multicolumn{2}{|c|}{ Cocktail cultivars $\left(<52\right.$ g fruit $\left.{ }^{-1}\right)$} \\
\hline Previa F1 & Red & Amoroso F1 & Red \\
\hline Garance F1 & Red & Annamay F1 & Red \\
\hline
\end{tabular}




\begin{tabular}{|c|c|c|c|}
\hline Green Zebra & Green-yellow & $\begin{array}{l}\text { Quedlinburger Frühe } \\
\text { Liebe }\end{array}$ & Red \\
\hline Diplom F1 & Red & Ruthje & Red \\
\hline Cappricia F1 & Red & König Humbert & Red \\
\hline Rougella F1 & Red & Clou & Yellow \\
\hline Sparta F1 & Red & Tastery F1 & Red \\
\hline Bocati F1 & Red & Primabella & Red \\
\hline Phantasia F1 & Red & Sakura F1 & Red \\
\hline Mecano F1 & Red & Black Cherry & Red-brown \\
\hline Hamlet F1 & Red & Cerise Gelb & Yellow \\
\hline Lyterno F1 & Red & Yellow Submarine & Yellow \\
\hline Nordica F1 & Red & Zuckertraube & Red \\
\hline Moneymaker & Red & Dorada & Yellow \\
\hline Pannovy F1 & Red & Primavera & Red \\
\hline Roterno F1 & Red & Philovita F1 & Red \\
\hline Hildares F1 & Red & Trixi & Red \\
\hline Bonner Beste & Red & Trilly F1 & Red \\
\hline Tica & Red & Benarys Gartenfreude $^{1}$ & Red \\
\hline Ricca & Red & Bartelly F1 & Red \\
\hline Aroma & Red & Golden Pearl F1 & Yellow \\
\hline Rheinlands Ruhm & Red & Resi & Red \\
\hline Lukullus & Red & Supersweet 100 F1 & Red \\
\hline Goldene Königin & Yellow & Goldita & Orange \\
\hline Harzfeuer F1 & Red & Sliwowidnij & Yellow \\
\hline Auriga & Orange & Rote Murmel & Red \\
\hline Haubners Vollendung & Red & Golden Currant & Yellow \\
\hline Dorenia & Red & & \\
\hline Roi Humbert Jaune & Yellow & & \\
\hline Hellfrucht & Red & & \\
\hline Campari F1 & Red & & \\
\hline Matina & Red & & \\
\hline Black Plum & Red-brown & & \\
\hline
\end{tabular}

\subsubsection{Sample collection, mineral nutrient, and quality determination}

Plant morphology: Plant height was measured at 19 weeks after planting (WAP) in 2015 and at 20 WAP in 2016. The total leaf number of each plant was counted from the first leaf above ground to the last fully developed leaf. Mature tomato fruits were harvested at two-week intervals, starting at 9 WAP in 2015 and 8 WAP in 2016. At each harvest, all fruits from each plant were weighed and counted, followed by calculation of average single fruit weight, total number of fruits, and total yield per plant. At 20 WAP in 2015 and 21 WAP in 2016, stem and 
leaf biomass were determined as fresh weight. Harvest index was then calculated as the total fruit weight proportion of total biomass above ground.

Leaf and fruit macronutrient concentration: Fully active leaves in the middle between apex and soil surface of each plant were sampled at 12 WAP in 2015 and at 13 WAP in 2016 to determine mineral concentrations. Fruits were sampled at 13 WAP in both the years to assess their quality parameters. Leaf and fruit samples from the eight field replications were pooled to create four replications for further sample preparation. Leaf samples were oven-dried at $70{ }^{\circ} \mathrm{C}$ for 72 hours and then ground with a Culatti grinder DFH 48 using a $0.5 \mathrm{~mm}$ sieve (Gemini BV, Netherlands). Ten fruits per cocktail cultivar and three fruits per salad cultivar were selected and freeze-dried by using EPSILON 2-40 (Christ, Germany) for four days. Fruit samples were then milled with Mixer Mill MM 400 (Retsch, Germany) to obtain a homogenous fine powder. The concentrations of phosphorus $(\mathrm{P})$, potassium $(\mathrm{K})$, calcium $(\mathrm{Ca})$, magnesium $(\mathrm{Mg})$, and sulfur $(\mathrm{S})$ in leaf and fruit samples were analyzed on the basis of the procedures described in Erika et al. (2020). The ground leaf samples were also used to determine nitrogen (N) and carbon (C) concentrations by dry combustion (Elementar, Germany).

Fruit dry matter (DM), total soluble solids (TSS), and titratable acidity (TA): A subsample of fruits harvested at 13 WAP in 2015 and 2016 were stored at $-20{ }^{\circ} \mathrm{C}$ for further quality analysis. Ten fruits per cocktail cultivar and three fruits per salad cultivar were used for the determination of dry matter, total soluble solids, and titratable acidity in accordance with the procedures described by Kanski et al. (2020).

Total phenolic concentration (TPC): Total phenolic compounds of tomato fruits were determined by using a Folin-Ciocalteu assay (Mohammed et al., 2012). A total of $250 \mathrm{mg}$ of freeze-dried sample was homogenized twice with $5 \mathrm{ml}$ of $80 \%$ ethanol and centrifuged for 10 min at 5,000 $\mathrm{g}$. The supernatant from the two steps was pooled and filled up to $10 \mathrm{ml}$ with $80 \%$ ethanol. For measurement, $500 \mu \mathrm{l}$ of the extract was suspended with $2.4 \mathrm{ml}$ water, $1 \mathrm{ml}$ of $0.5 \mathrm{M}$ $\mathrm{NaOH}$, and $100 \mu \mathrm{l}$ of Folin reagent. The mixture was incubated at $37{ }^{\circ} \mathrm{C}$ for $15 \mathrm{~min}$, and was 
then read in an HP 8453 UV-Vis spectrophotometer (Hewlett Packard, Germany) at $736 \mathrm{~nm}$ absorbance against blanks. Finally, the TPC was calculated based on gallic acid standard calibration curve and expressed as milligram gallic acid equivalents per 100 grams fresh matter (mg $\left.100 \mathrm{~g}^{-1} \mathrm{FM}\right)$

Fruit color: Eight and ten fruits of cocktail and salad cultivar respectively, harvested 13 WAP in both years, were measured for fruit color by using Minolta Chroma meter CR - 400 (Konica Minolta Optics, Japan), in accordance with Kanski et al. (2020).

\subsubsection{Statistical analysis}

The descriptive statistics of each measured trait were calculated. The effects of cultivar and year were analyzed through the analysis of variance. Tukey's Honest Significant Difference (HSD) was performed at $\mathrm{p}<0.05$ as post-hoc test. Pearson correlation was employed to investigate trait associations. The calculation and statistical analyses were conducted with Statistix 8.0 (Analytical Software, USA).

\subsection{Results}

\subsubsection{Variation of 60 cultivars}

Sixty tomato cultivars were grown in 2015 to assess their performance in growth, leaf mineral concentration, yield, and fruit quality in organic low-input management. A total of 28 parameters were investigated. Significant differences among cultivars were observed for all parameters (Table 2.2). Plant agronomic and morphological traits, such as leaf and stem biomass, fruit yield, fruit weight, and fruit number, had a high coefficient of variation (CV) ranging from $33.4 \%$ to $68.7 \%$. Traits associated with fruit quality characteristics (DM, TSS, TA, and TPC) also obtained medium to high CVs (14.7\% to $29.5 \%)$. The CVs of other traits related to leaf and fruit minerals were classified as low to high (1.8\% to $27.4 \%)$. Fruit colors varied and ranged from light green to red ( $\mathrm{a}^{*} ;-11.0$ to 27.4$)$ and yellow at different pigment intensities ( $\mathrm{b}^{*}$; 9.5 to 45.7 ) (Tables 2.1 and 2.2). These results indicate a high genetic diversity of the 60 tomato cultivars assessed. 
Table 2.2 Summary statistics for 28 traits of 60 tomato cultivars

\begin{tabular}{|c|c|c|c|c|c|c|c|c|c|}
\hline Parameters & Min & 1Q & Median & $3 \mathrm{Q}$ & Max & Mean & Variance & Significance & $\begin{array}{l}\text { CV } \\
(\%)\end{array}$ \\
\hline \multicolumn{10}{|l|}{ Plant morphological characteristics } \\
\hline Height $(\mathrm{cm})$ & 183.0 & 235.0 & 264.0 & 299.3 & 356.0 & 268.4 & 1733.9 & $* * *$ & 15.5 \\
\hline Leaf number ( plant $^{-1}$ ) & 32.0 & 36.0 & 39.0 & 42.0 & 57.0 & 39.7 & 26.2 & $* * *$ & 12.9 \\
\hline Leaf and stem biomass (g plant $\left.{ }^{-1}\right)$ & 562.0 & 1122.5 & 1387.5 & 1702.0 & 3064.0 & 1462.3 & 239077.0 & $* * *$ & 33.4 \\
\hline Fruit yield ${ }^{\#}\left(\right.$ g plant $\left.^{-1}\right)$ & 540.0 & 2736.3 & 3504.0 & 4495.8 & 5797.0 & 3493.9 & 1366000.0 & $* * *$ & 33.4 \\
\hline Fruit weight $\left(\mathrm{g}\right.$ fruit $\left.^{-1}\right)$ & 5.5 & 21.8 & 63.7 & 109.0 & 171.5 & 67.1 & 2127.0 & $* * *$ & 68.7 \\
\hline Fruit number $\left(\right.$ plant $\left.^{-1}\right)$ & 18.0 & 42.0 & 56.5 & 110.8 & 295.0 & 78.5 & 2694.8 & $* * *$ & 66.1 \\
\hline Harvest index & 0.24 & 0.73 & 0.80 & 0.83 & 0.87 & 0.76 & 0.01 & $* * *$ & 15.5 \\
\hline \multicolumn{10}{|l|}{ Leaf minerals ( $\left.\mathrm{mg} \mathrm{g}^{-1} \mathrm{DM}\right)$} \\
\hline Carbon (C) & 375.0 & 384.3 & 388.0 & 393.8 & 406.0 & 388.8 & 49.6 & $* * *$ & 1.8 \\
\hline Nitrogen $(\mathrm{N})$ & 20.5 & 22.9 & 23.9 & 25.9 & 28.6 & 24.2 & 3.3 & $* * *$ & 7.6 \\
\hline Phosphorus $^{\#}(\mathrm{P})$ & 1.4 & 1.6 & 1.7 & 1.8 & 2.2 & 1.7 & 0.0 & $* * *$ & 9.0 \\
\hline Potassium $^{\#}(\mathrm{~K})$ & 19.6 & 24.3 & 26.5 & 29.0 & 33.4 & 26.5 & 10.1 & $* * *$ & 12.0 \\
\hline Magnesium $^{\#}(\mathrm{Mg})$ & 2.6 & 3.4 & 3.7 & 4.2 & 6.1 & 3.9 & 0.6 & $* * *$ & 19.3 \\
\hline Calcium $^{\#}(\mathrm{Ca})$ & 36.7 & 46.9 & 52.2 & 56.9 & 69.2 & 52.1 & 51.2 & $* * *$ & 13.7 \\
\hline Sulfur (S) & 4.1 & 5.2 & 6.0 & 6.8 & 8.1 & 6.0 & 0.7 & $* * *$ & 14.4 \\
\hline \multicolumn{10}{|l|}{ Fruit minerals (mg $\left.100 \mathrm{~g}^{-1} \mathrm{FW}\right)$} \\
\hline Phosphorus (P) & 21.3 & 24.7 & 28.0 & 31.1 & 55.5 & 28.9 & 35.2 & $* * *$ & 20.5 \\
\hline Potassium $(\mathrm{K})$ & 211.3 & 243.2 & 274.2 & 295.8 & 441.3 & 272.5 & 1563.0 & $* * *$ & 14.5 \\
\hline Magnesium (Mg) & 8.0 & 9.6 & 10.7 & 12.4 & 20.0 & 11.1 & 4.5 & $* * *$ & 19.1 \\
\hline Calcium $(\mathrm{Ca})$ & 7.3 & 10.0 & 12.1 & 14.3 & 24.7 & 12.6 & 11.9 & $* * *$ & 27.4 \\
\hline Sulphur (S) & 11.7 & 13.4 & 14.6 & 16.7 & 30.5 & 15.4 & 9.0 & $* * *$ & 19.5 \\
\hline \multicolumn{10}{|l|}{ Fruit quality characteristics } \\
\hline Dry matter (\%) & 5.0 & 5.6 & 6.8 & 8.1 & 10.8 & 7.0 & 2.4 & $* * *$ & 22.1 \\
\hline Total soluble solid ( ${ }^{\circ}$ Brix) & 3.7 & 4.4 & 5.1 & 6.3 & 8.7 & 5.5 & 1.6 & $* * *$ & 23.4 \\
\hline Titratable acidity $(\%)$ & 0.25 & 0.32 & 0.35 & 0.40 & 0.53 & 0.36 & 0.03 & $* * *$ & 14.7 \\
\hline Total phenolics (mg $\left.100 \mathrm{~g}^{-1} \mathrm{FW}\right)$ & 1.1 & 1.6 & 1.9 & 2.3 & 4.4 & 2.0 & 0.3 & $* * *$ & 29.5 \\
\hline \multicolumn{10}{|l|}{ Fruit color } \\
\hline $\mathrm{L}^{*}$ & 47.7 & 51.1 & 53.4 & 55.5 & 69.7 & 54.2 & 19.8 & $* * *$ & 8.2 \\
\hline$a^{*}$ & -11.0 & 14.1 & 19.6 & 22.6 & 27.4 & 16.3 & 82.1 & $* * *$ & 55.7 \\
\hline$b^{*}$ & 9.5 & 22.8 & 25.9 & 29.1 & 45.7 & 27.1 & 42.8 & $* * *$ & 24.1 \\
\hline $\mathrm{C}^{*}$ & 11.4 & 29.5 & 33.4 & 37.2 & 46.1 & 33.2 & 32.3 & $* * *$ & 17.1 \\
\hline $\mathrm{h}^{\circ}$ & 46.2 & 48.6 & 51.7 & 57.8 & 107.5 & 58.5 & 261.1 & $* * *$ & 27.6 \\
\hline
\end{tabular}

Min=minimum value, $1 \mathrm{Q}=$ first quartile, $3 \mathrm{Q}=$ third quartile, Max=maximum value, $\mathrm{CV}=$ coefficient of variation, $\mathrm{DM}=$ dry matter, $\mathrm{FW}=$ fresh weight, ${ }^{\#}$ part of the data is taken from Erika et al. (2020).

$* * *$ indicates significant difference among cultivars in each trait at $\mathrm{p}<0.001$

Considering the high diversity of fruit weight (5.5 to $\left.171.5 \mathrm{~g} \mathrm{fruit}^{-1}\right)$, we classified the cultivars based on fruit weight into two groups viz. salad $\left(>52 \mathrm{~g} \mathrm{fruit}^{-1}\right)$ and cocktail $\left(<52 \mathrm{~g} \mathrm{fruit}^{-}\right.$ $\left.{ }^{1}\right)$. The results of analysis of variance within the two groups are shown in Table S3. In salad cultivars, year of release correlated positively with plant height, fruit yield, harvest index, and leaf $\mathrm{C}, \mathrm{Ca}$, and $\mathrm{S}$ concentrations (Fig. S2). A high variation of leaf and stem biomass, fruit weight, and fruit yield allowed us to select cultivars with superior performance with regard to plant morphology and yield (Fig. 2.1 A). 


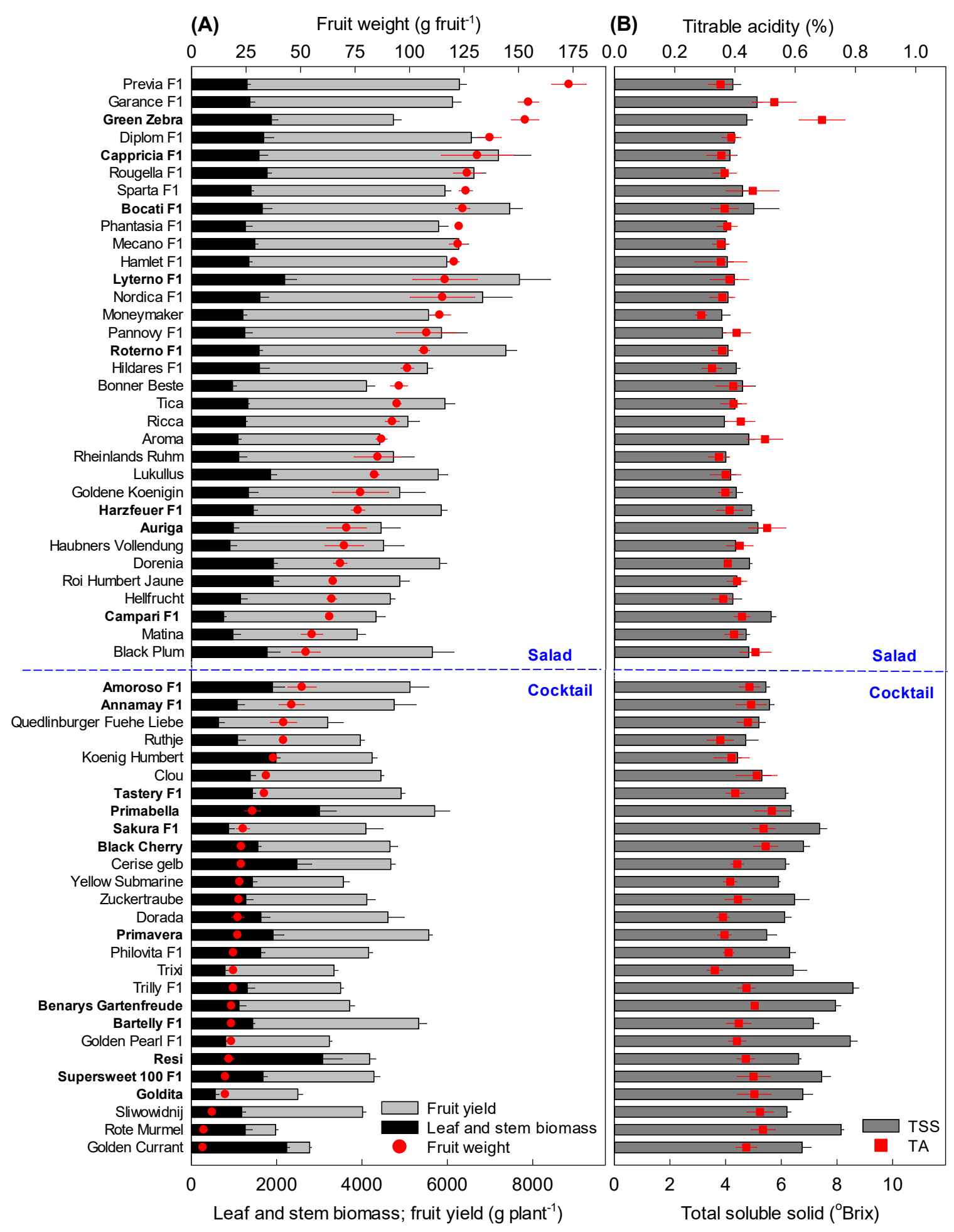

Fig. 2.1 (A) Leaf and stem biomass, fruit yield, and fruit weight and (B) fruit total soluble solid and titratable acidity of 60 tomato cultivars grown in 2015. The values for leaf and stem biomass, fruit yield, and fruit size were the averages from eight biological replications and the values for total soluble solid and titratable acidity were the averages of the pooled four biological replications. Error bars indicate standard error of means. Cultivars shown in bold are the cultivars selected from 2015 for further evaluation in 2016. Cultivar names "Goldene Koenigin", "Quedlinburger Fruehe Liebe", and "Koenig Humbert" have their original names written as “Goldene Königin”, “Quedlinburger Frühe Liebe”, and "König Humbert”, respectively. 


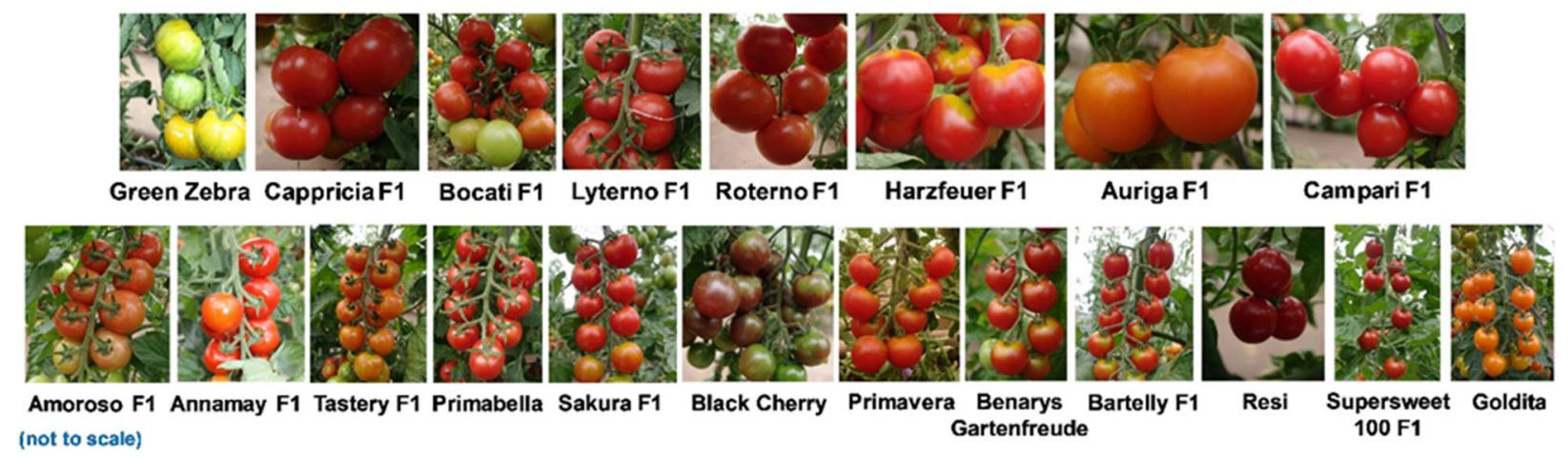

Fig. 2.2 Fruit phenotypes of 20 tomato cultivars consisting of eight salad and twelve cocktail cultivars selected in 2015 for further evaluation in 2016 (Photos: L. Chea and J. Lange)

Fruit TSS and TA were included in the selection criteria (Fig. 2.1 B), because they were among the most important traits for improving tomato fruit quality to gain consumer acceptance (Causse et al., 2010). We assumed that the variation in the traits used as selection criteria could be reflected in the variability of other traits on account of correlations (Fig. S3). Ultimately, eight salad and twelve cocktail cultivars with outstanding performance in one trait or a combination of traits were selected for further evaluation in 2016 (Figs. 2.1 and 2.2).

\subsubsection{Morphological and fruit quality characteristics of the selected 20 cultivars}

The selected 20 cultivars (Table 2.1; shown in bold) were grown in 2016 to further characterize plant morphology, yield, and fruit quality, and to identify the best performing ones for fruit yield and quality in organic low-input management.

Table 2.3 Plant morphological and agronomic characteristics of eight salad and twelve cocktail tomato cultivars grown in 2015 and 2016

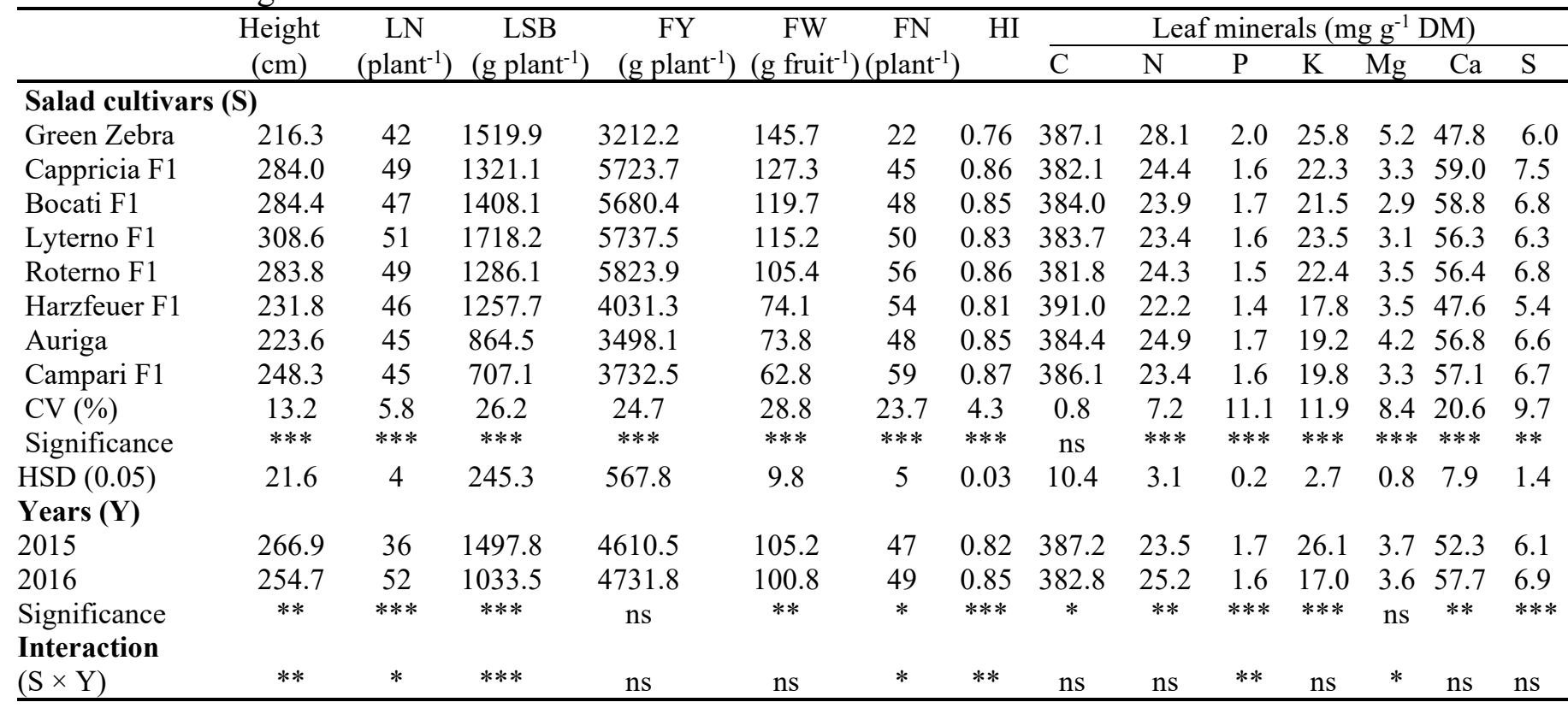




\begin{tabular}{|c|c|c|c|c|c|c|c|c|c|c|c|c|c|c|}
\hline \multicolumn{15}{|c|}{ Cocktail cultivars (C) } \\
\hline Amoroso F1 & 266.9 & 49 & 1650.6 & 3538.9 & 49.3 & 73 & 0.77 & 393.1 & 23.6 & 1.6 & 21.6 & 3.5 & 47.9 & 5.5 \\
\hline Annamay F1 & 303.5 & 53 & 974.2 & 3901.8 & 47.1 & 83 & 0.84 & 383.3 & 21.9 & 1.6 & 21.6 & 3.5 & 59.5 & 6.6 \\
\hline Tastery F & 307.8 & 51 & 1288.8 & 3598.2 & 33.0 & 110 & 0.79 & 394.7 & 26.5 & 1.7 & 25.2 & 3.2 & 48.9 & 6.5 \\
\hline Primabella & 320.0 & 62 & 2583.1 & 3088.1 & 27.9 & 111 & 0.62 & 402.9 & 24.8 & 1.9 & 24.7 & 3.1 & 39.4 & 4.5 \\
\hline Sakura F1 & 299.8 & 56 & 821.8 & 3367.5 & 23.9 & 141 & 0.84 & 384.0 & 23.0 & 1.5 & 19.6 & 3.3 & 63.2 & 6.0 \\
\hline Black Cherry & 325.9 & 49 & 1393.7 & 3161.7 & 24.1 & 133 & 0.76 & 394.4 & 26.2 & 1.7 & 18.9 & 4.4 & 51.6 & 5.2 \\
\hline Primavera & 336.4 & 59 & 1655.4 & 3837.9 & 21.4 & 181 & 0.74 & 386.8 & 24.6 & 1.7 & 26.5 & 3.0 & 53.4 & 5.3 \\
\hline $\begin{array}{l}\text { Benarys } \\
\text { Gartenfreude }\end{array}$ & 256.1 & 48 & 1048.3 & 2815.8 & 18.8 & 150 & 0.78 & 382.7 & 21.0 & 1.5 & 17.4 & 2.9 & 61.7 & 5.2 \\
\hline Bartelly F1 & 321.6 & 53 & 1295.1 & 4076.4 & 16.6 & 252 & 0.81 & 386.5 & 25.8 & 1.7 & 25.1 & 4.2 & 58.3 & 6.0 \\
\hline Resi & 346.0 & 59 & 2578.1 & 1185.8 & 18.6 & 64 & 0.37 & 398.1 & 25.0 & 1.8 & 21.5 & 4.2 & 40.9 & 5.2 \\
\hline Supersweet $100 \mathrm{~F} 1$ & 332.8 & 58 & 1592.9 & 2905.2 & 14.7 & 202 & 0.71 & 392.1 & 23.7 & 1.6 & 23.8 & 3.1 & 47.9 & 5.2 \\
\hline Goldita & 225.6 & 53 & 563.2 & 2114.9 & 16.3 & 129 & 0.83 & 401.2 & 23.7 & 1.4 & 21.2 & 3.1 & 46.8 & 4.5 \\
\hline CV $(\%)$ & 12.0 & 8.4 & 42.9 & 26.2 & 44.8 & 40.7 & 17.8 & 1.8 & 6.9 & 8.7 & 12.6 & 15.1 & 14.8 & 12.5 \\
\hline Significance & $* * *$ & $* * *$ & $* * *$ & $* * *$ & $* * *$ & $* * *$ & $* * *$ & $* * *$ & $* * *$ & $* * *$ & $* * *$ & $* * *$ & $* * *$ & $* * *$ \\
\hline $\operatorname{HSD}(0.05)$ & 30.1 & 5 & 417.0 & 485.2 & 2.9 & 25 & 0.05 & 8.5 & 3.2 & 0.2 & 4.1 & 0.7 & 7.9 & 1.1 \\
\hline \multicolumn{15}{|l|}{ Years (Y) } \\
\hline 2015 & 297.8 & 42 & 1621.0 & 2937.8 & 25.6 & 127 & 0.72 & 387.0 & 23.6 & 1.7 & 26.4 & 3.9 & 55.2 & 5.6 \\
\hline 2016 & 308.9 & 60 & 1286.9 & 3323.5 & 25.9 & 146 & 0.76 & 396.3 & 24.8 & 1.6 & 18.1 & 3.0 & 48.1 & 5.3 \\
\hline Significance & ** & $* * *$ & $* * *$ & $* * *$ & ns & $* * *$ & $* * *$ & $* * *$ & $* * *$ & $* * *$ & $* * *$ & $* * *$ & $* * *$ & $*$ \\
\hline \multicolumn{15}{|l|}{ Interaction } \\
\hline$(\mathrm{C} \times \mathrm{Y})$ & **** & $* * *$ & **** & **** & $* * *$ & $* * *$ & $* * *$ & ns & $* * *$ & $\mathrm{~ns}$ & $*$ & ns & ns & ns \\
\hline
\end{tabular}

$\mathrm{LN}=$ leaf number; $\mathrm{LSB}=$ leaf and stem biomass; $\mathrm{FY}=$ fruit yield; $\mathrm{FW}=$ fruit weight, $\mathrm{FN}=$ fruit number; $\mathrm{HI}=$ harvest index; $\mathrm{DM}=$ dry matter

${ }^{1} \mathrm{~ns}$ indicates non-significant difference; $*, * *$, and $* * *$ indicate significance difference of each factor and interaction at $\mathrm{p}<0.05, \mathrm{p}<0.01$, and $\mathrm{p}<0.001$ respectively.

$\operatorname{HSD}(0.05)=$ critical value for comparisons by Tukey's HSD test at $\mathrm{p}<0.05$.

Table 2.4 Fruit minerals, dry matter, total soluble solid, titratable acidity, total phenolic concentration, and color of eight salad and twelve cocktail cultivars grown in 2015 and 2016

\begin{tabular}{|c|c|c|c|c|c|c|c|c|c|c|c|c|c|c|}
\hline & \multicolumn{5}{|c|}{ Fruit minerals $\left(\mathrm{mg} 100 \mathrm{~g}^{-1} \mathrm{FW}\right)$} & \multirow{2}{*}{$\begin{array}{l}\mathrm{DM} \\
(\%)\end{array}$} & \multirow{2}{*}{$\begin{array}{c}\text { TSS } \\
\left({ }^{\circ} \text { Brix }\right)\end{array}$} & \multirow{2}{*}{$\begin{array}{l}\mathrm{TA} \\
(\%)\end{array}$} & \multirow{2}{*}{$\begin{array}{c}\text { TPC } \\
\left(\mathrm{mg} 100 \mathrm{~g}^{-1}\right. \\
\mathrm{FW})\end{array}$} & \multicolumn{5}{|c|}{ Fruit color } \\
\hline & $\overline{\mathrm{P}^{\#}}$ & $\mathrm{~K}^{\#}$ & $\mathrm{Mg}^{\#}$ & $\mathrm{Ca}^{\#}$ & $\mathrm{~S}$ & & & & & $\overline{L^{*}}$ & $a^{*}$ & $\mathrm{~b}^{*}$ & $\mathrm{C}^{*}$ & $\mathrm{~h}^{\circ}$ \\
\hline \multicolumn{15}{|c|}{ Salad cultivars (S) } \\
\hline Green Zebra & 30.7 & 297.4 & 14.2 & 13.2 & 15.6 & 5.7 & 5.1 & 0.65 & 139.2 & 58.9 & -10.7 & 37.0 & 41.9 & 105.4 \\
\hline Cappricia F1 & 25.9 & 246.9 & 8.5 & 15.3 & 13.0 & 5.6 & 4.6 & 0.35 & 109.0 & 53.4 & 22.5 & 28.4 & 39.6 & 54.0 \\
\hline Bocati F1 & 21.4 & 212.4 & 8.3 & 12.4 & 11.0 & 5.2 & 5.1 & 0.38 & 105.2 & 53.1 & 24.4 & 28.0 & 40.1 & 51.2 \\
\hline Lyterno F1 & 26.2 & 243.7 & 9.2 & 15.2 & 13.5 & 5.9 & 4.6 & 0.38 & 131.8 & 52.8 & 20.0 & 25.6 & 35.8 & 54.4 \\
\hline Roterno F1 & 24.4 & 237.9 & 9.4 & 14.5 & 13.2 & 5.5 & 4.5 & 0.37 & 119.3 & 53.3 & 21.6 & 27.8 & 38.3 & 54.4 \\
\hline Harzfeuer F1 & 26.8 & 303.2 & 10.9 & 11.7 & 14.4 & 6.8 & 5.5 & 0.42 & 143.4 & 50.4 & 19.5 & 23.8 & 34.1 & 53.4 \\
\hline Aur & 29.0 & 299.0 & 13.5 & 8.0 & 14.7 & 6.9 & 5.5 & 0.53 & 160.8 & 61.5 & 13.5 & 42.8 & 47.5 & 73.1 \\
\hline Campari F1 & 30.1 & 293.9 & 11.9 & 13.7 & 15.0 & 6.9 & 6.1 & 0.47 & 158.1 & 50.2 & 17.0 & 23.1 & 31.9 & 56.4 \\
\hline CV (\%) & 11.6 & 13.3 & 18.5 & 21.2 & 10.6 & 11.6 & 10.6 & 23.4 & 15.7 & 7.3 & 70.6 & 23.2 & 12.6 & 29.5 \\
\hline Significance $^{1}$ & $* * *$ & $* * *$ & $* * *$ & $* * *$ & $* * *$ & $* * *$ & $* * *$ & $* * *$ & $* * *$ & $* * *$ & $* * *$ & $* * *$ & $* * *$ & $* * *$ \\
\hline HSD $(0.05)$ & 5.8 & 56.5 & 2.2 & 4.6 & 2.8 & 1.1 & 1.0 & 0.08 & 21.7 & 1.9 & 2.0 & 2.8 & 3.3 & 6.4 \\
\hline \multicolumn{15}{|l|}{ Years (Y) } \\
\hline 2015 & 28.7 & 280.1 & 10.6 & 13.2 & 14.9 & 5.8 & 4.7 & 0.43 & 177.0 & 54.1 & 18.2 & 30.4 & 37.1 & 58.8 \\
\hline 2016 & 25.0 & 254.1 & 10.9 & 12.8 & 12.8 & 6.3 & 5.5 & 0.46 & 93.0 & 54.2 & 14.5 & 28.6 & 39.9 & 65.5 \\
\hline Significance & $* * *$ & $* *$ & ns & ns & $* * *$ & * & *** & ns & $* * *$ & $\mathrm{~ns}$ & $* * *$ & ** & ns & $* *$ \\
\hline \multicolumn{15}{|l|}{ Interaction } \\
\hline$(\mathrm{S} \times \mathrm{Y})$ & ns & ns & ns & ** & ns & ns & ns & ns & ns & ns & ns & ns & ns & ns \\
\hline \multicolumn{15}{|l|}{ Cocktail cultiv } \\
\hline Amoro & 27.8 & 233.8 & 9.8 & 12.9 & 13.9 & 7.4 & 6.0 & 0.49 & 151.7 & 49.6 & 13.3 & 20.4 & 27.9 & 59.6 \\
\hline Annamay F1 & 31.3 & 314.2 & 13.4 & 15.0 & 15.4 & 7.1 & 6.2 & 0.50 & 176.8 & 50.8 & 17.3 & 22.7 & 32.0 & 54.9 \\
\hline Tastery F1 & 31.5 & 266.9 & 11.6 & 13.7 & 15.1 & 8.3 & 6.7 & 0.39 & 167.8 & 51.4 & 13.1 & 23.1 & 30.1 & 62.5 \\
\hline Prima & 38.5 & 339.3 & 14.4 & 13.4 & 19.1 & 8.3 & 6.8 & 0.54 & 203.1 & 50.4 & 19.9 & 23.1 & 33.7 & 51.6 \\
\hline & 31.3 & 297.6 & 12.9 & 12.4 & 14.6 & 9.0 & 7.7 & 0.53 & 200.7 & 49.3 & 13.2 & 21.3 & 28.5 & 60.1 \\
\hline Black Cherry & 27.4 & 253.8 & 11.6 & 11.9 & 14.9 & 7.6 & 6.9 & 0.53 & 172.2 & 47.9 & 4.8 & 9.8 & 16.1 & 66.5 \\
\hline Primavera & 30.5 & 273.2 & 10.6 & 13.1 & 16.4 & 7.4 & 6.2 & 0.38 & 188.4 & 49.6 & 12.5 & 21.0 & 28.2 & 61.5 \\
\hline
\end{tabular}




\begin{tabular}{|c|c|c|c|c|c|c|c|c|c|c|c|c|c|c|}
\hline Benarys Gartenfreude & 36.6 & 334.3 & 12.8 & 9.6 & 18.0 & 10.4 & 8.3 & 0.55 & 177.6 & 50.0 & 13.9 & 20.5 & 28.5 & 58.6 \\
\hline Bartelly F1 & 39.0 & 320.9 & 13.5 & 16.9 & 18.8 & 8.5 & 7.7 & 0.45 & 211.8 & 49.9 & 14.0 & 20.2 & 28.2 & 57.6 \\
\hline Resi & 48.2 & 360.6 & 16.6 & 19.4 & 21.7 & 8.0 & 6.9 & 0.47 & 205.4 & 50.5 & 18.5 & 20.9 & 31.6 & 51.0 \\
\hline Supersweet $100 \mathrm{~F} 1$ & 42.7 & 344.8 & 15.5 & 9.7 & 19.9 & 10.1 & 8.2 & 0.54 & 224.2 & 49.7 & 15.9 & 21.4 & 30.1 & 55.7 \\
\hline Goldita & 33.6 & 310.6 & 13.2 & 17.7 & 20.1 & 9.5 & 7.4 & 0.51 & 275.6 & 56.2 & 7.0 & 31.3 & 35.5 & 78.3 \\
\hline $\mathrm{CV}(\%)$ & 18.1 & 13.0 & 21.7 & 14.9 & 15.0 & 12.7 & 10.9 & 11.6 & 16.6 & 4.0 & 31.7 & 22.0 & 16.4 & 12.2 \\
\hline Significance & $* * *$ & $* * *$ & $* * *$ & $* * *$ & $* * *$ & $* * *$ & $* * *$ & $* * *$ & $* * *$ & $* * *$ & $* * *$ & $* * *$ & $* * *$ & $* * *$ \\
\hline HSD (0.05) & 8.4 & 70.7 & 3.3 & 5.4 & 4.6 & 1.7 & 0.6 & 0.08 & 33.0 & 1.2 & 2.6 & 2.3 & 3.4 & 5.9 \\
\hline \multicolumn{15}{|l|}{ Years (Y) } \\
\hline 2015 & 35.0 & 297.5 & 12.2 & 14.3 & 17.5 & 8.3 & 6.6 & 0.45 & 250.3 & 50.2 & 14.5 & 22.0 & 26.8 & 56.3 \\
\hline 2016 & 34.7 & 310.9 & 13.8 & 13.4 & 17.2 & 8.7 & 7.6 & 0.53 & 142.3 & 50.7 & 12.7 & 20.6 & 31.6 & 63.4 \\
\hline Significance & ns & $* * *$ & $* * *$ & ns & ns & ns & $* * *$ & $* * *$ & $* * *$ & $* *$ & $* * *$ & $* * *$ & $*$ & $* * *$ \\
\hline \multicolumn{15}{|l|}{ Interaction } \\
\hline$(\mathrm{C} \times \mathrm{Y})$ & $*$ & $* *$ & $* *$ & $*$ & $*$ & ns & ns & ns & $* *$ & $* * *$ & $* * *$ & $* * *$ & ns & ns \\
\hline
\end{tabular}

$\mathrm{DM}=$ dry matter, $\mathrm{TSS}=$ total soluble solid, $\mathrm{TA}=$ titratable acidity, TPC=total phenolic concentration, $\mathrm{FW}=$ fresh weight, ${ }^{\#}$ part of the data is taken from Erika et al. (2020)

ns indicates non-significant difference; $* * *$, and $* * *$ indicate significance difference of each factor and interaction at $\mathrm{p}<0.05, \mathrm{p}<0.01$, and $\mathrm{p}<0.001$ respectively.

$\operatorname{HSD}(0.05)=$ critical value for comparisons by Tukey's HSD test at $\mathrm{p}<0.05$.

The dataset for evaluation of these 20 cultivars was obtained from 2015 and 2016 . We used an unpaired t-test to compare the performance of salad and cocktail cultivars. In both years, salad cultivars displayed lower plant height, leaf number, fruit number, fruit mineral concentrations (P, S, Mg, and $\mathrm{K}$ ), and fruit quality characteristics (DM, TSS, and TPC) by 10$70 \%$, but they had higher fruit yield, and leaf mineral concentrations $(\mathrm{S}, \mathrm{Mg}$, and $\mathrm{Ca}$ ) by $10-60 \%$ compared to cocktail cultivars (Fig. S4). Because of these differences, the results were analyzed separately for each group. For cocktail cultivars, the analysis of variance revealed a significant interaction between cultivar and year in plant morphological characteristics and fruit minerals. However, the significant interaction was not clearly observed for salad cultivars (Tables 2.3 and 2.4).

\subsubsection{Plant morphological characteristics}

Plant height, leaf number, stem and leaf biomass, fruit yield, fruit weight, fruit number, and harvest index differed significantly within salad and cocktail cultivars (Table 2.3). In salad cultivars, plant height, leaf number, and stem and leaf biomass reached $308.6 \mathrm{~cm}, 51$ plant $^{-1}$, and $1718.2 \mathrm{~g} \mathrm{plant}^{-1}$, respectively, in "Lyterno F1". However, "Roterno F1" displayed the highest fruit yield (5823.9 $\left.\mathrm{g} \mathrm{plant}^{-1}\right)$ and a high harvest index (0.86). In cocktail cultivars, the tallest plant height $(346.0 \mathrm{~cm})$ was observed in "Resi" and the highest leaf number $\left(62\right.$ plant $\left.^{-1}\right)$ and stem and leaf biomass (2583.1 g plant ${ }^{-1}$ ) were detected in "Primabella". "Bartelly F1" had the highest fruit 
yield (4076.4 g plant $\left.^{-1}\right)$ and fruit number (252 plant $\left.^{-1}\right)$. "Sakura F1" and "Annamay F1" obtained the highest harvest index (0.84). These results suggested that in both salad and cocktail cultivars, improved plant growth did not guarantee higher fruit yield.

\subsubsection{Leaf macronutrient concentration}

Leaf mineral analyses showed that the salad cultivars with superior growth and fruit yield mentioned above had leaf macronutrient within average ranges (Table 2.3). Nevertheless, it is worth mentioning that leaves of "Green Zebra" contained the highest $\mathrm{N}, \mathrm{P}, \mathrm{K}$, and $\mathrm{Mg}$ concentrations, which were $28.1,2.0,25.8$, and $5.2 \mathrm{mg} \mathrm{g}^{-1}$ respectively. The highest leaf $\mathrm{Ca}$ and S concentrations were observed in "Cappricia F1". Among cocktail cultivars, the one with highest stem and leaf biomass ("Resi") showed leaf concentrations of 398.1, 25.0, 1.8, and 4.2 $\mathrm{mg} \mathrm{g}^{-1}$ for $\mathrm{C}, \mathrm{N}, \mathrm{P}$, and $\mathrm{Mg}$ respectively, which were not significantly different from the highest values (Table 1.3). Moreover, leaf $\mathrm{N}, \mathrm{P}, \mathrm{K}, \mathrm{Ca}, \mathrm{Mg}$, and $\mathrm{S}$ of the cultivar with the highest fruit yield ("Bartelly F1") were at 25.8, 1.7, 25.1, 4.2, 58.3, and $6.0 \mathrm{mg} \mathrm{g}^{-1}$ respectively, and not significantly different from the highest values. Therefore, leaf macronutrient concentration could contribute to enhanced plant biomass and fruit yield of cocktail cultivars, but this tendency was not evident in salad cultivars.

\subsubsection{Fruit minerals}

Because minerals are essential for consumers' health, we also characterized fruit macronutrient concentrations. Fruit mineral concentrations of salad and cocktail cultivars were highly variable: Their CVs ranged from 10.6 to $18.5 \%$ and 13.0 to $18.1 \%$ respectively (Table 2.4). Relationships between leaf and fruit minerals were further determined by Pearson correlation analyses. We found a significant correlation between leaf and fruit $\mathrm{Mg}$ within salad cultivars (Fig. 2.3 A). "Auriga" and "Green Zebra" were the outstanding cultivars for $\mathrm{Mg}$ concentration in both leaves and fruits. In cocktail cultivars, "Resi" had the highest fruit Mg concentration and relatively high leaf $\mathrm{Mg}$ concentration (Fig. 2.3 A). No other significant correlation between leaf and fruit minerals was detected. 


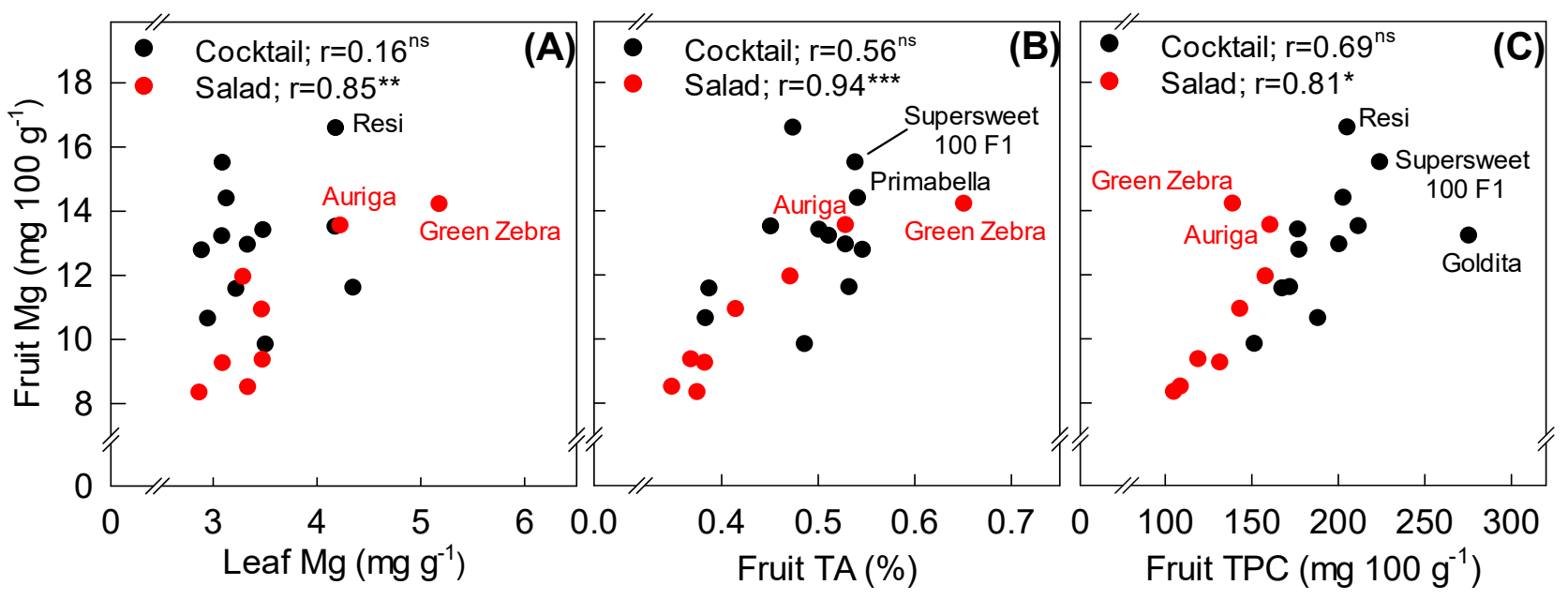

Fig. 2.3 Relationship between fruit $\mathrm{Mg}$ with (A) leaf $\mathrm{Mg}$, (B) fruit titratable acidity (TA), and (C) fruit total phenolic concentration (TPC) of salad $(n=8)$ and cocktail $(n=12)$ cultivars grown in 2015 and 2016. ns and ** indicate non-significant and significant correlation at $\mathrm{p}<0.01$ respectively. Cultivars mentioned in the figures are the potential cultivars with promising performance in trait combinations.

\subsubsection{Fruit quality characteristics and fruit color}

Fruit DM, TSS, TA, TPC, and color of salad and cocktail cultivars were measured because they are important parameters that determine tomato fruit quality and consumer acceptance. We found a high variability for each trait; the CVs ranged from $7.3 \%$ to $70.6 \%$ and $4.0 \%$ to $31.7 \%$ in salad and cocktail cultivars respectively. Within salad cultivars, "Auriga" and "Campari F1" had the highest fruit DM (6.9\%), and the fruits of both cultivars also contained relatively high TSS (5.5 and $6.1{ }^{\circ}$ Brix respectively) and TPC (160.8 and $158.1 \mathrm{mg}^{100 \mathrm{~g}^{-1}}$ respectively). The highest TA $(0.65 \%)$ was measured in "Green Zebra". In cocktail cultivars, "Benarys Gartenfreude" yielded the highest DM, TSS, and TA (10.4\%, $8.3 \circ$ Brix, and 0.55\% respectively). The highest TPC (275.6 mg $\left.100 \mathrm{~g}^{-1}\right)$ was detected in the fruits of "Goldita". The fruit color was less variable because fruits of most cultivars were red $\left(a^{*}>10\right)$, except salad cultivar "Green Zebra" and cocktail cultivar "Black Cherry" (Fig. 2.2, Table 2.4). In addition to the abovementioned positive correlation between fruit and leaf $\mathrm{Mg}$, we also found a positive correlation of fruit $\mathrm{Mg}$ with TA (Fig. 2.3 B) and TPC (Fig. 2.3 C) in salad cultivars. Even though we could not observe these significant relationships in cocktail cultivars, we could identify "Supersweet 100 F1", "Primabella", "Resi", and "“Goldita" as superior cultivars in the 
trait combinations of fruit $\mathrm{Mg}, \mathrm{TSS}$, and TPC. These cultivars had the potential for improved fruit quality under organic low-input management.

\subsubsection{Correlations between fruit yield and fruit quality}

We analyzed the correlation between fruit yield and fruit quality to determine whether the variations in fruit quality characteristics were associated with yield and fruit minerals. Pearson correlation analyses revealed that fruit yield was negatively correlated with fruit minerals $(\mathrm{P}, \mathrm{K}$, $\mathrm{Mg}$, and S) and quality characteristics (TSS, TA, and TPC) in salad cultivars (Fig. 2.4 A). In cocktail cultivars, significant relationships were observed only between fruit yield and the fruit P, Mg, and S (Fig. 2.4 B). These results imply a tradeoff between fruit yield and fruit quality at different magnitudes. In both salad and cocktail cultivars, we found a positive correlation among fruit minerals ( $\mathrm{P}, \mathrm{K}, \mathrm{Mg}$, and $\mathrm{S}$ ), which suggests synergistic effects of mineral allocation in the fruits.
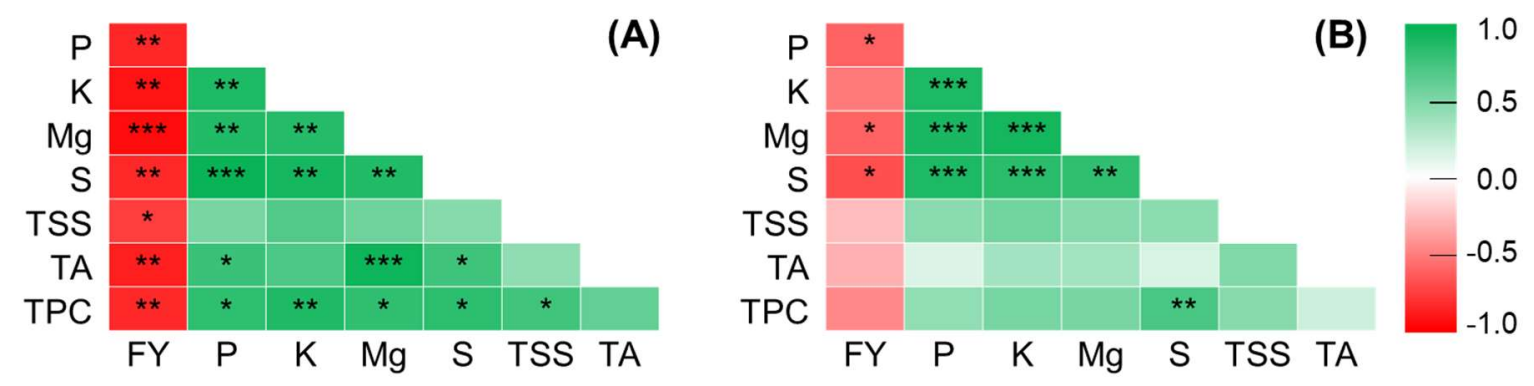

Fig. 2.4 Correlations among fruit quality traits of salad $(A, n=8)$ and cocktail $(B, n=12)$ tomato cultivars in 2015 and 2016. Color intensity represents the correlation coefficient. *,**, and *** indicate the significant correlation at $\mathrm{p}<0.05, \mathrm{p}<0.01$, and $\mathrm{p}<0.001$ respectively. $F Y=$ fruit yield; $\mathrm{TSS}=$ total soluble solids; $\mathrm{TA}=$ titratable acidity; $\mathrm{TPC}=$ total phenolic concentration

\subsection{Discussion}

The growing system used in our study can be characterized as very well ventilated indoor or covered outdoor. The use of a rainout shelter successfully limited the presence of major pathogens that restrict indoor and outdoor tomato production. Even though it is well known that tomato fruits provide numerous health benefits for humans, there is a lack of breeding programs for nutritional quality traits of the tomato (Capel et al., 2017). Information on genotypic variation in plant morphology and fruit quality is important for producers and breeders to identify cultivars 
for production and resources in breeding programs for improved yield and fruit quality under organic low-input management. In the present study, we first screened a diverse set of 60 tomato cultivars in 2015, and then, a subset of 20 potential cultivars in plant morphology, agronomic, and fruit quality traits were selected for further evaluation in 2016. From the results of a twoyear evaluation of these 20 cultivars, we finally identified superior cultivars in fruit yield and quality traits.

\subsubsection{Genotypic variability of 60 tomato cultivars}

We employed agronomic, morphological, and biochemical approaches to characterize 60 cultivars under organic low-input management. The variations of 28 traits were similar to or higher than those found in previous studies that tested tomato cultivars in organic outdoor conditions (Zörb et al., 2020). conventional plastic (Capel et al., 2017), and conventional outdoor conditions (Barrios-Masias and Jackson, 2014). The lower variation of some traits reported in these studies could have been caused by a smaller number of cultivars used in the trials. In addition to these reports, we provide the first evidence of tomato panels consisting of very diverse fruit weights, fruit numbers per plant, and stem and leaf biomass under rainout shelter in organic low-input conditions (Tables 2.1 and 2.2). These traits are considered as the main drivers for fruit yield variation in tomato (Barrios-Masias and Jackson, 2014; van der Ploeg et al., 2007). The harvest index of the cultivars in our study (0.24 to 0.87$)$ exceeded the range reported by Jones (1999). The wide range of variations in the abovementioned traits determined the final use of these cultivars. Because fruit weight plays an important role in determining fruit yield and fruit quality (van der Ploeg et al., 2007), it was necessary in our study to separately characterize the tomato cultivars into salad and cocktail groups. The positive correlations between year of release with fruit yield, harvest index, and leaf mineral concentration of salad cultivars indicates that breeding for yield improvement in large-fruited tomato has been successful. Similar to our finding, Barrios-Masias and Jackson (2014) and Higashide and Heuvelink (2009) also reported a significant increase in fruit yield of tomato cultivars released 
over the last 50 years which could be caused by enhanced fruit set, harvest index, and leaf photosynthetic capacity. Superior cultivars were derived from very different breeding backgrounds (Table S2). Salad tomato cultivars with superior performance particularly yield and harvest index, were mainly derived from recent breeding for intensive indoor production. Highyielding cocktail cultivars were mainly derived from organic and outdoor breeding programs. Many of the cultivars that stand out with important traits for organic low-input production were selected in outdoor breeding programs like the Organic Outdoor Tomato Project. This emphasizes the importance of selection in conditions with suboptimal climate and limited nutrient supply. From producer and consumer perspectives, 20 cultivars were selected for further evaluation based on stem and leaf biomass, fruit yield, TSS, and TA.

\subsubsection{Morphological and fruit quality characterization of the selected 20 cultivars}

In both years of evaluation, salad cultivars had better performance in growth and fruit yield, but their fruit quality was lower than that of cocktail cultivars (Fig. S4). Similar trends were also observed by Zörb et al. (2020), who evaluated 24 tomato cultivars and breeding lines under outdoor conditions. Higher stem and leaf biomass of cocktail compared with salad cultivars were caused by its greater plant height and leaf number (Van der Ploeg and Heuvelink, 2005). Salad cultivars have been mainly bred for improved fruit yield and harvested index; therefore, plant height and stem and leaf biomass are reduced (Barrios-Masias and Jackson, 2014; Causse et al., 2002). The absorbed mineral nutrients of these cultivars are allocated to the leaves for photosynthesis and to the fruits for yield formation. Nevertheless, fruit mineral concentrations and values of other quality characteristics are lower in salad cultivars than in cocktail cultivars because of dilution effects, which commonly occur when selective breeding successfully increases crop yields (Davis, 2009). Moreover, fruit quality traits might be considered less important in breeding for salad cultivars compared to cocktail cultivars (Causse et al., 2002; Zörb et al., 2020). Consumer preference for cocktail tomatoes has increased because 
of their attractive visual appearance and enhanced taste and aroma (Piombino et al., 2013; Rocha et al., 2013).

Considering genotypic differences between salad and cocktail cultivars, we also found high variations in plant growth and fruit quality characteristics in both years of evaluation (Tables 2.3 and 2.4). These variations provided the opportunity to further select cultivars with superior yield and fruit quality. Our results imply that improved growth does not necessarily result in higher fruit yield, but leaf mineral concentration remains an important factor because it is an indicator of plant nutritional status (Huett et al., 1997; Kirkby, 2012). Fruit weight is the important determinant of fruit yield. Fruit yield can be enhanced by increasing fruit weight, but the tradeoff between fruit weight and fruit number per plant should be minimized (BarriosMasias and Jackson, 2014). In organic farming, $\mathrm{N}$ and $\mathrm{P}$ are considered as limiting nutrients for plants (Horneburg and Myers, 2012). However, if we accept the optimal leaf N:P ratio to be between 14:1 and 16:1 (Abduelghader et al., 2011), plant biomass production (stem and leaf biomass and fruit yield) was not restricted in our study by the availability of these mineral nutrients in the soil. "Green Zebra", "Tastery F1", and "Primabella" had relatively high leaf N and $\mathrm{P}$ concentrations (Table 2.3). Potential $\mathrm{N}$ and $\mathrm{P}$ uptake by these cultivars may be enhanced by better root architecture and its response to mycorrhizal and plant growth-promoting rhizobacteria associations (Gamalero et al., 2004; Raklami et al., 2019), which become important with inadequate $\mathrm{N}$ and $\mathrm{P}$ availability in the soil.

It remains questionable whether high mineral concentrations in leaves also contribute to enhanced mineral concentrations in fruits. Therefore, we conducted correlation analyses of minerals in leaves and fruits. Interestingly, the results showed that salad cultivars with high $\mathrm{Mg}$ in leaves also contained high $\mathrm{Mg}$ in fruits. Moreover, fruit $\mathrm{Mg}$ also positively correlated with fruit TA and TPC (Fig. 2.3). These findings highlight the importance of $\mathrm{Mg}$ in improving tomato fruit quality, which has so far been underestimated in organic low-input conditions. In recent decades, greater emphasis has been placed on the balance of $\mathrm{N}, \mathrm{P}$, and $\mathrm{K}$ for improved crop 
production in organic farming because of the high rates of export from the farm, but their availabilities in the soil are frequently relatively low (Goulding et al., 2008). However, there are only a few studies on the improvement of soil exchangeable $\mathrm{Mg}$ in organic crop production. From a broader point of view, Mg plays an important role in photosynthesis and the transport of photoassimilates from sources to sink organs (Koch et al., 2019). Wang et al. (2020) reported that sufficient $\mathrm{Mg}$ supply increased vegetable leaf $\mathrm{Mg}$ by $34.4 \%$ and yield by $89 \%$ and considered $\mathrm{Mg}$ as an efficient nutrient to improve crop yield compared to the application of other nutrients. Kashinath et al. (2013) found a tomato yield increase from 7.7 to $17.9 \mathrm{t} \mathrm{ha}^{-1}$ because of optimum $\mathrm{Mg}$ application under conventional production. With respect to food quality, $\mathrm{Mg}$ concentration in vegetables has significantly declined over the past 50 years (Rosanoff, 2012). Dietary Mg deficiency poses a major problem in the world (Cakmak, 2013), and has been associated with cardiovascular diseases (Rosanoff, 2012). High Mg concentration in tomato fruits also contributes to enhanced $\mathrm{Mg}$ intake for consumers. We also found positive correlations of fruit Mg with fruit $\mathrm{P}, \mathrm{K}$, and $\mathrm{S}$ (Fig. 2.4), which suggested that increased accumulation of $\mathrm{Mg}$ might also result in high $\mathrm{P}, \mathrm{K}$, and $\mathrm{S}$ in fruits, due to the balance of these minerals in the soil (Hawkesford et al., 2012; Weih et al., 2018). The positive relationship between fruit Mg with TA and TPC indicates the contribution of Mg toward enhancing the flavor and the nutritional quality of tomato fruits. This contribution could be explained by an improved carbohydrate transport from leaves to fruits, which is facilitated by Mg nutrition (Bertin and Génard, 2018; Cakmak, 2013). Promising cultivars for one or combination of leaf $\mathrm{Mg}$, fruit $\mathrm{Mg}$, TA, and TPC traits are the salad cultivars "Auriga" and "Green Zebra" and "Supersweet $100 \mathrm{~F} 1$ " and the cocktail cultivars "Primabella", "Resi", and "Goldita".

\subsubsection{Tradeoffs between yield and fruit quality}

We observed negative correlations between fruit yield and fruit quality traits in salad and cocktail cultivars (Fig. 2.4). The results imply a tradeoff between achieving a high yield and improved fruit quality. Similar tendencies were also observed by Zörb et al. (2020). The negative 
correlations were stronger in salad than in cocktail cultivars, which suggested the possibility of improving fruit yield and fruit quality of cocktail cultivars. The same task is very challenging in salad cultivars. Despite the fact that there has been little improvement in the quality of salad cultivars, greater emphasis is at present being placed on improving traits, e.g., sugar concentration, due to a growing awareness that taste and flavor are determinant aspects of tomato marketability (Beckles, 2012). Cocktail cultivars are usually consumed fresh; therefore, fruit quality traits such as TSS and TA have become important. This information is crucial for producers as it helps them to select suitable cultivars based on marketing targets. For breeders, there are possibilities in crossing salad with cocktail cultivars, based on their breeding objectives (Zörb et al., 2020). Therefore, the characterization of salad and cocktail cultivars provides an outlook for organic breeding programs for improved tomato yield and fruit quality.

\subsection{Conclusion}

Our study revealed high genotypic variability of plant morphology and fruit quality of 60 tomato cultivars in organic low-input management. The selection of a subset of 20 cultivars was done for further characterization and selection of superior cultivars. The different response patterns of salad and cocktail cultivars provide an outlook on improving fruit yield and fruit quality in each group. According to this study, organic breeding has been successful for cocktail tomatoes but only to a limited extent for salad tomatoes. As an adaptation to the changed production systems, plant height, yield and harvest index of salad tomato cultivars increased with the year of release (1880-2015). It remains a challenge to simultaneously improve fruit yield and fruit quality of tomato in both groups; however, this up-to-date information is useful for producers and breeders to select superior cultivars for their production targets and breeding objectives. Our focus on the importance of Mg highlights a novel path for further research on improving soil available $\mathrm{Mg}$ of organic tomato production in order to enhance fruit mineral concentration and fruit quality in general. 


\section{Biodiversity in tomatoes: is it reflected in nutrient density and nutritional yields under organic outdoor production?}

Citation: Erika, C., Griebel, S., Naumann, M., Pawelzik, E., 2020. Biodiversity in Tomatoes: Is It Reflected in Nutrient Density and Nutritional Yields Under Organic Outdoor Production? Front. Plant Sci. 11, 589692. https://doi.org/10.3389/fpls.2020.589692

\subsection{Abstract}

In many regions of the world, human nutrition is still characterized by an insufficient intake of essential nutrients like minerals such as iron (Fe) and zinc ( $\mathrm{Zn})$. In view of decreasing resources and a growing world population, the efficiency and the sustainability of cultivation systems should be considered not only in terms of crop yield and profit margin but also in terms of the yield of essential nutrients. Tomatoes are the most consumed vegetable in the world. Organic outdoor tomato cultivation is generally characterized by a higher diversity of varieties and lower fertilization input compared to conventional production. A 2-year field experiment with a set of 20 cultivars was performed to evaluate their variation regarding fruit mineral concentrations [potassium $(\mathrm{K})$, calcium $(\mathrm{Ca})$, magnesium $(\mathrm{Mg})$, phosphorous $(\mathrm{P}), \mathrm{Fe}$, and $\mathrm{Zn}$ ], their contribution to the dietary reference intake (DRI), and the nutritional yields (adults ha ${ }^{-1}$ year $^{-1}$ ). Results show that mineral concentrations differed significantly by cultivar and by year. However, even though significant genotype-by-year effects appear, several cultivars exhibit high genotype stability across years for the single traits studied. Taking this together with medium-tohigh heritability, genetics strongly controls most studied traits. Among the cultivars, the contribution of $100 \mathrm{~g}$ fresh fruits varied from 4.5 to $7.7 \%$ for $\mathrm{K}, 0.8$ to $1.8 \%$ for $\mathrm{Ca}, 2.3$ to $4.4 \%$ for $\mathrm{Mg}, 3$ to $6.6 \%$ for $\mathrm{P}, 3.1$ to $6.9 \%$ for $\mathrm{Fe}$, and 1.9 to $4.2 \%$ for $\mathrm{Zn}$ to meet daily requirements. Based on average fruit yields per hectare, the cultivars varied with regard to the nutritional yields for all the studied minerals, but most strongly for Fe (44-120 adults $\mathrm{ha}^{-1}$ year $\left.^{-1}\right)$ and Zn (22-84 adults $\mathrm{ha}^{-1}$ year $^{-1}$ ). In terms of contribution to the DRI and nutritional yield for Fe, the cocktail cultivar "Bartelly F1" produced the highest results, while for $\mathrm{Zn}$ the salad cultivar "Bocati F1" showed the highest values. Our results show that the targeted use of tomato biodiversity in organic outdoor production can be suitable to achieve high fruit yields as well as to produce high nutritional yields per unit area, thus contributing to more effective land use and improved food security. These findings also provide valuable insights for tomato breeders to improve the tomato fruit quality while maintaining yield.

Keywords: tomato, biodiversity, nutrients, nutritional yield, dietary reference intake, genotypic stability

\subsection{Introduction}

The demand-oriented nutrition of a growing world population with a simultaneous reduction in the area of arable land per inhabitant and the shortage of other resources is one of the greatest challenges in the coming years (Springmann et al., 2018). In the past, increasing yields through improved nutrient utilization (e.g., Branca et al., 2013), crop protection, and 
cultivation techniques (Pretty and Bharucha, 2014) as well as breeding (Tieman et al., 2017) have been the main focus. Intensive land use has contributed to the increase in many environmental problems, such as rising emissions (Foley et al., 2011) as well as the contamination of soil and water with residues (Ridoutt et al., 2017). In global terms, there is still no substantial improvement in the nutritional situation, but rather many forms of malnutrition: on the one hand malnutrition due to a deficiency in micronutrients and obesity and diet-related diseases on the other hand (Fears et al., 2019). A major cause of this is the one- sided focus on the production of nutritional energy and protein, which has led to a steady decrease in the number of cultivated crops (FAOSTAT, 2019) and varieties within crops (Martin et al., 2019). Using FAO data, Martin et al. (2019) have compiled the changes in the number of cultivars for human nutrition over the period 1961-2014. In Western Europe, the number of tomato cultivars decreased by $78 \%$ and of potato cultivars by $77 \%$, while for wheat they increased by $43 \%$. Continuing concerns about global food security and food quality, particularly for increased nutrient content, need to be improved with reduced inputs (Tester and Langridge, 2010). While the biodiversity on and around agricultural land may be higher, organic agriculture may require more land than conventional to produce the same yield (Schrama et al., 2018).

Based on the increasing recognition of the link between sustainable land use and food security, more comprehensive evaluation parameters are necessary. The aim is not to consider the crop yield per hectare or calorie uptake as assessment criteria but the nutrients produced per hectare and the number of people who can be fed for a full year from the nutrients produced per hectare (DeFries et al., 2015). Nutritional yield (NY) was introduced, in the form described here, by DeFries et al. (2015) and is calculated on the basis of nutrient yield per hectare and the recommended food intake. This also allows the nutritional quality of the cultivated species to be considered. There are some studies on the NY of minerals in cereals (DeFries et al., 2015; Moreira-Ascarrunz et al., 2016), legumes (Graham et al., 2018), or of the constituents in several types of plant and animal foods (De Ruiter et al., 2018). Individual vegetable species, which are 
frequently consumed due to their easy availability and popularity, have not yet been examined in detail under the aspect of NY.

Globally, tomato (Solanum lycopersicum L.) is a major cultivated and consumed fruit vegetable with per capita consumption of either fresh or processed type of about $21 \mathrm{~kg}$ in $2017 \mathrm{or}$ around $19 \%$ of the total vegetable consumption per year (FAOSTAT, 2020) It is a rich source of macro- and micronutrients (Bauchet and Causse, 2012), vitamins, and phytochemicals for human diet (Tieman et al., 2017; Uluisik et al., 2016; Viskelis et al., 2015). In Germany, tomato production covered, in 2019, an area of 385.63 hectares, and organic production accounted for $21 \%$ of those cultivated (Statistischen Bundesamt, 2020). However, the quantities are expected to increase (Zörb et al., 2020) due to consumers' growing attention to organic systems for reasons of health, safety, and environmental benefits (Johansson et al., 2014; Ordóñez-Santos et al., 2011).

Tomatoes have been cultivated for about 400 years, and substantial breeding activities have been implemented for only eight decades. So far, more than 10,000 tomato cultivars have been developed (Bhattarai et al., 2018). Beginning in the 20th century, through intensive breeding activities, scientists and breeders worldwide created a wide array of morphologically different cultivars from the single species S. lycopersicum to modern tomato varieties with high variation in fruit weight, fruit size and shapes, and colors (Bai and Lindhout, 2007a).

The focus of modern breeding programs for fresh market use of tomato have usually laid emphasis on resistance, yield, and quality attributes such as firmness, color, texture, and traits related to fruit appearance (Foolad, 2007) rather than on sustainable production and nutritional quality (Mata-Nicolás et al., 2020).

In the present study, the approach of NY was applied to assess the trade-off between yields and nutrients, and the potential of tomato cultivars differing in fruit size and color to meet the human nutritional requirements of mineral nutrients. The objectives of the present work were (i) to estimate the production potential and contribution of the cultivars differing in their 
fruit type to meet human dietary needs for several nutrients, (ii) to assess the NY of the cultivars grown in a 2-year field experiment for selected macro- and micronutrients, and (iii) to evaluate the heritability of traits and the genotypic value and stability of the cultivars. The macronutrients $\mathrm{K}, \mathrm{Ca}, \mathrm{Mg}$, and $\mathrm{P}$ are the major elements in the tomato fruit (Hernández Suárez et al., 2007), and Fe and $\mathrm{Zn}$, as indispensable micronutrients, are involved in various metabolic processes (Costa et al., 2011; Jha and Warkentin, 2020).

The example of tomato will be used to investigate how a diversity of varieties is reflected in mineral composition and how this is expressed in NY. Selecting a cultivar with a greater NY will increase the contribution of tomato for human diet, with efficient use of land while still providing adequate amounts of nutrients and achieving agricultural sustainability.

\subsection{Materials and Methods}

\subsubsection{Plant material and cultural practice}

Twenty indeterminate tomato cultivars (Table 3.1) were grown in organic low-input conditions in the field under a well-ventilated rainout shelter. The study was carried out during summer 2015 and 2016 at the experimental research station of the University of Göttingen, Germany. The 20 cultivars included 12 cocktail and 8 salad cultivars and were grouped within their fruit type on the basis of the average fruit weight. The main determinant of the tomato type definition is not well specified in the scientific literature, although the traits related to fruit size and shape seem to be the most important factors for the fruit type classification (Lázaro, 2018). Cocktail tomatoes were described as small- sized type of tomatoes - they are hybrids of cherry tomatoes with normal-sized cultivars, e.g., salad tomatoes (Kagan-Zur and Mizrahi, 1993). In this study, cultivars with fruit weight less than $52 \mathrm{~g}$ were classified as cocktail tomatoes, while cultivars with higher fruit weight were categorized as salad tomatoes. The main selection criteria for these cultivars were the yield and the parameters that determine the taste and the aroma formation. 
The seeds were germinated in the substrate "Anzuchtsubstrat Organisch" (Kleeschulte GmbH \& Co. KG, Germany) on March 30, and the seedlings were potted after 20 days in the substrate "Hawita Fruhstorfer Bio-Aussaat-und Kräutererde" (HAWITA- Gruppe GmbH, Germany). The seedlings were maintained under greenhouse conditions $\left(20^{\circ} \mathrm{C}\right.$ day, $18{ }^{\circ} \mathrm{C}$ night, 16/8 h) before being transplanted to the field. The field trials were established in a randomized complete block design with eight replications. The cultivars were assessed with one plant per plot in 2015 and two plants per plot in 2016. All the plants were cultivated and spaced at $50 \mathrm{~cm}$ within the row and spaced at $100 \mathrm{~cm}$ at a population of two plants per square meter. In both years, the plants were grown under organic low-input conditions without fertilization and moderate irrigation. Further information on the growth conditions in the field is described in

Table 3.2.

Table 3.1 Overview of the tested cultivars

\begin{tabular}{lllrr}
\hline \multirow{2}{*}{ Cultivar } & & & \multicolumn{2}{c}{ Fruit weight $^{2}(\mathrm{~g})$} \\
\cline { 4 - 5 } & Fruit type $^{1}$ & Fruit color & 2015 & 2016 \\
\hline Goldita & Cocktail & orange & 15.6 & 17.2 \\
Supersweet 100 F1 & Cocktail & red & 15.7 & 13.7 \\
Resi & Cocktail & red & 17.3 & 20.4 \\
Bartelly F1 & Cocktail & red & 18.4 & 14.9 \\
Benarys Gartenfreude & Cocktail & red & 18.5 & 19.1 \\
Primavera & Cocktail & red & 21.3 & 21.6 \\
Black Cherry & Cocktail & red-brown & 23.0 & 25.2 \\
Sakura F1 & Cocktail & red & 23.7 & 24.1 \\
Primabella & Cocktail & red & 28.1 & 27.8 \\
Tastery F1 & Cocktail & red & 33.5 & 32.1 \\
Annamay F1 & Cocktail & red & 46.0 & 48.2 \\
Amoroso F1 & Cocktail & red & 50.8 & 47.4 \\
Campari F1 & Salad & red & 63.3 & 62.5 \\
Auriga & Salad & orange & 71.5 & 75.1 \\
Harzfeuer F1 & Salad & red & 76.4 & 72.1 \\
Roterno F1 & Salad & red & 106.7 & 104.6 \\
Lyterno F1 & Salad & red & 115.9 & 115 \\
Bocati F1 & Salad & red & 124.4 & 114.4 \\
Cappricia F1 & Salad & red & 131.5 & 124.1 \\
Green Zebra & Salad & green-yellow & 153.0 & 136.4 \\
\hline
\end{tabular}

${ }^{1}$ Fruit type is defined by an average fruit weight of $<52 \mathrm{~g}$ for cocktail cultivars and $>52 \mathrm{~g}$ for salad cultivars

${ }^{2}$ Fruit weight was calculated as average single fruit weight of each cultivar for each year derived from eight biological replicates 


\subsubsection{Determination of fruit yield}

At full maturity, the fruits were harvested at 2-week intervals, starting from 9 weeks after planting (WAP) in 2015 and 8 WAP in 2016. All the plants of each block from eight biological replications were harvested and weighed by pooled replications to obtain the total yield ( $\mathrm{kg}$ plant $^{-1}$ ) of fully ripe healthy fruits. Next, the mean fruit weight for each of the 20 evaluated plants was used to calculate the fruit yield per hectare and converted to fruit yield in tons per hectare (tons $\left.\mathrm{ha}^{-1}\right)$.

Table 3.2 Information about field location and cultural practices in 2015 and 2016

\begin{tabular}{|c|c|c|}
\hline & 2015 & 2016 \\
\hline Location & \multicolumn{2}{|c|}{$51^{\circ} 30^{\prime} 17.6^{\prime \prime N}, 9^{\circ} 55^{\prime} 16.2^{\prime \prime E}$} \\
\hline District/region & \multicolumn{2}{|c|}{ Goettingen, Lower Saxony } \\
\hline Experimental design & \multicolumn{2}{|c|}{ RCBD, eight replicates } \\
\hline Soil type/properties & \multicolumn{2}{|c|}{ Fluventic Eutrochrept soil } \\
\hline Average temperature $\left({ }^{\circ} \mathrm{C}\right)^{1}$ & $19 \pm 4.6$ & $19 \pm 7.0$ \\
\hline Average relative humidity $(\%)^{1}$ & $75 \pm 10.7$ & $75 \pm 18.9$ \\
\hline Pre-crop & faba bean (Vicia faba) & winter wheat (Triticum aestivum) \\
\hline -Soil pH & 7 & 6.9 \\
\hline -Humus content $(\%)$ & 1.89 & 1.87 \\
\hline -Phosphorus (mg 100g-1 soil) & 7 & 6 \\
\hline -Magnesium (mg $100 \mathrm{~g}^{-1}$ soil) & 4 & 7 \\
\hline -Potassium (mg 100g $\mathrm{g}^{-1}$ soil) & 9 & 9 \\
\hline Planting date & May $20^{\text {th }}$ & May $20^{\text {th }}$ \\
\hline Planting arrangement & one plant per plot & two plants per plot \\
\hline Plant density (plants ha ${ }^{-1}$ ) & \multicolumn{2}{|r|}{20.000} \\
\hline Weed control & \multirow{2}{*}{\multicolumn{2}{|c|}{$\begin{array}{c}\text { space between rows were covered with plastic layers } \\
\text { weekly, hand pruning }\end{array}$}} \\
\hline Main shoot pruning & & \\
\hline $\begin{array}{l}\text { Frequency/total amount of } \\
\text { irrigation }\end{array}$ & \multicolumn{2}{|c|}{ weekly/150 $1 \mathrm{~m}^{-2}$} \\
\hline
\end{tabular}

\subsubsection{Determination of minerals in fruits}

Samples from two harvest dates for both years (2015: 13 WAP and 18 WAP; 2016: 14 WAP and 19 WAP) were used for the determination of mineral concentration. At harvest, the fully ripe fruits of eight biological replicates were combined into four pooled replicates for further analysis. Each 10 fruits of cocktail cultivars and 3 fruits of salad cultivars were cut into wedges. The fruits were freeze-dried (EPSILON 2-40, Christ, Osterode am Harz, Germany) for 4 days and were later ground by using a ball mill $(45 \mathrm{~s}$ at $30 \mathrm{~Hz}$; Retsch, model: MM 400, Germany) to get fine powder of up to $0.5 \mathrm{~mm}$ in particle size. The mineral concentration was 
determined according to Koch et al., (2019), with minor changes. In total, $100 \mathrm{mg}$ of the ground fruit material was weighed in a Teflon vessel and digested in $4 \mathrm{ml}$ of $65 \%(\mathrm{v} / \mathrm{v})$ concentrated $\mathrm{HNO}_{3}$ and $2 \mathrm{ml}$ of $30 \%$ concentrated $\mathrm{H}_{2} \mathrm{O}_{2}$ (Carl Roth $\mathrm{GmbH} \& \mathrm{Co}$. KG, Germany) for 75 min at $200{ }^{\circ} \mathrm{C}$ and 40 bar in a microwave oven (ETHOS Professional Microwave System, MLS GmbH, Germany). After microwave digestion, the samples were transferred to volumetric flasks and filled up with distilled water to a total volume of $25 \mathrm{ml}$. The concentrations of macronutrients $(\mathrm{Ca}, \mathrm{K}, \mathrm{Mg}$, and $\mathrm{P})$ and micronutrients $(\mathrm{Fe}$ and $\mathrm{Zn})$ were analyzed using inductively coupled plasma-optical emission spectrometry (Vista-RL, Variance Inc., Palo Alto, CA, United States). The concentrations of minerals were expressed in $\mathrm{mg} / 100 \mathrm{~g}$ fresh weight $(\mathrm{FW})$.

\subsubsection{Calculations and statistical analysis}

In this study, the fraction of the dietary reference intake (DRI) was defined as the percentage of the nutrient requirement provided by $100 \mathrm{~g}$ of tomatoes based on the assessed mineral concentration for each cultivar. The DRIs are derived from the values released by the Food and Nutrition Board of the Institute of Medicine (IOM) and have been widely used in recommending quantitative estimates of nutrient intakes for the United States and Canadian populations (Institute of Medicine, 2006). The fraction of DRI is calculated as grams of a mineral divided by the DRI values. The values for $\mathrm{DRI}_{\mathrm{i}}$ are taken either from the recommended daily allowance or the adequate intake for average adult males and females (not pregnant or lactating) aged between 19 and 50 years (Table S4). The fraction of DRI of each mineral i from a tomato cultivar $\mathrm{j}$ was calculated as:

fraction $D R I=\frac{g_{i} / 100 g_{j}}{D R I_{i}}$

where $g_{i} / 100 g_{j}$ is the value for grams of a mineral $\mathrm{i}$ in $100 \mathrm{~g}$ of a tomato cultivar $\mathrm{j}$. The NY weighs the conventional yield measure (ton $\mathrm{ha}^{-1}$ ) by its nutritional content, and this value is divided by the dietary requirement necessary for one year (DeFries et al., 2016). This metric estimates the number of adults (average for male and female between 19 and 50 years old) who can fulfill $100 \%$ of their DRI for selected nutrients from 1 ha for 1 year (DeFries et al., 2016). 
Therefore, the NY of a mineral i from a tomato cultivar $\mathrm{j}$ was calculated as:

$N Y_{i j}=$ fraction of $D R I_{i} / 100 g_{j} \times$ tons $_{j} /$ ha $/$ year $\times 10^{4} / 365$

where the fraction of $D R I_{i} / 100 g_{j}=g_{i} / 100 g_{j} / D R I_{i}$

The fraction of DRI of nutrient $i$, provided by 100 grams of cultivar $j$, was calculated as grams of each mineral $\mathrm{i}$ in $100 \mathrm{~g}$ of each tomato cultivar $\mathrm{j}$ divided by the daily dietary requirement for the respective mineral $\mathrm{i}\left(\mathrm{g}_{\mathrm{i}} / 100 \mathrm{~g}_{\mathrm{j}}\right) / \mathrm{DRI}_{\mathrm{i}}$. For example, a tomato's $\mathrm{NY}$ for $\mathrm{K}$ is derived from the fraction of DRI for K supplied by $100 \mathrm{~g}$ of tomato (which is grams of $\mathrm{K}$ in 100 $\mathrm{g}$ of tomatoes divided by the daily dietary requirement for K) multiplied by the yield for the respective cultivar.

Four replications of each cultivar were maintained in each year of cultivation. The data were presented as means of each cultivar over two cultivation years. The effect of cultivar and year on the mineral concentration was evaluated by means of analysis of variance. The variances between the cultivar and the treatment means for all the traits were separated by pairwise means comparisons with Tukey's test at $\mathrm{p}<0.05$ by using the STATISTIX statistical software (Version $8.0)$.

The heritability and the genotypic values were calculated for single years based on a linear, fully randomized model using the R package lme4 (Bates et al., 2015). Heritability $\left(\mathrm{H}^{2}\right)$ was calculated as broad sense heritability for single years:

$\mathrm{H}^{2}=\frac{\delta^{2} g}{\left(\delta^{2} g+\delta^{2} e\right)}$

where $\delta^{2} \mathrm{~g}$ was the estimated genetic variance and $\delta^{2} \mathrm{e}$ was the residual variance. Best linear unbiased predictors (BLUPs) extracted from the model were reported as genotypic values. The genotypic values and the grand mean were summed up to obtain the predicted means of a trait for a single cultivar. Pearson and Spearman's rank correlations were calculated between each year's BLUPs of a single trait.

\subsection{Results}

\subsubsection{Fruit mineral concentrations and their contribution to the dietary reference}


The concentrations of macronutrients in the fruits of the cocktail cultivars ranged on the basis of fresh weight for $\mathrm{K}$ between $211 \mathrm{mg} 100 \mathrm{~g}^{-1}$ ("Roterno $\mathrm{F} 1$ ") and $361 \mathrm{mg} 100 \mathrm{~g}^{-1}$ (“Supersweet 100 F1"), Ca between 7.9 mg $100 \mathrm{~g}^{-1}$ (“Auriga”) and $17.7 \mathrm{mg} 100 \mathrm{~g}^{-1}$ ("Resi”); for Mg between $8.4 \mathrm{mg} 100 \mathrm{~g}^{-1}$ (“Cappricia F1") and $16 \mathrm{mg} 100 \mathrm{~g}^{-1}$ ("Supersweet $100 \mathrm{~F} 1$ ”); and for P between $20.9 \mathrm{mg} 100 \mathrm{~g}^{-1}$ ("Roterno F1") and $46.1 \mathrm{mg} 100 \mathrm{~g}^{-1}$ ("Resi”). The contents for $\mathrm{Zn}$ ranged between $0.18 \mathrm{mg} 100 \mathrm{~g}^{-1}$ ("Cappricia F1") and $0.40 \mathrm{mg} 100 \mathrm{~g}^{-1}$ ("Resi"), while the Fe content varied from $0.41 \mathrm{mg} 100 \mathrm{~g}^{-1}$ (“Cappricia F1") to $0.90 \mathrm{mg} 100 \mathrm{~g}^{-1}$ ("Resi"). The traits with a higher coefficient of variation (CV) were the concentrations of $\mathrm{Zn}(43.9 \%), \mathrm{Fe}(37.4 \%)$, and $\mathrm{Ca}(23.2 \%)$, while the lowest $\mathrm{CV}$ was found in the concentrations of $\mathrm{K}, \mathrm{Mg}$, and $\mathrm{P}$. Considering the fruit type, i.e. cocktail versus salad, it was found that cocktail cultivars tended to have higher concentrations of all nutrients studied. Based on the averaged sums of all nutrients, the cocktail cultivars contained about 20\% higher contents than the salad cultivars (Table 3.3).

Table 3.3 Fruit concentrations of $\mathrm{K}, \mathrm{Ca}, \mathrm{Mg}, \mathrm{P}, \mathrm{Fe}$ and $\mathrm{Zn}\left(\mathrm{mg} 100 \mathrm{~g}^{-1} \mathrm{FW}\right)$ by cultivar. The cultivars are arranged according to their average single fruit weight (see Table 3.1); cocktail cultivars are indicated in bold, the others are salad cultivars

\begin{tabular}{llrllll}
\hline Cultivar & \multicolumn{6}{c}{ Concentration $\left(\mathrm{mg} 100 \mathrm{~g}^{-1} \mathrm{FM}\right)$} \\
\hline Goldita & $\mathrm{K}$ & $\mathrm{Ca}$ & $\mathrm{Mg}$ & $\mathrm{P}$ & $\mathrm{Fe}$ & $\mathrm{Zn}$ \\
Supersweet 100 F1 & $312 \pm 32$ & $16.1 \pm 4.2$ & $14.0 \pm 2.0$ & $32.3 \pm 6.4$ & $0.76 \pm 0.37$ & $0.38 \pm 0.25$ \\
Resi & $361 \pm 45$ & $10.2 \pm 2.1$ & $16.0 \pm 1.2$ & $40.8 \pm 4.6$ & $0.79 \pm 0.27$ & $0.39 \pm 0.15$ \\
Bartelly F1 & $323 \pm 37$ & $17.7 \pm 4.0$ & $15.8 \pm 3.7$ & $46.1 \pm 8.5$ & $0.90 \pm 0.15$ & $0.40 \pm 0.16$ \\
Benarys Gartenfreude & $336 \pm 64$ & $8.8 \pm 3.3$ & $14.2 \pm 1.5$ & $35.8 \pm 4.8$ & $0.69 \pm 0.21$ & $0.34 \pm 0.08$ \\
Primavera & $278 \pm 27$ & $12.2 \pm 2.2$ & $11.2 \pm 3.5$ & $36.1 \pm 7.7$ & $0.82 \pm 0.54$ & $0.37 \pm 0.20$ \\
Black Cherry & $263 \pm 59$ & $11.1 \pm 2.9$ & $12.4 \pm 2.7$ & $29.9 \pm 3.2$ & $0.73 \pm 0.30$ & $0.39 \pm 0.37$ \\
Sakura F1 & $305 \pm 41$ & $12.1 \pm 3.0$ & $13.6 \pm 2.1$ & $31.8 \pm 3.5$ & $0.68 \pm 0.22$ & $0.31 \pm 0.08$ \\
Primabella & $324 \pm 39$ & $11.5 \pm 3.6$ & $14.2 \pm 1.7$ & $35.8 \pm 5.1$ & $0.78 \pm 0.19$ & $0.32 \pm 0.08$ \\
Tastery F1 & $271 \pm 28$ & $11.9 \pm 2.8$ & $12.2 \pm 1.4$ & $29.4 \pm 4.0$ & $0.62 \pm 0.13$ & $0.30 \pm 0.13$ \\
Annamay F1 & $299 \pm 29$ & $13.3 \pm 2.4$ & $13.5 \pm 1.3$ & $29.3 \pm 3.1$ & $0.62 \pm 0.15$ & $0.35 \pm 0.20$ \\
Amoroso F1 & $244 \pm 23$ & $12.4 \pm 2.0$ & $10.6 \pm 1.1$ & $27.7 \pm 2.3$ & $0.61 \pm 0.21$ & $0.28 \pm 0.10$ \\
Campari F1 & $278 \pm 34$ & $12.0 \pm 2.3$ & $12.0 \pm 1.4$ & $29.2 \pm 4.1$ & $0.60 \pm 0.43$ & $0.26 \pm 0.12$ \\
Auriga & $282 \pm 34$ & $7.9 \pm 1.3$ & $13.2 \pm 1.3$ & $27.3 \pm 3.2$ & $0.49 \pm 0.16$ & $0.22 \pm 0.04$ \\
Harzfeuer F1 & $294 \pm 34$ & $11.1 \pm 3.0$ & $10.7 \pm 1.1$ & $26.1 \pm 3.2$ & $0.54 \pm 0.23$ & $0.24 \pm 0.06$ \\
Roterno F1 & $211 \pm 58$ & $12.4 \pm 4.0$ & $8.6 \pm 2.4$ & $20.9 \pm 6.3$ & $0.42 \pm 0.12$ & $0.19 \pm 0.04$ \\
Lyterno F1 & $232 \pm 23$ & $12.8 \pm 3.6$ & $9.3 \pm 0.6$ & $24.3 \pm 3.4$ & $0.44 \pm 0.12$ & $0.21 \pm 0.06$ \\
Bocati F1 & $217 \pm 35$ & $11.9 \pm 2.7$ & $9.1 \pm 1.4$ & $21.6 \pm 3.6$ & $0.43 \pm 0.15$ & $0.19 \pm 0.05$ \\
Cappricia F1 & $236 \pm 41$ & $13.9 \pm 3.1$ & $8.4 \pm 1.0$ & $23.3 \pm 4.8$ & $0.41 \pm 0.17$ & $0.18 \pm 0.07$ \\
Green Zebra & $290 \pm 34$ & $12.3 \pm 2.1$ & $14.1 \pm 1.5$ & $29.4 \pm 3.4$ & $0.55 \pm 0.17$ & $0.24 \pm 0.08$ \\
Mean & 285.2 & 12.3 & 12.3 & 30.3 & 0.6 & 0.3 \\
CV (\%) & 12.9 & 23.2 & 13.0 & 14.8 & 37.4 & 43.9 \\
HSD & 46.20 & 3.57 & 2.00 & 5.61 & 0.29 & 0.16 \\
Year & & & & & & \\
2015 & $274 \pm 43.4$ & $12.0 \pm 3.8$ & $11.7 \pm 2.2$ & $29.6 \pm 6.4$ & $0.53 \pm 0.26$ & $0.34 \pm 0.20$ \\
& & & & & &
\end{tabular}


2016

Source of variation

Cultivar

Year

Cultivar $\times$ Year

Mean values are given for each 0 deviation (SD) $\mathrm{CV}=$ coefficient of variation, $\mathrm{HSD}=$ honestly significant different at $\mathrm{p}<0.05$. Significance: $\mathrm{ns}=$ not significant; $* * *, * * *$ significant for $\mathrm{p} \leq 0.05$, and $\mathrm{p} \leq 0.0,1$ and $\mathrm{p} \leq 0.001$, respectively

Overall, the nutrient densities of the determined minerals were lower in 2015 than in 2016, except for $\mathrm{Zn}$. The cultivar had a very strong effect on the variance of all nutrient concentrations, followed by the effect of year-except for $\mathrm{Ca}$. In general, the cultivar was dependent on the year of cultivation at different significance levels.

Over all cultivars and years, the study showed that tomatoes can contribute for $\mathrm{K}$ with $6.1 \%$ at most to the DRI of this nutrient, and it varied from $4.5 \%$ ("Roterno F1") to $7.7 \%$

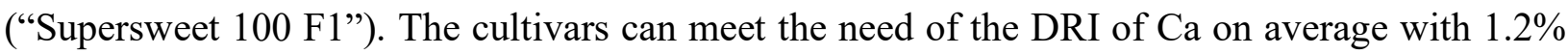
within a range from $0.8 \%$ ("Auriga") to $1.8 \%$ ("Resi"). Fresh consumption of $100 \mathrm{~g}$ of the studied cultivars will provide Mg from 2.3\% ("Cappricia F1") to 4.4\% ("Resi" and "Supersweet 100 F1") and P from 3.0\% ("Roterno F1") to 6.6\% ("Resi") of the DRI (Table 3.4). Based on the presented data, the consumption of $100 \mathrm{~g}$ tomato fruits will provide on average 3.4 and $4.3 \%$ of the DRI of $\mathrm{Mg}$ and $\mathrm{P}$, respectively. When the fruit type was considered, it was shown that cocktail cultivars contributed more to the DRI than salad cultivars; i.e., "Resi" contributed at most to the $\mathrm{Ca}, \mathrm{Mg}$, and $\mathrm{P}$ requirements in human nutrition, while "Supersweet $100 \mathrm{~F} 1$ " was the highest contributor for providing $\mathrm{K}$ and $\mathrm{Mg}$.

The studied cultivars can contribute with an average of $4.8 \%$ for Fe and $3.1 \%$ for $\mathrm{Zn}$ to the DRI. Among the cultivars, the fraction of DRI for Fe ranged between 3.1\% in "Cappricia F1" and $6.9 \%$ in "Resi." For $\mathrm{Zn}$, the lowest contribution to the DRI with $1.9 \%$ was found in "Cappricia F1" and the highest with 4.2\% in "Resi" (Table 3.4).

\subsubsection{Fruit yield and its variation in nutritional yield across years}


The cultivars showed a large variation in average fruit yield and NY (Table 3.5). The cultivar with the highest average fruit yield across the 2 years was the salad cultivar "Roterno F1" (116 tons ha $\left.{ }^{-1}\right)$, followed by other salad cultivars "Lyterno F1" (110.3 tons ha $\left.{ }^{-1}\right)$, "Bocati F1" (112.7 tons $\mathrm{ha}^{-1}$ ), and "Cappricia F1" (112.1 tons $\left.\mathrm{ha}^{-1}\right)$. The lowest average fruit yield showed the cocktail cultivar "Resi" (22.7 tons $\mathrm{ha}^{-1}$ ), which significantly differed from all the other investigated cultivars. On average, the cultivars produced 70.4 tons $\mathrm{ha}^{-1}$ in 2015 and 77.4 tons $\mathrm{ha}^{-1}$ of ripe fruits in 2016 . Although in both cultivation years the mean temperature $\left(19^{\circ} \mathrm{C}\right)$ and relative humidity (75\%) in the field were similar (Table 3.2), low temperatures (less than 10 ${ }^{\circ} \mathrm{C}$ ) occurred at early 18th WAP in 2015 and persisted for several days, while in 2016 temperatures below $10{ }^{\circ} \mathrm{C}$ were only observed later than 18th WAP (Figs S5.1 and S5.2).

Table 3.4 Contribution of cultivars to the dietary reference intake (DRI) for $\mathrm{K}, \mathrm{Ca}, \mathrm{Mg}, \mathrm{P}, \mathrm{Fe}$ and $\mathrm{Zn}$. The DRI is the fraction (\%) of mineral requirement provided by $100 \mathrm{~g}$ fresh tomato fruit based on the mineral concentration for each cultivar (see Table 3.3). The cultivars are arranged according to average single fruit weight (see Table 3.1); cocktail cultivars are indicated in bold, the others are salad cultivars

\begin{tabular}{|c|c|c|c|c|c|c|}
\hline \multirow[t]{2}{*}{ Cultivar } & \multicolumn{6}{|c|}{ DRI $(\%)$} \\
\hline & $\mathrm{K}$ & $\mathrm{Ca}$ & $\mathrm{Mg}$ & $\mathrm{P}$ & $\mathrm{Fe}$ & $\mathrm{Zn}$ \\
\hline Goldita & $6.6 \pm 0.7$ & $1.6 \pm 0.4$ & $3.9 \pm 0.5$ & $4.6 \pm 0.9$ & $5.9 \pm 2.8$ & $4.0 \pm 2.6$ \\
\hline Supersweet 100 F1 & $7.7 \pm 1.0$ & $1.0 \pm 0.2$ & $4.4 \pm 0.3$ & $5.8 \pm 0.7$ & $6.1 \pm 2.1$ & $4.1 \pm 1.5$ \\
\hline Resi & $7.2 \pm 1.3$ & $1.8 \pm 0.4$ & $4.4 \pm 1.0$ & $6.6 \pm 1.2$ & $6.9 \pm 1.2$ & $4.2 \pm 1.6$ \\
\hline Bartelly F1 & $6.9 \pm 0.8$ & $1.5 \pm 0.3$ & $3.9 \pm 0.4$ & $5.1 \pm 0.7$ & $5.3 \pm 1.6$ & $3.6 \pm 0.8$ \\
\hline Benarys Gartenfreude & $7.2 \pm 1.4$ & $0.9 \pm 0.2$ & $3.6 \pm 1.0$ & $5.2 \pm 1.1$ & $6.3 \pm 4.1$ & $3.9 \pm 2.2$ \\
\hline Primavera & $5.9 \pm 0.6$ & $1.2 \pm 0.2$ & $3.1 \pm 0.4$ & $4.3 \pm 0.5$ & $5.6 \pm 2.3$ & $3.1 \pm 0.6$ \\
\hline Black Cherry & $5.6 \pm 1.3$ & $1.1 \pm 0.3$ & $3.4 \pm 0.7$ & $4.0 \pm 0.9$ & $5.2 \pm 1.7$ & $3.2 \pm 0.9$ \\
\hline Sakura F1 & $6.5 \pm 0.9$ & $1.2 \pm 0.3$ & $3.7 \pm 0.6$ & $4.5 \pm 0.5$ & $5.4 \pm 2.8$ & $3.3 \pm 0.9$ \\
\hline Primabella & $6.9 \pm 0.8$ & $1.1 \pm 0.4$ & $3.9 \pm 0.5$ & $5.1 \pm 0.7$ & $6.0 \pm 1.5$ & $3.5 \pm 1.4$ \\
\hline Tastery F1 & $5.8 \pm 0.6$ & $1.2 \pm 0.3$ & $3.4 \pm 0.4$ & $4.2 \pm 0.6$ & $4.7 \pm 1.0$ & $3.2 \pm 1.3$ \\
\hline Annamay F1 & $6.4 \pm 0.6$ & $1.3 \pm 0.2$ & $3.7 \pm 0.4$ & $4.2 \pm 0.5$ & $4.8 \pm 1.2$ & $3.6 \pm 2.1$ \\
\hline Amoroso F1 & $5.2 \pm 0.5$ & $1.2 \pm 0.2$ & $2.9 \pm 0.3$ & $4.0 \pm 0.3$ & $4.7 \pm 1.6$ & $3.0 \pm 1.0$ \\
\hline Campari F1 & $5.9 \pm 0.7$ & $1.2 \pm 0.2$ & $3.3 \pm 0.4$ & $4.2 \pm 0.6$ & $4.6 \pm 3.3$ & $2.7 \pm 1.3$ \\
\hline Auriga & $6.0 \pm 0.7$ & $0.8 \pm 0.1$ & $3.6 \pm 0.4$ & $3.9 \pm 0.5$ & $3.8 \pm 1.2$ & $2.3 \pm 0.4$ \\
\hline Harzfeuer F1 & $6.3 \pm 0.7$ & $1.1 \pm 0.3$ & $3.0 \pm 0.3$ & $3.7 \pm 0.5$ & $4.1 \pm 1.8$ & $2.5 \pm 0.7$ \\
\hline Roterno F1 & $4.5 \pm 1.2$ & $1.2 \pm 0.4$ & $2.4 \pm 0.7$ & $3.0 \pm 0.9$ & $3.2 \pm 1.0$ & $2.0 \pm 0.5$ \\
\hline Lyterno F1 & $4.9 \pm 0.5$ & $1.3 \pm 0.4$ & $2.6 \pm 0.2$ & $3.5 \pm 0.5$ & $3.4 \pm 0.9$ & $2.2 \pm 0.6$ \\
\hline Bocati F1 & $4.6 \pm 0.7$ & $1.2 \pm 0.3$ & $2.5 \pm 0.4$ & $3.1 \pm 0.5$ & $3.3 \pm 1.2$ & $1.9 \pm 0.6$ \\
\hline Cappricia F1 & $5.0 \pm 0.9$ & $1.4 \pm 0.3$ & $2.3 \pm 0.3$ & $3.3 \pm 0.7$ & $3.1 \pm 1.3$ & $1.9 \pm 0.7$ \\
\hline Green Zebra & $6.2 \pm 0.7$ & $1.2 \pm 0.2$ & $3.9 \pm 0.4$ & $4.2 \pm 0.5$ & $4.2 \pm 1.3$ & $2.5 \pm 0.8$ \\
\hline Mean & 6.1 & 1.2 & 3.4 & 4.3 & 4.8 & 3.1 \\
\hline$C V$ & 12.9 & 23.2 & 13.0 & 14.8 & 38.8 & 35.3 \\
\hline$H S D$ & 0.98 & 0.36 & 0.55 & 0.80 & 2.94 & 1.37 \\
\hline
\end{tabular}


Mean values are given for each of 20 cultivars as mean from boths years and from each year \pm standard deviation (SD). $\mathrm{CV}=$ coefficient of variation, $\mathrm{HSD}=$ honestly significant different at $\mathrm{p} \leq 0.05$.

The NYs of $\mathrm{Ca}, \mathrm{K}, \mathrm{Mg}$, and $\mathrm{P}$ varied significantly among the cultivars. The variations of NY for the different minerals were as follows: K (46-155 adults year $\left.{ }^{-1} \mathrm{ha}^{-1}\right), \mathrm{Ca}(11-43$ adults year $\left.^{-1} \mathrm{ha}^{-1}\right), \mathrm{Mg}\left(28-88\right.$ adults year $\left.{ }^{-1} \mathrm{ha}^{-1}\right)$, and $\mathrm{P}$ (42-114 adults year $\left.{ }^{-1} \mathrm{ha}^{-1}\right)$. As shown in Table 3.5, "Bartelly F1" was the highest yielding cultivar among cocktail tomatoes and showed the highest NY for all nutrients. "Resi," known as the lowest yielding cultivar in the present investigation, had also the lowest NY for all the studied minerals.

The salad varieties showed a slightly greater variation in relation to NY. While "Auriga" produced the lowest NY for all the other nutrients with the exception of K ("Green Zebra") and Mg ("Harzfeuer F1"), the highest NYs were achieved as follows: by "Cappricia F1" for K and Ca, by "Lyterno F1" for Mg, P, and Fe, by "Roterno F1" for Fe, and by "Bocati F1" for Zn. As compared to the NY of macronutrients, higher $\mathrm{CV}$ was found for $\mathrm{Fe}$ and $\mathrm{Zn}$ with values of 37.1 and 31.8\%, respectively (Table 3.5).

Table 3.5 Variation of fruit yield and nutritional yield (adults year ${ }^{-1} \mathrm{ha}^{-1}$ ) for $\mathrm{K}, \mathrm{Ca}, \mathrm{Mg}, \mathrm{P}, \mathrm{Fe}$ and $\mathrm{Zn}$ by cultivar. The NY is the number of adult males and females who can obtain $100 \%$ of annual recommended dietary allowance from one ha of land per year. The cultivars are arranged according to average single fruit weight (see Table 3.1); cocktail cultivars are indicated in bold, the others are salad cultivars

\begin{tabular}{|c|c|c|c|c|c|c|c|}
\hline \multirow[t]{2}{*}{ Cultivar } & \multirow[t]{2}{*}{$\begin{array}{l}\text { Fruit yield } \\
\left(\text { tons } \mathrm{ha}^{-1}\right)\end{array}$} & \multicolumn{6}{|c|}{ Nutritional yield (adults year ${ }^{-1} \mathrm{ha}^{-1}$ ) } \\
\hline & & $\mathrm{K}$ & $\mathrm{Ca}$ & $\mathrm{Mg}$ & $\mathrm{P}$ & $\mathrm{Fe}$ & $\mathrm{Zn}$ \\
\hline $\begin{array}{l}\text { Goldita } \\
\text { Supersweet }\end{array}$ & $42.5 \pm 5.6$ & $78 \pm 16.6$ & $19 \pm$ & $45 \pm 9.0$ & 54 & $71 \pm$ & $44 \pm 15.1$ \\
\hline $100 \mathrm{~F} 1$ & $58.0 \pm 7.9$ & $123 \pm 27.3$ & $16 \pm 3.7$ & $70 \pm 13.4$ & $93 \pm 17.3$ & $100 \pm 38.9$ & $55 \pm 26.4$ \\
\hline Resi & $22.7 \pm 5.1$ & $46 \pm 17.2$ & $11 \pm 4.5$ & $28 \pm 11.7$ & $42 \pm 15.6$ & $44 \pm 13.0$ & $22 \pm 11.0$ \\
\hline $\begin{array}{l}\text { Bartelly F1 } \\
\text { Benarys }\end{array}$ & $81.5 \pm 5.4$ & $154 \pm 23.1$ & $32 \pm 7.0$ & $88 \pm 13.2$ & $114 \pm 19$ & $120 \pm 38.8$ & $72 \pm 20.7$ \\
\hline Gartenfreude & $56.5 \pm 5.3$ & $112 \pm 30.6$ & $14 \pm 4.2$ & $57 \pm 20.0$ & $81 \pm 23.8$ & $102 \pm 72.8$ & $45 \pm 15.9$ \\
\hline Primavera & $76.6 \pm 6.2$ & $125 \pm 19.7$ & $26 \pm 6.3$ & $65 \pm 11.4$ & $90 \pm 13.9$ & $118 \pm 48.3$ & $61 \pm 16.6$ \\
\hline Black Cherry & $62.8 \pm 4.1$ & $96 \pm 22.8$ & $19 \pm 5.3$ & $59 \pm 13.4$ & $68 \pm 15.8$ & $91 \pm 30.5$ & $49 \pm 19.6$ \\
\hline Sakura F1 & $66.3 \pm 7.2$ & $118 \pm 21.6$ & $22 \pm 6.3$ & $68 \pm 14.2$ & $83 \pm 14.5$ & $89 \pm 38.3$ & $57 \pm 12.6$ \\
\hline Primabella & $59.1 \pm 12.5$ & $113 \pm 30.8$ & $19 \pm 8.8$ & $64 \pm 17.1$ & $83 \pm 21.6$ & $95 \pm 22.2$ & $49 \pm 20$ \\
\hline Tastery F1 & $71.5 \pm 4.2$ & $113 \pm 13.8$ & $23 \pm 5.5$ & $66 \pm 8.0$ & $82 \pm 10.9$ & $93 \pm 18.2$ & $68 \pm 21.2$ \\
\hline Annamay F1 & $73.7 \pm 12.9$ & $129 \pm 26.4$ & $27 \pm 6.6$ & $75 \pm 16.7$ & $85 \pm 18.1$ & $99 \pm 32.9$ & $68 \pm 8.1$ \\
\hline Amoroso F1 & $68.6 \pm 10.3$ & $98 \pm 18.3$ & $23 \pm 3.9$ & $55 \pm 11.0$ & $74 \pm 10.7$ & $88 \pm 32.1$ & $60 \pm 23.6$ \\
\hline Campari F1 & $74.4 \pm 10.2$ & $121 \pm 25.4$ & $24 \pm 5.7$ & $68 \pm 13.3$ & $85 \pm 18.2$ & $93 \pm 55.6$ & $52 \pm 15.2$ \\
\hline Auriga & $67.9 \pm 8.9$ & $111 \pm 17.4$ & $15 \pm 3.1$ & $67 \pm 9.1$ & $72 \pm 10.4$ & $71 \pm 26.7$ & $44 \pm 20.3$ \\
\hline Harzfeuer F1 & $80.3 \pm 10.8$ & $137 \pm 21.7$ & $24 \pm 5.1$ & $65 \pm 9.5$ & $82 \pm 14.3$ & $89 \pm 35.9$ & $62 \pm 16.2$ \\
\hline
\end{tabular}




\begin{tabular}{llllllll} 
Roterno F1 & $116.0 \pm 7.6$ & $143 \pm 40.5$ & $39 \pm 13.1$ & $75 \pm 21.1$ & $95 \pm 28.5$ & $103 \pm 31.3$ & $75 \pm 18.6$ \\
Lyterno F1 & $110.3 \pm 18.5$ & $150 \pm 29.3$ & $39 \pm 13.6$ & $78 \pm 15.2$ & $104 \pm 18.4$ & $103 \pm 31.8$ & $70 \pm 23.1$ \\
Bocati F1 & $112.7 \pm 6.7$ & $143 \pm 23.3$ & $37 \pm 9.1$ & $77 \pm 12.8$ & $95 \pm 16.8$ & $102 \pm 37.1$ & $84 \pm 17.7$ \\
Cappricia F1 & $112.1 \pm 13.7$ & $155 \pm 31.3$ & $43 \pm 10.7$ & $71 \pm 11.8$ & $103 \pm 24.6$ & $98 \pm 46.0$ & $76 \pm 35.1$ \\
Green Zebra & $63.9 \pm 10.1$ & $110 \pm 19.6$ & $22 \pm 4.9$ & $70 \pm 12.6$ & $75 \pm 12.8$ & $76 \pm 27.1$ & $47 \pm 13.9$ \\
Mean & 73.9 & 119 & 25 & 66 & 83 & 91 & 58 \\
CV & 10.7 & 17.7 & 28.6 & 16.9 & 18.6 & 37.1 & 31.8 \\
HSD & 9.9 & 26.3 & 8.9 & 13.9 & 19.3 & 42.3 & 23.2 \\
Year & & & & & & & \\
2015 & $70.4 \pm 26.1$ & $109 \pm 34.4$ & $23 \pm 12.0$ & $59 \pm 17.1$ & $77 \pm 23.5$ & $75 \pm 35.9$ & $61 \pm 22.5$ \\
2016 & $77.4 \pm 23.6$ & $128 \pm 33.3$ & $26 \pm 10.2$ & $72 \pm 17.2$ & $88 \pm 22.4$ & $107 \pm 38.4$ & $56 \pm 24.6$ \\
\hline
\end{tabular}

Mean values are given for each of 20 cultivars as mean from boths years and from each year \pm standard deviation (SD). $\mathrm{CV}=$ coefficient of variation, $\mathrm{HSD}=$ honestly significant different at $\mathrm{p} \leq 0.05$.

Looking at the variation in fruit yield and NY as a function of fruit type, the spectrum of cultivars examined showed different variations in minimum and maximum values. Among the cocktail cultivars, "Resi" had the lowest yield with 22.7 tons ha ${ }^{-1}$, clearly far away from the other cocktail cultivars, while "Bartelly F1" produced a yield 3.5 times higher. This was also reflected in the NYs, where "Resi" produced the lowest NY for all nutrients and "Bartelly F1" the highest; the NYs were $2.7(\mathrm{P})$ to $3.3(\mathrm{~K})$ times higher than in "Resi." Also, for Fe and Zn, "Bartelly F1" produced 2.7- and 3.3-fold higher NY. For salad cultivars, it was found that, in terms of fruit yield, "Roterno F1" produced about twice as much as "Green Zebra," the cultivar with the lowest fruit yield. With regard to NY, the differences between the cultivars with the lowest values ("Green Zebra" for K; "Auriga” for Ca, P, Fe, and Zn; "Harzfeuer F1" for Mg) and the highest values ("Cappricia F1" for $\mathrm{K}$ and $\mathrm{Ca}$, "Lyterno F1" for Mg and P, "Roterno F1" and "Lyterno F1" for Fe, and "Bocati F1" for Zn) were $0.2(\mathrm{Mg})$ to $2.9(\mathrm{Ca})$ times higher than those with the lowest values. For the micronutrients $\mathrm{Fe}$ and $\mathrm{Zn}$, the maximum values in the above-mentioned cultivars were 0.5 and 2 times higher than in "Auriga."

\subsubsection{Heritabilities of traits and genotypic values of cultivars and their stability across years}

The heritabilities and genotypic values of cultivars were calculated for each trait on a single year basis (Tables 3.6 and 3.7). For the majority of traits such as fruit yield $\left[\mathrm{H}^{2}=0.86\right.$ (2015), 0.95 (2016)] and densities of $\mathrm{K}\left[\mathrm{H}^{2}=0.51\right.$ (2015), 0.61 (2016)], $\mathrm{P} \quad\left[\mathrm{H}^{2}=0.54\right.$ (2015), 0.74 (2016)], Fe $\left[\mathrm{H}^{2}=0.24\right.$ (2015), 0.31 (2016)], and $\mathrm{Zn} \quad\left[\mathrm{H}^{2}=0.21\right.$ (2015), 0.43 (2016)], the heritabilities increased in 2016, as expected, since up to four plants were included in the pooled 
replicates for the traits' analyses instead of only two plants in 2015. For the traits' $\mathrm{Mg}$ density $\left[\mathrm{H}^{2}=0.76(2015), 0.66(2016)\right]$ and $\mathrm{Ca}$ density $\left[\mathrm{H}^{2}=0.40\right.$ (2015), 0.37 (2016)], the heritabilities remained more or less the same. Traits with the lowest heritabilities were $\mathrm{Ca}, \mathrm{Fe}$, and $\mathrm{Zn}$ density, respectively.

To make conclusions about genotypic stability across years, the genotypic values were presented as BLUPs and ranked for single years, and correlations were calculated (Tables 3.6 and 3.7). High correlations between BLUPs of each year for single traits can be observed, and cultivar ranks do not change much across years. This was observed for fruit yield, $\mathrm{K}, \mathrm{Mg}$, and $\mathrm{P}$ densities, all having medium-high heritability combined with a strong correlation between genotypic values (fruit yield: 0.88 Spearman's, 0.95 Pearson; K density: 0.80 Spearman's, 0.83 Pearson; Mg density: 0.80 Spearman's, 0.82 Pearson; P density: 0.89 Spearman's, 0.89 Pearson). The traits Ca density (0.55 Spearman's, 0.66 Pearson), Fe density (0.52 Spearman's, 0.49 Pearson), and Zn density (0.64 Spearman's, 0.66 Pearson) have medium high correlations, resulting in moderate genotype stabilities since the ranks change likely due to genotype-by-year effects but not completely across years. $\mathrm{Ca}, \mathrm{Fe}$, and $\mathrm{Zn}$ are also reported with larger $\mathrm{CV}$ values than those of the other traits under study (Table 3.3). 
Table 3.6 Genetic parameters [(heritability as broad sense heritability $\left(\mathrm{H}^{2}\right)$ and genotypic values (BLUPS)] of fruit yield and micronutrient densities $(\mathrm{Fe}, \mathrm{Zn}, \mathrm{Ca})$ created from a linear fully randomized model on a year basis. The genotypic values are presented as BLUPS, ranked for single years and correlations between both years were calculated.

\begin{tabular}{|c|c|c|c|c|c|c|c|c|c|c|c|c|c|c|c|c|c|c|c|c|c|c|c|c|}
\hline & \multicolumn{6}{|c|}{ Fruit yield kg/Pooled Rep } & \multicolumn{6}{|c|}{ Fe density (mg 100g-1 FW) } & \multicolumn{6}{|c|}{ Zn Density (mg 100g-1 FW) } & \multicolumn{6}{|c|}{ Ca Density (mg 100g-1 FW) } \\
\hline & \multicolumn{3}{|c|}{2015} & \multicolumn{3}{|c|}{2016} & \multicolumn{3}{|c|}{2015} & \multicolumn{3}{|c|}{2016} & \multicolumn{3}{|c|}{2015} & \multicolumn{3}{|c|}{2016} & \multicolumn{3}{|c|}{2015} & \multicolumn{3}{|c|}{2016} \\
\hline $\mathrm{H}^{2}$ (broad sense) & \multicolumn{3}{|c|}{0.86} & \multicolumn{3}{|c|}{0.95} & \multicolumn{3}{|c|}{0.24} & \multicolumn{3}{|c|}{0.31} & \multicolumn{3}{|c|}{0.21} & \multicolumn{3}{|c|}{0.43} & \multicolumn{3}{|c|}{0.40} & \multicolumn{3}{|c|}{0.37} \\
\hline Grand mean (tstd error) & \multicolumn{3}{|c|}{$3.519( \pm 0.2881)$} & \multicolumn{3}{|c|}{$3.868( \pm 0.279)$} & \multicolumn{3}{|c|}{$( \pm 0.0$} & $0.696( \pm$ & \pm 0.04759 & & 0.348 & \pm 0.0261 & & 0.248 & \pm 0.012 & & 12.066 & $( \pm 0.663$ & & 12.553 & $( \pm 0.5733$ & \\
\hline Spearman's rank corr rho & & $0.88 p$ & $p$-valu & $\mathrm{e}<2.2 \mathrm{e}-16$ & & & & 0.52 & p-valu & $e=0.02098$ & & & & $0.64 p-$ & value & $=0.002778$ & & & & 0.55 & p-valu & $\mathrm{ue}=0.01351$ & & \\
\hline Pearson's corr & & $0.95 p-$ & -value & $=2.582 \mathrm{e}-1$ & & & & 0.49 & $p$-valu & $e=0.02709$ & & & & $0.66 \mathrm{p}$ & -value & $e=0.00158$ & & & & $0.66 \mathrm{p}$ & -value & $e=0.00144$ & & \\
\hline Cultivar = Genotype & $\begin{array}{c}\text { genotypic } \\
\text { value }\end{array}$ & \begin{tabular}{|c|} 
mean \\
(pred.)
\end{tabular} \mid & Rank & $\begin{array}{c}\text { genotypic } \\
\text { value }\end{array}$ & $\left|\begin{array}{c}\text { mean } \\
\text { (pred.) }\end{array}\right|$ & Rank & $\begin{array}{c}\text { genotypic } \\
\text { value }\end{array}$ & \begin{tabular}{|c|} 
mean \\
(pred.)
\end{tabular} & Rank & $\begin{array}{c}\text { genotypic } \\
\text { value }\end{array}$ & $\begin{array}{c}\text { mean } \\
\text { (pred.) }\end{array} \mid$ & Rank & $\begin{array}{c}\text { genotypic } \\
\text { value }\end{array}$ & \begin{tabular}{|c|} 
mean \\
(pred.)
\end{tabular} & Rank & $\begin{array}{c}\text { genotypic } \\
\text { value }\end{array}$ & \begin{tabular}{|c|} 
mean \\
(pred.)
\end{tabular} & Rank & $\begin{array}{c}\text { genotypic } \\
\text { value }\end{array}$ & \begin{tabular}{|l|} 
mean \\
(pred.)
\end{tabular} & Rank & $\begin{array}{c}\text { genotypic } \\
\text { value }\end{array}$ & \begin{tabular}{|c|} 
mean \\
(pred.)
\end{tabular} \mid & Rank \\
\hline Amoroso F1 & -0.454 & 3.065 & 14 & -0.054 & 3.814 & 9 & 0.036 & 0.574 & 7 & -0.050 & 0.646 & 13 & 0.004 & 0.351 & 10 & -0.020 & 0.228 & 13 & 0.753 & 12.820 & 7 & -0.574 & 11.979 & 13 \\
\hline Annamay F1 & -0.222 & 3.297 & 11 & 0.209 & 4.077 & 6 & 0.000 & 0.539 & 10 & -0.034 & 0.662 & 12 & 0.099 & 0.447 & 4 & -0.002 & 0.246 & 11 & 1.247 & 13.313 & 6 & 0.377 & 12.931 & 7 \\
\hline Auriga & -0.209 & 3.310 & 10 & -0.373 & 3.495 & 14 & -0.097 & 0.442 & 18 & -0.092 & 0.604 & 15 & -0.083 & 0.264 & 17 & -0.025 & 0.223 & 15 & -4.035 & 8.031 & 20 & -3.264 & 9.290 & 20 \\
\hline Bartelly F1 & 0.357 & 3.876 & 6 & 0.386 & 4.254 & 5 & -0.006 & 0.533 & 11 & 0.100 & 0.796 & 4 & 0.016 & 0.363 & 9 & 0.057 & 0.305 & 3 & 2.468 & 14.534 & 4 & 1.346 & 13.899 & 3 \\
\hline Benarys Gartenfreude & -0.889 & 2.630 & 17 & -0.803 & 3.065 & 18 & -0.014 & 0.525 & 12 & 0.302 & 0.998 & 1 & 0.027 & 0.374 & 8 & 0.086 & 0.333 & 1 & -3.447 & 8.620 & 19 & -2.401 & 10.153 & 19 \\
\hline Black Cherry & -0.408 & 3.111 & 12 & -0.678 & 3.190 & 17 & 0.006 & 0.545 & 9 & 0.075 & 0.771 & 8 & -0.008 & 0.340 & 11 & 0.035 & 0.283 & 6 & -1.023 & 11.043 & 14 & -0.914 & 11.640 & 17 \\
\hline Bocati F1 & 2.192 & 5.711 & 1 & 1.588 & 5.456 & 4 & -0.086 & 0.452 & 15 & -0.199 & 0.497 & 20 & -0.088 & 0.260 & 18 & -0.082 & 0.166 & 20 & 0.066 & 12.132 & 10 & -0.749 & 11.805 & 16 \\
\hline Campari F1 & 0.047 & 3.566 & 8 & 0.003 & 3.871 & 8 & -0.083 & 0.456 & 14 & 0.068 & 0.764 & 9 & -0.071 & 0.277 & 16 & 0.019 & 0.267 & 8 & 0.120 & 12.186 & 9 & -0.605 & 11.948 & 14 \\
\hline Cappricia F1 & 1.845 & 5.364 & 3 & 1.879 & 5.747 & 3 & -0.149 & 0.389 & 20 & -0.168 & \begin{tabular}{|l|}
0.529 \\
\end{tabular} & 17 & -0.101 & 0.247 & 20 & -0.064 & 0.184 & 18 & 2.496 & 14.563 & 3 & 0.344 & 12.897 & 8 \\
\hline Goldita & -1.523 & \begin{tabular}{|l|}
1.996 \\
\end{tabular} & 19 & -1.537 & 2.331 & 19 & 0.094 & \begin{tabular}{|l|}
0.633 \\
\end{tabular} & 3 & 0.099 & \begin{tabular}{|l|}
0.795 \\
\end{tabular} & 5 & 0.115 & \begin{tabular}{|l|}
0.463 \\
\end{tabular} & 1 & 0.017 & 0.265 & 9 & 4.583 & \begin{tabular}{|l|}
16.649 \\
\end{tabular} & 1 & 1.773 & \begin{tabular}{|l|}
14.327 \\
\end{tabular} & 2 \\
\hline Green Zebra & -0.637 & \begin{tabular}{|l|}
2.882 \\
\end{tabular} & 15 & -0.330 & 3.538 & 13 & 0.028 & \begin{tabular}{|l|}
0.567 \\
\end{tabular} & 8 & -0.140 & 0.556 & 16 & -0.036 & 0.312 & 13 & -0.052 & 0.196 & 16 & -0.323 & 11.743 & 12 & 0.165 & 12.718 & 9 \\
\hline Harzfeuer F1 & 0.850 & \begin{tabular}{|l|}
4.369 \\
\end{tabular} & 5 & -0.233 & 3.635 & 11 & -0.095 & 0.444 & 17 & -0.021 & 0.675 & 11 & -0.068 & 0.280 & 14 & -0.019 & 0.228 & 12 & -2.685 & 9.382 & 18 & 0.642 & 13.195 & 6 \\
\hline Lyterno F1 & 1.511 & \begin{tabular}{|l|}
5.029 \\
\end{tabular} & 4 & 2.047 & 5.915 & 1 & -0.081 & \begin{tabular}{|l|}
0.458 \\
\end{tabular} & 13 & -0.185 & \begin{tabular}{|l|}
0.511 \\
\end{tabular} & 18 & -0.069 & \begin{tabular}{|l|}
0.279 \\
\end{tabular} & 15 & -0.062 & 0.186 & 17 & 1.423 & \begin{tabular}{|c|}
13.489 \\
\end{tabular} & 5 & -0.530 & 12.023 & 12 \\
\hline Primabella & -1.008 & 2.511 & 18 & -0.426 & 3.442 & 15 & 0.210 & \begin{tabular}{|l|}
0.749 \\
\end{tabular} & 2 & 0.024 & 0.720 & 10 & 0.039 & 0.387 & 6 & 0.015 & 0.263 & 10 & -1.567 & \begin{tabular}{|l|}
10.499 \\
\end{tabular} & 17 & 0.123 & 12.676 & 10 \\
\hline \begin{tabular}{|l|} 
Primavera \\
\end{tabular} & 0.125 & 3.644 & 7 & 0.141 & 4.009 & 7 & 0.076 & 0.615 & 5 & 0.076 & 0.772 & 7 & 0.103 & 0.451 & 2 & 0.035 & 0.283 & 7 & -0.950 & 11.117 & 13 & 0.730 & 13.284 & 5 \\
\hline Resi & -2.421 & 1.098 & 20 & -2.562 & 1.306 & 20 & 0.222 & \begin{tabular}{|l|}
0.760 \\
\end{tabular} & 1 & 0.168 & \begin{tabular}{|l|}
0.864 \\
\end{tabular} & 2 & 0.103 & 0.451 & 3 & 0.050 & 0.297 & 4 & 3.059 & 15.126 & 2 & 5.828 & 18.382 & 1 \\
\hline Roterno F1 & 2.175 & 5.694 & 2 & 1.929 & 5.797 & 2 & -0.108 & 0.431 & 19 & -0.193 & 0.504 & 19 & -0.096 & 0.252 & 19 & -0.067 & 0.181 & 19 & 0.217 & 12.284 & 8 & -0.146 & 12.407 & 11 \\
\hline \begin{tabular}{|l|} 
Sakura F1 \\
\end{tabular} & -0.409 & 3.110 & 13 & -0.329 & 3.539 & 12 & -0.095 & 0.444 & 16 & 0.081 & 0.777 & 6 & -0.009 & 0.339 & 12 & 0.046 & 0.294 & 5 & -1.172 & 10.894 & 15 & 0.883 & 13.436 & 4 \\
\hline Supersweet 100 F1 & -0.886 & 2.633 & 16 & -0.660 & 3.208 & 16 & 0.093 & \begin{tabular}{|l|}
0.632 \\
\end{tabular} & 4 & 0.156 & \begin{tabular}{|l|}
0.852 \\
\end{tabular} & 3 & 0.084 & 0.432 & 5 & 0.057 & 0.305 & 2 & -1.285 & \begin{tabular}{|l|}
10.781 \\
\end{tabular} & 16 & -2.297 & 10.257 & 18 \\
\hline Tastery F1 & -0.035 & 3.484 & 9 & -0.198 & 3.670 & 10 & 0.051 & 0.589 & 6 & -0.066 & 0.630 & 14 & 0.039 & 0.387 & 7 & -0.024 & 0.224 & 14 & 0.055 & 12.122 & 11 & -0.732 & 11.822 & 15 \\
\hline
\end{tabular}


Table 3.7 Genetic parameters [(heritability as broad sense heritability $\left(\mathrm{H}^{2}\right)$ and genotypic values (BLUPS)] of macronutrient densities (K, Mg, P) created from a linear fully randomized model on a year basis. The genotypic values are presented as BLUPS, ranked for single years and correlations between both years were calculated.

\begin{tabular}{|c|c|c|c|c|c|c|c|c|c|c|c|c|c|c|c|c|c|c|}
\hline & \multicolumn{6}{|c|}{ K density* (mg 100g-1 FW) } & \multicolumn{6}{|c|}{ Mg Density* (mg 100g-1 FW) } & \multicolumn{6}{|c|}{ P Density (mg 100g-1 FW) } \\
\hline & \multicolumn{3}{|c|}{2015} & \multicolumn{3}{|c|}{2016} & \multicolumn{3}{|c|}{2015} & \multicolumn{3}{|c|}{2016} & \multicolumn{3}{|c|}{2015} & \multicolumn{3}{|c|}{2016} \\
\hline $\mathrm{H}^{2}$ (broad sense) & \multicolumn{3}{|c|}{0.51} & \multicolumn{3}{|c|}{0.61} & \multicolumn{3}{|c|}{0.76} & \multicolumn{3}{|c|}{0.66} & \multicolumn{3}{|c|}{0.54} & \multicolumn{3}{|c|}{0.74} \\
\hline Grand mean ( \pm std error) & \multicolumn{3}{|c|}{$273.64( \pm 7.46)$} & \multicolumn{3}{|c|}{$296.18( \pm 12.16)$} & \multicolumn{3}{|c|}{$11.636(0.4513)$} & \multicolumn{3}{|c|}{12.973 (0.6239) } & \multicolumn{3}{|c|}{$29.508( \pm 1.138)$} & \multicolumn{3}{|c|}{$30.987( \pm 1.771)$} \\
\hline Spearman's rank corr rho & \multicolumn{6}{|c|}{$0.80 p$-value $=2.833 \mathrm{e}-05$} & \multicolumn{6}{|c|}{$0.80 p$-value $=2.603 \mathrm{e}-05$} & \multicolumn{6}{|c|}{$0.89 p$-value $<2.2 e-16$} \\
\hline Pearson's corr & \multicolumn{6}{|c|}{$0.83 p$-value $=5.666 \mathrm{e}-06$} & \multicolumn{6}{|c|}{$0.82 p$-value $=1.024 \mathrm{e}-05$} & & $0.89 \mathrm{p}$ & -value & $=1.649 \mathrm{e}-0$ & & \\
\hline Cultivar = Genotype & $\begin{array}{c}\text { genotypic } \\
\text { value }\end{array}$ & \begin{tabular}{|c} 
mean \\
(pred.)
\end{tabular} & Rank & $\begin{array}{c}\text { genotypic } \\
\text { value }\end{array}$ & \begin{tabular}{|c|} 
mean \\
(pred.)
\end{tabular} & Rank & $\begin{array}{c}\text { genotypic } \\
\text { value }\end{array}$ & \begin{tabular}{|c|} 
mean \\
(pred.)
\end{tabular} & Rank & $\begin{array}{c}\text { genotypic } \\
\text { value }\end{array}$ & $\left|\begin{array}{c}\text { mean } \\
\text { (pred.) }\end{array}\right|$ & Rank & $\begin{array}{c}\text { genotypic } \\
\text { value }\end{array}$ & \begin{tabular}{|c|} 
mean \\
(pred.)
\end{tabular} & Rank & $\begin{array}{c}\text { genotypic } \\
\text { value }\end{array}$ & \begin{tabular}{|c|} 
mean \\
(pred.)
\end{tabular} \mid & Rank \\
\hline Amoroso F1 & -28.457 & 245.183 & 16 & -46.150 & 250.030 & 16 & -1.287 & 10.348 & 15 & -2.005 & 10.968 & 16 & -1.228 & 28.280 & 13 & -3.523 & 27.464 & 15 \\
\hline Annamay F1 & 16.265 & 289.905 & 7 & 9.872 & 306.052 & 8 & 1.453 & 13.088 & 7 & 0.791 & 13.764 & 9 & -0.204 & 29.304 & 10 & -1.553 & 29.434 & 9 \\
\hline Auriga & 4.639 & \begin{tabular}{|l|}
278.279 \\
\end{tabular} & 11 & -11.042 & 285.138 & 11 & 1.002 & 12.638 & 8 & 0.649 & 13.622 & 10 & -2.392 & 27.116 & 15 & -3.163 & 27.824 & 13 \\
\hline Bartelly F1 & 36.079 & \begin{tabular}{|l|}
309.719 \\
\end{tabular} & 2 & 33.506 & 329.686 & 6 & 1.812 & 13.447 & 3 & 1.756 & 14.729 & 6 & 4.526 & 34.034 & 4 & 5.777 & 36.764 & 4 \\
\hline Benarys Garter & 8.060 & 281.700 & 9 & 86.933 & 383.113 & 1 & -1.213 & 10.423 & 14 & 2.822 & 15.795 & 3 & 0.311 & 29.819 & 8 & 10.852 & 41.839 & 2 \\
\hline Black Cherry & -16.916 & 256.724 & 15 & -23.949 & \begin{tabular}{|l|}
272.231 \\
\end{tabular} & 14 & 0.136 & 11.771 & 11 & 0.051 & 13.023 & 11 & -1.495 & 28.013 & 14 & -3.229 & 27.758 & 14 \\
\hline Bocati F1 & -44.697 & 228.943 & 19 & -78.557 & 217.623 & 19 & -2.130 & 9.506 & 17 & -4.006 & 8.967 & 18 & -5.911 & 23.597 & 19 & -10.233 & 20.754 & 19 \\
\hline Campari F1 & 4.249 & \begin{tabular}{|l|}
277.889 \\
\end{tabular} & 12 & -16.367 & 279.813 & 13 & 0.059 & 11.695 & 12 & -0.588 & 12.385 & 12 & 0.124 & 29.632 & 9 & -2.083 & 28.904 & 10 \\
\hline Cappricia F1 & -40.778 & \begin{tabular}{|l|}
232.862 \\
\end{tabular} & 17 & -49.669 & 246.511 & 17 & -3.432 & 8.203 & 20 & -4.108 & 8.865 & 19 & -5.225 & 24.283 & 18 & -7.485 & 23.502 & 18 \\
\hline Goldita & 20.635 & 294.275 & 6 & 29.590 & 325.770 & 7 & 1.562 & 13.198 & 5 & 1.623 & 14.596 & 7 & 2.090 & 31.598 & 5 & 1.658 & 32.645 & 7 \\
\hline Green Zebra & 21.710 & 295.350 & 5 & -13.052 & 283.128 & 12 & 2.370 & 14.006 & 2 & 1.096 & 14.068 & 8 & 0.986 & 30.494 & 6 & -2.563 & 28.424 & 12 \\
\hline Harzfeuer F1 & 7.915 & 281.555 & 10 & 9.359 & \begin{tabular}{|l|}
305.539 \\
\end{tabular} & 9 & -1.412 & 10.224 & 16 & -1.609 & 11.364 & 15 & -3.648 & 25.860 & 16 & -4.049 & 26.938 & 16 \\
\hline Lyterno F1 & -42.979 & 230.661 & 18 & -52.890 & 243.290 & 18 & -2.605 & 9.031 & 18 & -3.130 & 9.843 & 17 & -4.364 & 25.144 & 17 & -6.814 & 24.173 & 17 \\
\hline Primabella & 27.919 & 301.559 & 3 & 43.660 & \begin{tabular}{|l|}
339.840 \\
\end{tabular} & 4 & 1.673 & 13.308 & 4 & 1.979 & 14.952 & 5 & 4.873 & 34.381 & 3 & 5.422 & 36.409 & 5 \\
\hline Primavera & -10.619 & \begin{tabular}{|l|}
263.021 \\
\end{tabular} & 14 & -0.904 & 295.276 & 10 & -1.165 & 10.471 & 13 & -0.936 & 12.037 & 14 & -1.035 & 28.473 & 12 & 0.486 & 31.473 & 8 \\
\hline Resi & 22.657 & 296.297 & 4 & 78.903 & 375.083 & 3 & 1.557 & 13.193 & 6 & 5.087 & 18.060 & 1 & 9.715 & 39.223 & 1 & 19.999 & 50.986 & 1 \\
\hline Roterno F1 & -53.413 & 220.227 & 20 & -80.999 & 215.181 & 20 & -2.948 & 8.687 & 19 & -4.157 & 8.816 & 20 & -6.781 & 22.727 & 20 & -10.681 & 20.306 & 20 \\
\hline Sakura F1 & 2.471 & 276.111 & 13 & 35.221 & 331.401 & 5 & 0.261 & 11.896 & 10 & 2.146 & 15.119 & 4 & -0.597 & 28.911 & 11 & 3.530 & 34.517 & 6 \\
\hline Supersweet 100 F1 & 57.020 & 330.660 & 1 & 81.075 & 377.255 & 2 & 3.600 & 15.235 & 1 & 3.372 & 16.345 & 2 & 9.425 & 38.933 & 2 & 10.182 & \begin{tabular}{|l|l|}
41.169 \\
\end{tabular} & 3 \\
\hline Tastery F1 & 8.240 & 281.880 & 8 & -34.539 & 261.641 & 15 & 0.705 & 12.341 & 9 & -0.833 & 12.140 & 13 & 0.829 & 30.337 & 7 & -2.529 & \begin{tabular}{|l|}
28.458 \\
\end{tabular} & 11 \\
\hline
\end{tabular}

${ }^{*}$ Could not estimate Pooled Rep cause of singularity but we kept it in the model. After checking, it did not change the model results. 


\subsection{Discussion}

\subsubsection{Nutrient concentration}

Vegetables are an important part of daily diet, and therefore the concentrations of mineral nutrients in them could contribute significantly to the mineral nutrient intake in human diet (Marles, 2017). The present study confirms that mineral concentrations in tomato fruits were strongly influenced by the cultivar (Kapoulas et al., 2013), and the influence of the cultivar on both macroand micronutrients depends only to some extent on the cultivation year. A high correlation between genotypic values of each year for a single trait showed that, even though there were significant genotype-by-year effects, the cultivar ranks did not change much (Tables 3.6 and 3.7). A strong correlation of genotypic values across years together with a high heritability of the trait shows that genetics control the trait strongly and genotypes are stable across environments. Thus, the cultivars exhibit a good genotype stability across years for the traits $\mathrm{K}, \mathrm{Mg}$, and $\mathrm{P}$ density, respectively. The traits $\mathrm{Ca}$ density, Fe density, and $\mathrm{Zn}$ density exhibited medium-strong correlations and medium heritabilities and therefore resulted in moderate genotype stability. Overall, most cultivars have relatively high genotype stability for different traits across years. It may be that there is a stronger environmental influence on the density of micronutrients ( $\mathrm{Fe}$ and $\mathrm{Zn}$ ) than for most of the macronutrients.

Micronutrient density, defined as the amount of a nutrient per unit weight in a food, is important to achieve an optimal micronutrient status in human diet (Miller and Welch, 2013). Basically, the analysis of the mineral concentration of tomatoes in the present study shows that these cultivars can potentially provide essential nutrients to a large population (Table 3.3). From the present study, data for $\mathrm{K}, \mathrm{Mg}, \mathrm{P}, \mathrm{Fe}$, and $\mathrm{Zn}$ concentrations were comparable to those from other studies for organically grown tomatoes (Hernández Suárez et al., 2007; Kapoulas et al., 2013; Mohammed et al., 2019; Ordóñez-Santos et al., 2011). However, the range of the Ca

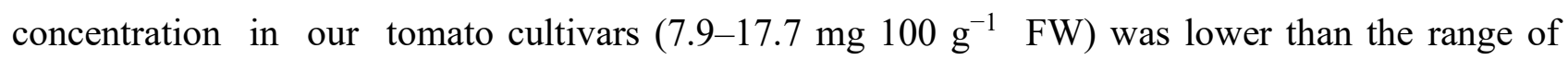
earlier experiments with 28 cultivars (11.2-24.5 mg $100 \mathrm{~g}^{-1} \mathrm{FW}$ ) (Mohammed et al., 2019), but, 
with the exception of the concentration in one cultivar, it was higher than the range presented by Kapoulas et al. (2013) (8.1-9.0 mg $100 \mathrm{~g}^{-1} \mathrm{FW}$ ) as well as for three tomato cultivars grown in a greenhouse and for five cultivars in open-field cultivation (5.9-7.0 mg $100 \mathrm{~g}^{-1} \mathrm{FW}$ ) (Hernández Suárez et al., 2007). Ca is a mineral with the lowest levels of adequately estimated intake worldwide (Beal et al., 2017).

Potassium is the most abundant mineral nutrient in fresh tomato fruits (Labate et al., 2018; Sager, 2017), while $\mathrm{Mg}$ is the mineral nutrient most frequently lacking in the human diet (White and Broadley, 2005). Phosphorus is one of the 17 key elements required in plant metabolism (Dixon et al., 2020) and is essential for human nutrition, but dietary P deficiency occurs very rarely, as it is contained in many foods and is well absorbed (Vorland et al., 2017). High fruit K concentrations (211-361 mg $100 \mathrm{~g}^{-1} \mathrm{FW}$ ), which exceed the range presented by others (Hernández Suárez et al., 2007; Kapoulas et al., 2013; Mohammed et al., 2019; Ordóñez-Santos et al., 2011), were determined in the present study. The achieved result showed a higher maximum content of $\mathrm{Mg}$ (16 mg $100 \mathrm{~g}^{-1} \mathrm{FW}$ ) than in other studies (Mohammed et al., 2019; Ordóñez-Santos et al., 2011). The maximum value of $\mathrm{P}$ in our tomato cultivars (46.1 $\mathrm{mg} 100 \mathrm{~g}^{-1} \mathrm{FW}$ ) was slightly higher than those previously reported by Mohammed et al. (2019), who had found P contents up to $43.7 \mathrm{mg} 100$ $\mathrm{g}^{-1}$ FW and far higher than the one presented by Hernández Suárez et al. (2007) (27.1 mg $100 \mathrm{~g}^{-1}$ FW). The differences in the range of mineral concentrations reported in different studies may result from variations in the number of the cultivars studied, the type of genetic materials used, the location, and the growing environment evaluated. Regardless of their variation in nutrient concentration, the reductions in the levels of $\mathrm{K}, \mathrm{Ca}$, and $\mathrm{Mg}$ as well as the increasing concentrations of $\mathrm{P}$ and Fe in tomatoes grown in the 1930s and the 1980s [UK Government's Composition of Foods tables, cited in Mayer (1997)] were reported by Mayer (1997). The author noted that the average concentration of $\mathrm{K}, \mathrm{Ca}$, and $\mathrm{Mg}$ in tomato fruits decreased from 288 to $250 \mathrm{mg} 100 \mathrm{~g}^{-1} \mathrm{FW}$,

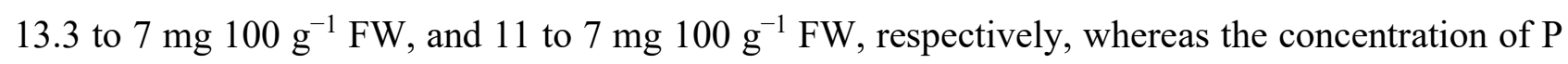
had witnessed a slight increase from 21 to $24 \mathrm{mg} 100 \mathrm{~g}^{-1} \mathrm{FW}$ over an approximate 50- year period. 
Several agrobiodiversity-related studies have focused on improving diets or dietary quality, including intake of key nutrients, dietary diversity, and consumption of micronutrient- rich foods (e.g., Herrero et al., 2017; Powell et al., 2015). From the nutritional perspective, Fe and $\mathrm{Zn}$ are essential micronutrients for both humans and plants, but they remain deficient in the diets of the global population ( $\mathrm{Li}$ et al., 2017). As reported in earlier studies, Fe is identified as a major micronutrient in the tomato fruit. Comparing the micronutrient contents in tomato fruits between the 1930s and 1980s, only Fe was found in higher concentrations in the fruits, with an increase of $16 \%$ in tomatoes cultivated 50 years later (Mayer, 1997). In the present study, the range of Fe concentrations was lower than the one measured by Mohammed et al. (2019) and Ordóñez-Santos et al. (2011). On the other hand, the range of the $\mathrm{Zn}$ concentration exceeds the range presented by Hernández Suárez et al. (2007); Kapoulas et al. (2013), and Mohammed et al. (2019).

Different values of $\mathrm{CV}$ between the traits for the nutrient concentration and also for the fraction of DRI and NY were observed in the present study (Tables 3.3, 3.4 and 3.5). The CV, a mean-standardized measure of variation, is often used to compare the variability of quantitative traits, and higher CVs are ascribed to a greater relative variability (Ogunniyan and Olakojo, 2014; Pélabon et al., 2020). For nutrient concentrations, the highest CV was obtained for Zn followed by Fe (Table 3.3). The genetic parameters support these findings as $\mathrm{Zn}$ and Fe densities exhibit the lowest heritabilities (Table 3.7). High CVs (Table 3.3) are related to low heritabilities (Tables 3.6 and 3.7). These results imply that the concentration of the micronutrients had higher variability than those for macronutrients among the studied parameters. These high CV values of the traits were adequate to distinguish the cultivars. With the CVs between 20 and 30\%, Ca had high data dispersion around the mean, thereby reflecting a relatively higher genetic variation (Ene et al., 2016), while $\mathrm{K}, \mathrm{Mg}$, and $\mathrm{P}$ traits showed the lowest CVs within the range of 10 to $20 \%$ (Table 3) and highest heritabilities (Table 3.6). No CV was lower than 10\%-this means that the observed traits in the study displayed moderate to high variability. The variations for $\mathrm{CV}$ and the genetic 
parameters calculated in the present study confirm that the traits were often more controlled by the cultivar (genotype) than by the environment (Kapoulas et al., 2013).

\subsubsection{Contribution of tomatoes to the DRI of mineral nutrients}

The contribution of tomato, in terms of macro- and micronutrients, to daily requirements is not very high due to the low dry matter content of the fruit. It was not the primary purpose of this study to evaluate the contribution of the cultivars investigated, but the fraction of DRI was determined in order to calculate the NY. However, the variations in the variety spectrum are also reflected here, so the contribution to the intake of the minerals was rather low, except for $\mathrm{K}$ and $\mathrm{Fe}$ (Table 3.4). Our result indicated that $100 \mathrm{~g}$ of "Supersweet $100 \mathrm{~F} 1$ " contributed up to $7.7 \%$ of the DRI of K, which agrees with the data reported by Mohammed et al. (2019) after recalculation of the data. Consumption of one serving of tomato ( $200 \mathrm{~g})$ provided $10 \%$ of the DRI of K (Labate et al., 2018). Compared to $\mathrm{Ca}$, a greater contribution of $\mathrm{Mg}$ and $\mathrm{P}$ in the cultivars was observed, with maximal contribution of $100 \mathrm{~g}$ fresh fruits up to 4.4 and $6.6 \%$ of the DRI reference value for average adult male and female, respectively. These results are important because the intake of minerals, particularly $\mathrm{K}, \mathrm{Ca}$, and $\mathrm{Mg}$, in human diets is below healthful levels and often insufficient (Labate et al., 2018).

Interestingly, the cocktail cultivar "Resi" contributed the most to the DRI among the investigated minerals - except for $\mathrm{K}$, thereby showing a valuable performance of this cultivar in terms of nutritional value. In spite of its low fruit productivity, "Resi" has excellent fruit quality and moderate resistance against Phytophthora infestans (Zörb et al., 2020).

\subsubsection{Fruit yield and its variation in the nutritional yields of the cultivars}

The trait fruit yield exhibits a strong correlation between the genotypic values of both years, and even though significant genotype-by-year effects may appear, the cultivars' ranks across years do not change much (Table 3.7). A strong correlation together with a high heritability of fruit yield shows that genetics strongly control the trait. Thus, the cultivars exhibit a high genotype stability for fruit yield across years. The mean fruit yield of the 20 studied cultivars $\left(73.9\right.$ ton $\left.\mathrm{ha}^{-1}\right)$ exceeded 
the estimated average yield of global tomato released by FAO (2018), which was about 42 tons ha $^{-1}$ (FAOSTAT, 2020), and higher than the mean of 14 tomato landraces (34.2 ton $\mathrm{ha}^{-1}$ ) reported by Firas et al. (2012). Considering the average yields among all the tested cultivars, "Roterno F1", "Lyterno F1", "Bocati F1", and "Cappricia F1" exhibited the highest fruit yields in both cultivation years (Table 3.5). These four salad cultivars may represent good materials for tomato production under outdoor organic conditions for fruit yield. "Bartelly F1" showed the highest fruit yield among all cocktail cultivars across the 2 years, and it is, therefore, considered a feasible plant material for cocktail fruit-type tomato production.

With respect to NY, the present study identifies open-field tomato cultivars suitable for organic production with high NYs for the minerals Ca, K, Mg, P, Fe, and Zn (Table 3.5). The NY incorporates measures of two important dimensions for future food systems: the production of nutritious food and the efficient use of land (DeFries et al., 2015). The present study shows a high variation of the $\mathrm{NY}$ of $\mathrm{Zn}$ and Fe within the 20 tomato cultivars, thereby indicating a wide variability for these traits in the fruits. Several studies for the organic production of tomatoes (Kapoulas et al., 2013; Ordóñez-Santos et al., 2011; Pavithra et al., 2015) confirm that the genotype has important effects on most of the variations in the micronutrient content (e.g., Fe and Zn), while environmental effects have only a small impact. The metrics of NY opens up options to compare the usefulness of different production systems for food production to feed the growing global population (Moreira-Ascarrunz et al., 2016). Hence, a comparison of the mean average NYs of macronutrients ( $\mathrm{Ca}, \mathrm{K}, \mathrm{Mg}$, and $\mathrm{P}$ ) and micronutrients (Fe and $\mathrm{Zn}$ ) of the studied tomato cultivars with the calculated NYs for vegetables under organic production was performed, i.e., for eggplant (Raigón et al., 2010), potato tuber (Hajšlová et al., 2005; Järvan and Edesi, 2009), and tomato (Kapoulas et al., 2013) (Table 3.8). The means of NY of the eggplant (Raigón et al., 2010) and potato varieties (Järvan and Edesi, 2009) were considerably lower for all the studied nutrients compared to that of the tomato cultivars from the present study (Table 3.8). The NYs of Fe and Zn calculated from eight potato varieties during 3 years of cultivation (Hajšlová et al., 2005) also only 
amounted to one third of the NY obtained in the tomato cultivars that we studied. Compared to the study of Kapoulas et al. (2013) with three tomato cultivars, the mean of NYs in the present study showed 1.03-fold higher NY for Fe and 1.66-fold higher NY for Zn. Although the tomato cultivars in the present study had substantially higher NYs for $\mathrm{K}$ and $\mathrm{Ca}$, the $\mathrm{NYs}$ for $\mathrm{Mg}$ and $\mathrm{P}$ of the tomato cultivars calculated based on the data in Kapoulas et al. (2013) were 1.70- and 1.52-fold higher than the NY generated from the present study (Table 3.8). The reasons for the different results are, on the one hand, the different cultivars and, on the other hand, the cultivation conditions. In contrast to our experiment, the trials described in Kapoulas et al. (2013) were carried out under greenhouse conditions and with a higher nutrient supply (including for P). Among different crop species compared from the cited studies, the tomato cultivars that we studied were leading in the NYs for Fe and $\mathrm{Zn}$, and eggplant was the lowest micronutrient-yielding vegetable crop (Table 3.8).

It is notable in the present investigation that the cultivars with the highest yield ("Roterno F1", "Lyterno F1", "Bocati F1", and "Cappricia F1") were not the cultivars with the highest concentrations (expressed in $\mathrm{mg} 100 \mathrm{~g}^{-1} \mathrm{FW}$ ) of the six minerals studied. Conversely, the cultivar with the highest mineral concentrations, such as "Resi", did not show a high yield and was even recorded as the lowest-yielding cultivar. Thus, the results generally show significant antagonism effects of yield trait and mineral concentrations, which means that the positive effect of a high fruit yield is diminished by a decreased nutrient concentration in the fruits. Earlier studies already reported the negative relationship between yield components and mineral concentrations among tomato cultivars (Chávez-Servia et al., 2018; Costa et al., 2011). Davis (2009) reveals inverse relationships between crop yield and mineral concentration, suggesting the presence of the so-called dilution effect, which commonly occurs when selective breeding successfully increases crop yields. The dilution effect of an increased crop yield or harvest index without a proportional increase in the mineral concentration has been well documented in several vegetable and grain crops (Marles, 2017). In this study, we use the metrics of NY which weigh the conventional yield measure 
(tons/ha) by its nutritional content, and therefore our selected tomato cultivars are supposed to be adequately dense in mineral nutrients to fulfill the requirements with a high yield potential.

Table 3.8 Nutritional yield (adults $\mathrm{ha}^{-1}$ year $^{-1}$ ) of macro and micronutrients from different vegetables (organically cultivated) in comparison with data of the present study

\begin{tabular}{|c|c|c|c|c|c|c|c|c|c|}
\hline \multirow{2}{*}{ Study } & \multirow{2}{*}{ Species } & \multirow[t]{2}{*}{$\begin{array}{l}\text { Year of } \\
\text { cultivation }\end{array}$} & \multirow[t]{2}{*}{$\begin{array}{l}\text { No. of } \\
\text { cultivars }\end{array}$} & \multicolumn{4}{|c|}{$\begin{array}{l}\text { Nutritional yield } \\
\text { (adults } \text { ha }^{-1} \text { year }^{-1} \text { ) }\end{array}$} & \multirow[b]{2}{*}{$\mathrm{Fe}$} & \multirow[b]{2}{*}{$\mathrm{Zn}$} \\
\hline & & & & $\mathrm{Ca}$ & $\mathrm{K}$ & $\mathrm{Mg}$ & $\mathrm{P}$ & & \\
\hline Raigón et al., 2010 & Eggplant & 2008 & 3 & 11 & 69 & 29 & 50 & 19 & 26 \\
\hline Hajšlová et al., 2005 & Potato & 1996-1998 & 8 & - & - & - & - & 30 & 18 \\
\hline Järvan and Edesi, 2009 & Potato & $2007-2008$ & 2 & 8 & 57 & 46 & 52 & 30 & 18 \\
\hline Kapoulas et al., 2013 & Tomato & $2008-2010$ & 3 & 17 & 66 & 112 & 126 & 88 & 35 \\
\hline Present study & Tomato & 2015-2016 & 20 & 25 & 119 & 66 & 83 & 91 & 58 \\
\hline
\end{tabular}

The nutritional yield values of other studies were calculated based on the given data in the cited studies.

The data from the present study shows that 1 ha of land of cultivated "Bartelly F1" can annually produce $\mathrm{Mg}$ for 88 adults, $\mathrm{P}$ for 114 adults, and Fe for 120 adults. Despite having fewer metric tons per hectare compared to the salad cultivar "Cappricia F1" and other high-yielding cultivars, the cocktail cultivar "Bartelly F1" was excellent in providing $\mathrm{Mg}, \mathrm{P}$, and Fe for a high number of people. Nevertheless, "Cappricia F1" was an excellent salad cultivar to supply the dietary intake of $\mathrm{Ca}, \mathrm{K}$, and Zn with NYs of 43, 155, and 76 adults year ${ }^{-1} \mathrm{ha}^{-1}$, respectively. The determined NY can influence the choice of varieties if both a high fruit yield and a high nutrient density per unit area are to be produced. Moreover, this study provides information about the number of people that can be fed according to their need for different nutrients with the respective tomato cultivars for 1 year from 1 ha of land. In addition, the NY might be an additional metric considered in exploiting the diversity of tomato to satisfy the nutritional needs of an increasing population.

In terms of contribution to the DRI and NY for Fe, the cocktail cultivar "Bartelly F1" produced the highest results, while the salad cultivar "Bocati F1" showed the highest values for Zn. Thus, to gain both maximum agronomic productivity in terms of fruit yield and Fe and Zn NYs, choosing "Bartelly F1" and "Bocati F1" as genotypes for breeding and/or selection in terms of micronutrients would be more feasible. Nevertheless, it should not be interpreted as implying that those cultivars were the sole source of any given nutrient since other cultivars also had significantly 
high concentrations of $\mathrm{Fe}$ and $\mathrm{Zn}$. For example, "Lyterno F1" and "Roterno F1" did not differ significantly from "Bartelly F1" in the NY of Fe, and "Cappricia F1" and "Roterno F1" did not vary significantly with "Bocati F1" for the NY of Zn. However, if we compare the cultivars within the group of fruit type, it is clear that, among cocktail tomatoes, "Bartelly F1" produced the highest NY for both Fe and Zn. Incidentally, while comparing within the salad tomatoes, "Bocati F1" would be the best choice because it had the highest NY for both Fe and Zn.

Across the 2-year investigation, our data indicate that the cocktail cultivar "Resi" accounted for three- to fourfold lower NY values as compared to the highest-performing salad cultivars of the respective determined nutrients - for instance, the NY for Zn of "Bocati F1" (84 adults year ${ }^{-1}$ ha $\left.^{-1}\right)$ was about fourfold higher than that measured in "Resi" (22 adults year $\left.{ }^{-1} \mathrm{ha}^{-1}\right)$. Therefore, it might be possible to increase the mineral concentrations in tomatoes by incorporating the micronutrientdense cultivars in breeding programs that have a higher ability to accumulate the Fe and $\mathrm{Zn}$ contents in the fruits. Even though the NY covers both yield and nutrient concentration, it should not imply that a single crop be consumed as the sole source of any given nutrient (Graham et al., 2018) as monotonous diets are likely to increase the risk of various nutrient deficiencies (Arimond et al., 2010). The NY should rather be considered as a policy tool to emphasize how any number of agronomic decisions are implicitly biased against either yield or nutrient concentration (Graham et al., 2018).

The current study reveals that a cultivar with the highest fruit yield was not automatically the cultivar with the highest NY. However, high yielding-cultivars with considerable nutrient contents were likely to have higher NYs. Similarly, the cultivar with the highest nutrient content did not always show a high NY. The results show that it is a challenge to evaluate genotypes for breeding and/or selection in terms of overall nutritional quality (Gascuel et al., 2017; MoreiraAscarrunz et al., 2016) because no single cultivar might be rich in all relevant compounds or nutrients (Vicente et al., 2009), and no parent is a good general combiner for all desirable traits (Agarwal et al., 2017). Nonetheless, the metric of NY could be useful for plant breeders and 
growers in the selection, development, and choice of cultivars, and on the global scale, it provides another perspective for policymakers in projections of food demand and requirements of nutrients (DeFries et al., 2015). The results of this study regarding DRI and NY, together with the high genotypic stability of several cultivars for yield and micro- and macronutrients across years, provide valuable input to growers' and plant breeders' decisions. However, consumer demand will still determine the growers' choice on tomato cultivars and influence the plant breeders' cultivar development program.

The NYs of the micronutrients mentioned in the present study were much higher and satisfying in comparison with the NYs of tomatoes and other vegetables calculated from previous reports. In fact, the comparison with other plant species should consider the effects of diverse cultivation systems. Data for both mineral contents and crop yields are also lacking in many studies. The results show that the tomato biodiversity used in the present study can contribute to satisfying the nutritional needs of the ever-growing human population while minimizing the negative impact on the environment. Hence, the metrics of NY can also be useful in selecting the cultivar with improved nutrients to increase food security and conserve the biodiversity of tomato in organic outdoor production. 


\section{Characterization of different tomato cultivars from organic low-input production with respect to their sensory properties}

\subsection{Abstract}

This study was conducted to determine the volatile organic compounds (VOCs) associated with fruit flavor in commonly grown tomato cultivars. The objective of this investigation was to characterize flavor related-traits, particularly the VOCs and their associations with sensory traits. For this objective, 12 cocktail and 8 salad fruit types differing in fruit weight, fruit color were grown in an outdoor organic low-input system in a temperate climate. The diversity of instrumentally determined traits such as total soluble solids (TSS), titratable acidity (TA), color components, VOCs) and sensory properties (fruit firmness, juiciness, skin firmness, sweetness, sourness, tomato typical-aroma, acceptability) were investigated at two harvest dates in 2015 and 2016. Cultivar had the most important effect on all instrumentally determined traits, while the cultivar $\times$ harvest date $\times$ year interaction was significant for $17 \mathrm{VOCs}$, but not for TSS and TA. The VOCs with the highest percentage $(>8 \%)$ were hexanal, 6-methyl-5-heptene-2-one, 2isobutylthiazole and (E)-2-hexenal, which were identified in all cultivars. Twelve VOCs were significantly correlated with one or more sensory attributes and these VOCs also allowed differentiation of the fruit type. Among these VOCs, 2-phenylethyl alcohol and benzyl alcohol were positively correlated with acceptability in the cocktail cultivars, while 2-isobuthylthiazole and 6me-5-hepten-2-ol were negatively correlated with cultivar acceptability in the salad cultivars in both the breeder's and sensory panel tests. The observed correlations between the VOCs provide evidence for their biosynthesis pathways. The present results, especially on the above-mentioned VOCs, could provide preliminary insights for a more efficient cultivar selection in breeding programs that perform better flavor and are suitable for organic low-input production systems.

Keywords: tomato cultivars, VOCs, organic low-input system, flavor, 2-phenylethyl alcohol, 2isobutylthiazole, sensory analysis

\subsection{Introduction}

Tomato (Solanum lycopersicum L.) is one of the most important vegetable crops in the world at present (Cortina et al., 2018). The tomato fruit constitute an essential component of the dietary intake of human as they provide a source of minerals, vitamins and phytochemicals (Uluisik et al., 2016). For decades, domestication and the considerable attempts in tomato breeding have mainly focused on improving agronomic traits such as fruit yield and weight, to a lesser extent color and shape, firmness for mechanical harvest, disease resistance and adaptation to diverse production areas (Blanca et al., 2015; Lin et al., 2014; Saliba-Colombani et al., 2001). These approaches, while significantly increasing productivity, have proved detrimental effects on sensory and nutritional quality in commercial modern cultivars, often regarded by consumer as less flavorful tomatoes 
(Cortina et al., 2018; Klee and Tieman, 2013; Paolo et al., 2018). Such a significant drop-off in flavor of commercially produced tomatoes often lead to consumer dissatisfaction and complaints (Tieman et al., 2017; Libin Wang et al., 2016). Over the last years, there has been a rising demand for better-flavored tomatoes which is coupled with ongoing breeding attempts towards production of genotypes with improved sensory qualities and with multidisciplinary approaches to sensory assessment of the fruits (Baldina et al., 2016; Causse et al., 2010b)

While fruit-related trait such as yield can be simply specified, flavor is much more complex. Tomato flavor results from a combination of the activity of volatile compounds and non-volatile taste-associated components (Paolo et al., 2018). In strawberry, flavor has obviously been put as a secondary breeding target and particular attention is paid (Olbricht et al., 2007), while tomato was reported as an excellent and important model organism for fleshy fruit studies to investigate flavor at the molecular level (Klee and Tieman, 2013; Lin et al., 2014; Pesaresi et al., 2014). From the physicist's point of view, flavor of the food is overall perception of taste, aroma and texture (Vilgis, 2013). Distinguishing characteristics of these attributes typically influence consumer preferences of tomato (Barrett et al., 2010; Causse et al., 2010). Texture is closely related to flavor, especially to the formation of VOCs, as texture is related to the degradation of cell walls, among other factors. At the simplest level, breaking of the cell wall will stimulate contact between enzymes and substrates involved in the release of VOCs (Wang and Seymour, 2017). Texture perception is the sensations perceived when eating and the greatest contributor to the texture of tomato products are insoluble solids, which comprised of roughly $10-20 \%$ of total solids in the fruit cell wall (Causse et al., 2010; Waldron et al., 2003).

Flavor of a fresh fruit is the sum of an interaction between taste and olfaction (Vogel et al., 2010) generated from a complex interaction of sugars, organic acids and VOCs (Rambla et al., 2013). Sugars and acids activate taste receptors, while a various set of volatile compounds stimulate olfactory receptors (Baldwin et al., 2000; Tieman et al., 2012). The principal sugar contributors are glucose and fructose while the major organic acids include citrate, malate, ascorbate and glutamate 
(Vogel et al., 2010). The characteristic sweet-sour flavor of tomato fruit is not solely as the result of the interactions of the non-volatile compounds such as sugars, acids and amino acids in the fruit (Liu et al., 2017), but it is determined by a complex combination of volatile and nonvolatile metabolites that is not yet understood (Cortina et al., 2018). Previous sensory studies in tomato revealed that flavor is the most important characteristic to improve the sensory quality of fruits and is necessary to meet consumers expectations (Causse et al., 2010; El Hadi et al., 2013; Tieman et al., 2012).

Tomato aroma is a very complex trait (Libin Wang et al., 2016), since aroma perception is not the result of the effect of a single VOC, but the outcome of interactions between different VOCs (Rambla et al., 2013). To date, breeding efforts leading to improved aroma is a challenge for breeders in the coming years (Quinet et al., 2019).

Besides many primary and secondary metabolites such as sugars, amino acids, fatty acids and carotenoids can impact sensory properties of the fruit directly, they are also precursors of some important volatile compounds of tomato (Liu et al., 2017). VOCs, in particular, play a critical role for a good flavor (Tieman et al., 2017). Of more than 400 VOCs detected in tomato fruits (PetroTurza, 1986), usually only 20-30 are perceived by the human olfactory system (Baldwin et al., 2000). These VOCs are generated from a diverse set of precursors including fatty acids, and carotenoids (Klee and Giovannoni, 2011).

The production system may influence the fruit quality (e.g., the concentration of organic acids, phenolic content, and lycopene) rather than the fruit yield and these compounds in fruits produced in organic and low-input system were often higher than ones in conventional system (Ghorbani et al., 2012). In general, field grown tomatoes has been reported to have higher levels of VOCs than greenhouse-grown fruits (Ilahy et al., 2019). Tomato fruits from a single plant harvested on different days can vary widely in taste properties, even within a single growing season, and seasonal and site variation in tomato taste properties can be greater than the plant-to-plant variation (Klee and Tieman, 2013). As an example, even the fruits are chosen from the same genotypes and 
cultivated with identical field management, people usually complain about off-season tomato fruits not as good as in-seasonal ones in term of overall flavor and eating quality (Liu et al., 2017). Flavor properties are important breeding targets in order to meet consumer requirements for tomatoes (Kimbara et al., 2018; Klee, 2010). Besides that, growing interest on environmentally friendly produced food (Araujo and Telhado, 2015) could encourage breeders to develop cultivars with excellent flavor characteristics for organic low-input cultivation as well.

While studies on the chemistry and variability of quality parameters of tomatoes especially their flavor compounds are largely available (Casals et al., 2018; Paolo et al., 2018; Piombino et al., 2013; Quinet et al., 2019), knowledge about the difference between the chemical properties and volatile compounds accumulation in tomato grown under organic low-input production as well as their correlation with the overall and specific sensory attributes is scare. Most of the studies concentrated on tomato cultivars grown conventionally in the field or greenhouse (Tikunov, 2005; Ursem et al., 2008; Zanor et al., 2009).

Therefore aims of the present study were (i) to characterize different cocktail and salad tomato cultivars with respect to their sensory properties under the conditions of organic low-input cultivation. The focus of the investigations is on instrumentally determined traits [color, total soluble solid (TSS), titratable acidity (TA), and VOCs] and on human-sensory perception (fruit firmness, juiciness, skin firmness, sweetness, sourness, tomato-typical aroma, and acceptability) of a set of cocktail and salad tomato cultivars grown in two years under organic low-input conditions, (ii) to investigate possible relationships among VOCs, taste-related traits (TSS and TA) and sensory attributes of these cultivars. The output of this study is expected to provide preliminary information of the cultivars on the basis of volatile and nonvolatile organic components that performs better in flavor and is best suited for organic low-input production. 


\subsection{Materials and Methods}

\subsubsection{Plant materials}

The experiments were performed on 20 indeterminate tomato cultivars (S. lycopersicum $\mathrm{L}$.) varying in fruit color and fruit weight (Erika et al., 2020). Photographs of the fruit phenotypes are shown in Chea et al. (under review). All cultivars, namely cocktail (single fruit weight $<52 \mathrm{~g}$ ) and salad (fruit weight $>52 \mathrm{~g}$ ) fruit types, were grown during summers of 2015 and 2016 (Erika et al., 2020). The average weight of a single fruit was $26 \mathrm{~g}$ for cocktail and $103 \mathrm{~g}$ for salad cultivars. The field trial was arranged in a randomized complete block design with eight replications (one and two plants per plot in 2015 and 2016, respectively). Tomato seedlings were raised in a greenhouse at an average mean temperature of $20^{\circ} \mathrm{C}, 18{ }^{\circ} \mathrm{C}$, and $16 / 8 \mathrm{~h}$ (day/night) photoperiod and transplanted in the field under a shelter in an organic low-input condition. All cultivars received the same agricultural practices. Further information on agronomic treatments and growth conditions were described in Erika et al. (2020). All fruits were harvested at the ripe stage and the harvest was performed at two harvest dates (2015: 13 week after planting (WAP), and 18 WAP; 2016: 14 WAP and 19 WAP). The ripe fruits were packed and delivered immediately to the laboratory for further quality analysis.

\subsubsection{Preliminary treatment of the samples prior to analysis}

Samples from two harvest dates for both years were used for the determination of color, TSS, TA, VOCs and sensory attributes. At harvest, the ripe healthy fruits of eight biological replications were combined into four pooled replicates $(1+8,2+7,3+6$ and $4+5)$ and only samples derived from three replications $(2+7,3+6$ and $4+5)$ were used in this experiment. All samples coming from the field to the laboratory were at first measured for color and then divided into subsamples for the instrumental analysis (TSS, TA and VOCs) and the sensory evaluation. Ten fruits of each cocktail cultivar and three fruits of each salad cultivar per biological replication were used for each of the analysis described in the following sub-chapters. While fresh fruits were used for the measurement of color, VOCs and the sensory evaluation, the determination of TSS and TA was 
performed on frozen materials. Prior frozen, the fruits were cleaned with water, cut into wedges and were immediately stored at $-20^{\circ} \mathrm{C}$ until analysis.

\subsubsection{Extraction and analysis of VOCs}

\subsubsection{Headspace solid-phase micro-extraction (HS-SPME) procedure}

HS-SPME was used to extract the volatile compounds according to the method for analysis of VOCs in fruit and vegetables (Olbricht et al., 2007) with minor changes. The fresh fruits were washed with the ionized water, sliced and weighed in $1 \mathrm{~L}$ glass beaker. The weighed sample was homogenized in two parts of volume of $20 \% \mathrm{NaCl}$ solution $(\mathrm{w} / \mathrm{v})$ with a hand mixer (Braun, Germany) at medium speed for $2 \mathrm{~min}$. The homogenate was filled in $50 \mathrm{ml}$ centrifuge tubes and centrifuged at $4{ }^{\circ} \mathrm{C}$ (3000 rpm, $30 \mathrm{~min}$, centrifuge 5416 Eppendorf $\mathrm{GmbH}$, Germany) to separate clear supernatant. Ten $\mathrm{mL}$ of the supernatant was mixed carefully with $20 \mu \mathrm{L}$ internal standard $[(5 \%(\mathrm{v} / \mathrm{v}) ; 1$-octanol dissolved in ethanol]. For each sample, $8 \mathrm{~mL}$ aliquot was transferred into a 20 mL-headspace-vial (Gerstel GmbH, Germany) already containing $4 \mathrm{~g} \mathrm{NaCl}$, sealed with a screw cap septum, vortexed for $10 \mathrm{~s}$ and stored at $-20{ }^{\circ} \mathrm{C}$ until analysis. The volatile compounds were extracted using headspace solid-phase-micro-extraction (SPME) by exposing a $100 \mu \mathrm{m}$ polydimethylsiloxane (PDMS) fiber (Supelco, Bellefonte, PA) using an MPS2 auto-sampler (Gerstel, Mülheim an der Ruhr, Germany) to the vial headspace for 15 min at $35{ }^{\circ} \mathrm{C}$ under continuous shaking. Before sampling, the frozen VOC extract in the sealed 20-mL-HS-vials was incubated at $35{ }^{\circ} \mathrm{C}$ in a thermal block (with a shaking operation mode of $300 \mathrm{rpm}$ ) for 10 min to allow equilibration of volatiles in the headspace. After extraction, the fiber was inserted into the injector port of a gas chromatography (GC) and thermal desorption was performed for 2 min at $250{ }^{\circ} \mathrm{C}$ (splitless mode), followed by 3 min additional thermal cleaning in split mode (split ratio 1:10).

\subsubsection{Gas chromatography-mass spectrometry (GC-MS) analysis}

The qualitative and quantitative analyses of VOCs were carried out using a gas chromatography coupled with mass spectrometry GC-MS 6890 (Agilent Technologies Deutschland $\mathrm{GmbH}$, Germany) equipped with a flame ionization detector (FID) for separation and detection. The 
FID temperature was at $250{ }^{\circ} \mathrm{C}$ and hydrogen was employed as carrier gas with constant column flow rate of $1.1 \mathrm{~mL} \mathrm{~min}^{-1}$. The temperature program used for the column oven was isothermal processing at $45{ }^{\circ} \mathrm{C}(5 \mathrm{~min})$; heating from $45{ }^{\circ} \mathrm{C}$ to $210{ }^{\circ} \mathrm{C}$ at a rate of $3 \mathrm{~K} \mathrm{~min}^{-1}$; isothermal processing at $210{ }^{\circ} \mathrm{C}$ for $25 \mathrm{~min}$. For compound separation, a polar capillary column HP INNOWAX (0.25 mm i.d., $30 \mathrm{~m}$ length; $0.25 \mu \mathrm{m}$ film thickness) were selected to separate volatiles trapped on the fiber. For compound identification, a GC with an Agilent 5973 MSD with electron impact ionization at $70 \mathrm{eV}$ in the full scan mode was used. Tentative identification of the VOCs was performed by comparing the mass spectra of the samples with the National Institute of Standards and Technology (NIST) mass spectral library (Wiley, Nbs75k, USA). Mass spectrometry identification was confirmed with the co-elution of authentic references. The abundant level of 31 VOCs are reported in relative concentration (the normalized sample preparation) and presented as non-dimensional values, which were calculated from the raw data (exported from ChromStat) using absolute peak areas in counts. The relative concentrations of VOCs were calculated by measuring the area under the curve of the VOC peak. Semi quantification by the software ChromStat 2.6 was performed on the identified 31 VOCs (Table 4. 1). Finally, the results from the VOCs analysis are expressed as the percentage of each compounds integrated area relative to the total integration of the identified compounds or abundance of each VOC as a proportion of the total profile abundance.

Table 4.1 List of VOCs identified across all samples and abbreviation used for the statistical analysis

\begin{tabular}{lllll}
${ }^{\mathbf{a} C A S}$ number & ${ }^{\mathbf{b}}$ IUPAC name & Abbreviation & ${ }^{\mathbf{c}}$ Identification & $\begin{array}{l}{ }^{\mathbf{d} F u n c t i o n a l} \\
\text { group }\end{array}$ \\
\hline $66-25-1$ & hexanal & hexanal & 2 & ALD \\
$624-41-9$ & 2-methylbutyl acetate & mebuOAc & 2 & EST \\
$6728-26-3$ & $(E)$-2-hexenal & hexenal & 2 & ALD \\
$124-13-0$ & octanal & octanal & 2 & ALD \\
$110-93-0$ & 6-methyl-5-hepten-2-one & meheptone & 2 & KET \\
$111-27-3$ & 1-hexanol & hexanol & 2 & ALC \\
$928-96-1$ & (Z)-3-hexen1-ol & hexenol & 2 & ALC \\
$18640-74-9$ & 2-isobutylthiazole & isobut & 2 & SDC \\
$1569-60-4$ & 6-methyl-5-hepten-2-ol & meheptenol & 2 & ALC \\
$104-76-7$ & 2-ethyl-1-hexanol & ethexanol & 2 & ALC \\
$78-70-6$ & linalool & linalool & 2 & ALD \\
$432-25-7$ & B-cyclocitral & cyclocit & 1 & ALC \\
$503-74-2$ & 3-methyl-butanoic acid & mebutacid & 2 & KET \\
$98-55-5$ & $\alpha$-terpineol & terpineol & 2 & ALD
\end{tabular}




\begin{tabular}{lllll}
$5392-40-5$ & citral & citral & 2 & ALA \\
$119-36-8$ & methyl salicylate & meOSal & 2 & ALC \\
$23696-85-7$ & $\beta$-damascenone & damasc & 2 & ALD \\
$3796-70-1$ & $($ E)-geranylacetone & gera & 1 & ALD \\
$79-31-2$ & 2-methyl-propanoic acid & mepropacid & 2 & ALD \\
$100-51-6$ & benzyl alcohol & benzylalc & 2 & EST \\
$60-12-8$ & phenylethyl alcohol & phenylet & 2 & KET \\
$14901-07-6$ & $\beta$-ionone & ionone & 2 & KET \\
$97-53-0$ & eugenol & eugenol & 2 & ALA \\
$1117-52-8$ & farnesyl acetone & farnesylac & 1 & ALC \\
$100-52-7$ & benzaldehyde & benzald & 2 & ALC \\
& methyl heptadione & meheptdione & 1 & KET \\
$141-27-5$ & geranial & geranial & 2 & ALC \\
$25152-84-5$ & decadienal & deca & 2 & KET \\
$110-27-0$ & isopropyl myristate & iprop & 2 & EST \\
$124-07-2$ & octanoic acid & octacid & 2 & ALA \\
$112-05-0$ & nonanoic acid & nonacid & 2 & ALA \\
\hline
\end{tabular}

${ }^{\mathrm{a} C A S}$ : Chemical Abstracts Service (a numeric identifier of the chemical compounds); ${ }^{\mathrm{b}}$ IUPAC: International Union of Pure and Applied Chemistry; 'Identification code: 1- tentatively identified by MS library search (NIST, Wiley, Nbs75k); 2- fully identified by MS library search and co-elution of authentic reference substances; ${ }^{\mathrm{A} A L D}$ : aldehyde, EST: ester, ALC: alcohol, SDC: sulfur derived-compound, KET: ketone, ALA: Aliphatic acids.

\subsubsection{Instrumental Analysis}

The color was measured by using a colorimeter (Konica Minolta Chroma meter CR-400, Osaka, Japan) in accordance with the CIELAB L*a*b* (The International Commission on Illumination) system. Color coordinates $\mathrm{L}^{*}$ indicates the darkness/lightness (represents total darkness and 100 total lightness) of the sample, a* is a measurement of greenness/redness (negative values indicate green and positive ones red color), and $b^{*}$ is the extent of blueness/yellowness (blue color is related to negative values and yellow to positive ones) were determined. The $\mathrm{C}^{*}$ (chroma) and $\mathrm{h}^{\circ}$ (hue angle) were also recorded on the basis of the color reading $\mathrm{L}^{*}, \mathrm{a}^{*}, \mathrm{~b}^{*}$ system. Two different positions equally spaced of the equatorial region of each fruit were measured and the mean values of eight and 10 composite fruits respectively obtained from each salad and cocktail cultivars were used for the data analysis. TSS and TA was determined according to the established procedure as described in Kanski et al. (2020).

\subsubsection{Descriptive sensory evaluation}

Due to the high number of cultivars in 2015 , the sensory evaluation was carried out using the breeder's sensory test (Hagenguth et al., 2018) as follows: three panelists (male from 25 to 50 
years of age) with experience in the sensory evaluation of tomatoes and knowledge of the varieties to be evaluate and terminology to be used, were trained for several hours in preparation for the sensory examination. The samples were labelled with a 3-digit code and served to the panelists. Cocktail cultivars were evaluated separately from salad cultivars. The sensory attributes for fruit firmness, juiciness, skin firmness, sweetness, sourness, tomato-typical aroma, and acceptability were assessed. The scoring was based on a 9-point scale where $1=$ minimum intensity and $9=$ maximum intensity.

In 2016, quantitative descriptive analysis (QDA) was used to evaluate sensory attributes of tomato fruits. Eleven panelists, aged 25-55 years (45\% male and 65\% female, majority between 25 30 years old), were trained in descriptive evaluation of tomatoes according to the ISO (International Organization for Standardization) standards 8586 (ISO, 2012). The technical procedure for all panel training and sensory evaluation sessions used in this study was in line with previous study of Kanski et al. (2020) with some modifications. The panelists undertook two weeks training (four days a week) which accounted eight sessions prior to evaluation. An initial training with general sensory techniques was introduced and the descriptive terms to characterize flavor (fruit firmness, juiciness, skin firmness, sweetness, sourness and tomato-typical aroma) and overall acceptability of tomatoes were established during the first three sessions. In the following sessions, each of the attributes was defined and different references to represent each attribute were presented to panelist. The panel leader mediated group discussions to reach a consensus. The sensory analysis, consisted of three sessions, was carried out in individual sensory booths in the sensory laboratory at the University of Goettingen under daylight equivalent lighting conditions which complied the specifications of ISO 8589 (ISO, 2007). Panelists were asked to rate samples for the intensity of each flavor attribute (fruit firmness, juiciness, skin firmness, sweetness, sourness, tomato-typical aroma) and the acceptable level of each sample on a sensory score sheet with an unstructured line scale $(0=$ not perceptible to $100=$ strongly perceptible $)$. The samples were removed from storage $(7$ ${ }^{\circ} \mathrm{C}$ ) about 30 minutes prior to evaluation to equilibrate to room temperature, cut into halves (for 
cocktail tomatoes) or $1 / 8$ wedges (for salad tomatoes) and presented to the panelists in small bowls. Water and plain crackers were provided between servings for cleansing the palates. To reduce the effect of sensory fatigue, a regular 10 to 15 minutes break was taken at which time a discussion was initiated to ensure that all panelists were in close agreement in their evaluation of the sensory attributes.

\subsubsection{Statistical analysis}

Overall mean abundance of VOCs, instrumental (color components, TSS and TA) and sensory data (fruit firmness, juiciness, skin firmness, sweetness, sourness, tomato typical-aroma and acceptability) were subjected to one-way analysis of variance (ANOVA) and Tukey's honestly significant difference (Tukey's HSD) test in order to define possible differences in means at $\mathrm{p} \leq$ $0.05, \mathrm{p} \leq 0.01$ and $\mathrm{p} \leq 0.001)$. Pearson's correlation analysis between and within VOCs significantly ( $\mathrm{p} \leq 0.05$ and $\mathrm{p} \leq 0.01)$ associated to instrumental and sensory parameters was conducted. Principal component analysis (PCA) was performed to highlight the principal components responsible for the majority of the variations within the dataset. The PCA was performed on the analytical data and the mean sensory ratings (based on the correlation matrix) across two years. The relative concentration of VOCs values were normalized to the total mean abundance of identified compounds and presented in norm $\%$, calculated according to the following formula:

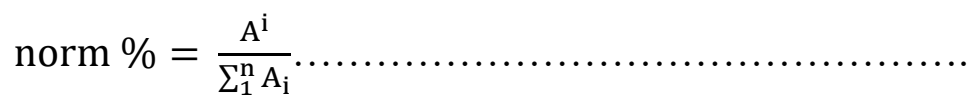

Where $\mathrm{i}=$ substance $\mathrm{i} ; \mathrm{A}_{\mathrm{i}}=$ relative concentration of observation $\mathrm{i}$ (dimensionless); and $\mathrm{n}=$ number of observations (identified VOCs). All the analyses were performed using the Statistica 13.3 package (TIBCO Software Inc., Chicago, USA).

\subsection{Results}

\subsubsection{Identification and classification of the VOCs}

A total of 31 VOCs was putatively identified in the 20 cultivars across two years, belonging six functional classes of organic compounds: alcohols (ALC) were with nine VOCs as the largest group, eight aldehydes (ALD), followed by six ketones (KET), four aliphatic acids (ALA), three 
esters (EST) and one sulfur derived-compound (SDC). Twenty-seven of these VOCs were fully identified by both MS library search and co-elution of authentic standards while four VOCs were tentatively identified based on MS library search (Table 4.1). In terms of relative contribution, ALD were the most abundant compounds, accounting for $51.1 \%$ of the total quantified VOCs, followed by KET (27.4\%), SDC (11.2\%) and ALC (6.7\%) ALA-VOCs accounted for 0.8\% and EST-VOCs represented $0.73 \%$ and these VOCs were mostly detected at very low concentrations in the tomato samples (Fig. 4.1 A).
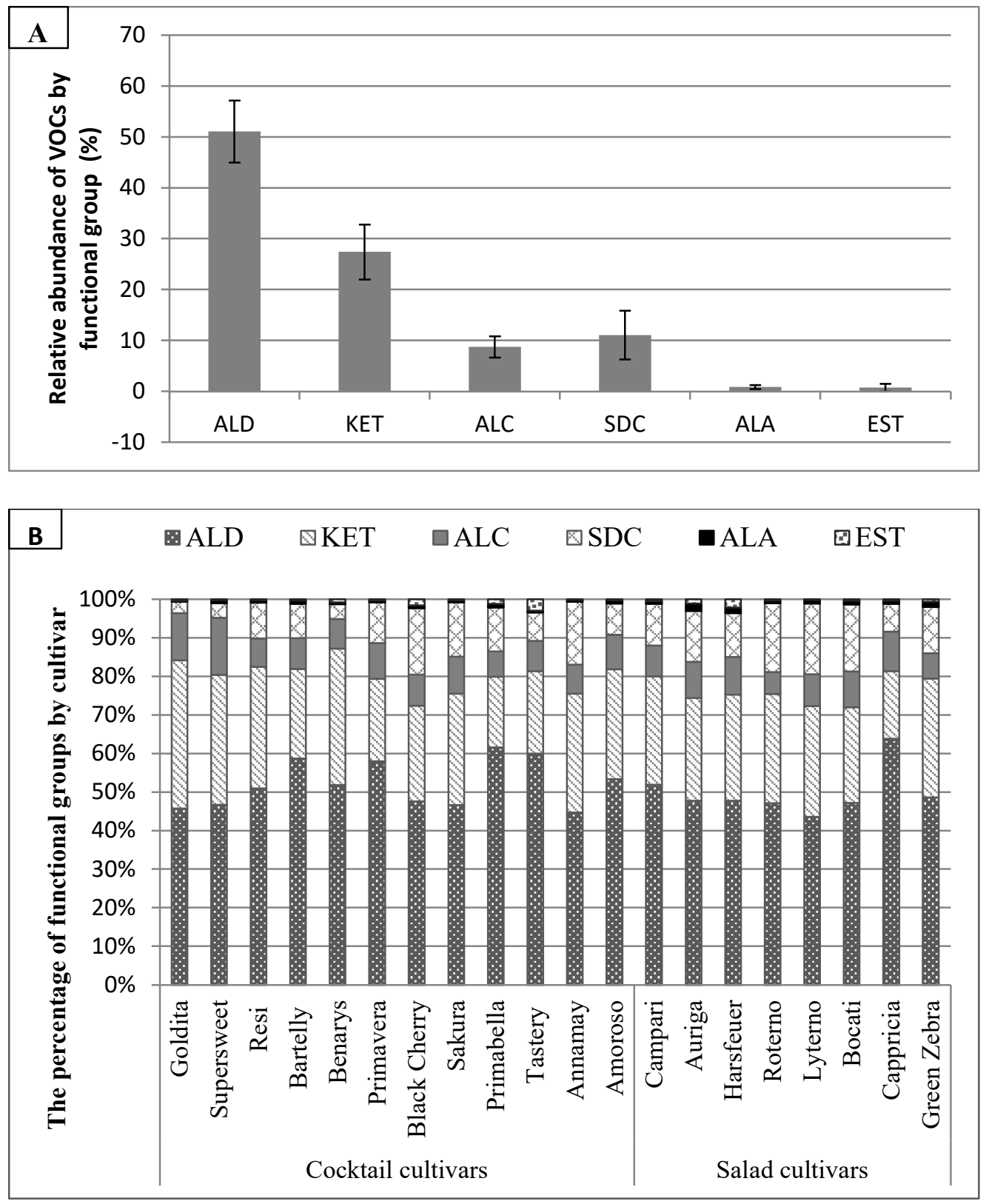

Fig. 4.1 Percentage of relative abundance of VOCs accumulated in five different functional groups in the 20 tomato cultivars across two harvests and two years, by group across all cultivars (A) by cultivars (B). Functional group: $\mathrm{ALD}=$ aldehydes, KET=ketones, ALC $=$ alcohols, SDC $=$ sulfur derived-compound, $\mathrm{ALA}=$ aliphatic acids, and $\mathrm{EST}=\mathrm{esters}$ 
In terms of the relative abundance of particular VOCs groups, it was found that each of the 20 cultivars across two years, with exception of "Cappricia F1", contained 45 to $60 \%$ ALD-VOCs. Among cocktail cultivars, "Goldita" had the lowest proportion of SDC-VOCs (3\%) while the largest one was found in "Black Cherry" (17\%). Most of salad cultivars showed considerably higher relative concentration of SDC-VOCs than cocktail cultivars, especially in "Roterno F1" and "Lyterno F1". Esters were detected at very low relative levels and only in some cultivars such as in "Tastery F1", "Harzfeuer F1" and "Black Cherry". The orange cultivar "Goldita" had a relative lower abundance of SDC-, ALA-, and EST-VOCs, but this was not true for "Auriga" (also orange), as this cultivar contained the above functional VOCs groups in much higher amounts (Fig. 4.1B).

The ANOVA and the relative concentration (relative to the internal standard) of VOCs in the tomatoes across two years were shown in Table 4.2. The effect of cultivar on all identified VOCs, except for $\alpha$-terpineol, was always significant at different confidence levels. The cultivar $(\mathrm{C}) \times$ harvest date $(\mathrm{H}) \times$ year $(\mathrm{Y})$ interaction showed significant effects on 17 VOCs but had no significant influences on the other VOCs. The VOCs quantified in the present study composed of, in descending order, hexanal (35.2\%), 6-me-5-heptene-2-one (17.4\%), 2-isobutylthiazole (11.1\%), (E)-2-hexenal (8.78\%), geranylacetone (5.33\%), octanal (3.7\%), and $\beta$-damascenone (3.28\%). The other VOCs were detected in relative concentration less than $3 \%$ of the total quantified VOCs.

Result of Student's T-test showed that the relative concentrations of 2-isobutylthiazole, linalool, phenylethyl alcohol and nonanoic acid were significantly different $(p \leq 0.001)$ between cocktail and salad cultivars, indicating large variation of the tomato aroma between the groups of fruit type. With regard to cultivar comparison, variation of the relative concentration for each of the 31 VOCs within cocktail and salad cultivars is shown in Tables 4.3 and 4.4. There were 23 VOCs in the cocktail cultivars and 15 VOCs in the salad cultivars, each with significant differences at different confident levels. However, these differences were not consistent within the fruit type. For example, hexanal, octanal and 1-hexanol significantly differed among cocktail cultivars but they were not different between salad cultivars. In general, the number of VOCs in cocktail cultivars 
ranged from 21 to 31 and from 24 to 31 in salad ones. Taken together, the following 14 VOCs were identified in all cultivars: hexanal, (E)-2-hexenal, octanal, 6-me-5-heptene-2-one, 1-hexanol, (Z)-3hexen-1-ol, 2-isobutylthiazole, 2-ethyl-1-hexanol, linalool, $\beta$-cyclocitral, methylsalicylate, $\beta$ damascenone, geranylacetone and octanoic acid (Table 4.3 and 4.4).

Hexanal was the predominant ALD-VOC in both cocktail and salad cultivars followed by (E)-2-hexenal and octanal. The concentration of hexanal showed a wide variation within the cocktail cultivars ranging from $25.1 \%$ ("Supersweet $100 \mathrm{~F} 1$ ") to $48.7 \%$ ("Black Cherry") of the total of VOCs. However, there was no significant difference with regard to relative concentration of hexanal among salad cultivars. Relative high proportion of (E)-2-hexenal ranging from $7.08 \%$ to $13.64 \%$ was measured in cocktail cultivars but they were not statistically different at $\mathrm{p} \leq 0.05$, while significant variation of (E)-2-hexenal was found in salad cultivars $(3.37 \%$ to $9.94 \%)$. The relative amount of 2-isobutylthiazole in salad cultivars was considerably higher than in cocktail cultivars $(\mathrm{p} \leq 0.001)$, where the highest percentage was measured in "Lyterno F1", "Roterno F1" and "Campari F1" accounting 17\% to $18 \%$ of total identified VOCs. With regard to ALC-VOCs, 6-me5-hepten-2-ol and linalool were found to have higher levels in salad cultivars, while the levels of benzyl alcohol and phenylethyl alcohol were significantly higher in the cocktail cultivars. The highest content of phenylethyl alcohol was detected in "Supersweet 100 F1" (3.11\%) and "Goldita" $(2.96 \%)$. On the other hand, significant higher level of 2 -isobutylthiazole $(\mathrm{p} \leq 0.001)$ was observed in salad cultivars than in cocktail cultivars. Within ALA-VOCs and EST-VOCs, only octanoic acid and methylsalicylate, respectively, were found well distributed in each cultivar, while the other compounds within these groups were detected at trace level in some cultivars (Table 4.3 and 4.4). 
Table 4.2 ANOVA of relative concentration of VOCs (\%) in the 20 tomato cultivars over two harvest dates and two years as well as comparison between its fruit type with the student $t$-test for significance

\begin{tabular}{|c|c|c|c|c|c|c|c|c|c|c|c|c|}
\hline \multirow[t]{3}{*}{ VOCs } & \multicolumn{6}{|c|}{ ANOVA, source of variation } & \multicolumn{5}{|c|}{ Relative concentration (mean \pm SD) } & \multirow[t]{3}{*}{$\begin{array}{l}\text { Student's } \\
\text { t-test }^{\mathrm{a}}\end{array}$} \\
\hline & $\begin{array}{c}\text { Cultivar, } \\
\text { C }\end{array}$ & $\begin{array}{c}\text { Harvest, } \\
\text { H }\end{array}$ & $\begin{array}{l}\text { Year, } \\
\text { Y }\end{array}$ & $\mathbf{C} \times \mathbf{H}$ & $\mathbf{C} \times \mathbf{Y}$ & $\begin{array}{c}\mathbf{C} \times \mathbf{H} \\
\times \mathbf{Y}\end{array}$ & Year 1 & Year 2 & $\begin{array}{l}\text { Over two } \\
\text { years }\end{array}$ & $\begin{array}{l}\text { Cocktail } \\
\text { cultivar }\end{array}$ & Salad cultivar & \\
\hline & & & & & & & $n=120$ & $\mathrm{n}=\mathbf{1 2 0}$ & $\mathrm{n}=\mathbf{2 4 0}$ & $n=144$ & $n=96$ & \\
\hline hexanal $^{\mathrm{a}, \mathrm{b}}$ & $* * *$ & $* * *$ & $* * *$ & ns & $* * *$ & ns & $26.4 \pm 11.6$ & $44.0 \pm 9.36$ & $35.2 \pm 13.7$ & $36.5 \pm 12.9$ & $33.3 \pm 14.7$ & ns \\
\hline 2-methylbutylacetate ${ }^{\mathrm{a}, \mathrm{b}}$ & $* * *$ & ns & $* * *$ & ns & $* * *$ & ns & $0.00 \pm 0.00$ & $0.59 \pm 2.57$ & $0.29 \pm 1.83$ & $0.40 \pm 2.17$ & $0.14 \pm 1.17$ & ns \\
\hline (E)-2-hexenal ${ }^{\mathrm{a}, \mathrm{b}}$ & $* * *$ & $* * *$ & $* * *$ & $* * *$ & $* * *$ & $* * *$ & $11.2 \pm 6.53$ & $6.36 \pm 2.95$ & $8.78 \pm 5.61$ & $9.49 \pm 6.30$ & $7.74 \pm 4.21$ & $*$ \\
\hline octanal $^{\mathrm{a}, \mathrm{b}}$ & $* * *$ & $* *$ & $* * *$ & $* * *$ & $* * *$ & ns & $5.09 \pm 1.62$ & $2.30 \pm 1.10$ & $3.70 \pm 1.96$ & $3.63 \pm 1.79$ & $3.79 \pm 2.20$ & ns \\
\hline 6-me-5-heptene-2-one ${ }^{\mathrm{a}, \mathrm{b}}$ & $* * *$ & $* * *$ & $* * *$ & $* * *$ & $* * *$ & $*$ & $18.3 \pm 7.33$ & $16.5 \pm 6.99$ & $17.4 \pm 7.21$ & $16.84 \pm 7.08$ & $18.2 \pm 7.34$ & ns \\
\hline 1-hexanol ${ }^{\mathrm{a}, \mathrm{b}}$ & $* * *$ & ns & $* * *$ & $* * *$ & $* * *$ & $*$ & $2.12 \pm 1.22$ & $1.16 \pm 0.66$ & $1.64 \pm 1.09$ & $1.75 \pm 1.02$ & $1.49 \pm 1.17$ & ns \\
\hline (Z)-3-hexen-1-ol ${ }^{\mathrm{a}, \mathrm{b}}$ & $* * *$ & $* * *$ & $* * *$ & $* * *$ & ns & $* *$ & $4.02 \pm 1.87$ & $1.37 \pm 0.93$ & $2.69 \pm 1.98$ & $2.89 \pm 2.10$ & $2.39 \pm 1.77$ & ns \\
\hline 2-isobutylthiazole ${ }^{\mathrm{a}, \mathrm{b}}$ & $* * *$ & $* * *$ & $* * *$ & $* * *$ & $* *$ & ns & $10.3 \pm 4.87$ & $11.9 \pm 6.17$ & $11.1 \pm 5.60$ & $9.72 \pm 5.70$ & $13.1 \pm 4.80$ & $* * *$ \\
\hline 6-me-5-hepten-2-ol ${ }^{\mathrm{a}, \mathrm{b}}$ & $* * *$ & $*$ & $* * *$ & $* *$ & $* * *$ & $* *$ & $0.00 \pm 0.00$ & $0.41 \pm 0.38$ & $0.20 \pm 0.34$ & $0.15 \pm 0.28$ & $0.28 \pm 0.40$ & $* *$ \\
\hline 2-ethyl-1-hexanol ${ }^{\mathrm{a}, \mathrm{b}}$ & $* * *$ & ns & $* * *$ & ns & ns & ns & $0.96 \pm 0.61$ & $0.70 \pm 0.29$ & $0.83 \pm 0.49$ & $0.84 \pm 0.51$ & $0.81 \pm 0.48$ & ns \\
\hline benzaldehyde $\mathrm{a}^{\mathrm{a}, \mathrm{b}}$ & $* *$ & ns & $* * *$ & ns & $* *$ & ns & $0.20 \pm 0.28$ & $0.00 \pm 0.00$ & $0.10 \pm 0.22$ & $0.08 \pm 0.18$ & $0.14 \pm 0.27$ & $*$ \\
\hline linalool $^{\mathrm{a}, \mathrm{b}}$ & $* * *$ & $* * *$ & $* * *$ & ns & $* * *$ & $* *$ & $2.68 \pm 1.82$ & $1.34 \pm 1.08$ & $2.01 \pm 1.64$ & $1.64 \pm 1.55$ & $2.56 \pm 1.62$ & $* * *$ \\
\hline methylheptadione ${ }^{a}$ & $*$ & $* *$ & $* * *$ & $*$ & $*$ & $*$ & $0.04 \pm 0.13$ & $0.00 \pm 0.00$ & $0.02 \pm 0.09$ & $0.01 \pm 0.08$ & $0.03 \pm 0.11$ & $\mathrm{~ns}$ \\
\hline$\beta$-cyclocitral ${ }^{\mathrm{a}}$ & $* * *$ & $* * *$ & $* * *$ & ns & $* * *$ & ns & $1.72 \pm 1.47$ & $1.30 \pm 0.91$ & $1.51 \pm 1.23$ & $1.43 \pm 0.82$ & $1.63 \pm 1.66$ & ns \\
\hline 3-mebutanoic acid ${ }^{\mathrm{a}, \mathrm{b}}$ & $* * *$ & $* * *$ & $* * *$ & ns & $* * *$ & $*$ & $0.40 \pm 0.48$ & $0.10 \pm 0.21$ & $0.25 \pm 0.40$ & $0.19 \pm 0.34$ & $0.33 \pm 0.47$ & $*$ \\
\hline a-terpineol ${ }^{\mathrm{a}, \mathrm{b}}$ & $\mathrm{ns}$ & $* * *$ & $\mathrm{~ns}$ & ns & $\mathrm{ns}$ & ns & $0.33 \pm 1.11$ & $0.19 \pm 0.28$ & $0.26 \pm 0.81$ & $0.26 \pm 0.89$ & $0.27 \pm 0.67$ & ns \\
\hline geraniala $^{\mathrm{a}, \mathrm{b}}$ & $* * *$ & ns & $* * *$ & $* *$ & $* * *$ & $* *$ & $1.55 \pm 0.95$ & $0.00 \pm 0.00$ & $0.78 \pm 1.03$ & $0.74 \pm 0.90$ & $0.83 \pm 1.19$ & ns \\
\hline citral $^{\mathrm{a}, \mathrm{b}}$ & $* * *$ & ns & $* * *$ & ns & $* * *$ & ns & $0.00 \pm 0.00$ & $1.78 \pm 1.14$ & $0.89 \pm 1.20$ & $0.98 \pm 1.28$ & $0.76 \pm 1.06$ & ns \\
\hline decadienal $^{\mathrm{a}, \mathrm{b}}$ & $* * *$ & $* * *$ & $* * *$ & $* * *$ & $* * *$ & $* * *$ & $0.03 \pm 0.17$ & $0.00 \pm 0.00$ & $0.02 \pm 0.12$ & $0.03 \pm 0.15$ & $0.00 \pm 0.00$ & ns \\
\hline methylsalicylate $e^{a, b}$ & $* * *$ & $* * *$ & $* * *$ & $* * *$ & $* * *$ & $* * *$ & $0.00 \pm 0.00$ & $1.15 \pm 1.66$ & $0.58 \pm 1.30$ & $0.53 \pm 1.25$ & $0.64 \pm 1.39$ & ns \\
\hline$\beta$-damascenone $\mathrm{e}^{\mathrm{a}, \mathrm{b}}$ & $* * *$ & $* *$ & $* * *$ & $* * *$ & $* * *$ & $* * *$ & $5.15 \pm 2.75$ & $1.41 \pm 1.75$ & $3.28 \pm 2.96$ & $3.19 \pm 2.84$ & $3.41 \pm 3.15$ & ns \\
\hline geranylacetone $\mathrm{a}^{\mathrm{a}}$ & $* * *$ & ns & $* * *$ & $* * *$ & $* * *$ & $* * *$ & $6.03 \pm 4.11$ & $4.63 \pm 4.33$ & $5.33 \pm 4.27$ & $5.46 \pm 4.34$ & $5.14 \pm 4.17$ & ns \\
\hline 2-mepropanoic acid ${ }^{\mathrm{a}, \mathrm{b}}$ & $*$ & $* *$ & ns & ns & ns & ns & $0.26 \pm 0.51$ & $0.24 \pm 0.30$ & $0.25 \pm 0.42$ & $0.26 \pm 0.44$ & $0.23 \pm 0.38$ & ns \\
\hline benzylalcohol ${ }^{\mathrm{a}, \mathrm{b}}$ & $* * *$ & ns & $* * *$ & $*$ & $* * *$ & $* * *$ & $0.10 \pm 0.30$ & $0.23 \pm 0.44$ & $0.16 \pm 0.38$ & $0.22 \pm 0.44$ & $0.08 \pm 0.24$ & $* *$ \\
\hline phenylethylalcohol ${ }^{\mathrm{a}, \mathrm{b}}$ & $* * *$ & $* * *$ & $* * *$ & $* * *$ & $* * *$ & $* * *$ & $0.92 \pm 1.19$ & $0.79 \pm 0.97$ & $0.86 \pm 1.09$ & $1.12 \pm 1.27$ & $0.46 \pm 0.54$ & $* * *$ \\
\hline$\beta$-ionone ${ }^{\mathrm{a}, \mathrm{b}}$ & $* * *$ & $*$ & $* * *$ & $* * *$ & $* * *$ & $* * *$ & $1.47 \pm 1.22$ & $1.09 \pm 0.66$ & $1.28 \pm 1.00$ & $1.21 \pm 0.66$ & $1.39 \pm 1.34$ & ns \\
\hline eugenol $^{\mathrm{a}, \mathrm{b}}$ & $* * *$ & ns & $* * *$ & ns & $* * *$ & ns & $0.00 \pm 0.00$ & $0.18 \pm 0.22$ & $0.09 \pm 0.18$ & $0.07 \pm 0.16$ & $0.12 \pm 0.21$ & $*$ \\
\hline farnesylacetone $\mathrm{a}^{\mathrm{a}}$ & $* * *$ & $*$ & $* * *$ & ns & $* * *$ & ns & $0.00 \pm 0.00$ & $0.29 \pm 0.39$ & $0.14 \pm 0.31$ & $0.13 \pm 0.31$ & $0.17 \pm 0.32$ & ns \\
\hline isopropylmyristate ${ }^{\mathrm{a}, \mathrm{b}}$ & - & - & - & - & - & - & $0.00 \pm 0.00$ & $0.00 \pm 0.00$ & $0.00 \pm 0.00$ & - & - & - \\
\hline octanoic acid ${ }^{\mathrm{a}, \mathrm{b}}$ & $* * *$ & ns & $* * *$ & ns & $* * *$ & ns & $0.44 \pm 0.41$ & $0.00 \pm 0.00$ & $0.22 \pm 0.36$ & $0.18 \pm 0.29$ & $0.27 \pm 0.44$ & ns \\
\hline nonanoic acid ${ }^{\mathrm{a}, \mathrm{b}}$ & $* * *$ & ns & $* * *$ & $* * *$ & $* * *$ & $* * *$ & $0.24 \pm 0.50$ & $0.00 \pm 0.00$ & $0.12 \pm 0.38$ & $0.04 \pm 0.25$ & $0.23 \pm 0.48$ & $* * *$ \\
\hline
\end{tabular}

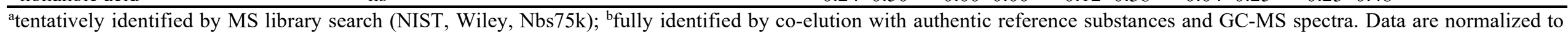

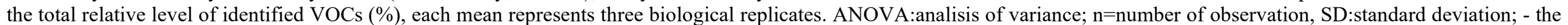
concentration was not detectable. 'Significantly different with *P value $\leq 0.05, * * \mathrm{P}$ value $\leq 0.01$ and $* * * \mathrm{P}$ value $\leq 0.001$ by the performance of Student's $t$-tests 
Table 4.3 Variation of relative concentration of VOCs (\%) in the 12 cocktail tomato cultivars over two harvests and two years with the Tukey's HSD test for significance

\begin{tabular}{|c|c|c|c|c|c|c|c|c|c|c|c|c|c|c|c|c|}
\hline \multirow[t]{3}{*}{ VOCs } & \multicolumn{12}{|c|}{ Cocktail tomato cultivars } & \multirow[t]{3}{*}{ Sign. } & \multirow[t]{3}{*}{$\begin{array}{l}\text { Tukey's } \\
\text { HSD }\end{array}$} & \multirow{2}{*}{\multicolumn{2}{|c|}{$\begin{array}{c}\text { Concentration (mean } \\
\pm \text { SD) } \\
\text { Year }(n=72)\end{array}$}} \\
\hline & \multirow[b]{2}{*}{ Goldi } & \multirow[b]{2}{*}{ Super } & \multirow[b]{2}{*}{ Resi } & \multirow[b]{2}{*}{ Barte } & \multirow[b]{2}{*}{ Benarys } & \multirow[b]{2}{*}{ Primav } & \multirow[b]{2}{*}{ Black } & \multirow[b]{2}{*}{ Sakura } & \multirow[b]{2}{*}{ Primab } & \multirow[b]{2}{*}{ Taste } & \multirow[b]{2}{*}{ Anna } & \multirow[b]{2}{*}{ Amor } & & & & \\
\hline & & & & & & & & & & & & & & & 2015 & 2016 \\
\hline hexanal & 30.06 & 25.11 & 34.64 & 40.44 & 37.16 & 40.10 & 48.67 & 26.26 & 47.50 & 42.17 & 30.31 & 37.71 & $* * *$ & 16.94 & $29.1 \pm 11.2$ & $43.9 \pm 9.90$ \\
\hline 2-methylbutylacetate & $\mathrm{Nd}$ & $\mathrm{Nd}$ & 5.54 & $\mathrm{Nd}$ & $\mathrm{Nd}$ & $\mathrm{Nd}$ & $\mathrm{Nd}$ & $\mathrm{Nd}$ & $\mathrm{Nd}$ & $\mathrm{Nd}$ & $\mathrm{Nd}$ & $\mathrm{Nd}$ & $* * *$ & 2.65 & $0.00 \pm 0.00$ & $0.80 \pm 3.03$ \\
\hline (E)-2-hexenal & 10.07 & 12.62 & 7.25 & 11.50 & 7.08 & 9.23 & 9.00 & 13.64 & 9.59 & 9.01 & 7.24 & 7.92 & $\mathrm{~ns}$ & 8.94 & $12.8 \pm 7.07$ & $6.19 \pm 2.80$ \\
\hline octanal & 3.94 & 4.32 & 3.26 & 3.13 & 3.68 & 4.19 & 3.63 & 3.46 & 1.90 & 4.73 & 3.74 & 4.53 & $* * *$ & 2.34 & $4.83 \pm 1.49$ & $2.44 \pm 1.16$ \\
\hline 6-me-5-heptene-2-one & 14.61 & 22.43 & 22.51 & 14.26 & 28.97 & 13.41 & 11.48 & 16.99 & 10.57 & 10.80 & 20.28 & 17.67 & $* * *$ & 6.87 & $16.7 \pm 6.68$ & $17.0 \pm 7.52$ \\
\hline 1-hexanol & 2.13 & 1.35 & 2.37 & 1.12 & 2.25 & 2.87 & 2.01 & 1.38 & 1.43 & 1.54 & 1.71 & 1.65 & $* * *$ & 1.34 & $2.27 \pm 1.08$ & $1.23 \pm 0.61$ \\
\hline (Z)-3-hexen-1-ol & 3.53 & 3.98 & 2.83 & 2.04 & 3.70 & 4.10 & 2.45 & 2.61 & 2.34 & 3.16 & 2.60 & 2.31 & ns & 2.94 & $4.30 \pm 2.00$ & $1.48 \pm 0.91$ \\
\hline 2-isobutylthiazole & 2.99 & 3.74 & 8.74 & 8.89 & 3.89 & 10.52 & 7.18 & 14.09 & 11.41 & 7.33 & 16.34 & 8.06 & $* * *$ & 3.39 & $8.38 \pm 4.44$ & $11.1 \pm 6.49$ \\
\hline 6-me-5-hepten-2-ol & 0.18 & 0.07 & 0.12 & 0.07 & $\mathrm{Nd}$ & $\mathrm{Nd}$ & 0.28 & 0.21 & 0.29 & 0.05 & 0.17 & 0.09 & $* * *$ & 0.27 & $0.00 \pm 0.00$ & $0.30 \pm 0.34$ \\
\hline 2-ethyl-1-hexanol & 1.10 & 0.84 & 0.54 & 0.80 & 0.60 & 1.22 & 0.78 & 0.92 & 0.55 & 1.28 & 0.67 & 0.96 & $*$ & 0.69 & $0.97 \pm 0.63$ & $0.72 \pm 0.30$ \\
\hline benzaldehyde & $\mathrm{Nd}$ & 0.11 & 0.07 & 0.16 & 0.04 & 0.04 & 0.07 & 0.13 & 0.02 & $\mathrm{Nd}$ & 0.05 & 0.21 & ns & 0.26 & $0.15 \pm 0.24$ & $0.00 \pm 0.00$ \\
\hline linalool & 1.08 & 4.54 & 0.65 & 0.97 & 0.51 & 0.25 & 3.63 & 2.22 & 0.53 & 1.06 & 1.44 & 2.30 & $* * *$ & 1.41 & $2.11 \pm 1.79$ & $1.17 \pm 1.08$ \\
\hline methylheptadione & $\mathrm{Nd}$ & $\mathrm{Nd}$ & $\mathrm{Nd}$ & 0.10 & $\mathrm{Nd}$ & $\mathrm{Nd}$ & $\mathrm{Nd}$ & $\mathrm{Nd}$ & $\mathrm{Nd}$ & $\mathrm{Nd}$ & 0.04 & $\mathrm{Nd}$ & ns & 0.12 & $0.02 \pm 0.11$ & $0.00 \pm 0.00$ \\
\hline$\beta$-cyclocitral & 0.73 & 1.84 & 0.97 & 1.55 & 1.17 & 2.53 & 0.88 & 1.56 & 1.16 & 2.24 & 1.19 & 1.37 & $* * *$ & 0.73 & $1.47 \pm 0.76$ & $1.39 \pm 0.88$ \\
\hline 3-mebutanoic acid & $\mathrm{Nd}$ & 0.14 & 0.55 & 0.24 & 0.16 & 0.07 & 0.24 & 0.08 & 0.37 & $\mathrm{Nd}$ & 0.12 & 0.21 & $* *$ & 0.46 & $0.31 \pm 0.42$ & $0.08 \pm 0.19$ \\
\hline a-terpineol & $\mathrm{Nd}$ & 0.37 & 0.14 & 0.06 & 0.32 & 0.84 & 0.63 & 0.20 & 0.06 & $\mathrm{Nd}$ & 0.10 & 0.32 & ns & 1.33 & $0.37 \pm 1.23$ & $0.14 \pm 0.26$ \\
\hline geranial & 0.32 & 0.81 & 0.87 & 0.66 & 1.03 & 0.46 & 0.77 & 0.80 & 0.61 & 1.20 & 0.57 & 0.82 & ns & 1.29 & $1.48 \pm 0.73$ & $0.00 \pm 0.00$ \\
\hline citral & 0.72 & 1.94 & 1.16 & 1.32 & 1.51 & 1.41 & 0.76 & 0.81 & 0.87 & 0.66 & 1.64 & 0.74 & ns & 1.85 & $0.00 \pm 0.00$ & $1.95 \pm 1.17$ \\
\hline decadienal & $\mathrm{Nd}$ & $\mathrm{Nd}$ & $\mathrm{Nd}$ & 0.04 & 0.24 & $\mathrm{Nd}$ & $\mathrm{Nd}$ & $\mathrm{Nd}$ & $\mathrm{Nd}$ & $\mathrm{Nd}$ & $\mathrm{Nd}$ & 0.05 & $*$ & 0.21 & $0.05 \pm 0.21$ & $0.00 \pm 0.00$ \\
\hline methylsalicylate & 0.16 & 0.08 & 0.08 & 0.20 & 0.54 & 0.26 & 0.34 & 0.14 & 1.05 & 2.97 & 0.13 & 0.16 & $* * *$ & 1.51 & $0.00 \pm 0.00$ & $1.06 \pm 1.60$ \\
\hline$\beta$-damascenone & 2.61 & 4.44 & 2.80 & 2.94 & 0.72 & 1.50 & 2.77 & 6.32 & 2.32 & 1.90 & 4.62 & 3.83 & $* * *$ & 3.70 & $5.01 \pm 2.41$ & $1.37 \pm 1.91$ \\
\hline geranylacetone & 20.17 & 5.39 & 3.48 & 4.43 & 4.43 & 4.23 & 2.63 & 4.28 & 4.42 & 6.42 & 4.73 & 5.69 & $* * *$ & 3.40 & $6.19 \pm 4.92$ & $4.73 \pm 3.57$ \\
\hline 2-mepropanoic acid & 0.22 & 0.26 & $\mathrm{Nd}$ & 0.36 & 0.06 & 0.31 & 0.40 & 0.28 & 0.09 & 0.47 & 0.20 & 0.32 & ns & 0.63 & $0.30 \pm 0.54$ & $0.23 \pm 0.30$ \\
\hline benzylalcohol & 1.25 & 0.59 & 0.08 & 0.47 & $\mathrm{Nd}$ & $\mathrm{Nd}$ & 0.24 & 0.48 & $\mathrm{Nd}$ & $\mathrm{Nd}$ & $\mathrm{Nd}$ & $\mathrm{Nd}$ & $* * *$ & 0.40 & $0.16 \pm 0.37$ & $0.28 \pm 0.50$ \\
\hline phenylethylalcohol & 2.96 & 3.10 & 0.26 & 2.39 & 0.30 & $\mathrm{Nd}$ & 0.18 & 1.60 & 1.14 & 0.43 & 0.74 & 1.29 & $* * *$ & 1.00 & $1.29 \pm 1.38$ & $0.96 \pm 1.14$ \\
\hline$\beta$-ionone & 0.88 & 1.35 & 0.82 & 1.35 & 1.12 & 2.19 & 0.67 & 1.23 & 0.91 & 2.24 & 1.08 & 1.23 & $* * *$ & 0.64 & $1.25 \pm 0.72$ & $1.18 \pm 0.59$ \\
\hline eugenol & $\mathrm{Nd}$ & $\mathrm{Nd}$ & 0.04 & 0.11 & $\mathrm{Nd}$ & 0.06 & 0.06 & $\mathrm{Nd}$ & 0.21 & 0.30 & 0.10 & 0.08 & $* *$ & 0.21 & $0.00 \pm 0.00$ & $0.14 \pm 0.20$ \\
\hline farnesylacetone & 0.23 & 0.20 & 0.19 & 0.12 & 0.27 & 0.07 & $\mathrm{Nd}$ & 0.12 & 0.14 & $\mathrm{Nd}$ & 0.05 & 0.12 & $* *$ & 0.34 & $0.00 \pm 0.00$ & $0.25 \pm 0.40$ \\
\hline isopropylmyristate & $\mathrm{Nd}$ & $\mathrm{Nd}$ & $\mathrm{Nd}$ & $\mathrm{Nd}$ & $\mathrm{Nd}$ & $\mathrm{Nd}$ & $\mathrm{Nd}$ & $\mathrm{Nd}$ & $\mathrm{Nd}$ & $\mathrm{Nd}$ & $\mathrm{Nd}$ & $\mathrm{Nd}$ & $\mathrm{Nd}$ & $\mathrm{Nd}$ & $\mathrm{Nd}$ & $\mathrm{Nd}$ \\
\hline octanoic acid & 0.03 & 0.36 & 0.05 & 0.30 & 0.26 & 0.13 & 0.24 & 0.20 & 0.04 & 0.05 & 0.16 & 0.36 & $*$ & 0.40 & $0.36 \pm 0.33$ & $0.00 \pm 0.00$ \\
\hline nonanoic acid & $\mathrm{Nd}$ & $\mathrm{Nd}$ & $\mathrm{Nd}$ & $\mathrm{Nd}$ & $\mathrm{Nd}$ & $\mathrm{Nd}$ & $\mathrm{Nd}$ & $\mathrm{Nd}$ & 0.49 & $\mathrm{Nd}$ & $\mathrm{Nd}$ & $\mathrm{Nd}$ & $* * *$ & 0.30 & $0.08 \pm 0.35$ & $0.00 \pm 0.00$ \\
\hline
\end{tabular}

Each mean represents three biological replicates. ${ }^{\text {} T u k e y ' s ~ H S D: ~ h o n e s t l y ~ s i g n i f i c a n t ~ d i f f e r e n t ; ~ n: n u m b e r ~ o f ~ o b s e r v a t i o n ; ~ S D: s t a n d a r d ~ d e v i a t i o n ; ~ s i g n .: s i g n i f i c a n c e ~}$

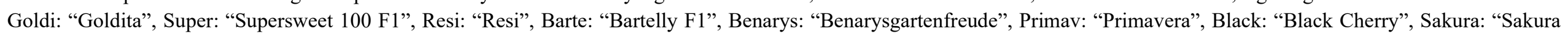
F1", Primab: "Primabella", Taste: "Tastery F1", Anna: "Annamay F1", Amor: "Amoroso F1" 
Table 4.4 Variation of relative concentration of VOCs (\%) of eight salad tomato cultivars over two harvests and two years with the Tukey's HSD test for significance

\begin{tabular}{|c|c|c|c|c|c|c|c|c|c|c|c|c|}
\hline \multirow[t]{3}{*}{ VOCs } & \multicolumn{8}{|c|}{ Salad tomato cultivars } & \multirow[t]{3}{*}{ Sign. } & \multirow[t]{3}{*}{$\begin{array}{l}\text { Tukey's } \\
\text { HSD }\end{array}$} & \multirow{2}{*}{\multicolumn{2}{|c|}{$\begin{array}{c}\text { Concentration }(\text { mean } \pm \text { SD) } \\
\text { Year }(n=48)\end{array}$}} \\
\hline & \multirow[b]{2}{*}{$\begin{array}{l}\text { Campari } \\
\text { F1 }\end{array}$} & \multirow[b]{2}{*}{ Auriga } & \multirow[b]{2}{*}{$\begin{array}{l}\text { Harzfeuer } \\
\text { F1 }\end{array}$} & \multirow[b]{2}{*}{$\begin{array}{l}\text { Roterno } \\
\text { F1 }\end{array}$} & \multirow[b]{2}{*}{$\begin{array}{l}\text { Lyterno } \\
\text { F1 }\end{array}$} & \multirow[b]{2}{*}{$\begin{array}{l}\text { Bocati } \\
\text { F1 }\end{array}$} & \multirow[b]{2}{*}{$\begin{array}{l}\text { Cappricia } \\
\text { F1 }\end{array}$} & \multirow[b]{2}{*}{$\begin{array}{l}\text { Green } \\
\text { Zebra }\end{array}$} & & & & \\
\hline & & & & & & & & & & & 2015 & 2016 \\
\hline hexanal & 29.60 & 29.28 & 31.52 & 37.43 & 28.24 & 36.61 & 37.01 & 36.13 & ns & 20.74 & $22.4 \pm 11.1$ & $44.1 \pm 8.60$ \\
\hline 2-methylbutylacetate & $\mathrm{Nd}$ & 0.12 & $\mathrm{Nd}$ & $\mathrm{Nd}$ & 0.09 & $\mathrm{Nd}$ & $\mathrm{Nd}$ & 0.06 & $* * *$ & 0.21 & $0.00 \pm 0.00$ & $0.28 \pm 1.65$ \\
\hline (E)-2-hexenal & 9.94 & 9.74 & 9.03 & 3.37 & 6.20 & 5.79 & 7.72 & 9.78 & $*$ & 5.58 & $8.86 \pm 4.82$ & $6.62 \pm 3.16$ \\
\hline octanal & 4.77 & 2.93 & 3.97 & 3.48 & 4.86 & 2.95 & 4.23 & 2.30 & ns & 3.02 & $5.47 \pm 1.75$ & $2.11 \pm 0.97$ \\
\hline 6-me-5-heptene-2-one & 16.08 & 13.24 & 18.75 & 20.80 & 17.86 & 15.90 & 15.80 & 24.67 & $*$ & 9.75 & $20.7 \pm 7.66$ & $15.7 \pm 6.13$ \\
\hline 1-hexanol & 1.59 & 1.65 & 2.23 & 1.14 & 0.82 & 1.62 & 0.72 & 1.31 & ns & 1.63 & $1.91 \pm 1.38$ & $1.06 \pm 0.71$ \\
\hline (Z)-3-hexen-1-ol & 2.85 & 3.48 & 3.27 & 1.49 & 2.00 & 1.96 & 1.65 & 1.47 & ns & 2.51 & $3.59 \pm 1.58$ & $1.19 \pm 0.95$ \\
\hline 2-isobutylthiazole & 17.32 & 13.25 & 11.45 & 17.88 & 18.27 & 17.19 & 10.82 & 12.02 & $* * *$ & 5.09 & $13.1 \pm 4.04$ & $13.2 \pm 5.49$ \\
\hline 6-me-5-hepten-2-ol & 0.35 & $\mathrm{Nd}$ & 0.38 & 0.37 & 0.55 & 0.42 & 0.50 & $\mathrm{Nd}$ & $\mathrm{ns}$ & 0.55 & $0.00 \pm 0.00$ & $0.56 \pm 0.39$ \\
\hline 2-ethyl-1-hexanol & 0.85 & 0.72 & 0.73 & 0.69 & 1.05 & 0.66 & 0.95 & 0.68 & ns & 0.70 & $0.95 \pm 0.58$ & $0.67 \pm 0.28$ \\
\hline benzaldehyde & 0.16 & 0.28 & 0.20 & 0.14 & 0.10 & 0.10 & 0.00 & 0.14 & ns & 0.39 & $0.28 \pm 0.33$ & $0.00 \pm 0.00$ \\
\hline linalool & 1.93 & 2.83 & 2.48 & 1.67 & 3.23 & 2.98 & 3.47 & 2.46 & $* *$ & 2.08 & $3.51 \pm 1.54$ & $1.60 \pm 1.04$ \\
\hline methylheptadione & 0.08 & $\mathrm{Nd}$ & 0.05 & 0.05 & $\mathrm{Nd}$ & $\mathrm{Nd}$ & $\mathrm{Nd}$ & 0.02 & ns & 0.16 & $0.05 \pm 0.15$ & $0.00 \pm 0.00$ \\
\hline$\beta$-cyclocitral & 1.03 & 5.57 & 1.16 & 0.97 & 1.63 & 0.97 & 1.47 & 0.22 & $* * *$ & 1.19 & $2.08 \pm 2.08$ & $1.18 \pm 0.93$ \\
\hline 3-mebutanoic acid & 0.21 & 0.48 & 0.34 & 0.33 & 0.19 & 0.27 & 0.40 & 0.55 & ns & 0.68 & $0.52 \pm 0.55$ & $0.13 \pm 0.25$ \\
\hline a-terpineol & 0.73 & 0.19 & 0.30 & 0.04 & 0.09 & 0.11 & 0.48 & 0.26 & ns & 0.99 & $0.28 \pm 0.91$ & $0.27 \pm 0.28$ \\
\hline geranial & 0.94 & 0.09 & 1.14 & 0.98 & 1.62 & 0.71 & 1.17 & $\mathrm{Nd}$ & $*$ & 1.59 & $1.66 \pm 1.21$ & $0.00 \pm 0.00$ \\
\hline citral & 0.75 & 0.09 & 0.79 & 0.72 & 0.89 & 0.56 & 0.37 & $\mathrm{Nd}$ & $* * *$ & 1.11 & $0.00 \pm 0.00$ & $1.52 \pm 1.05$ \\
\hline decadienal & $\mathrm{Nd}$ & $\mathrm{Nd}$ & $\mathrm{Nd}$ & $\mathrm{Nd}$ & $\mathrm{Nd}$ & $\mathrm{Nd}$ & $\mathrm{Nd}$ & $\mathrm{Nd}$ & & $\mathrm{Nd}$ & $0.00 \pm 0.00$ & $0.00 \pm 0.00$ \\
\hline methylsalicylate & 0.39 & 0.51 & 2.00 & 0.31 & 0.07 & 1.43 & 0.22 & 0.66 & ns & 1.95 & $0.00 \pm 0.00$ & $1.28 \pm 1.75$ \\
\hline$\beta$-damascenone & 3.21 & 5.97 & 2.35 & 1.62 & 3.26 & 2.25 & 4.97 & 5.00 & $* *$ & 3.99 & $5.34 \pm 3.20$ & $1.48 \pm 1.48$ \\
\hline geranylacetone & 4.44 & 2.77 & 5.28 & 4.92 & 6.07 & 5.67 & 5.88 & 1.11 & $* * *$ & 2.75 & $5.79 \pm 2.53$ & $4.49 \pm 5.29$ \\
\hline 2-mepropanoic acid & 0.27 & 0.54 & 0.24 & 0.21 & 0.40 & 0.15 & 0.13 & 0.18 & ns & 0.56 & $0.20 \pm 0.45$ & $0.27 \pm 0.31$ \\
\hline benzylalcohol & $\mathrm{Nd}$ & 0.09 & 0.04 & $\mathrm{Nd}$ & $\mathrm{Nd}$ & $\mathrm{Nd}$ & $\mathrm{Nd}$ & 0.05 & $* * *$ & 0.17 & $0.00 \pm 0.00$ & $0.16 \pm 0.32$ \\
\hline phenylethylalcohol & 0.81 & 0.38 & 0.20 & 0.21 & 0.34 & 0.19 & 0.25 & 0.26 & $* * *$ & 0.50 & $0.38 \pm 0.46$ & $0.55 \pm 0.60$ \\
\hline$\beta$-ionone & 0.98 & 4.15 & 0.95 & 0.92 & 1.51 & 0.82 & 1.29 & $\mathrm{Nd}$ & $* * *$ & 1.05 & $1.80 \pm 1.66$ & $0.97 \pm 0.74$ \\
\hline eugenol & 0.19 & 0.08 & 0.13 & 0.05 & 0.15 & 0.18 & 0.03 & 0.03 & $* * *$ & 0.26 & $0.00 \pm 0.00$ & $0.24 \pm 0.24$ \\
\hline farnesylacetone & $\mathrm{Nd}$ & 0.64 & 0.17 & 0.04 & 0.08 & 0.17 & 0.24 & $\mathrm{Nd}$ & $* * *$ & 0.37 & $0.00 \pm 0.00$ & $0.34 \pm 0.39$ \\
\hline isopropylmyristate & $\mathrm{Nd}$ & $\mathrm{Nd}$ & $\mathrm{Nd}$ & $\mathrm{Nd}$ & $\mathrm{Nd}$ & $\mathrm{Nd}$ & $\mathrm{Nd}$ & $\mathrm{Nd}$ & & $\mathrm{Nd}$ & $\mathrm{Nd}$ & $\mathrm{Nd}$ \\
\hline octanoic acid & 0.33 & 0.50 & 0.43 & 0.17 & 0.42 & 0.02 & 0.20 & 0.14 & ns & 0.61 & $0.55 \pm 0.49$ & nd \\
\hline nonanoic acid & 0.20 & 0.42 & 0.41 & $\mathrm{Nd}$ & $\mathrm{Nd}$ & 0.35 & $\mathrm{Nd}$ & 0.48 & ns & 0.67 & $0.46 \pm 0.60$ & nd \\
\hline
\end{tabular}

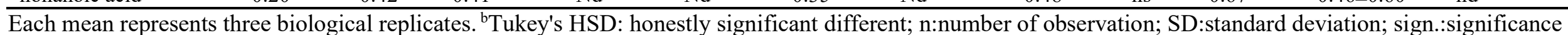




\subsubsection{Correlations between VOCs}

Pearson's correlation revealed 31 significant associations (out of 210 possible single correlations) existed between VOCs in the 20 cultivars across two years (Table S5). Most of the correlations were positive at statistical significant level at $\mathrm{p} \leq 0.01$. The highest coefficient of correlation occurred between $\beta$-cyclocitral and $\beta$-ionone $\left(\mathrm{r}=0.98^{* *}\right)$ followed by phenylethyl alcohol and benzyl alcohol $\left(\mathrm{r}=0.83^{* *}\right)$, benzyl alcohol and geranial $\left(\mathrm{r}=0.73^{* *}\right)$, octanoic acid and benzaldehyde $(\mathrm{r}=0.72 * *)$ as well as $\beta$-cyclocitral and farnesyl acetone $\left(\mathrm{r}=0.71^{* *}\right)$. Other positive correlations were detected at lower correlation coefficients. By contrast, few VOCs negatively correlated to each other at $\mathrm{p} \leq 0.01$, such as between 3-mebutanoic acid and 2-ethyl-1-hexanol (r=$\left.0.66^{* *}\right)$ as well as 3-mebutanoic acid and octanal $(\mathrm{r}=-0.57 * *)$.

\subsubsection{Variation within instrumental and sensory traits}

In order to characterize fruit quality of the tomato cultivars, instrumental measurements as well as two types of sensory tests were carried out. There were significant differences at different confident levels among the cultivars for all instrumental traits, as TSS, TA, color components (Table S6), and VOCs, except for $\alpha$-terpineol (Table 4.2). Over all harvest dates and years, the average TSS content ranged from $4.39 \%$ to $8.61 \%$ and the TA ranged from $0.27 \%$ to $0.50 \%$. In addition, the TSS and TA contents were higher in the fruits cultivated in 2016, while the color readings $\mathrm{L}^{*}, \mathrm{a}^{*}$ and $\mathrm{b}^{*}$ of the fruit were lower, compared to those in 2015 . There were significant $\mathrm{C}$ $\times \mathrm{H}$ and $\mathrm{C} \times \mathrm{Y}$ interactions for TSS, TA and most of the color components, indicating that some cultivars performed better than others either at certain harvest date or year. Interestingly, $\mathrm{C} \times \mathrm{H} \times \mathrm{Y}$ interactions had significant effects on $\mathrm{L}^{*}, \mathrm{a}^{*}$ and $\mathrm{b}^{*}$ value, but not on TSS and TA which suggest for these traits high stability of the cultivar toward environmental changes.

Cultivars "Supersweet 100 F1", "Benarys Gartenfreude", "Sakura F1" and "Bartelly F1" had the highest TSS content among all cultivars (Table S6). They were also rated as the cultivars with the highest acceptability score in the sensory test in each year (Tables S7 and S8). The highest average TA-value (Table S6) was found in "Green Zebra", but it was not significantly different 
from "Supersweet 100 F1", "Benarys Gartenfreude", "Goldita", and "Sakura F1". "Green Zebra" was also scored with the highest intensity of sourness in both the breeder's and panel sensory tests (Tables S7 and S8, respectively). The highest L* value of fruit skin was detected in "Goldita" while the lowest one was observed in "Black Cherry". "Green Zebra" had the lowest a* and the highest $b^{*}$ value of all cultivars. The highest sensory rating for fruit firmness, juiciness and skin firmness in each sensory test were consistently found in "Tastery F1", "Green Zebra" and "Benarys Gartenfreude", respectively. The highest score of tomato typical-aroma in the breeder's sensory test in respective order were found in "Black Cherry", "Resi", "Goldita", "Supersweet 100 F1" and "Sakura F1" while in the panel sensory test "Supersweet 100 F1", "Sakura F1", "Bartelly F1", "Goldita" and "Black Cherry" were rated with the highest score of tomato typical-aroma. In terms of overall acceptability, "Sakura F1" and "Supersweet 100 F1" were found to be the cultivars with the highest scores in both the breeder's and the panel sensory tests.

\subsubsection{Correlations between instrumental and human sensory data}

Several VOCs had significant correlations with TSS and/or TA, color components and/or sensory attributes (Table S10). The VOCs with higher positive correlations $(r>0.6)$ with TSS were citral and phenylethyl alcohol, while (E)-2 hexenal and (Z)-3-hexen-1-ol had positive correlations with TSS higher than 0.50. In contrast, 2-isobutylthiazole and 6-me-5-hepten-2-ol showed a negative correlation with TSS $(r=-0.68$ and $r=-0.52$, respectively). Geranial correlated negatively with TA $(r=-0.60)$ and sourness, while a positive relationship was determined for (E)-2-hexenal and TA ( $r=0.54)$. Correlations between VOCs and color components with $r>0.60$ occurred very rarely, e.g., citral was negatively correlated with $\mathrm{L}^{*}$ and $\mathrm{b}^{*}$, and geranial was positively correlated with $\mathrm{h}^{\circ}$. Among the 31 VOCs, 12 compounds were correlated with at least one sensory attribute. Geranial was the VOC that showed a highly significant positive correlation $(r>0.60)$ with fruit firmness and it was negatively correlated with juiciness. Fruit skin firmness showed a high positive correlation (r>0.60) with (Z)-3-hexen-1-ol, 1-hexanol, but a negative correlation with 2-isobutylthiazole. (E)-2hexenal and phenylethyl alcohol were strongly associated with increasing perception of sweetness 
$(r>0.60)$, and in contrast, 6-me-5-hepten-2-ol and 2-isobutylthiazole had a negative correlation with sweetness. In line with the sweetness, tomato typical-aroma was positively correlated with (E)-2hexenal and phenylethyl alcohol, and negatively correlated with 6-me-5-hepten-2-ol and 2isobuthylthiazole. Overall, cultivar acceptability was positively correlated with increasing concentrations of (E)-2-hexenal and phenylethyl alcohol ( $r>0.60)$.

\subsubsection{Principal component analysis (PCA)}

According to statistical results, the instrumental and sensory data of 20 tomato cultivars were divided into four groups shown by four principal components (PC) accounted for $59.9 \%$ of the variation in the dataset (Table S11). PC1 explained $23.9 \%$ of the total variance, PC2 described 17.3\%, PC3 made up for 10.9\% and PC4 accounted for additional 7.9\%. More specifically, Fig. 4.2 showed a satisfactory classification of the samples in terms of their fruit types. The PCA plot established the relative importance of each variable (TSS, TA, color components, sensory parameters) and the relations between those variables and samples on the two first principal components (PC1, PC2), representing the differences among the 20 cultivars. PC1 distinguished the characteristics of cocktail cultivars ("Goldita" and "Supersweet 100 F1") from salad cultivars ("Bocati F1", "Cappricia F1", "Lyterno F1", "Roterno F1") (Table S11) by the variation of TSS, sweetness, tomato typical-aroma and acceptability (Table S12). To a lesser extent, seven VOCs (2isobuthylthiazole, 6-me-5-hepten-2-ol, (E)-2-hexenal, (Z)-3-hexen-1-ol, 2-phenylethyl alcohol and benzyl alcohol) were responsible for the separation of PC1. While the above mentioned cocktail

cultivars had higher score of (E)-2-hexenal, (Z)-3-hexen-1-ol, 2-phenylethyl alcohol and benzyl alcohol, these VOCs were present at very low level in salad cultivars. In contrast to cocktail cultivars, the salad cultivars had high levels of 2-isobuthylthiazole and 6-me-5-hepten-2-ol. PC2 contained "Auriga" and "Green Zebra" and separated these salad cultivars from others in the same PC (Table S11). These two cultivars were found to contribute to high loading of TA, color attributes $\left(\mathrm{L}^{*}, \mathrm{~b}^{*}, \mathrm{C}^{*}\right.$, and $\left.\mathrm{h}^{\circ}\right)$, sensory (sourness and juiciness) and a number of VOCs including nonanoic acid, 3-mebutanoic acid, $\beta$-damascenone, farnesyl acetone and benzaldehyde (Table S12). 
In PC3, "Resi" was distinguished from other cultivars with higher positive contribution of some VOCs, as 2-mepropanoic acid, $\beta$-ionone, $\beta$-cyclocitral, and 2-ethyl-1-hexanol and octanal (Tables S11 and S12). PC4 contained only "Tastery F1" (Table S11), and differed from the other PCs with higher loading values of 6-me-5-heptene-2-one and lower levels of hexanal and methylsalicylate (Table S12).

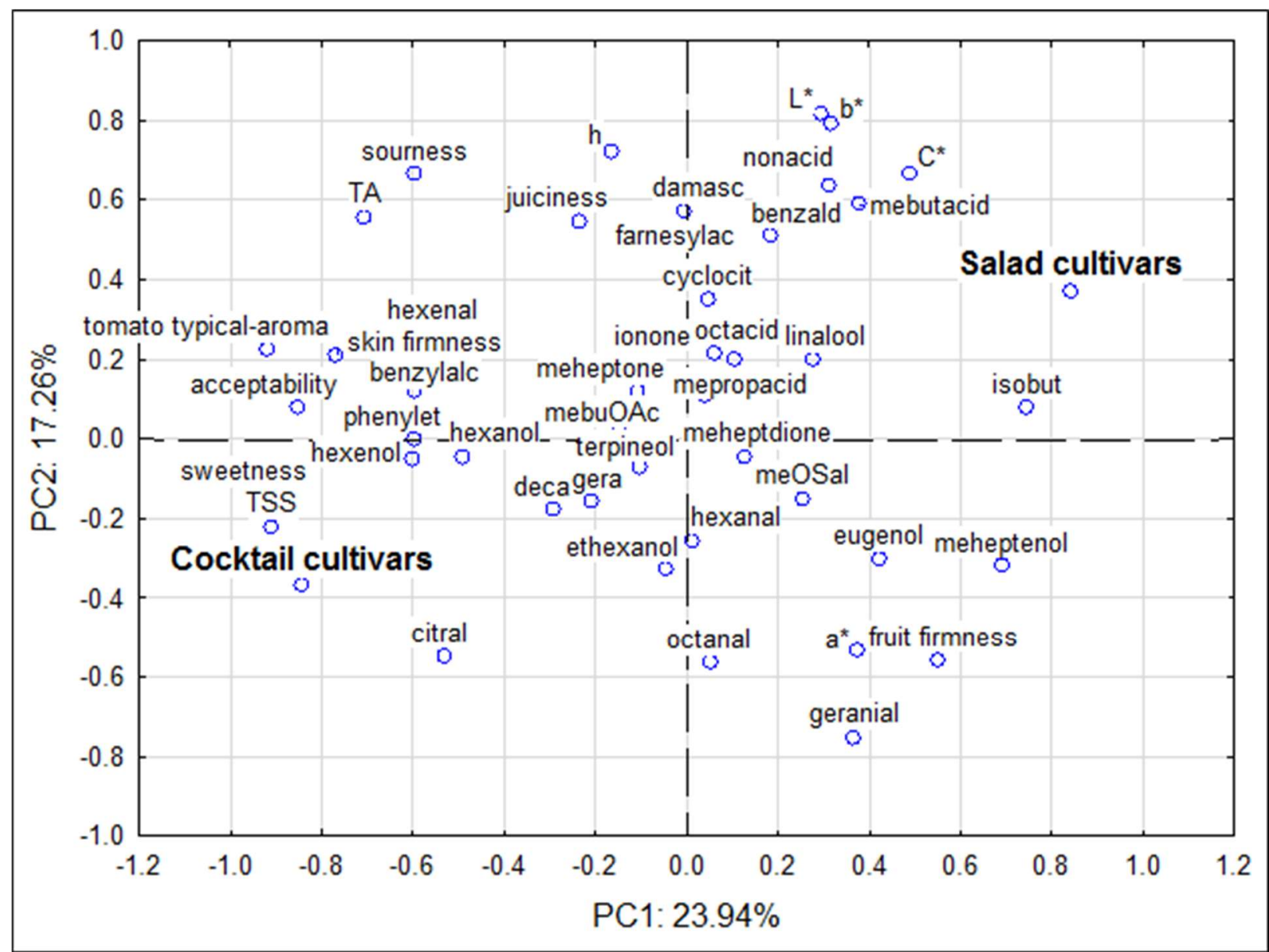

Fig. 4.2 PC1 vs. PC2 scatter plot of the main sources of variability between cocktail and salad cultivars; abbreviations of the VOCs are described in Tables 4.1. Instrumental parameters: TSS (total soluble solids); TA (titratable acid); L*: lightness; $a^{*}$ : red $(+) /$ green $(-) ; b^{*}$ : yellow $(+) /$ blue $(-)$; $\mathrm{C}^{*}$ : chroma; h०: hue angle. Sensory attributes: sweetness, sourness, tomato typical-aroma, acceptability

\subsection{Discussion}

With the aim of assessing flavor related-traits and their associations with sensory traits, in the present work we report instrumental data (e.g., VOCs, TA and TSS) and sensory properties of 12 cocktail along with 8 salad tomato cultivars. Flavor-associated VOCs plays a main role in defining the fruit quality by consumers (Bodner and Scampicchio, 2020). 


\subsubsection{VOCs profile of the tomato cultivars}

There were in total 31 VOCs, mainly aldehydes and ketones, and most were similar in all cultivars. The detected VOCs were distributed within eight chemical classes, and ALD-VOCs accounted the largest percentage of the total VOCs concentration in the fruits. This result is in agreement with Li-bin Wang et al. (2016) who reported that ALD-VOCs comprised the highest proportion of the total VOCs concentration in tomato fruits, followed by ALC- and KET-VOCs, and all three compound classes constituted more than $95 \%$ of total VOCs concentration. Selli et al. (2014) quantified that $77.2 \%$ of the total VOCs in tomatoes was ALD-VOCs.

Of more than 400 VOCs identified in tomato fruits (Buttery et al., 1987), most studies agreed that about 16 VOCs had likely a significant contribution to tomato aroma (Baldwin et al., 2000; Buttery et al., 1989; Klee, 2010). Of these, nine VOCs believed to contribute to tomato aroma were identified in this study, such as ALD-VOCs (hexanal and trans-2-hexenal), ALC-VOCs (cis-3hexenol and 2-phenylethyl alcohol), KET-VOCs (6-methyl-5-hepten-2-one, $\beta$-damascenone and $\beta$ ionone), SDC-VOC 2-isobutylthiazole, and EST-VOC methyl salicylate (Table 4.1). These important VOCs could be classified in four groups according to different precursors (Bauchet et al., 2017; Rambla et al., 2013; Zanor et al., 2009): hexanal, trans-2-hexenal, cis-3-hexenol are derived from fatty acids; 6-methyl-5-hepten-2-one, $\beta$-damascenone and $\beta$-ionone are volatiles-derived carotenoids; 2-phenylethyl alcohol and methylsalicylate are derived from the amino acid phenylalanine, whereas 2-isobutylthiazole is synthesized from branched chain amino acid precursors. Regardless of these identified VOCs, several VOCs also considered as principal contributors to the ripe tomato, including ALD-VOCs (cis-3-hexenal, 2+3-methylbutanal, trans-2heptenal and phenylacetaldehyde), the ALC-VOC 3-methylbutanol and the KET-VOC 1-penten-3one, as well as the nitrogen containing-VOC 1-nitro-2-phenylethane (Baldwin et al., 2000; Carrari and Fernie, 2006; Rambla et al., 2013) but they were not detected in our study.

The C6 fatty acid-derived hexanal was the most abundant VOC found in both crop years, with a mean value of $35.05 \%$. Hexanal is often linked with "green" "grassy" perception in tomato 
fruits (Selli et al., 2014) and has been associated with sweetness ratings of ripe tomatoes (Maul et al., 2000). The open chain apocarotenoid cleavage product, 6-methyl-5-heptene-2-one that is derived from lycopene (Klee, 2010), found as the second largest abundant VOC (17.77\%), followed by the branched chain amino acid-derived VOC 2-isobutylthiazole with a relative concentration of $11.37 \%$. The latter one is one of the important and interesting tomato aroma contributors since its concentration remained stable during fruit ripening (Libin Wang et al., 2016) and is not affected by crushing and oxygen exposition (Piombino et al., 2013). The content of cyclic apocarotenoid VOCs (i.e., $\beta$-damascenone and $\beta$-ionone), which accounted for $3.28 \%$ and $1.28 \%$ of the total VOCs concentration respectively, was much higher than the concentration of the linear apocarotenoid 6methyl-5-heptene-2-one (Table 4.2). In spite of their low concentrations, contribution of these VOCs to the fruity aroma perception was important, particularly due to their low odor thresholds (Buttery et al., 1989). Two esters were identified in the VOCs of tomato fruits, although as a chemical class their impact on the overall sensory properties may be negligible and they are not relevant for the tomato aroma (Rambla et al., 2013).

\subsubsection{Influence of cultivar, harvest date and year on instrumental traits of the fruits}

Considerable efforts have been undertaken by breeders to improve tomato quality traits. However, the development of cultivars suitable for certain location may necessarily perform differently in other locations (Panthee et al., 2012). Usually, inconsistent quality performance in various growing environments is a result of genotype by environment $(\mathrm{G} \times \mathrm{E})$ interaction $($ Kwabena Osei et al., 2019). Generally, breeders face the genotype-by-environment interaction (GEI) to select genotypes with high and stable performance in multiple environments, and the genotypes whose GEI is insignificant are assigned to be stable (Ssemakula and Dixon, 2007). In this study, the extent of variation on instrumental traits including TSS, TA, color components and VOCs in tomato cultivars resulting from cultivar-by-harvest date interaction $(\mathrm{C} \times \mathrm{H})$, cultivar-by-year interaction $(\mathrm{C}$ $\times \mathrm{Y})$, and cultivar-by-harvest date-by-year $(\mathrm{C} \times \mathrm{H} \times \mathrm{Y})$ interactions were observed. 
A wide significant cultivar variation for fruit quality traits indicated that some of cultivars could be used as parents to develop well-adapted cultivars with improved flavor across multiple environments (harvest date and year) in organic low-input management. Compared to the $\mathrm{C} \times \mathrm{H}$ interaction, the variation due to $\mathrm{C} \times \mathrm{Y}$ interaction showed greater significances for most of the tested parameters, especially for VOCs. The effect of cultivar alone was much more important. It was significant for almost all the compounds, excluding $\alpha$-terpineol. Paolo et al. (2018) and Rambla et al. (2013) reported that although oxygenated terpenoides are among the most abundant volatiles in vegetative tissues of tomato plants and particularly in trichomes, few of them, including $\alpha$-terpineol, are present in the ripe fruit but their influence on fruit flavor is negligible.

The $\mathrm{C} \times \mathrm{H} \times \mathrm{Y}$ interactions were significant for 13 VOCs; nine VOCs were found to be at most influenced and eight VOCs were lesser influenced. Twelve VOCs were not significantly influenced, highlighting the stable performance of the cultivars under different harvest date, year and their interactions. The significant $\mathrm{C} \times \mathrm{H}$ x Y interaction effects on VOCs suggest prospects for advances in breeding for these traits, as plant breeders need to develop cultivars that perform consistently well under different environmental conditions and season. Bauchet et al. (2017) reported that VOCs exhibiting a variable pattern of heritability indicate a high sensitivity of VOCs to environmental conditions. This may be a problem for plant breeders because it is too laborintensive to develop cultivars for each specific site (Panthee et al., 2012) or specific growing period. As in the present study, a non-significant $\mathrm{C} \times \mathrm{H} \times \mathrm{Y}$ interaction on TSS and TA has been reported (Causse et al., 2003; Cebolla-Cornejo et al., 2011), indicating a high stability of these taste-relate traits to seasonal and environmental variation. This was in line with Gautier et al. (2008) who found that the influence of temperature and irradiance was more pronounced on the level of secondary metabolites than on primary ones (e.g., total soluble solids). Based on heritability and $\mathrm{G} \times \mathrm{E}$ interaction, TA was the least environmentally sensitive trait and much more likely to persist when the cultivar was grown in a different location (Ssemakula and Dixon, 2007). Basically, the extend of 
a genotype-by-environment interaction is influenced by the genetic structure of the genotype (Baye et al., 2011).

Despite the variation among cultivars was for all quality traits, it was not always significant within each group of fruit types, e.g., very little variation was found for the range of hexanal, octanal, and 1-hexanol as well as for TSS content in salad cultivars, but cocktail fruits contained much lower TSS. Cocktail tomatoes are usually consumed raw, therefore, sensory attributes such as sweetness and juiciness and a fruitlike appearance are more important (Zörb et al., 2020). Sweetness, with TSS typically used as an indirect measure of sugar content, is considered as the trait with the highest influence on cherry tomato purchase preference (Casals et al., 2018).

Cultivar, harvest date and year had significant effects on all color components, independently. From all measured color components, only $\mathrm{L}^{*}, \mathrm{a}^{*}$ and $\mathrm{b}^{*}$ values were apparently affected by $\mathrm{C} \times \mathrm{H} \times \mathrm{Y}$. The highest $\mathrm{L}^{*}$ values were found in non-red fruits of "Auriga" followed by "Green Zebra" and "Goldita", respectively, while "Black Cherry" showed the lowest values for L*, $a^{*}, b^{*}$ and $C^{*}$. Lower $L^{*}$ values in red fruit cultivars reflects darkening of the fruit resulting from carotenoid synthesis and the loss of greenness (Arias et al., 2000). "Auriga" is an orange cultivar, while the fruit color of "Goldita" and "Green Zebra" is dominated by yellow, which also leads to higher values of $b^{*}$. In our study, high $b^{*}$ values in non-red cultivars can be related to the carotenoid composition of the fruits. In this context, we found that geranial positively correlated with $a^{*}$ and $b^{*}$ levels, whereas citral and farnecylacetone had a positive relationship with $b^{*}$ value (Table S10). In tomato, these three VOCs are apparently biosynthesized from carotenoids. Genotype is an important determinant of the extent of variability in carotenoid content of ripe tomato fruits (Ilahy et al., 2019). While most red-fruited cultivars had higher a* values (e.g., "Bocati F1", "Cappricia F1", "Roterno F1"), due to synthesis of lycopene and depletion of chlorophyll (Arias et al., 2000), an orange genotype accumulated high levels of $\beta$-carotene in addition to low levels of lycopene (Lewinsohn et al., 2005). Based on heritability and genotype by environment interaction, lycopene, which accounts for more than $85 \%$ of total carotenoids in many 
red-colored cultivars (Zörb et al., 2020), was the most environmentally sensitive trait (Ssemakula and Dixon, 2007). The higher $\mathrm{a}^{*}$ and $\mathrm{b}^{*}$ levels found in some cultivars in our study may result from the accumulation of derivatives of carotenoid metabolism, such as C8-ketone 6-methyl-5hepten-2-one, $\mathrm{C} 10$-aldehyde geranial, $\beta$-ionone, and $\beta$-damascenone, which were also present at higher levels. Although these carotenoid-derived VOCs have been quantified, our results suggest that, with the exception of geranial, they do not significantly affect flavor perception. However, while the higher abundance of 6-methyl-5-hepten-2-one might be mainly due to a higher lycopene content in the pericarp (Li-bin Wang et al., 2016), no significant correlation between the abundance of this carotenoid derivate and any of the sensory attributes of the cultivars was found.

Within the cocktail and salad cultivars, our study revealed that the cultivars with the highest TSS content and subsequently the greatest acceptability were "Supersweet 100 F1" and "Campari F1" respectively. "Supersweet $100 \mathrm{~F} 1$ " also showed the highest TA value among the cocktail cultivars, while the overall highest TA content across all cultivars was found in "Green Zebra", reflecting a high concentration of acids in the fruit. From a commercial perspective, organic acid content in fruits is one of the most important characteristics that influence the sensorial qualities of the product (Quinet et al., 2019).

\subsubsection{Sensory characteristics among the cultivars}

In term of tomato typical-aroma, each sensory test confirmed that "Supersweet $100 \mathrm{~F} 1$ ", "Black Cherry", "Sakura F1" and "Goldita" had the most intensive aroma. Both breeders' sensory test and sensory panel test revealed that "Supersweet 100 F1", "Sakura F1" and "Black Cherry" were among the most acceptable cultivars. Regardless of their superiority in sweetness, it seems that higher score of tomato typical-aroma and $\mathrm{a}^{*}$ values (redness of skin color) could be important factors to enhance the acceptability of "Supersweet 100 F1" and "Sakura F1". Red-colored tomatoes are more familiar and attractive to consumers than other colored fruits (Oltman et al., 2014; Pagliarini et al., 2001). The highest values for tomato typical-aroma and juiciness were obtained for "Black Cherry", which was among the most acceptable cultivars in both breeder's and 
panel sensory tests (Tables S7 and S8). "Black Cherry" is known as traditional or heirloom type usually tended to be prized for its distinctive aroma especially in comparison with modern varieties (Bai and Lindhout, 2007; Wang and Seymour, 2017). High consumer acceptance of heirloom tomatoes was resulted from their outstanding fruit quality in terms of TSS, TA, TSS/TA ratio and sensory properties in term of sweetness, sourness and tomato like-taste (Gioia et al., 2010). Besides performing the best in aroma, "Black Cherry" was also found to have a unique fruit color of red deep brown. Barry and Pandey (2009) stated that a red-brown color of a tomato fruit could be the result of the retention of chlorophyll and the simultaneous accumulation of lycopene during fruit ripening. It was also interesting to note that the sensory outputs from both sensory tests revealed a consistent result for all studied attributes. The cultivars identified with the highest breeders' sensory score in 2015 were also rated as the cultivars with the highest sensory score by the panel in 2016, e.g., the highest sensory rating for fruit firmness, juiciness and skin firmness were consistently detected in "Tastery F1", "Green Zebra" and "Benarys Gartenfreude”, respectively.

\subsubsection{Correlation between the traits}

Correlation analysis between VOCs, other instrumental measured traits (color components, TSS and TA) as well as the results obtained from sensory panel tests were performed to find out possible relationships among these parameters. Although hexanal had the highest concentration in the cultivars, it did not show any significant correlation with the instrumental and sensory traits. This finding confirmed that the compounds with high abundance levels do not always necessarily characterize the fruit aroma (Lubes and Goodarzi, 2017). However, contrary to the present findings, Cebolla-Cornejo et al. (2011) pointed out that hexanal is precisely one of most important VOC contributing to tomato aroma. In addition, the abundances of either $\beta$-damascenone or $\beta$-ionone was also not positively correlated to both breeder's and panel sensory properties of the fruits (Tables S7 and S8), which was different from the results of Vogel et al. (2010).

Lower levels of sugars, organic acids, and some VOCs, including (E)-2-hexenal lead to poor aroma of modern tomato varieties (Wang and Seymour, 2017). The phenolic compound 2- 
phenylethyl alcohol which contributes to a floral aroma, has been described as an enhancer of sweetness perception in tomatoes and increased tropical and fruity notes in tomato puree when added in combination with sugar or sugar plus acid (Baldwin et al., 2008). In our study, a positive association was found between geranial and sourness, while Tieman et al. (2012) reported a positive association between geranial and sweetness. This suggests that consumer preference for tomato could be improved by increasing the concentrations of this VOC the fruit.

The sweetness was negatively correlated with 2-isobutylthiazole (Table S10) which was also shown by Vogel et al. (2010), who found that increasing level of 2-isobutylthiazole correlated with lower sweetness. The concentration of 2-isobutylthiazole was lower in the cocktail cultivars than in the salad cultivars. Our result is in line with Ursem et al. (2008), who found a lower relative content of 2-isobutylthiazole in cherry tomatoes compared to the cultivars with higher fruit weight. In tomato homogenate, 2-isobutylthiazole was reported as "pungent" (Tandon et al., 2000). Besides 2-isobutylthiazole, negative correlations were also found between 6-me-5-hepten-2-ol and all sensory attributes, except for fruit firmness. The breeder's and panel sensory tests across two years showed, that with higher concentration of 6-me-5-hepten-2-ol in the fruit sample, lower scores for juiciness, skin firmness, sweetness, sourness, tomato typical-aroma and acceptability of the cultivars were obtained. The inverse correlation of 6-me-5-hepten-2-ol and 2-isobutylthiazole with acceptability may indicate that not all VOCs confer positive taste attributes to tomato (Carrari and Fernie, 2006). Therefore, determining the contributions of each VOC, whether positive or negative, is a critical aspect of improving fruit aroma (Vogel et al., 2010). Thus, lower levels of 2isobutylthiazole and 6- me-5-hepten-2-ol could lead to higher sensory score, esp. for sweetness, sourness and tomato typical-aroma as well as to increase acceptability of the cultivars as found by both the breeder's and sensory panel tests. Data from the sensory evaluation of each year presented a consistent pattern for most of the salad cultivars, except for "Campari F1" and "Green Zebra", which had a lower acceptability than the other cultivars. In contrast, all cocktail cultivars had 
always higher acceptability scores in both the breeder's and in the panel sensory test, which suggests their superior sensory quality in comparison with the salad cultivars.

With regard to the correlations among VOCs, we observed the strongest positive correlation between the apocarotenoid-derived VOCs $\beta$-cyclocitral and $\beta$-ionone. These compounds are synthesized from the oxidative cleavage of carbon-carbon double bonds in carotenoids (Ahrazem et al., 2016). The apocarotenoid VOCs are generally described as having fruity and/or floral attributes and are commonly not abundant in tomato fruits, but they have very low odor thresholds that allow humans to perceive their odor characteristics (Kreissl and Schieberle, 2017). Although Vogel et al. (2010) showed a positive relationship between $\beta$-cyclocitral and $\beta$-ionone and taste-related traits, and acceptability, no correlation between the accumulation of these VOCs and cultivar acceptability, neither in the breeder's nor in the sensory panel tests was found.

\subsubsection{PCA of instrumental and sensory data}

PCA was applied to whole data of mean across both years obtained from VOCs, instrumental and sensory analyses. According to PCA results, the analyzed data were divided into four groups (Table S11) with cumulative variance accounting for approximately $60 \%$. The PC1 explained the highest percentage of variance $(23.9 \%)$ and PC2 made up to $17.3 \%$ of the total variability when instrumental and sensory traits were used to characterize the cultivars according to their fruit types. Cocktail cultivars were located on the right of the plot, on the opposite side of salad cultivars (Fig. 4.2). In the PC1, the most important variable among the instrumental traits was TSS, followed by the sensory traits sweetness and tomato typical-aroma. PC2 was associated with a high contribution of $\mathrm{L}^{*}$ and sourness. In general, the PCA substantially strengthened the identified correlations, e.g., high loading values of TSS in PC1 and L* in PC2 highlighting the importance of sugar in the cluster of PC1 and lightness of fruit color in PC2.

Among the measured VOCs, 2-isobutylthiazole, 6-me-5-hepten-2-ol, (E)-2-hexenal, (Z)-3hexen-1-ol, 2-phenylethyl alcohol, and benzyl alcohol can be considered as the most authentic volatile marker compounds for the tomato cultivars, since they have high loading scores in the PC1 
(see Table S12). A high loading score of 2-phenylethyl alcohol was found in association with cocktail cultivars, indicating the contribution of this volatile compound to tomato aroma (Rambla et al., 2013; Libin Wang et al., 2016). This compound was measured in 6- to 13-fold higher concentrations in the small-fruited tomato cultivars than in large-fruited cultivars (Ursem et al., 2008). "Auriga" and "Green Zebra" differed from other cultivars (Table S11, PC2). The reason for this separation probably lies in their quality characteristics, as they had the highest loading of sourness and color components in terms of $\mathrm{L}^{*}, \mathrm{~b}^{*}$ and ho (Table S12, PC2). Chea et al. (under review) reported outstanding characteristic in terms of $\mathrm{Mg}$ concentration in leaf and fruit in “Auriga" and "Green Zebra, which was later positively correlated with TA content in the fruit.

Finally, among the discriminating components of VOCs on PC1, it could be highlighted that three compounds correlated positively [(E)-2-hexenal, 2-phenylethyl alcohol and benzyl alcohol)] and two negatively (2-isobutylthiazole and 6-me-5-hepten-2-ol) with the acceptability of the cultivars (Table S10). The five VOCs can discriminate the cocktail cultivars ("Supersweet 100 F1" and "Goldita") from the salad ones ("Roterno F1", "Lyterno F1", "Bocati F1" and "Cappricia F1"). This finding was in agreement with the work of Ursem et al. (2008). In addition, "Supersweet 100 F1" and "Goldita" were found to have high TSS content and very high sensory scores for sweetness and tomato typical-aroma compared to other cocktail and salad cultivars, so that these cultivars can be further differentiated from the other cultivars based on the TSS.

\subsection{Conclusion}

Although the values of instrumental analyzed traits and sensory properties varied among the cultivars, taste component (i.e., TSS and sensory sweetness) of cocktail cultivars exceeded the levels observed in salad cultivars. Cultivar was the most important factor influencing the concentration of all measured instrumental and sensory traits. The cultivar-by-harvest date by-year interaction had a significant effect on most color components, but not on TSS and TA. We found correlations between individual aroma compounds and sensory attributes in tomato cultivars and identified 31 significant relationships. In addition to the important contribution of TSS, (E)-2- 
hexenal and 2-phenylethyl alcohol were positively associated with increasing sensory scores for sweetness, tomato typical aroma, and acceptability. On the other hand, 2-isobutylthiazole and 6-me5-hepten-2-ol were negatively correlated to flavor related-traits especially TSS, sweetness, tomato typical-aroma, as well as acceptability. Based on the result of the breeder's and panel sensory tests, "Supersweet 100 F1" and "Sakura F1" exhibited the highest acceptability, while "Cappricia F1" and "Bocati F1" showed the lowest. Overall, these results could improve knowledges of breeders and provide recommendations for future organic breeding strategies to produce tomato cultivars with improved sensory quality and acceptability. 


\section{General discussion and conclusion}

Tomato growers and consumers demand a wide range of different aspects of fruit yield (FY) and quality related-traits (Bertin and Génard, 2018; Kimbara et al., 2018). Breeders have paid much attention traits related to production and handling, while fruit quality and, in particular flavor has not been a high priority (Tieman et al., 2006). Fruit quality-related traits, especially nutrient contents and flavor components, are important to consumers and therefore, represent important targets for development of tomato cultivars (Kimbara et al., 2018). Therefore, the challenge is to develop tomato cultivars with higher nutritional quality and better flavor without compromising the agronomic traits required by growers. Sixty tomato cultivars were studied in 2015 and a subset of 20 cultivars was selected for further evaluation in following year. Due to the high variation of fruit weight (FY) and consumer expectations for fresh tomato quality, which may differ by fruit type, cultivars were classified into salads and cocktails. Hence, information on the variation within and between these groups, based on the needs of growers and breeders in outdoor organic tomato could be beneficial.

\subsection{Agronomic, morphological and fruit quality performance of the cultivars}

Cocktail cultivars were superior in terms of fruit quality traits, while salad cultivars had lower value in most of the plant morphological traits but contained higher leaf mineral content, fruit weight and yield. FY is the most important characteristic for the justification of genotypes in tomato evaluation (Kibria et al., 2016) and have significant influence on fruit quality (Hernández-Bautista et al., 2016). However, domestication led to a substantial increase of FY, and changes primarily occurred in fruit morphology or plant development (Prudent et al., 2009). The very high variation in the observed traits indicates high diversity of the cultivar performance that may occur due to cultivar trait alteration through the interaction with the organic low input environment. Harvest index was noted higher than the range reported by Jones (1999), while variation in number of internodes could explain the difference in height of cultivars (Van der Ploeg and Heuvelink, 2005). In addition, cultivar-by-year interaction had a significant effect on plant morphological traits and 
fruit mineral contents within cocktail cultivars, but it was not pronounced in salad cultivars. This indicates greater stability of the salad cultivars for these studied traits.

While little breeding progress has been made overall for fruit quality compared to yield (Liabeuf and Francis, 2017), improving fruit quality has been more important to breeders rather than increasing yield, especially in cocktail tomatoes (Zörb et al., 2020). High variability for each of these following fruit quality traits was observed: DM, TSS, TA, TPC, and color with CV ranges from 7.3 to $70.6 \%$ and 4.0 to $31.7 \%$ in salad and cocktail cultivars respectively. Among these quality traits, TSS and TA are important factors that contribute to the taste of tomato products, which are also important indices of eating and processing quality (Kimbara et al., 2018).

The antagonistic effect of FY on fruit quality (e.g., TSS, TA, TPC) was found (Casals et al., 2018; Georgelis et al., 2004 ). The trade-off was much more pronounced among salad cultivars, while among cocktail cultivars a significant correlation was only found with fruit minerals (P, K, $\mathrm{Mg}$, and S) suggesting that finding viable trade-offs between FY and quality remains a challenge. Despite the fact that there has been little improvement in the quality for salad cultivars, greater attention is currently being paid to improving taste- related traits as it is increasingly recognized that flavor are critical aspects of tomato marketability (Beckles, 2012). Superior cultivars in terms of one or a combination of traits related-plant growth, FY and fruit quality are being identified. "Lyterno F1" and "Bartelly F1" were respectively the highest fruit yielding-cultivars among salad and cocktail cultivars. The best performing cultivars with the trait combinations of fruit $\mathrm{Mg}$, TSS, and TPC were "Supersweet 100 F1", "Primabella", "Resi", and "“Goldita". The information could be used by the tomato growers and breeders in organic low-input management in order to select cultivar with lower trade-off between fruit quality and agronomic traits.

\section{2 Nutrient density and nutritional yield of the cultivars}

While several cultivars exhibit high genotype stability across years for the single traits studied, significant variation in mineral concentrations (i.e., $\mathrm{K}, \mathrm{Ca}, \mathrm{Mg}, \mathrm{P}, \mathrm{Fe}$ and $\mathrm{Zn}$ ) by cultivarby-year interaction was found. The difference among cultivars is the main factor determining the 
variation of mineral concentration in organic tomatoes rather than growing methods (OrdóñezSantos et al., 2011). The level and the ratio of minerals present in the tomato fruits, influence all aspects of fruit quality ranging from sweetness and firmness to overall flavor (Dorais et al., 2001; Ibrahim et al., 2017). Mineral composition, therefore, constitutes as a key factor for consumer acceptance (Capel et al., 2017).

To date, study of micronutrients content in tomatoes has not only been scarce, but also out of date and the contributions of the micronutrients to the daily dietary intake are low (Hernández Suárez et al., 2007). Therefore, the contribution of $100 \mathrm{~g}$ fruit to meet the recommended dietary reference intake of macronutrients $(\mathrm{K}, \mathrm{Ca}, \mathrm{Mg}$ and $\mathrm{P})$ and two essential micronutrients ( $\mathrm{Fe}$ and $\mathrm{Zn}$ ) was determined. Among the cultivars, the contribution of $100 \mathrm{~g}$ fresh fruits to meet daily dietary requirements for the different minerals ranged from 0.8 to $7.7 \%$. This result highlights that the investigated tomato cultivars can be a major source of micronutrients, despite their relative low concentration in the fruits.

In regard with the demand for an adequate and healthy diet for the growing world population and the need for a sustainable and efficient use of land areas, it is a necessity to develop new metrics that incorporate human nutrition as a primary goal in agricultural production (De Ruiter et al., 2018). In the present study, the data of FY were linked with different fruit macro- and micronutrients concentrations in order to estimate their nutritional yields (NY). The metrics of NY should obviously integrate not only the quality of agricultural products (i.e. nutrient content) but also the quantity of food production (DeFries et al., 2015). From perspective of land use efficiency, tomato could deliver mineral nutrients to feed a mean number of 91 and 58 adults per hectare for one year (adults $\mathrm{ha}^{-1}$ year $^{-1}$ ) for the essential micronutrients Fe and $\mathrm{Zn}$, respectively, which were higher than similar NYs of tomatoes from previous study (Kapoulas et al., 2013). Overall, "Bartelly F1" and "Bocati F1" were identified as superior cultivars in terms of NY of Fe and Zn, respectively.

Based on the coefficient $(\mathrm{CV})$ of variation and heritability parameters, it is suggested that cultivar or genetics controlled most of the fruit minerals more than environment, which was also 
reported with similar statement by Kapoulas et al. (2013). The highest CV and, hence the lowest heritability, was found in $\mathrm{Fe}$ and $\mathrm{Zn}$ densities which implies that micronutrient densities in the cultivars can vary greatly.

\subsection{VOCs and sensory profiles of the cultivars}

Complaints about the flavor of fresh tomatoes, which is generally considered as poor by consumers, have been increasing in the past decades (Kanski et al., 2020; Vogel et al., 2010). Hence, understanding the contributions of individual VOCs, both positive and negative, is an important factor in improving flavor quality (Vogel et al., 2010). The correlation pattern between instrumental and sensory traits is reasonable despite the different measurement principles: if the VOC showed a positive correlation with TSS, the sweetness and tomato typical-aroma increased and therefore, overall acceptance of the cultivar was also high. From the 12 identified VOCs that showed a significant correlation to one or more sensory attributes, 2-isobuthylthiazole and 6-me-5hepten-2-ol had negative correlation with acceptability, while 2-phenylethyl alcohol and benzyl alcohol were positively correlated with cultivar acceptability in both the breeder's and sensory panel tests. Klee and Tieman (2018) confirmed that several compounds, including sugars and VOCs, in a single cultivar can contribute to differential liking across different seasons or locations.

Principal component analysis allowed identifying few VOCs such 2-isobuthylthiazole, 6me-5-hepten-2-ol, (E)-2-hexenal, (Z)-3-hexen-1-ol, 2-phenylethyl alcohol and benzyl alcohol as good discriminators to classify the cultivars according to fruit type. Significant negative correlations of 2-isobuthylthiazole and 6-me-5-hepten-2-ol; and positive correlations of 2phenylethyl alcohol and benzyl alcohol with sweetness and tomato typical aroma as well as overall acceptability were also found, despite their lower relative concentration in the studied cultivars. This suggests the abundance of VOCs did not guarantee their significant contribution to flavorrelated traits and consumer acceptability; although hexanal is one of most important VOC contributing to tomato aroma (Cebolla-Cornejo et al., 2011), it was not occurred in our samples. The first principal component, representing the highest variability of the data set, was highly 
associated with cocktail cultivars "Supersweet 100 F1" and "Goldita" in one hand and the salad ones "Roterno F1", "Lyterno F1", "Bocati F1" and "Cappricia F1". As indicated by Bertin and Génard (2018), cocktail cultivars are the most tasteful cultivars, while the taste of large-fruitedcultivars is rather poor, suggesting antagonistic relationships between FW and taste. Premium quality of these cocktail cultivars is not only the result of flavor related-quality traits but also that of other fruit quality traits. "Supersweet $100 \mathrm{~F} 1$ " and "Goldita" (cocktail cultivars) are among superior cultivars in the trait combinations of fruit $\mathrm{Mg}$, TSS, and TPC (chapter two). These findings strengthen the importance of further characterization of these cultivars to preserve or improve desirable flavor and other quality traits in cocktail tomato fruits under organic low-input production system.

\subsection{Conclusion}

All studied agronomic and quality traits (especially VOCs) appear to be influenced in a very strong way by variation due to cultivar/genetic characteristics. The study revealed that cultivar was the most important determining factor for variation of all studied traits (agronomic related-traits, fruit quality parameters and sensory properties). In relation to fruit yield, "Roterno F1" produced the highest FY (5823.9 $\mathrm{g} \mathrm{plant}^{-1}$ ) within salad cultivars, whereas "Bartelly F1" showed the best performance (4076.4 g plant ${ }^{-1}$ ) among cocktail cultivars. "Supersweet $100 \mathrm{~F} 1$ " and "Goldita" (cocktail cultivars) are the best cultivars for fruit quality characteristics. Micronutrient densities exhibited lower heritability than that of macronutrients, which suggest the potential for the selection of specific cultivars for improving micronutrient composition. In general, cocktail cultivars showed considerable higher mineral concentrations than salad cultivars. The NY values of the tomato cultivars ranged from 25 to 119 adults $\mathrm{ha}^{-1}$ year $^{-1}$ with high considerable contribution for Fe (91 adults $\mathrm{ha}^{-1}$ year $\left.^{-1}\right)$ and $\mathrm{Zn}\left(58\right.$ adults $\mathrm{ha}^{-1}$ year $\left.^{-1}\right)$. "Bartelly F1" (cocktail cultivar) and "Bocati F1" (salad cultivar) were the highest nutrient-yielding cultivars, which is not only important in the context of food and nutrition security, but also in the context of environmental sustainability. Identifying cultivars with desirable quality traits is critical to maintain tomato crop productivity 
while improving fruit quality, and at the same time protecting agricultural biodiversity. Cocktail cultivars exhibited greater acceptability with higher scores of mainly TSS, sweetness, and tomato typical-aroma, as well as for TA for most of the cultivars. Few VOCs, especially 2isobuthylthiazole and 6-me-5-hepten-2-ol were negatively correlated with acceptability, whereas 2phenylethyl alcohol and benzyl alcohol were positively correlated with the acceptability in both the breeder's and sensory panel tests. "Supersweet $100 \mathrm{~F} 1$ " was the cultivar with the highest acceptability among the panelists from both sensory panels. Finally, this study provides information to the tomato growers, consumers and plant breeders to produce tomatoes improved in terms of sensory characteristics and health benefits, and with better performance of agronomic traits. 


\section{Summary}

Tomatoes (Solanum lycopersicum L.) are the second-largest cultivated vegetables in the world after potato. They are considered to be one of the most economically important crops worldwide, in terms of their production and consumption per capita. Tomato fruits contribute to a healthy, well-balanced diet due to their valuable content of minerals, vitamins, sugars and total phenolic compounds. The production and consumption includes both tomatoes consumed as fresh and industrially processed tomato products. Consumer demand and preference for fresh tomatoes between the countries and areas especially with regard to sensory properties varies. To date, the effect of cultivars on fruit quality, especially their relationship with fruit yield and leaf mineral nutrients as well as sensory properties in organic low-input system, has not been extensively studied. It is an important goal for breeders to improve fruit quality and enhance yield simultaneously, but mostly fruit quality improvement is often accompanied by the decline in production yield. To our knowledge, all available data of nutritional yields (NY) have been concentrated on cereals produced in conventional systems. Therefore, determination of NY is important to assist farmers and breeders to select cultivar for a more efficient crop production without comprising fruit quality traits. Total soluble solid (TSS), titratable acid (TA), volatile organic compounds (VOCs) and texture are the most important traits associated with flavor. Many studies have been investigating in what extent the flavor-related traits correlate to sensory properties of tomato. However, the studies mostly focused on cultivars grown under a protected and conventional production system.

Sixty cultivars from old cultivars released in the 1880 s to the most recently developed cultivars were investigated in 2015 and a subset of 20 cultivars was selected for further evaluation in 2016. The cultivars were classified into cocktail and salad cultivars, according to their fruit weight. A breeder's sensory panel in 2015 and a trained panel for quantitative descriptive sensory analyses in 2016 were applied on a subset of 20 tomato cultivars. The objective of the present study were to evaluate the effect of cultivars on plant morphology and fruit quality, to estimates the NY of 
fruit mineral, and to characterize traits contributes to human-sensory perception (fruit firmness, juiciness, skin firmness, sweetness, sourness, tomato-typical aroma, and acceptability).

Significant variation in plant morphological traits, leaf mineral concentration, fruit biochemical composition and sensory characteristic were observed. Agronomic and morphological traits presented a high variation; whereas fruit quality traits varied significantly with lower extend of variation, suggesting potential selection for new cultivars with improved yield and superior fruit quality under organic low-input production. The cultivar with higher plant growth did not guarantee to higher fruit yield. "Lyterno F1" and "Bartelly F1" were the highest yielding-cultivars within salad and cocktail cultivars, respectively, while "Supersweet $100 \mathrm{~F} 1$ " and "Goldita" were superior cultivars for most of the quality traits. In addition, the cultivars have also different contribution for daily intake of the studied macro- and micronutrient for human, but considerable high contribution was observed for Fe and Zn, two essential micronutrients commonly lack in food crop. Nutritional yield of Fe and $\mathrm{Zn}$ of our cultivar were found to be higher than the NY of other vegetable crops (e.g., eggplant and potato). "Bartelly F1" was potential for providing Fe, while "Bocati F1" was superior for supplying $\mathrm{Zn}$ for people.

A total of 31 VOCs were identified, comprising of nine alcohols, eight aldehydes, six ketones, four aliphatic acids, three esters, and one sulfur derived-compound. The cultivar-byharvest date-by-year interaction had a significant influence on 17 VOCs, but not on the taste-related traits of TSS and TA. Across two years evaluation, 12 VOCs significantly correlated to one or more sensory attributes. "Supersweet $100 \mathrm{~F} 1$ " had the highest score for overall acceptability and most of sensory properties in both sensory tests.

We conclude that the performance of the cultivars is strongly cultivar-dependent rather than cultivar-by-year interaction. Trade-offs between fruit weight and fruit quality was clearly observed. The metrics of NY can be used to select cultivar with reduced trade-offs between yield and mineral density with increased land efficiency. Correlations between instrumental traits and sensory properties are important to be considered in flavor improvement of tomato cultivars. 


\section{References}

Abduelghader, A.A., Sanders, F.E., Pilbeam, D.J., 2011. Growth and biomass partitioning in tomato in relation to ratio of nitrogen:phosphorus supply. Journal of Plant Nutrition 34, 2018-2038. https://doi.org/10.1080/01904167.2011.610488

Acquaah, G., 2012. Principles of plant genetics and breeding: breeding tomato, Second Edition. ed. John Wiley \& Sons, Ltd, Chichester, UK. https://doi.org/10.1002/9781118313718.ch39

Adhikari, D., Kobashi, Y., Kai, T., Kawagoe, T., Kubota, K., Araki, K.S., Kubo, M., 2018. Suitable soil conditions for tomato cultivation under an organic farming system. Journal of Agricultural Chemistry and Environment 7, 117-132. https://doi.org/10.4236/jacen.2018.73011

Agarwal, A., Sharma, U., Ranjan, R., Nasim, M., 2017. Combining ability analysis for yield, quality, earliness, and yield-attributing traits in tomato. International Journal of Vegetable Science 23, 605615. https://doi.org/10.1080/19315260.2017.1355864

Ahrazem, O., Gómez-Gómez, L., Rodrigo, M.J., Avalos, J., Limón, M.C., 2016. Carotenoid cleavage oxygenases from microbes and photosynthetic organisms: features and functions. International Journal of Molecular Sciences 17, 1-38. https://doi.org/10.3390/ijms17111781

Aldrich, H.T., Salandanan, K., Kendall, P., Bunning, M., Stonaker, F., Külen, O., Stushnoff, C., 2010. Cultivar choice provides options for local production of organic and conventionally produced tomatoes with higher quality and antioxidant content. J. Sci. Food Agric. 90, 2548-2555. https://doi.org/10.1002/jsfa.4116

Araujo, J., Telhado, S., 2015. Organic food: a comparative study of the effect of tomato cultivars and cultivation conditions on the physico-chemical properties. Foods 4, 263-270. https://doi.org/10.3390/foods4030263

Arias, R., Lee, T.-C., Logendra, L., Janes, H., 2000. Correlation of lycopene measured by HPLC with the L*, $\mathrm{a}^{*}, \mathrm{~b}^{*}$ color readings of a hydroponic tomato and the relationship of maturity with color and lycopene content. Journal of Agricultural and Food Chemistry 48, 1697-1702. https://doi.org/10.1021/jf990974e

Arimond, M., Wiesmann, D., Becquey, E., Carriquiry, A., Daniels, M.C., Deitchler, M., Fanou-Fogny, N., Joseph, M.L., Kennedy, G., Martin-Prevel, Y., Torheim, L.E., 2010. Simple Food Group Diversity Indicators Predict Micronutrient Adequacy of Women's Diets in 5 Diverse, Resource-Poor Settings. The Journal of Nutrition 140, 2059S-2069S. https://doi.org/10.3945/jn.110.123414

Aspuru, R., Villa, C., Bermejo, F., Herrero, P., García López, S., 2011. Optimal management of iron deficiency anemia due to poor dietary intake. International Journal of General Medicine 4, 741-750. https://doi.org/10.2147/IJGM.S17788

Atkinson, S.A., Koletzko, B., 2007. Determining life-stage groups and extrapolating nutrient Intake values (NIVs). Food and Nutrition Bulletin 28, S61-S76. https://doi.org/10.1177/15648265070281S107

Bai, Y., Lindhout, P., 2007a. Domestication and breeding of tomatoes: what have we gained and what can we gain in the future? Annals of Botany 100, 1085-1094. https://doi.org/10.1093/aob/mcm150

Bai, Y., Lindhout, P., 2007b. Domestication and Breeding of Tomatoes: What have We Gained and What Can We Gain in the Future? Annals of Botany 100, 1085-1094. https://doi.org/10.1093/aob/mcm150

Bailey, R.L., West Jr., K.P., Black, R.E., 2015. The Epidemiology of Global Micronutrient Deficiencies. Ann Nutr Metab 66, 22-33. https://doi.org/10.1159/000371618

Baldina, S., Picarella, M.E., Troise, A.D., Pucci, A., Ruggieri, V., Ferracane, R., Barone, A., Fogliano, V., Mazzucato, A., 2016. Metabolite Profiling of Italian Tomato Landraces with Different Fruit Types. Front. Plant Sci. 7. https://doi.org/10.3389/fpls.2016.00664

Baldwin, E.A., Goodner, K., Plotto, A., 2008. Interaction of Volatiles, Sugars, and Acids on Perception of Tomato Aroma and Flavor Descriptors. Journal of Food Science 73, S294-S307. https://doi.org/10.1111/j.1750-3841.2008.00825.x

Baldwin, E.A., Scott, J.W., Shewmaker, C.K., Schuch, W., others, 2000. Flavor trivia and tomato aroma: biochemistry and possible mechanisms for control of important aroma components. HortScience 35, 1013-1021.

Barrett, D.M., Beaulieu, J.C., Shewfelt, R., 2010. Color, Flavor, Texture, and Nutritional Quality of FreshCut Fruits and Vegetables: Desirable Levels, Instrumental and Sensory Measurement, and the Effects of Processing. Critical Reviews in Food Science and Nutrition 50, 369-389.

https://doi.org/10.1080/10408391003626322 
Barrios-Masias, F.H., Jackson, L.E., 2014. California processing tomatoes: Morphological, physiological and phenological traits associated with crop improvement during the last 80 years. European Journal of Agronomy 53, 45-55. https://doi.org/10.1016/j.eja.2013.11.007

Barry, C.S., Pandey, P., 2009. A survey of cultivated heirloom tomato varieties identifies four new mutant alleles at the green-flesh locus. Molecular Breeding 24, 269-276. https://doi.org/10.1007/s11032009-9289-4

Bates, D., Mächler, M., Bolker, B., Walker, S., 2015. Fitting Linear Mixed-Effects Models Using 1me4. J. Stat. Soft. 67. https://doi.org/10.18637/jss.v067.i01

Bauchet, G., Causse, M., 2012. Genetic Diversity in Tomato (Solanum lycopersicum) and Its Wild Relatives, in: Caliskan, M. (Ed.), Genetic Diversity in Plants. InTech. https://doi.org/10.5772/33073

Bauchet, G., Grenier, S., Samson, N., Segura, V., Kende, A., Beekwilder, J., Cankar, K., Gallois, J.-L., Gricourt, J., Bonnet, J., Baxter, C., Grivet, L., Causse, M., 2017. Identification of major loci and genomic regions controlling acid and volatile content in tomato fruit: implications for flavor improvement. New Phytol 215, 624-641. https://doi.org/10.1111/nph.14615

Baye, T.M., Abebe, T., Wilke, R.A., 2011. Genotype-environment interactions and their translational implications. Personalized Medicine 8, 59-70. https://doi.org/10.2217/pme.10.75

Beal, T., Massiot, E., Arsenault, J.E., Smith, M.R., Hijmans, R.J., 2017. Global trends in dietary micronutrient supplies and estimated prevalence of inadequate intakes. Plos One 12, e0175554. https://doi.org/10.1371/journal.pone.0175554

Beckles, D.M., 2012. Factors affecting the postharvest soluble solids and sugar content of tomato (Solanum lycopersicum L.) fruit. Postharvest Biology and Technology 63, 129-140. https://doi.org/10.1016/j.postharvbio.2011.05.016

Behr, H.-C., 2018. AMI Markt Bilanz Gemüse 2018. Agrarmarkt Informations-Gesellschaft mbH, Bonn.

Bergougnoux, V., 2014. The history of tomato: from domestication to biopharming. Biotechnology Advances 32, 170-189. https://doi.org/10.1016/j.biotechadv.2013.11.003

Bertin, N., Génard, M., 2018. Tomato quality as influenced by preharvest factors. Scientia Horticulturae 233, 264-276. https://doi.org/10.1016/j.scienta.2018.01.056

Bettiol, W., Ghini, R., Galvão, J.A.H., Siloto, R.C., 2004. Organic and conventional tomato cropping systems. Scientia Agricola 61, 253-259. https://doi.org/10.1590/S0103-90162004000300002

Bhandari, S.R., Lee, J.G., 2016. Ripening-Dependent Changes in Antioxidants, Color Attributes, and Antioxidant Activity of Seven Tomato ( Solanum lycopersicum L.) Cultivars. Journal of Analytical Methods in Chemistry 2016, 1-13. https://doi.org/10.1155/2016/5498618

Bhattarai, K., Sharma, S., Panthee, D.R., 2018. Diversity among Modern Tomato Genotypes at Different Levels in Fresh-Market Breeding. International Journal of Agronomy 2018, 1-15. https://doi.org/10.1155/2018/4170432

Blanca, J., Montero-Pau, J., Sauvage, C., Bauchet, G., Illa, E., Díez, M.J., Francis, D., Causse, M., van der Knaap, E., Cañizares, J., 2015. Genomic variation in tomato, from wild ancestors to contemporary breeding accessions. BMC Genomics 16, 257. https://doi.org/10.1186/s12864-015-1444-1

Bodner, M., Scampicchio, M., 2020. Does bruising influence the volatile profile of pears? Nutrition \& Food Science 1-10. https://doi.org/10.1108/NFS-05-2020-0213

Boyhan, G.E., Tate, S., McNeill, R., McConnaughey, J., 2014. Evaluation of tomato varieties under organic production practices in Georgia. Horticultural Technology 24, 252-258. https://doi.org/10.21273/HORTTECH.24.2.252

Branca, G., Lipper, L., McCarthy, N., Jolejole, M.C., 2013. Food security, climate change, and sustainable land management. A review. Agron. Sustain. Dev. 33, 635-650. https://doi.org/10.1007/s13593-0130133-1

Bruhn, C.M., Feldman, N., Garlitz, C., Harwood, J., Ivans, E., Marshall, M., Riley, A., Thurber, D., Williamson, E., 1991. Consumer perceptions of quality: Apricots, cantaloupes, peaches, pears, strawberries and tomatoes. Journal of Food Quality 14, 187-195.

Bumgarner, N.R., Scheerens, J.C., Kleinhenz, M.D., 2012. Nutritional yield: a proposed index for fresh food improvement illustrated with leafy vegetable data. Plant Foods for Human Nutrition 67, 215-222. https://doi.org/10.1007/s11130-012-0306-0

Buttery, R.G., Teranishi, R., Flath, R.A., Ling, L.C., 1989. Fresh Tomato Volatiles: Composition and Sensory Studies, in: Teranishi, R., Buttery, R.G., Shahidi, F. (Eds.), Flavor Chemistry. American Chemical Society, Washington, DC, pp. 213-222. https://doi.org/10.1021/bk-1989-0388.ch017

Buttery, R.G., Teranishi, R., Ling, L.C., 1987. Fresh tomato aroma volatiles: a quantitative study. Journal of Agricultural and Food Chemistry 35, 540-544. https://doi.org/10.1021/jf00076a025 
Cakmak, I., 2013. Magnesium in crop production, food quality and human health. Plant Soil 368, 1-4. https://doi.org/10.1007/s11104-013-1781-2

Capel, C., Yuste-Lisbona, F.J., López-Casado, G., Angosto, T., Heredia, A., Cuartero, J., Fernández-Muñoz, R., Lozano, R., Capel, J., 2017. QTL mapping of fruit mineral contents provides new chances for molecular breeding of tomato nutritional traits. Theor Appl Genet 130, 903-913. https://doi.org/10.1007/s00122-017-2859-7

Carrari, F., Fernie, A.R., 2006. Metabolic regulation underlying tomato fruit development. Journal of Experimental Botany 57, 1883-1897. https://doi.org/10.1093/jxb/erj020

Casals, J., Rivera, A., Sabaté, J., Romero del Castillo, R., Simó, J., 2018. Cherry and fresh market tomatoes: differences in chemical, morphological, and sensory traits and their implications for consumer acceptance. Agronomy 9, 9. https://doi.org/10.3390/agronomy9010009

Causse, M., Buret, M., Robini, K., Verschave, P., 2003. Inheritance of nutritional and sensory quality traits in fresh market tomato and relation to consumer preferences. Journal of Food Science 68, 23422350. https://doi.org/10.1111/j.1365-2621.2003.tb05770.x

Causse, M., Friguet, C., Coiret, C., Lépicier, M., Navez, B., Lee, M., Holthuysen, N., Sinesio, F., Moneta, E., Grandillo, S., 2010a. Consumer Preferences for Fresh Tomato at the European Scale: A Common Segmentation on Taste and Firmness. Journal of Food Science 75, S531-S541. https://doi.org/10.1111/j.1750-3841.2010.01841.x

Causse, M., Friguet, C., Coiret, C., Lépicier, M., Navez, B., Lee, M., Holthuysen, N., Sinesio, F., Moneta, E., Grandillo, S., 2010b. Consumer Preferences for Fresh Tomato at the European Scale: A Common Segmentation on Taste and Firmness. Journal of Food Science 75, S531-S541. https://doi.org/10.1111/j.1750-3841.2010.01841.x

Causse, M., Saliba-Colombani, V., Lecomte, L., Duffe, P., Rousselle, P., Buret, M., 2002. QTL analysis of fruit quality in fresh market tomato: a few chromosome regions control the variation of sensory and instrumental traits. Journal of Experimental Botany 53, 2089-2098. https://doi.org/10.1093/jxb/erf058

Causse, M., Stevens, R., Amor, B.B., Faurobert, M., Muños, S., 2011. Breeding for fruit quality in tomato, in: Jenks, M.A., Bebeli, P.J. (Eds.), Breeding for Fruit Quality. John Wiley \& Sons, Inc., Hoboken, NJ, USA, pp. 279-305. https://doi.org/10.1002/9780470959350.ch13

Cebolla-Cornejo, J., Roselló, S., Valcárcel, M., Serrano, E., Beltrán, J., Nuez, F., 2011. Evaluation of Genotype and Environment Effects on Taste and Aroma Flavor Components of Spanish Fresh Tomato Varieties. J. Agric. Food Chem. 59, 2440-2450. https://doi.org/10.1021/jf1045427

Chávez-Servia, J., Vera-Guzmán, A., Linares-Menéndez, L., Carrillo-Rodríguez, J., Aquino-Bolaños, E., 2018. Agromorphological traits and mineral content in tomato accessions from El Salvador, Central America. Agronomy 8, 1-14. https://doi.org/10.3390/agronomy8030032

Chung, M., Balk, E.M., Ip, S., Lee, J., Terasawa, T., Raman, G., Trikalinos, T., Lichtenstein, A.H., Lau, J., 2010. Systematic review to support the development of nutrient reference intake values: challenges and solutions. The American Journal of Clinical Nutrition 92, 273-276. https://doi.org/10.3945/ajen.2009.29092

Cortés-Olmos, C., Valcárcel, J.V., Roselló, J., Díez, M.J., Cebolla-Cornejo, J., 2015. Traditional Eastern Spanish varieties of tomato. Scientia Agricola 72, 420-431. https://doi.org/10.1590/0103-90162014-0322

Cortina, P.R., Santiago, A.N., Sance, M.M., Peralta, I.E., Carrari, F., Asis, R., 2018. Neuronal network analyses reveal novel associations between volatile organic compounds and sensory properties of tomato fruits. Metabolomics 14, 57. https://doi.org/10.1007/s11306-018-1355-7

Costa, F., de Lurdes Baeta, M., Saraiva, D., Verissimo, M.T., Ramos, F., 2011. Evolution of mineral contents in tomato fruits during the ripening process after harvest. Food Analytical Methods 4, 410-415. https://doi.org/10.1007/s12161-010-9179-8

Costa, M., Heuvelink, E., 2018. The global tomato industry, in: Heuvelink, E. (Ed.), Tomatoes. Crop Production Science in Horticulture. Wallingford: CAB International.

Davies, J.N., Hobson, G.E., 1981. The constituents of tomato fruit - the influence of environment, nutrition, and genotype. C R C Critical Reviews in Food Science and Nutrition 15, 205-280. https://doi.org/10.1080/10408398109527317

Davis, D.R., 2009. Declining fruit and vegetable nutrient composition: what is the evidence? Horticultural Science 44, 15-19. 
Dawson, J.C., Murphy, K.M., Jones, S.S., 2008. Decentralized selection and participatory approaches in plant breeding for low-input systems. Euphytica 160, 143-154. https://doi.org/10.1007/s10681-0079533-0

de Ponti, T., Rijk, B., van Ittersum, M.K., 2012. The crop yield gap between organic and conventional agriculture. Agricultural Systems 108, 1-9. https://doi.org/10.1016/j.agsy.2011.12.004

De Ruiter, H., Macdiarmid, J.I., Matthews, R.B., Smith, P., 2018. Moving beyond calories and protein: Micronutrient assessment of UK diets and land use. Global Environmental Change 52, 108-116. https://doi.org/10.1016/j.gloenvcha.2018.06.007

DeFries, R., Fanzo, J., Remans, R., Palm, C., Wood, S., Anderman, T.L., 2015. Metrics for land-scarce agriculture. Science 349, 238-240. https://doi.org/10.1126/science.aaa5766

DeFries, R., Mondal, P., Singh, D., Agrawal, I., Fanzo, J., Remans, R., Wood, S., 2016. Synergies and tradeoffs for sustainable agriculture: Nutritional yields and climate-resilience for cereal crops in Central India. Global Food Security 11, 44-53. https://doi.org/10.1016/j.gfs.2016.07.001

DeVerma, J.W., Paterson, A.H., 1991. Genetics of Lycopersicon, in: Genetic Improvement of Tomato. Monographs on Theoretical and Applied Genetics. Springer, Berlin, Heidelberg.

Didier, T., Lucie, S., 2008. Measuring consumer's willingness to pay for organic and Fair Trade products. International Journal of Consumer Studies 32, 479-490. https://doi.org/10.1111/j.14706431.2008.00714.x

Dixon, M., Simonne, E., Obreza, T., Liu, G., 2020. Crop Response to Low Phosphorus Bioavailability with a Focus on Tomato. Agronomy 10, 617. https://doi.org/10.3390/agronomy10050617

Doets, E.L., de Wit, L.S., Dhonukshe-Rutten, R.A.M., Cavelaars, A.E.J.M., Raats, M.M., Timotijevic, L., Brzozowska, A., Wijnhoven, T.M.A., Pavlovic, M., Totland, T.H., Andersen, L.F., Ruprich, J., Pijls, L.T.J., Ashwell, M., Lambert, J.P., van ’t Veer, P., de Groot, L.C.P.G.M., 2008. Current micronutrient recommendations in Europe: towards understanding their differences and similarities. European Journal of Nutrition 47, 17-40. https://doi.org/10.1007/s00394-008-1003-5

Dorais, M., 2007. Effect of cultural management on tomato fruit health qualities. Acta Horticulturae 744, 279-294. https://doi.org/10.17660/ActaHortic.2007.744.29

Dorais, M., Papadopoulos, A.P., Gosselin, A., 2001. Greenhouse tomato fruit quality, in: Horticultural Reviews. Wiley \& Sons, New York, pp. 239-319.

Dufera, J.T., 2013. Evaluation of agronomic performance and lycopene variation in tomato (Lycopersicon esculantum Mill.) genotypes in Mizan, Southwestern Ethiopia. World Applied Sciences Journal 27, 1450-1454. https://doi.org/DOI: 10.5829/idosi.wasj.2013.27.11.783

El Hadi, M., Zhang, F.-J., Wu, F.-F., Zhou, C.-H., Tao, J., 2013. Advances in fruit aroma volatile research. Molecules 18, 8200-8229. https://doi.org/10.3390/molecules 18078200

Ene, C.O., Ogbonna, P.E., Agbo, C.U., Chukwudi, U.P., 2016. Studies of phenotypic and genotypic variation in sixteen cucumber genotypes. Chilean J. Agric. Res. 76, 307-313. https://doi.org/10.4067/S071858392016000300007

Erba, D., Casiraghi, M.C., Ribas-Agustí, A., Cáceres, R., Marfà, O., Castellari, M., 2013. Nutritional value of tomatoes (Solanum lycopersicum L.) grown in greenhouse by different agronomic techniques. Journal of Food Composition and Analysis 31, 245-251. https://doi.org/10.1016/j.jfca.2013.05.014

Erika, C., Griebel, S., Naumann, M., Pawelzik, E., 2020. Biodiversity in Tomatoes: Is It Reflected in Nutrient Density and Nutritional Yields Under Organic Outdoor Production? Front. Plant Sci. 11, 589692. https://doi.org/10.3389/fpls.2020.589692

European Council, 2008. Commission Regulation (EC) No 889/2008 of 5 September 2008 laying down detailed rules for the implementation of Council Regulation (EC) No 834/2007 on organic production and labelling of organic products with regard to organic production, labelling and control, OJ L.

FAO, 2018. Tomato [WWW Document]. URL http://www.fao.org/faostat/en/\#data/QC/ (accessed 8.16.18).

FAO, 2001. World Markets for Organic Fruit and Vegetables - Opportunities for Developing Countries in the Production and Export of Organic Horticultural Products, Rome [WWW Document]. URL http://www.fao.org/agroecology/database/detail/en/c/1202184/ (accessed 6.12.21).

FAOSTAT, 2020. Crop production quantity by regions. Food and Agriculture Organization [WWW Document]. URL < http://www.fao.org/faostat/en/\#data/QC> (accessed 2.9.20).

FAOSTAT, 2019. Food and Agriculture Organisation of the United Nations [WWW Document]. URL http://www.fao.org/faostat/en/?\#data (accessed 4.14.19).

Fears, R., ter Meulen, V., von Braun, J., 2019. Global food and nutrition security needs more and new science. Sci. Adv. 5, eaba2946. https://doi.org/10.1126/sciadv.aba2946 
Federal Statistical Office, 2020. Organic farming: complete organic cultivated area [WWW Document]. URL https://www.destatis.de/EN/Themes/Economic-Sectors-Enterprises/Agriculture-ForestryFisheries/Fruit-Vegetables-Horticulture/Tables/1-1-organic-farming.html (accessed 6.12.21).

Fernández-Ruiz, V., Olives, A.I., Cámara, M., Sánchez-Mata, M. de C., Torija, M.E., 2011. Mineral and trace elements content in 30 accessions of tomato fruits (Solanum lycopersicum L.,) and wild relatives (Solanum pimpinellifolium L., Solanum cheesmaniae L. Riley, and Solanum habrochaites S. Knapp \& D.M. Spooner). Biological Trace Element Research 141, 329-339. https://doi.org/10.1007/s12011-010-8738-6

Fernqvist, F., Hunter, E., 2012. Who's to Blame for Tasteless Tomatoes? The Effect of Tomato Chilling on Consumers' Taste Perceptions. Europ.J.Hort.Sci., 77, 193-198.

Fess, T., Benedito, V., 2018. Organic versus conventional cropping sustainability: a comparative system analysis. Sustainability 10, 272. https://doi.org/10.3390/su10010272

Fess, T.L., Kotcon, J.B., Benedito, V.A., 2011a. Crop Breeding for Low Input Agriculture: A Sustainable Response to Feed a Growing World Population. Sustainability 3, 1742-1772. https://doi.org/10.3390/su3101742

Fess, T.L., Kotcon, J.B., Benedito, V.A., 2011b. Crop Breeding for Low Input Agriculture: A Sustainable Response to Feed a Growing World Population. Sustainability 3, 1742-1772. https://doi.org/10.3390/su3101742

FiBL, 2012. Organic imports to Germany, Research Institute of Organic Agriculture, Bonn, Germany [WWW Document]. URL https://www.fibl.org/en/info-centre/news/organic-imports-togermany.html (accessed 6.12.21).

Firas, A.-A., Hussein, K., Mahmood, S., Mahmood, A.-Z., Mohammad, A.A.-N., 2012. Genetic Analysis and Correlation Studies of Yield and Fruit Quality Traits in Tomato (Solanum lycopersicum L.). New York Science Journal 5, 42-145.

Foley, J.A., Ramankutty, N., Brauman, K.A., Cassidy, E.S., Gerber, J.S., Johnston, M., Mueller, N.D., O’Connell, C., Ray, D.K., West, P.C., Balzer, C., Bennett, E.M., Carpenter, S.R., Hill, J., Monfreda, C., Polasky, S., Rockström, J., Sheehan, J., Siebert, S., Tilman, D., Zaks, D.P.M., 2011. Solutions for a cultivated planet. Nature 478, 337-342. https://doi.org/10.1038/nature 10452

Folta, K.M., Klee, H.J., 2016. Sensory sacrifices when we mass-produce mass produce. Hortic Res 3, 16032. https://doi.org/10.1038/hortres.2016.32

Foolad, M.R., 2007. Genome mapping and molecular breeding of tomato. International Journal of Plant Genomics 2007, 1-52. https://doi.org/10.1155/2007/64358

Gamalero, E., Trotta, A., Massa, N., Copetta, A., Martinotti, M.G., Berta, G., 2004. Impact of two fluorescent pseudomonads and an arbuscular mycorrhizal fungus on tomato plant growth, root architecture and P acquisition. Mycorrhiza 14, 185-192. https://doi.org/10.1007/s00572-003-0256-3

Gascuel, Q., Diretto, G., Monforte, A.J., Fortes, A.M., Granell, A., 2017. Use of Natural Diversity and Biotechnology to Increase the Quality and Nutritional Content of Tomato and Grape. Front. Plant Sci. 8, 652. https://doi.org/10.3389/fpls.2017.00652

Gautier, H., Diakou-Verdin, V., Bénard, C., Reich, M., Buret, M., Bourgaud, F., Poëssel, J.L., Caris-Veyrat, C., Génard, M., 2008. How does tomato quality (sugar, acid, and nutritional quality) vary with ripening stage, temperature, and irradiance? Journal of Agricultural and Food Chemistry 56, 12411250. https://doi.org/10.1021/jf072196t

George, B., Kaur, C., Khurdiya, D.S., Kapoor, H.C., 2004. Antioxidants in tomato (Lycopersium esculentum) as a function of genotype. Food Chemistry $84,45-51$. https://doi.org/10.1016/S03088146(03)00165-1

Georgelis, N., Scott, J.W., Baldwin, E.A., 2004. Relationship of tomato fruit sugar concentration with physical and chemical traits and linkage of RAPD markers. Journal of the American Society for Horticultural Science 129, 839-845. https://doi.org/10.21273/JASHS.129.6.0839

Ghorbani, R., Poozesh, V., Khorramdel, S., 2012. Tomato production for human health, not only for food, in: Lichtfouse, E. (Ed.), Organic Fertilisation, Soil Quality and Human Health. Springer Netherlands, Dordrecht, pp. 187-225. https://doi.org/10.1007/978-94-007-4113-3_8

Gioia, F.D., Serio, F., Buttaro, D., Ayala, O., Santamaria, P., 2010. Influence of rootstock on vegetative growth, fruit yield and quality in 'Cuore di Bue', an heirloom tomato. The Journal of Horticultural Science and Biotechnology 85, 477-482. https://doi.org/10.1080/14620316.2010.11512701

Godfray, H.C.J., Beddington, J.R., Crute, I.R., Haddad, L., Lawrence, D., Muir, J.F., Pretty, J., Robinson, S., Thomas, S.M., Toulmin, C., 2010. Food security: the challenge of feeding 9 billion people. Science 327 (5967), 812-818. https://doi.org/10.1126/science.1185383 
Goulding, K., Stockdale, E., Watson, A.C., 2008. Plant nutrients in organic farming, in: Organic Crop Production: Ambitions and Limitations. Springer, Dordrecht.

Graham, C., Beck, R., Thavarajah, D., 2018. Dietary reference intake and nutritional yield of lentils in the Northern Great Plains. Crop Science 58, 1-7. https://doi.org/10.2135/cropsci2017.10.0617

Granell, A., Rambla, J.L., 2013. Biosynthesis of Volatile Compounds, in: Seymour, G.B., Poole, M., Giovannoni, J.J., Tucker, G.A. (Eds.), The Molecular Biology and Biochemistry of Fruit Ripening. Blackwell Publishing Ltd., Oxford, UK, pp. 135-161. https://doi.org/10.1002/9781118593714.ch6

Hagenguth, J., Kanski, L., Kahle, H., Persch, A., Becker, H., Horneburg, B., 2018. The potential of a breeders` sensory test in the F2 generation of tomato, in: XIX EUCARPIA Meeting of the Tomato Working Group - Programme and Abstracts. Naples, Italy, p. 32.

Hajšlová, J., Schulzová, V., Slanina, P., Janné, K., Hellenäs, K.E., Andersson, C., 2005. Quality of organically and conventionally grown potatoes: Four-year study of micronutrients, metals, secondary metabolites, enzymic browning and organoleptic properties. Food Additives and Contaminants 22, 514-534. https://doi.org/10.1080/02652030500137827

Hawkesford, M., Horst, W., Kichey, T., Lambers, H., Schjoerring, J., Møller, I.S., White, P., 2012. Functions of macronutrients, in: Marschner's Mineral Nutrition of Higher Plant. Academic Press, USA.

Hernández Suárez, M., Rodríguez Rodríguez, E.M., Díaz Romero, C., 2007. Mineral and trace element concentrations in cultivars of tomatoes. Food Chemistry 104, 489-499. https://doi.org/10.1016/j.foodchem.2006.11.072

Hernández-Bautista, A., Lobato-Ortiz, R., García-Zavala, J.J., López-Fortoso, F., Cruz-Izquierdo, S., Chávez-Servia, J.L., Cadeza-Espinosa, M., 2016. Quantitative trait locus mapping associated with earliness and fruit weight in tomato. Scientia Agricola 73, 478-486. https://doi.org/10.1590/01039016-2015-0245

Herrero, M., Thornton, P.K., Power, B., Bogard, J.R., Remans, R., Fritz, S., Gerber, J.S., Nelson, G., See, L., Waha, K., Watson, R.A., West, P.C., Samberg, L.H., van de Steeg, J., Stephenson, E., van Wijk, M., Havlík, P., 2017. Farming and the geography of nutrient production for human use: a transdisciplinary analysis. The Lancet Planetary Health 1, e33-e42. https://doi.org/10.1016/S25425196(17)30007-4

Higashide, T., Heuvelink, E., 2009. Physiological and Morphological Changes Over the Past 50 Years in Yield Components in Tomato. J. Amer. Soc. Hort. Sci. 134, 460-465. https://doi.org/10.21273/JASHS.134.4.460

Ho, L.C., 1996. The mechanism of assimilate partitioning and carbohydrate compartmentation in fruit in relation to the quality and yield of tomato. Journal of Experimental Botany 47, 1239-1243.

Horneburg, B., Myers, J., 2012. Tomato: breeding for improved disease resistance in fresh market and home garden varieties, in: Lammerts van Bueren, E.T., Myers, J.R. (Eds.), Organic Crop Breeding. WileyBlackwell, Chichester, West Sussex, Ames, Iowa, pp. 239-249.

Huett, D., Maier, N., Sparrow, L., Piggott, T., 1997. Vegetable crops, in: Reuter, D., Robinson, J., Dutkiewicz, C. (Eds.), Plant Analysis. An Interpretation Manual. CSIRO Pub., Collingwood, VIC, Australia, pp. 383-464.

Ibrahim, M., Helali, M., Alam, A., Talukder, D., Akhter, S., 2017. Physiological and biochemical characteristics of different tomato grown in Rajshahi region of Bangladesh. Bangladesh J. Sci. Ind. Res. 52, 195-200. https://doi.org/10.3329/bjsir.v52i3.34155

Ilahy, R., Tlili, I., Siddiqui, M.W., Hdider, C., Lenucci, M.S., 2019. Inside and Beyond Color: Comparative Overview of Functional Quality of Tomato and Watermelon Fruits. Front. Plant Sci. 10, 769. https://doi.org/10.3389/fpls.2019.00769

Ilic, Z.S., Kapoulas, N., Milenkovic, L., 2013. Micronutrient composition and quality characteristics of tomato (Lycopersicon esculentum) from conventional and organic production. Indian Journal of Agricultural Sciences 6, 651-655.

Ilić, Z.S., Kapoulas, N., Šunić, L., 2014. Tomato fruit quality from organic and conventional production, in: Pilipavicius, V. (Ed.), Organic Agriculture Towards Sustainability. InTech. https://doi.org/10.5772/58239

Institute of Medicine, 2006. DRI, dietary reference intakes: the essential guide to nutrient requirements. National Academies Press, Washington D.C, U.S.

ISO, 2012. ISO 8586:2012: Sensory analysis - General Guidelines for the Selection, Training and Monitoring of Selected Assessors and Expert Sensory Assessors; German Version EN ISO 8586, 2014. Geneva. 
ISO, 2007. ISO 8589:2007 + A1:2014: Sensory analysis - General guidance for the design of test rooms; German version EN ISO 8589:2010 + A1:2014. Geneva.

Järvan, M., Edesi, L., 2009. The effect of cultivation methods on the yield and biological quality of potato. Agronomy Research 7, 289-299.

Jha, A.B., Warkentin, T.D., 2020. Biofortification of Pulse Crops: Status and Future Perspectives. Plants 9, 73. https://doi.org/10.3390/plants9010073

Johansson, E., Hussain, A., Kuktaite, R., Andersson, S., Olsson, M., 2014. Contribution of organically grown crops to human health. International Journal of Environmental Research and Public Health 11, 38703893. https://doi.org/10.3390/ijerph110403870

Jones, J., 1999. Tomato plant culture. In the field, greenhouse, and home garden. CRC Press, Boca Raton, London.

Kagan-Zur, V., Mizrahi, Y., 1993. Long shelf-life small sized (cocktail) tomatoes may be picked in bunches. Scientia Horticulturae 56, 31-41. https://doi.org/10.1016/0304-4238(93)90099-C

Kanski, L., Naumann, M., Pawelzik, E., 2020. Flavor-Related Quality Attributes of Ripe Tomatoes Are Not Significantly Affected Under Two Common Household Conditions. Front. Plant Sci. 11, 472. https://doi.org/10.3389/fpls.2020.00472

Kapoulas, N., Ilić, Z.S., Milenković, L., Mirecki, N., 2013. Effects of organic and conventional cultivation methods on mineral content and taste parameters intomato fruit. Agriculture \& Forestry 59, 23-34.

Kashinath, B.L., Murthy, A.N.G., Senthivel, T., Pitchai, G.J., Sadashiva, A.T., 2013. Effect of applied magnesium on yield and quality of tomato in Alfisols of Karnataka 8, 5.

Kibria, M., Islam, M., Alamgir, M., 2016. Yield and nutritional quality of tomato as affected by chemical fertilizer and biogas plant residues. International Journal of Plant \& Soil Science 13, 1-10. https://doi.org/10.9734/IJPSS/2016/29434

Kimbara, J., Ohyama, A., Chikano, H., Ito, H., Hosoi, K., Negoro, S., Miyatake, K., Yamaguchi, H., Nunome, T., Fukuoka, H., Hayashi, T., 2018. QTL mapping of fruit nutritional and flavor components in tomato (Solanum lycopersicum) using genome-wide SSR markers and recombinant inbred lines (RILs) from an intra-specific cross. Euphytica 214, 2-12. https://doi.org/10.1007/s10681-018-2295-z

Kirkby, E., 2012. Introduction, definition and classification of nutrients, in: Marschner's Mineral Nutrition of Higher Plant. Academic Press, USA.

Klee, H.J., 2010. Improving the flavor of fresh fruits: genomics, biochemistry, and biotechnology: Tansley review. New Phytologist 187, 44-56. https://doi.org/10.1111/j.1469-8137.2010.03281.x

Klee, H.J., Giovannoni, J.J., 2011. Genetics and control of tomato fruit ripening and quality attributes. Annual Review of Genetics 45, 41-59. https://doi.org/10.1146/annurev-genet-110410-132507

Klee, H.J., Tieman, D.M., 2018. The genetics of fruit flavour preferences 10.

Klee, H.J., Tieman, D.M., 2013. Genetic challenges of flavor improvement in tomato. Trends in Genetics 29, 257-262. https://doi.org/10.1016/j.tig.2012.12.003

Koch, M., Busse, M., Naumann, M., Jákli, B., Smit, I., Cakmak, I., Hermans, C., Pawelzik, E., 2019. Differential effects of varied potassium and magnesium nutrition on production and partitioning of photoassimilates in potato plants. Physiol Plantarum 166, 921-935. https://doi.org/10.1111/ppl.12846

Kreissl, J., Schieberle, P., 2017. Characterization of aroma-active compounds in Italian tomatoes with emphasis on new odorants. Journal of Agricultural Food Chemistry 65, 5198-5208. https://doi.org/10.1021/acs.jafc.7b01108

Kwabena Osei, M., Annor, B., Adjebeng- Danquah, J., Danquah, A., Danquah, E., Blay, E., Adu-Dapaah, H., 2019. Genotype $\times$ Environment Interaction: A Prerequisite for Tomato Variety Development, in: Tatu Nyaku, S., Danquah, A. (Eds.), Recent Advances in Tomato Breeding and Production. IntechOpen. https://doi.org/10.5772/intechopen.76011

Labate, J.A., Breksa, A.P., Robertson, L.D., King, B.A., King, D.E., 2018. Genetic differences in macroelement mineral concentrations among 52 historically important tomato varieties. Plant Genetic Resources: Characterization and Utilization 16, 343-351. https://doi.org/10.1017/S1479262117000417

Lammerts van Bueren, E.T., Jones, S.S., Tamm, L., Murphy, K.M., Myers, J.R., Leifert, C., Messmer, M.M., 2011. The need to breed crop varieties suitable for organic farming, using wheat, tomato and broccoli as examples: A review. NJAS - Wageningen Journal of Life Sciences 58, 193-205. https://doi.org/10.1016/j.njas.2010.04.001 
Lázaro, A., 2018. Tomato landraces: an analysis of diversity and preferences. Plant Genet. Resour. 16, $315-$ 324. https://doi.org/10.1017/S1479262117000351

Lehesranta, S.J., Koistinen, K.M., Massat, N., Davies, H.V., Shepherd, L.V.T., McNicol, J.W., Cakmak, I., Cooper, J., Lück, L., Kärenlampi, S.O., Leifert, C., 2007. Effects of agricultural production systems and their components on protein profiles of potato tubers. PROTEOMICS 7, 597-604. https://doi.org/10.1002/pmic.200600889

Lewinsohn, E., Sitrit, Y., Bar, E., Azulay, Y., Meir, A., Zamir, D., Tadmor, Y., 2005. Carotenoid Pigmentation Affects the Volatile Composition of Tomato and Watermelon Fruits, As Revealed by Comparative Genetic Analyses. Journal of Agricultural and Food Chemistry 53, 3142-3148. https://doi.org/10.1021/jf047927t

Li, H., Lian, C., Zhang, Z., Shi, X., Zhang, Y., 2017. Agro-Biofortification of Iron and Zinc in Edible Portion of Crops for the Global South. Adv Plants Agric Res 6, 52-54. https://doi.org/10.15406/apar.2017.06.00210

Liabeuf, D., Francis, D.M., 2017. The use of historical datasets to develop multi-trait selection models in processing tomato. Euphytica 213, 100. https://doi.org/10.1007/s10681-017-1876-6

Lin, T., Zhu, G., Zhang, J., Xu, X., Yu, Q., Zheng, Z., Zhang, Z., Lun, Y., Li, S., Wang, X., Huang, Z., Li, Junming, Zhang, C., Wang, T., Zhang, Yuyang, Wang, A., Zhang, Yancong, Lin, K., Li, C., Xiong, G., Xue, Y., Mazzucato, A., Causse, M., Fei, Z., Giovannoni, J.J., Chetelat, R.T., Zamir, D., Städler, T., Li, Jingfu, Ye, Z., Du, Y., Huang, S., 2014. Genomic analyses provide insights into the history of tomato breeding. Nat Genet 46, 1220-1226. https://doi.org/10.1038/ng.3117

Liu, T., Zhu, W., Huang, J., Chen, H., Nie, R., Li, C., 2017. Comparison of the nutritional as well as the volatile composition of in-season and off-season Hezuo 903 tomato at red stage. Eur Food Res Technol 243, 203-214. https://doi.org/10.1007/s00217-016-2736-7

Lubes, G., Goodarzi, M., 2017. Analysis of volatile compounds by advanced analytical techniques and multivariate chemometrics. Chemical Reviews 117, 6399-6422.

https://doi.org/10.1021/acs.chemrev.6b00698

Marles, R.J., 2017. Mineral nutrient composition of vegetables, fruits and grains: The context of reports of apparent historical declines. Journal of Food Composition and Analysis 56, 93-103. https://doi.org/10.1016/j.jfca.2016.11.012

Martin, A.R., Cadotte, M.W., Isaac, M.E., Milla, R., Vile, D., Violle, C., 2019. Regional and global shifts in crop diversity through the Anthropocene. PLoS ONE 14, e0209788. https://doi.org/10.1371/journal.pone.0209788

Martínez-Valverde, I., Periago, M.J., Provan, G., Chesson, A., 2002. Phenolic compounds, lycopene and antioxidant activity in commercial varieties of tomato ( Lycopersicum esculentum ): Phenolics, lycopene and antioxidant activity in tomatoes. Journal of the Science of Food and Agriculture 82, 323-330. https://doi.org/10.1002/jsfa.1035

Mata-Nicolás, E., Montero-Pau, J., Gimeno-Paez, E., Garcia-Carpintero, V., Ziarsolo, P., Menda, N., Mueller, L.A., Blanca, J., Cañizares, J., van der Knaap, E., Díez, M.J., 2020. Exploiting the diversity of tomato: the development of a phenotypically and genetically detailed germplasm collection. Hortic Res 7, 66. https://doi.org/10.1038/s41438-020-0291-7

Maul, F., Sargent, S.A., Sims, C.A., Baldwin, E.A., Balaban, M.O., Huber, D.J., 2000. Tomato Flavor and Aroma Quality as Affected by Storage Temperature. Journal of Food Science 65, 1228-1237. https://doi.org/10.1111/j.1365-2621.2000.tb10270.x

Mayer, A., 1997. Historical changes in the mineral content of fruits and vegetables. British Food Journal 99, 207-211. https://doi.org/10.1108/00070709710181540

Miller, B.D.D., Welch, R.M., 2013. Food system strategies for preventing micronutrient malnutrition. Food Policy 42, 115-128. https://doi.org/10.1016/j.foodpol.2013.06.008

Mohammed, A.E., Smit, I., Pawelzik, E., Keutgen, A.J., Horneburg, B., 2019. Organically grown outdoor tomato: fruit mineral nutrients and plant infection by Phytophthora infestans. Org. Agr. https://doi.org/10.1007/s13165-019-00253-7

Mohammed, A.E., Smit, I., Pawelzik, E., Keutgen, A.J., Horneburg, B., 2012. Organically grown tomato ( Lycopersicon esculentum Mill.): bioactive compounds in the fruit and infection with Phytophthora infestans: Bioactive compounds in organic tomato fruits. J. Sci. Food Agric. 92, 1424-1431. https://doi.org/10.1002/jsfa.4720

Moreira-Ascarrunz, S., Larsson, H., Prieto-Linde, M., Johansson, E., 2016. Mineral Nutritional Yield and Nutrient Density of Locally Adapted Wheat Genotypes under Organic Production. Foods 5, 1-18. https://doi.org/10.3390/foods5040089 
Murphy, S.P., Poos, M.I., 2002. Dietary reference intakes: summary of applications in dietary assessment. Public Health Nutrition 5, 843-849. https://doi.org/10.1079/PHN2002389

Naika, S., van Lidt de Jeude, J., de Goffau, M., Hilmi, M., van Dam, B., 2005. Cultivation of tomato. Digigrafi, Wageningen, Netherlands.

NIH, 2018. Nutrient recommendations : Dietary Reference Intakes (DRI) [WWW Document]. National Institutes of Health, Office of Dietary Supplements. URL https://ods.od.nih.gov/Health_Information/Dietary_Reference_Intakes.aspx (accessed 8.20.18).

Ogunniyan, D.J., Olakojo, S.A., 2014. Genetic variation, heritability, genetic advance and agronomic character association of yellow elite inbred lines of maize (Zea mays L.). Nigerian Journal of Genetics 28, 24-28. https://doi.org/10.1016/j.nigjg.2015.06.005

Olbricht, K., Grafe, C., Weiss, K., Ulrich, D., 2007. Inheritance of aroma compounds in a model population of Fragaria $\times$ ananassa Duch. Plant Breeding 127, 87-93. https://doi.org/10.1111/j.14390523.2007.01422.x

Oltman, A.E., Jervis, S.M., Drake, M.A., 2014. Consumer attitudes and preferences for fresh market tomatoes. Journal of Food Science 79, S2091-S2097. https://doi.org/10.1111/1750-3841.12638

Ordóñez-Santos, L.E., Vázquez-Odériz, M.L., Romero-Rodríguez, M.A., 2011. Micronutrient contents in organic and conventional tomatoes (Solanum lycopersicum L.): Micronutrient contents of tomato. International Journal of Food Science \& Technology 46, 1561-1568. https://doi.org/10.1111/j.13652621.2011.02648.x

Pagliarini, E., Monteleone, E., Ratti, S., 2001. Sensory profile of eight tomato cultivars (lycopersicon esculentum) and its relationship to consumer preference. Italian Journal of Food Science 13, 285296.

Panthee, D.R., Cao, C., Debenport, S.J., Rodríguez, G.R., Labate, J.A., Robertson, L.D., Breksa, A.P., van der Knaap, E., McSpadden Gardener, B.B., 2012. Magnitude of Genotype $\times$ Environment Interactions Affecting Tomato Fruit Quality. horts 47, 721-726. https://doi.org/10.21273/HORTSCI.47.6.721

Paolo, D., Bianchi, G., Scalzo, R.L., Morelli, C.F., Rabuffetti, M., Speranza, G., 2018. The Chemistry behind Tomato Quality. Natural Product Communications 13, 1934578X1801300. https://doi.org/10.1177/1934578X1801300927

Pavithra, G.J., Salimath, M., Geetha, K.N., Shankar, A.G., 2015. Genetic variability studies in tomato germplasm for zinc and iron content and its relationship with growth and yield parameters. Eco. Env. \& Cons 21, AS355-AS360.

Pélabon, C., Hilde, C.H., Einum, S., Gamelon, M., 2020. On the use of the coefficient of variation to quantify and compare trait variation. Evolution Letters 4, 180-188. https://doi.org/10.1002/evl3.171

Pesaresi, P., Mizzotti, C., Colombo, M., Masiero, S., 2014. Genetic regulation and structural changes during tomato fruit development and ripening. Front. Plant Sci. 5. https://doi.org/10.3389/fpls.2014.00124

Petro-Turza, M., 1986. Flavor of tomato and tomato products. Food Reviews International 2, 309-351. https://doi.org/10.1080/87559128609540802

Piombino, P., Sinesio, F., Moneta, E., Cammareri, M., Genovese, A., Lisanti, M.T., Mogno, M.R., Peparaio, M., Termolino, P., Moio, L., Grandillo, S., 2013. Investigating physicochemical, volatile and sensory parameters playing a positive or a negative role on tomato liking. Food Research International 50, 409-419. https://doi.org/10.1016/j.foodres.2012.10.033

Powell, B., Thilsted, S.H., Ickowitz, A., Termote, C., Sunderland, T., Herforth, A., 2015. Improving diets with wild and cultivated biodiversity from across the landscape. Food Sec. 7, 535-554. https://doi.org/10.1007/s12571-015-0466-5

Pretty, J., Bharucha, Z.P., 2014. Sustainable intensification in agricultural systems. Annals of Botany 114, 1571-1596. https://doi.org/10.1093/aob/mcu205

Prudent, M., Causse, M., Génard, M., Tripodi, P., Grandillo, S., Bertin, N., 2009. Genetic and physiological analysis of tomato fruit weight and composition: influence of carbon availability on QTL detection. Journal of Experimental Botany 60, 923-937. https://doi.org/10.1093/jxb/ern338

Quinet, M., Angosto, T., Yuste-Lisbona, F.J., Blanchard-Gros, R., Bigot, S., Martinez, J.-P., Lutts, S., 2019. Tomato Fruit Development and Metabolism. Front. Plant Sci. 10, 1554. https://doi.org/10.3389/fpls.2019.01554

Raigón, M.D., Rodríguez-Burruezo, A., Prohens, J., 2010. Effects of Organic and Conventional Cultivation Methods on Composition of Eggplant Fruits. J. Agric. Food Chem. 58, 6833-6840.

https://doi.org/10.1021/jf904438n 
Raklami, A., Bechtaoui, N., Tahiri, A., Anli, M., Meddich, A., Oufdou, K., 2019. Use of Rhizobacteria and Mycorrhizae Consortium in the Open Field as a Strategy for Improving Crop Nutrition, Productivity and Soil Fertility. Front. Microbiol. 10, 1106. https://doi.org/10.3389/fmicb.2019.01106

Rambla, J.L., Tikunov, Y.M., Monforte, A.J., Bovy, A.G., Granell, A., 2013. The expanded tomato fruit volatile landscape. Journal of Experimental Botany 65, 4613-4623. https://doi.org/10.1093/jxb/eru128

Rauber, R., Schmidtke, K., Kimpel-Freund, H., 2001. The performance of pea (Pisum sativum L.) and its role in determining yield advantages in mixed stands of pea and oat (Avena sativa L.). Journal of Agronomy and Crop Science 187, 137-144. https://doi.org/10.1046/j.1439-037X.2001.00508.x

Reganold, J.P., Wachter, J.M., 2016. Organic agriculture in the twenty-first century. Nature Plants 2. https://doi.org/10.1038/nplants.2015.221

Ridoutt, B.G., Hendrie, G.A., Noakes, M., 2017. Dietary Strategies to Reduce Environmental Impact: A Critical Review of the Evidence Base. Adv Nutr 8, 933-946. https://doi.org/10.3945/an.117.016691

Rocha, M. de C., Deliza, R., Corrêa, F.M., Carmo, M.G.F. do, Abboud, A.C.S., 2013. A study to guide breeding of new cultivars of organic cherry tomato following a consumer-driven approach. Food Research International 51, 265-273. https://doi.org/10.1016/j.foodres.2012.12.019

Rosa, A.J.S., Sala, F.C., Cardoso, J.C., 2019. Performance and selection of tomato cultivars for organic cultivation in greenhouse. Rev. Ceres 66, 94-101. https://doi.org/10.1590/0034-737x201966020003

Rosanoff, A., 2012. Changing crop magnesium concentrations: impact on human health. Plant Soil 368, 139-153. https://doi.org/10.1007/s11104-012-1471-5

Sager, M., 2017. Main and trace element contents of tomatoes grown in Austria. Journal of Food Science and Engineering 7, 239-248. https://doi.org/10.17265/2159-5828/2017.05.002

Sainju, U.M., Dris, R., Singh, B., 2003. Mineral nutrition of tomato 9.

Saliba-Colombani, V., Causse, M., Langlois, D., Philouze, J., Buret, M., 2001. Genetic analysis of organoleptic quality in fresh market tomato. 1. Mapping QTLs for physical and chemical traits: Theoretical and Applied Genetics 102, 259-272. https://doi.org/10.1007/s001220051643

Santos Neto, J. dos, Schwan-Estrada, K.R.F., Sena, J.O.A. de, Telles, T.S., 2017. Economic viability of tomato cultivation in organic farming system. Brazilian Archives of Biology and Technology 60. https://doi.org/10.1590/1678-4324-2017161229

Sauer, A.K., Hagmeyer, S., Grabrucker, A.M., 2016. Zinc deficiency, in: Erkekoglu, P., Kocer-Gumusel, B. (Eds.), Nutritional Deficiency. InTech. https://doi.org/10.5772/63203

Schouten, H.J., Tikunov, Y., Verkerke, W., Finkers, R., Bovy, A., Bai, Y., Visser, R.G.F., 2019. Breeding Has Increased the Diversity of Cultivated Tomato in The Netherlands. Front. Plant Sci. 10, 1606. https://doi.org/10.3389/fpls.2019.01606

Schrama, M., de Haan, J.J., Kroonen, M., Verstegen, H., Van der Putten, W.H., 2018. Crop yield gap and stability in organic and conventional farming systems. Agriculture, Ecosystems \& Environment 256, 123-130. https://doi.org/10.1016/j.agee.2017.12.023

Scott, J.W., Myers, J.R., Boches, P.S., Nichols, C.G., Angell, F.F., 2013. Classical genetics and traditional breeding, in: Genetics, Genomics and Breeding of Tomato. Genetics, Genomics and Breeding of Crop Plants. CRC Press, Boca Raton.

Selli, S., Kelebek, H., Ayseli, M.T., Tokbas, H., 2014. Characterization of the most aroma-active compounds in cherry tomato by application of the aroma extract dilution analysis. Food Chemistry 165, 540 546. https://doi.org/10.1016/j.foodchem.2014.05.147

Sinesio, F., Cammareri, M., Moneta, E., Navez, B., Peparaio, M., Causse, M., Grandillo, S., 2010. Sensory quality of fresh French and Dutch market tomatoes: a preference mapping study with Italian consumers. Journal of Food Science 75, S55-S67. https://doi.org/10.1111/j.1750-3841.2009.01424.x

Slimestad, R., Verheul, M., 2009. Review of flavonoids and other phenolics from fruits of different tomato (Lycopersicon esculentum Mill.) cultivars. J Sci Food Agric 16.

Springmann, M., Clark, M., Mason-D’Croz, D., Wiebe, K., Bodirsky, B.L., Lassaletta, L., de Vries, W., Vermeulen, S.J., Herrero, M., Carlson, K.M., Jonell, M., Troell, M., DeClerck, F., Gordon, L.J., Zurayk, R., Scarborough, P., Rayner, M., Loken, B., Fanzo, J., Godfray, H.C.J., Tilman, D., Rockström, J., Willett, W., 2018. Options for keeping the food system within environmental limits. Nature 562, 519-525. https://doi.org/10.1038/s41586-018-0594-0

Ssemakula, G., Dixon, A., 2007. Genotype X environment interaction, stability and agronomic performance of carotenoid-rich cassava clones. Scientific Research and Essay 2, 390-399.

Statistischen Bundesamt, 2020. Betriebe, Anbauflächen, Erträge und Erntemengen von Gemüse [WWW Document]. Statistisches Bundesamt. URL https://www.destatis.de/DE/Themen/Branchen- 
Unternehmen/Landwirtschaft-Forstwirtschaft-Fischerei/Obst-Gemuese-Gartenbau/Tabellen/betriebeanbau-erntemenge-gemuese.html (accessed 5.7.20).

Stewart, A.J., Bozonnet, S., Mullen, W., Jenkins, G.I., Lean, M.E.J., Crozier, A., 2000. Occurrence of flavonols in tomatoes and tomato-based products. J. Agric. Food Chem. 48, 2663-2669. https://doi.org/DOI: 10.1021/jf000070p

Stolz, H., Stolze, M., Hamm, U., Janssen, M., Ruto, E., 2011. Consumer attitudes towards organic versus conventional food with specific quality attributes. NJAS - Wageningen Journal of Life Sciences 58, 67-72. https://doi.org/10.1016/j.njas.2010.10.002

Ströhle, A., Richter, M., González-Gross, M., Neuhäuser-Berthold, M., Wagner, K.-H., Leschik-Bonnet, E., Egert, S., 2019. The Revised D-A-CH-Reference Values for the Intake of Vitamin B12: Prevention of Deficiency and Beyond. Molecular Nutrition \& Food Research 63, 1801178. https://doi.org/10.1002/mnfr.201801178

Tandon, K.S., Baldwin, E.A., Shewfelt, R.L., 2000. Aroma perception of individual volatile compounds in fresh tomatoes (Lycopersicon esculentum, Mill.) as affected by the medium of evaluation. Postharvest Biology and Technology 20, 261-268. https://doi.org/10.1016/S0925-5214(00)00143-5

Tanksley, S.D., 2004. The genetic, developmental, and molecular bases of fruit size and shape variation in tomato. The Plant Cell 16, S181-S189. https://doi.org/10.1105/tpc.018119

Tester, M., Langridge, P., 2010. Breeding technologies to increase crop production in a changing world. Science 327 (5967), 818-822. https://doi.org/10.1126/science.1183700

Tieman, D., Bliss, P., McIntyre, L.M., Blandon-Ubeda, A., Bies, D., Odabasi, A.Z., Rodríguez, G.R., van der Knaap, E., Taylor, M.G., Goulet, C., Mageroy, M.H., Snyder, D.J., Colquhoun, T., Moskowitz, H., Clark, D.G., Sims, C., Bartoshuk, L., Klee, H.J., 2012. The chemical interactions underlying tomato flavor preferences. Current Biology 22, 1035-1039.

https://doi.org/10.1016/j.cub.2012.04.016

Tieman, D., Taylor, M., Schauer, N., Fernie, A.R., Hanson, A.D., Klee, H.J., 2006. Tomato aromatic amino acid decarboxylases participate in synthesis of the flavor volatiles 2-phenylethanol and 2phenylacetaldehyde. Proceedings of the National Academy of Sciences 103, 8287-8292. https://doi.org/10.1073/pnas.0602469103

Tieman, D., Zhu, G., Resende, M.F.R., Lin, T., Nguyen, C., Bies, D., Rambla, J.L., Beltran, K.S.O., Taylor, M., Zhang, B., Ikeda, H., Liu, Z., Fisher, J., Zemach, I., Monforte, A., Zamir, D., Granell, A., Kirst, M., Huang, S., Klee, H., 2017. A chemical genetic roadmap to improved tomato flavor. Science 355, 391-394. https://doi.org/10.1126/science.aal1556

Tikunov, Y., 2005. A Novel Approach for Nontargeted Data Analysis for Metabolomics. Large-Scale Profiling of Tomato Fruit Volatiles. PLANT PHYSIOLOGY 139, 1125-1137. https://doi.org/10.1104/pp.105.068130

Toor, R.K., Savage, G.P., 2005. Antioxidant activity in different fractions of tomatoes. Food Research International 38, 487-494. https://doi.org/10.1016/j.foodres.2004.10.016

Uluisik, S., Chapman, N.H., Smith, R., Poole, M., Adams, G., Gillis, R.B., Besong, T.M.D., Sheldon, J., Stiegelmeyer, S., Perez, L., Samsulrizal, N., Wang, D., Fisk, I.D., Yang, N., Baxter, C., Rickett, D., Fray, R., Blanco-Ulate, B., Powell, A.L.T., Harding, S.E., Craigon, J., Rose, J.K.C., Fich, E.A., Sun, L., Domozych, D.S., Fraser, P.D., Tucker, G.A., Grierson, D., Seymour, G.B., 2016. Genetic improvement of tomato by targeted control of fruit softening. Nature Biotechnology 34, 950-952. https://doi.org/10.1038/nbt.3602

Ursem, R., Tikunov, Y., Bovy, A., van Berloo, R., van Eeuwijk, F., 2008. A correlation network approach to metabolic data analysis for tomato fruits. Euphytica 161, 81-193. https://doi.org/DOI 10.1007/s10681-008-9672-y

Van der Ploeg, A., Heuvelink, E., 2005. Influence of sub-optimal temperature on tomato growth and yield: a review. The Journal of Horticultural Science and Biotechnology 80, 652-659. https://doi.org/10.1080/14620316.2005.11511994

van der Ploeg, A., van der Meer, M., Heuvelink, E., 2007. Breeding for a more energy efficient greenhouse tomato: past and future perspectives. Euphytica 158, 129-138. https://doi.org/10.1007/s10681-0079437-z

van Heusden, S., Lindhout, P., 2018. Genetics and breeding, in: Tomatoes: Crop Production Science in Horticulture, 2nd Ed. CAB International, Wallingford, pp. 27-56.

Vicente, A., Manganaris, G., Sozzi, G., Crisosto, C., 2009. Nutritional quality of fruits and vegetables, in: Florkowski, W.J., Shewfelt, R., Brueckner, B., Prussia, S. (Eds.), Postharvest Handling: A Systems Approach, Food Science and Technology. Academic Press, Burlington, MA. 
Vilgis, T.A., 2013. Texture, taste and aroma: multi-scale materials and the gastrophysics of food. Flavour 2, 12. https://doi.org/10.1186/2044-7248-2-12

Vincente, A.R., Manganaris, G.A., Ortiz, C.M., Sozzi, G.O., Crisosto, C.H., 2014. Nutritional quality of fruits and vegetables, in: Postharvest Handling. Elsevier Inc., California, USA, pp. 69-122. https://doi.org/10.1016/B978-0-12-408137-6.00005-3

Vinson, J.A., Hao, Y., Su, X., Zubik, L., 1998. Phenol antioxidant quantity and quality in foods: vegetables. Journal of Agricultural and Food Chemistry 46, 3630-3634. https://doi.org/10.1021/jf980295o

Viskelis, P., Radzevicius, A., Urbonaviciene, D., Viskelis, J., Karkleliene, R., Bobinas, C., 2015. Biochemical Parameters in Tomato Fruits from Different Cultivars as Functional Foods for Agricultural, Industrial, and Pharmaceutical Uses, in: El-Shemy, H. (Ed.), Plants for the Future. InTech, pp. 45-77. https://doi.org/10.5772/60873

Vogel, J.T., Tieman, D.M., Sims, C.A., Odabasi, A.Z., Clark, D.G., Klee, H.J., 2010. Carotenoid content impacts flavor acceptability in tomato (Solanum lycopersicum). Journal of the Science of Food and Agriculture 90, 2233-2240. https://doi.org/10.1002/jsfa.4076

Vorland, C.J., Stremke, E.R., Moorthi, R.N., Hill Gallant, K.M., 2017. Effects of Excessive Dietary Phosphorus Intake on Bone Health. Curr Osteoporos Rep 15, 473-482. https://doi.org/10.1007/s11914-017-0398-4

Waldron, K.W., Parker, M.L., Smith, A.C., 2003. Plant Cell Walls and Food Quality. Comp Rev Food Sci Food Safety 2, 128-146. https://doi.org/10.1111/j.1541-4337.2003.tb00019.x

Wang, D., Seymour, G.B., 2017. Tomato flavor: lost and found? Molecular Plant 10, 782-784. https://doi.org/10.1016/j.molp.2017.04.010

Wang, Li-bin, Bai, J., Yu, Z., 2016. Difference in volatile profile between pericarp tissue and locular gel in tomato fruit. Journal of Integrative Agriculture 15, 2911-2920. https://doi.org/10.1016/S20953119(15)61324-7

Wang, Libin, Baldwin, E.A., Bai, J., 2016. Recent advance in aromatic volatile research in tomato fruit: the metabolisms and regulations. Food and Bioprocess Technology 9, 203-216. https://doi.org/10.1007/s11947-015-1638-1

Wang, Z., Hassan, M.U., Nadeem, F., Wu, L., Zhang, F., Li, X., 2020. Magnesium Fertilization Improves Crop Yield in Most Production Systems: A Meta-Analysis. Front. Plant Sci. 10, 1727. https://doi.org/10.3389/fpls.2019.01727

Weih, M., Hamnér, K., Pourazari, F., 2018. Analyzing plant nutrient uptake and utilization efficiencies: comparison between crops and approaches. Plant Soil 430, 7-21. https://doi.org/10.1007/s11104018-3738-y

Welch, R., 2002. The impact of mineral nutrients in food crops on global human health, in: Horst, W.J., Bürkert, A., Claassen, N., Flessa, H., Frommer, W.B., Goldbach, H., Merbach, W., Olfs, H.-W., Römheld, V., Sattelmacher, B., Schmidhalter, U., Schenk, M.K., v. Wirén, N. (Eds.), Progress in Plant Nutrition: Plenary Lectures of the XIV International Plant Nutrition Colloquium. Springer Netherlands, Dordrecht, pp. 83-90. https://doi.org/10.1007/978-94-017-2789-1_6

White, P., Broadley, M., 2005. Biofortifying crops with essential mineral elements. Trends in Plant Science 10, 586-593. https://doi.org/10.1016/j.tplants.2005.10.001

Wieringa, F., Dijkhuizen, M., Fiorentino, M., Laillou, A., Berger, J., 2015. Determination of zinc status in humans: which indicator should we use? Nutrients 7, 3252-3263. https://doi.org/10.3390/nu7053252

Willcox, J.K., Catignani, G.L., Lazarus, S., 2003. Tomatoes and cardiovascular health. Critical Reviews in Food Science and Nutrition 43, 1-18. https://doi.org/10.1080/10408690390826437

Willer, E.H., Lernoud, J., 2019. The world of organic agriculture - statistics and emerging trends 2019 (FiBL-IFOAM). Frick, Switzerland.

Williamson, G., Holst, B., 2008. Dietary reference intake (DRI) value for dietary polyphenols: are we heading in the right direction? British Journal of Nutrition 99, S55-S58. https://doi.org/10.1017/S0007114508006867

Yilmaz, E., 2001. The chemistry of fresh tomato flavor. Turkish Journal of Agriculture and Forestry 25, 149-155.

Zanor, M.I., Rambla, J.-L., Chaïb, J., Steppa, A., Medina, A., Granell, A., Fernie, A.R., Causse, M., 2009. Metabolic characterization of loci affecting sensory attributes in tomato allows an assessment of the influence of the levels of primary metabolites and volatile organic contents. Journal of Experimental Botany 60, 2139-2154. https://doi.org/10.1093/jxb/erp086

Zörb, C., Piepho, H.-P., Zikeli, S., Horneburg, B., 2020. Heritability and Variability of Quality Parameters of Tomatoes in Outdoor Production. Research 2020, 1-9. https://doi.org/10.34133/2020/6707529 


\section{Supplementary materials}

Table S1. Soil available nitrogen $\left(\mathrm{kg} \mathrm{ha}^{-1} 0-30 \mathrm{~cm}\right)$ of the experiment sites in 2015 and 2016

\begin{tabular}{lcc}
\hline & 2015 & 2016 \\
\hline Beginning of season $^{1}$ & 111.5 & 37.2 \\
Mid-season $^{2}$ & 23.5 & 28.5 \\
End of season $^{3}$ & 7.0 & 19.4 \\
\hline
\end{tabular}

${ }^{1}$ Jun $2^{\text {nd }}, 2015$ and May $20^{\text {th }}, 2016$

${ }^{2}$ September $1^{\text {st }}, 2015$ and August $2^{\text {nd }}, 2016$

${ }^{3}$ October $12^{\text {th }}, 2015$ and October $13^{\text {th }}, 2016$

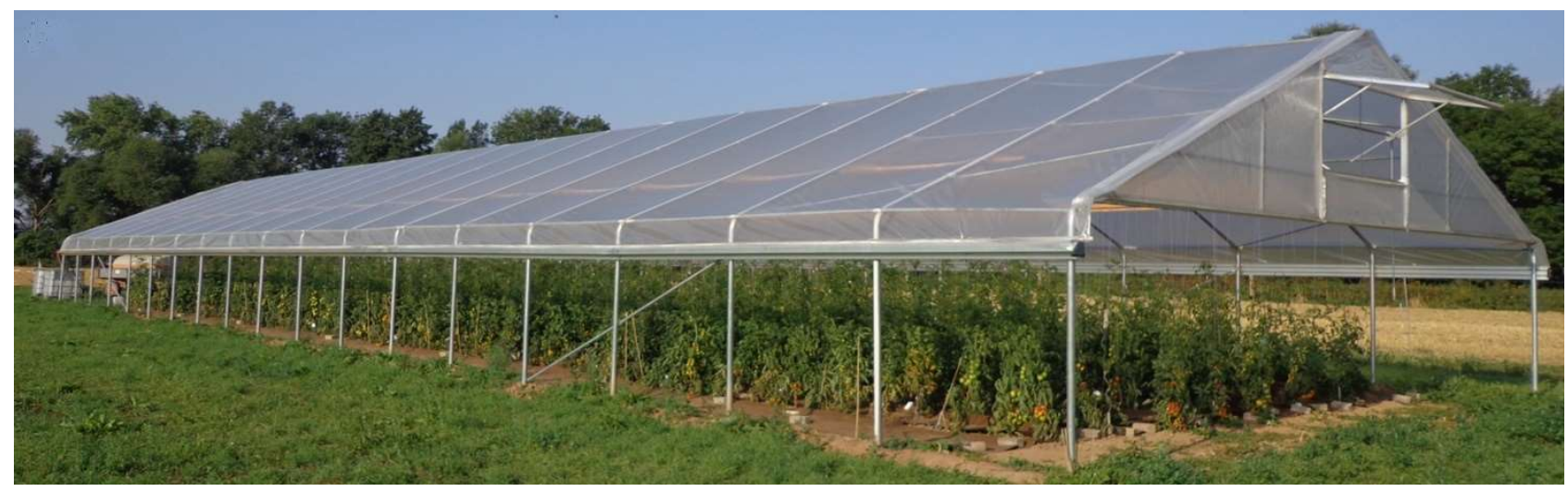

Fig. S1. Organic low-input tomato production under a rainout shelter

Table S2. Year of release, breeding background, average fruit weight, and suitable production system of 60 tomato cultivars used in Germany, Switzerland, and Austria

\begin{tabular}{|c|c|c|c|c|c|}
\hline Cultivar name & $\begin{array}{l}\text { Year of } \\
\text { release }\end{array}$ & Breeder & $\begin{array}{c}\text { Breeding } \\
\text { background a }\end{array}$ & $\begin{array}{c}\text { Fruit } \\
\text { weight }^{\mathrm{b}}(\mathrm{g})\end{array}$ & $\begin{array}{c}\text { Production } \\
\text { systems }\end{array}$ \\
\hline \multicolumn{6}{|c|}{ Salad cultivars (>52g fruit $\left.^{-1}\right)$} \\
\hline Previa $F_{1}$ & $2011^{2}$ & Gautier & $\mathrm{CON}$ & 173.1 & $\mathrm{a}, \mathrm{c}$ \\
\hline Garance $F_{1}$ & $2015^{2}$ & Agri Obtentions & $\mathrm{CON}$ & 154.5 & $\mathrm{e}$ \\
\hline Green Zebra & $1972^{3}$ & Wagner & ORG & 153.0 & $\mathrm{c}$ \\
\hline Diplom $F_{1}$ & $1989^{4}$ & Hild & $\mathrm{CON}$ & 136.8 & $\mathrm{~b}$ \\
\hline Cappricia $\mathrm{F}_{1}$ & $2009^{2}$ & Rijk Zwaan & $\mathrm{CON}$ & 131.5 & $\mathrm{~g}$ \\
\hline Rougella $F_{1}$ & $1999^{2}$ & Rijk Zwaan & $\mathrm{CON}$ & 126.4 & $\mathrm{c}$ \\
\hline Sparta $\mathrm{F}_{1}$ & $1994^{5}$ & Enza & $\mathrm{CON}$ & 125.8 & $\mathrm{e}$ \\
\hline Bocati $F_{1}$ & $2011^{2}$ & Enza & $\mathrm{CON}$ & 124.4 & $\mathrm{c}, \mathrm{d}$ \\
\hline Phantasia $F_{1}$ & $2006^{2}$ & De Ruiter & $\mathrm{CON}$ & 122.7 & $a, b$ \\
\hline Mecano $\mathrm{F}_{1}$ & $2004^{2}$ & Rijk Zwaan & $\mathrm{CON}$ & 122.2 & $e, g$ \\
\hline Hamlet $F_{1}$ & $2009^{2}$ & Nunhems & $\mathrm{CON}$ & 120.4 & $\mathrm{~d}$ \\
\hline Lyterno $\mathrm{F}_{1}$ & $2010^{2}$ & Rijk Zwaan & $\mathrm{CON}$ & 115.9 & $e, f, g$ \\
\hline Nordica $F_{1}$ & $2014^{2}$ & Enza & $\mathrm{CON}$ & 115.5 & $\mathrm{c}, \mathrm{d}, \mathrm{e}$ \\
\hline Moneymaker & $1972^{2}$ & Hild & $\mathrm{CON}$ & 113.8 & $a, c$ \\
\hline Pannovy $F_{1}$ & $1991^{5}$ & Syngenta & $\mathrm{CON}$ & 107.6 & $\mathrm{c}, \mathrm{e}$ \\
\hline Roterno $\mathrm{F}_{1}$ & $2007^{2}$ & Rijk Zwaan & $\mathrm{CON}$ & 106.7 & $\mathrm{~d}, \mathrm{e}, \mathrm{f}$ \\
\hline Hildares $F_{1}$ & $1978^{2}$ & Hild & $\mathrm{CON}$ & 99.0 & $\mathrm{~b}$ \\
\hline Bonner Beste & $1955^{4}$ & Reinhold & ND & 95.2 & $*$ \\
\hline Tica & $2011^{2}$ & Kultursaat & ORG & 94.2 & $\mathrm{c}, \mathrm{e}$ \\
\hline Ricca & $2015^{6}$ & Reinsaat & ORG & 92.1 & $\mathrm{e}$ \\
\hline Aroma & $2015^{7}$ & Kultursaat & ORG & 87.1 & $\mathrm{c}$ \\
\hline Rheinlands Ruhm & $1945^{8}$ & Unknown & ND & 85.0 & $\mathrm{~b}$ \\
\hline Lukullus & $1956^{4}$ & Reinhold & ND & 83.9 & $*$ \\
\hline Goldene Königin & $1882^{14}$ & Unknown & ND & 76.6 & $\mathrm{c}, \mathrm{d}$ \\
\hline
\end{tabular}




\begin{tabular}{|c|c|c|c|c|c|}
\hline Harzfeuer $\mathrm{F}_{1}$ & $1959^{4}$ & IZQ & $\mathrm{CON}$ & 76.4 & $a, b, c, d$ \\
\hline Auriga & $1980^{4}$ & Saatzucht Quedlinburg & $\mathrm{CON}$ & 71.5 & $\mathrm{c}, \mathrm{e}$ \\
\hline Haubners Vollendung & $1950^{8}$ & Unknown & ND & 70.3 & $*$ \\
\hline Dorenia & $2012^{2}$ & Kultursaat & ORG & 68.2 & $\mathrm{a}$ \\
\hline Roi Humbert Jaune & $1898^{9}$ & Unknown & ND & 64.9 & $\mathrm{c}$ \\
\hline Hellfrucht & $1955^{4}$ & Fetzer & ND & 64.3 & $*$ \\
\hline Campari $\mathrm{F}_{1}$ & $1996^{2}$ & Enza & $\mathrm{CON}$ & 63.3 & $e, f$ \\
\hline Matina & $1978^{2}$ & Hild & $\mathrm{CON}$ & 55.2 & $a, b, c, d$ \\
\hline Black Plum & $1998^{10}$ & Unknown & ND & 52.2 & $\mathrm{a}, \mathrm{c}$ \\
\hline \multicolumn{6}{|c|}{ Cocktail cultivars $\left(<52 \mathrm{~g}\right.$ fruit $\left.^{-1}\right)$} \\
\hline Amoroso $\mathrm{F}_{1}$ & $2005^{2}$ & Rijk Zwaan & $\mathrm{CON}$ & 50.8 & $f, g$ \\
\hline Annamay $\mathrm{F}_{1}$ & $2010^{2}$ & Enza & $\mathrm{CON}$ & 46.0 & e \\
\hline Quedlinburger Frühe Liebe & $1951^{8}$ & Unknown & ND & 43.4 & $\mathrm{a}$ \\
\hline Ruthje & $2008^{4}$ & Kultursaat & ORG & 42.3 & $\mathrm{c}, \mathrm{e}$ \\
\hline König Humbert & $1880^{11}$ & Unknown & ND & 37.7 & $*$ \\
\hline Clou & $2010^{2}$ & OОTP & ORG & 34.4 & $a, b$ \\
\hline Tastery $\mathrm{F}_{1}$ & $2011^{2}$ & Rijk Zwaan & $\mathrm{CON}$ & 33.5 & $\mathrm{~d}, \mathrm{e}, \mathrm{f}, \mathrm{g}$ \\
\hline Primabella & $2012^{2}$ & OOTP & ORG & 28.1 & $\mathrm{a}, \mathrm{c}$ \\
\hline Sakura $F_{1}$ & $1999^{2}$ & Enza & $\mathrm{CON}$ & 23.7 & $\mathrm{c}, \mathrm{d}, \mathrm{e}, \mathrm{f}$ \\
\hline Black Cherry & $2009^{2}$ & Reinsaat & ND & 23.0 & $\mathrm{c}, \mathrm{d}$ \\
\hline Cerise Gelb & $2005^{12}$ & OOTP & ND & 22.9 & $a, b$ \\
\hline Yellow Submarine & $2002^{2}$ & Unknown & ND & 22.2 & $\mathrm{c}$ \\
\hline Zuckertraube & $1994^{2}$ & Reinsaat & ND & 21.9 & $a, b, c$ \\
\hline Dorada & $2010^{2}$ & OOTP & ORG & 21.3 & $a, b$ \\
\hline Primavera & $2010^{2}$ & OOTP & ORG & 21.3 & $a, b$ \\
\hline Philovita $\mathrm{F}_{1}$ & $2007^{2}$ & De Ruiter & $\mathrm{CON}$ & 19.4 & $a, b, c$ \\
\hline Trixi & $2014^{4}$ & Kultursaat & ORG & 19.3 & $\mathrm{c}, \mathrm{e}$ \\
\hline Trilly $F_{1}$ & $2006^{2}$ & ISI Sementi & $\mathrm{CON}$ & 19.3 & $\mathrm{~d}$ \\
\hline Benarys Gartenfreude $^{1}$ & $1950^{4}$ & Benary & $\mathrm{CON}$ & 18.5 & $*$ \\
\hline Bartelly $F_{1}$ & $2014^{2}$ & De Bolster & ORG & 18.4 & $\mathrm{c}, \mathrm{e}$ \\
\hline Golden Pearl F 1 & $2008^{2}$ & Hild & $\mathrm{CON}$ & 18.4 & d \\
\hline Resi & $2010^{2}$ & OOTP & ND & 17.3 & $a, b$ \\
\hline Supersweet $100 \mathrm{~F}_{1}$ & $1992^{2}$ & Syngenta & $\mathrm{CON}$ & 15.7 & $\mathrm{a}, \mathrm{b}, \mathrm{c}, \mathrm{d}$, \\
\hline Goldita & $1997^{8}$ & De Ruiter/ Arche Noah & $\mathrm{CON}$ & 15.6 & $\mathrm{c}$ \\
\hline Sliwowidnij & $2012^{13}$ & Unknown & ND & 9.6 & $\mathrm{c}$ \\
\hline Rote Murmel & $1995^{13}$ & Unknown & ND & 5.7 & $a, b$ \\
\hline Golden Currant & $1975^{13}$ & Unknown & ND & 5.4 & $a, b$ \\
\hline
\end{tabular}

Cultivars shown in bold are the 20 cultivars selected from 2015 for further evaluation in 2016

Year of release in italic are not known with certainty

$\mathrm{IZQ}=$ Institut für Züchtungsforschung Quedlinburg; OOTP=Organic Outdoor Tomato Project (https:/www.unigoettingen.de/en/the+organic+outdoor+tomato+project/571805.html)

${ }^{1}$ Syn. Freude, syn. Gardener's Delight; ${ }^{2}$ European Commission (2015); ${ }^{3}$ T. Wagner (2016) pers. comm.;

${ }^{4}$ Bundessortenamt (2016) pers. comm. (www.bundessortenamt.de); ${ }^{5}$ Bundessortenamt (1997); ${ }^{6}$ Reinsaat (2015) pers. comm. (www.reinsaat.at); ${ }^{7}$ S. Wedemeyer/Kultursaat e.V. (2016) pers. comm. (www.kultursaat.org); ${ }^{8}$ Arche Noah (2015) pers. comm. (www.arche-noah.at); ${ }^{9}$ Haage and Schmidt (1989); ${ }^{10}$ ProSpecieRara (2016) pers. comm. (www.prospecierara.de); ${ }^{11}$ Munro (2014); ${ }^{12}$ Dreschflegel (2005); ${ }^{13}$ Culinaris (2015) pers. comm. (www.culinarissaatgut.de); ${ }^{14}$ Livingston and Smith (1998)

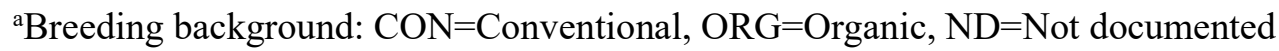
${ }^{\mathrm{b}}$ Fruit weight $=$ average single fruit weight $(\mathrm{g})$ derived from the experiment 2015

'Suitable production system of the cultivars: $a=$ organic outdoor, $b=$ conventional outdoor, $c=$ extensive organic indoor, $\mathrm{d}=$ extensive conventional indoor, $\mathrm{e}=$ intensive organic indoor, $\mathrm{f}=$ intensive conventional indoor, $\mathrm{g}=$ hydroponic, $*=$ hardly grown anymore. This information was collected with extension services, research stations, breeders, seed companies, and the IPK Genebank 
Table S3. Analysis of variance (ANOVA) of cocktail and salad cultivars and mean comparison between these two groups of cultivars

\begin{tabular}{|c|c|c|c|c|c|c|c|c|}
\hline \multirow[t]{2}{*}{ Parameter } & \multicolumn{4}{|c|}{ Cocktail cultivars } & \multicolumn{4}{|c|}{ Salad cultivars } \\
\hline & F-test & Mean \pm SD & Min & Max & F-test & Mean \pm SD & Min & $\operatorname{Max}$ \\
\hline \multicolumn{9}{|c|}{ Plant morphological characteristics } \\
\hline Plant height (cm) & $* * *$ & $294.7 \pm 44.6$ & 179.2 & 391.3 & $* * *$ & $250.2 \pm 38.1$ & 158.0 & 367.0 \\
\hline Leaf number (plant ${ }^{-1}$ ) & $* * *$ & $43 \pm 7$ & 29 & 65 & $* * *$ & $38 \pm 4$ & 21 & 51 \\
\hline Stem and leaf biomass (g plant $\left.{ }^{-1}\right)$ & $* * *$ & $1498.8 \pm 686.6$ & 337.4 & 4621.1 & $* * *$ & $1435.5 \pm 420.5$ & 386.0 & 2780.0 \\
\hline Harvest index & $* * *$ & $0.7 \pm 0.2$ & 0.2 & 0.9 & $* * *$ & $0.8 \pm 0.1$ & 0.5 & 0.9 \\
\hline Fruit yield (g plant ${ }^{-1}$ ) & $* * *$ & $2578.7 \pm 867.4$ & 472.0 & 4650.0 & $* * *$ & $4232.1 \pm 1006.5$ & 1925.0 & 7209.0 \\
\hline Fruit weight ( g fruit $^{-1}$ ) & $* * *$ & $23.5 \pm 11.6$ & 4.0 & 50.0 & $* *$ & $101.5 \pm 32.0$ & 52.0 & 174.0 \\
\hline Fruit number $\left(\right.$ plant $\left.^{-1}\right)$ & $* * *$ & $122 \pm 53$ & 43 & 333 & $* * *$ & $44 \pm 12$ & 15 & 101 \\
\hline \multicolumn{9}{|l|}{ Leaf minerals ( $\left.\mathrm{mg} \mathrm{g}^{-1} \mathrm{DM}\right)$} \\
\hline Carbon (C) & $* * *$ & $387.9 \pm 9.1$ & 369.9 & 414.8 & $* * *$ & $389.6 \pm 8.8$ & 360.3 & 414.1 \\
\hline Nitrogen $(\mathrm{N})$ & $*$ & $23.9 \pm 3.2$ & 17.0 & 34.5 & ns & $24.4 \pm 3.0$ & 17.3 & 31.9 \\
\hline Phosphorus (P) & $* * *$ & $1.7 \pm 0.2$ & 1.2 & 2.3 & $* * *$ & $1.8 \pm 0.2$ & 1.4 & 2.3 \\
\hline Potassium (K) & $* * *$ & $26.0 \pm 4.8$ & 17.2 & 37.7 & $* *$ & $26.9 \pm 4.0$ & 18.5 & 37.3 \\
\hline Magnesium (Mg) & $* * *$ & $4.2 \pm 1.0$ & 2.4 & 6.6 & $* * *$ & $3.7 \pm 0.7$ & 2.2 & 5.9 \\
\hline Calcium (Ca) & $* * *$ & $53.7 \pm 9.3$ & 31.6 & 75.1 & $* * *$ & $50.7 \pm 7.9$ & 30.7 & 74.7 \\
\hline Sulphur (S) & $* * *$ & $5.7 \pm 1.1$ & 3.5 & 9.0 & $* * *$ & $6.1 \pm 1.2$ & 3.5 & 9.6 \\
\hline \multicolumn{9}{|l|}{ Fruit minerals (mg $100 \mathrm{~g}^{-1} \mathrm{FM}$ ) } \\
\hline Phosphorus (P) & $* * *$ & $35.1 \pm 7.5$ & 22.4 & 62.3 & $* * *$ & $29.6 \pm 4.6$ & 20.2 & 43.0 \\
\hline Potassium (K) & $* * *$ & $293.1 \pm 51.1$ & 206.2 & 475.1 & $* * *$ & $291.0 \pm 40.8$ & 202.1 & 410.0 \\
\hline Magnesium (Mg) & $* * *$ & $11.9 \pm 2.4$ & 7.3 & 20.2 & $* * *$ & $10.5 \pm 1.7$ & 6.7 & 15.2 \\
\hline Calcium (Ca) & $* * *$ & $15.9 \pm 8.2$ & 6.5 & 85.7 & $* * *$ & $13.6 \pm 3.9$ & 5.0 & 28.2 \\
\hline Sulphur (S) & $* * *$ & $18.2 \pm 4.4$ & 12.5 & 34.7 & $* * *$ & $15.4 \pm 2.3$ & 10.8 & 23.4 \\
\hline \multicolumn{9}{|l|}{ Fruit quality characteristics } \\
\hline Dry matter (\%) & $* * *$ & $8.0 \pm 1.4$ & 4.8 & 13.1 & $*$ & $5.6 \pm 1.0$ & 3.1 & 8.4 \\
\hline Total soluble solids ( ${ }^{\circ}$ Brix) & $* * *$ & $6.5 \pm 1.2$ & 3.9 & 9.2 & $* * *$ & $4.4 \pm 0.6$ & 3.2 & 7.7 \\
\hline Titratable acidity (\%) & ns & $0.4 \pm 0.1$ & 0.3 & 0.7 & $* * *$ & $0.4 \pm 0.1$ & 0.2 & 0.9 \\
\hline $\begin{array}{l}\text { Total phenolic concentration } \\
\left(\mathrm{mg} 100 \mathrm{~g}^{-1} \mathrm{FW}\right)\end{array}$ & $* * *$ & $260.1 \pm 74.5$ & 152.3 & 544.5 & $* * *$ & $176.0 \pm 41.0$ & 107.2 & 324.4 \\
\hline \multicolumn{9}{|l|}{ Fruit color } \\
\hline $\mathrm{L}^{*}$ & $* * *$ & $52.7 \pm 5.2$ & 46.3 & 68.5 & $* * *$ & $53.7 \pm 3.4$ & 46.7 & 68.1 \\
\hline$a^{*}$ & $* * *$ & $11.4 \pm 7.3$ & -4.0 & 22.5 & $* * *$ & $21.6 \pm 7.8$ & -11.1 & 31.6 \\
\hline$b^{*}$ & $* * *$ & $26.0 \pm 7.7$ & 9.3 & 43.1 & $* * *$ & $29.3 \pm 5.6$ & 18.2 & 53.2 \\
\hline $\mathrm{C}^{*}$ & $* * *$ & $29.8 \pm 6.2$ & 10.9 & 43.2 & $* * *$ & $37.4 \pm 5.2$ & 23.9 & 53.4 \\
\hline $\mathrm{h}^{\circ}$ & $* * *$ & $64.4 \pm 16.1$ & 44.1 & 96.2 & $* * *$ & $53.6 \pm 12.3$ & 42.7 & 107.8 \\
\hline
\end{tabular}

$\mathrm{ns}=$ non-significant difference; $*, * *$, and $* * *=$ significant difference at $\mathrm{p}<0.05, \mathrm{p}<0.01$, and $\mathrm{p}<0.001$ respectively 

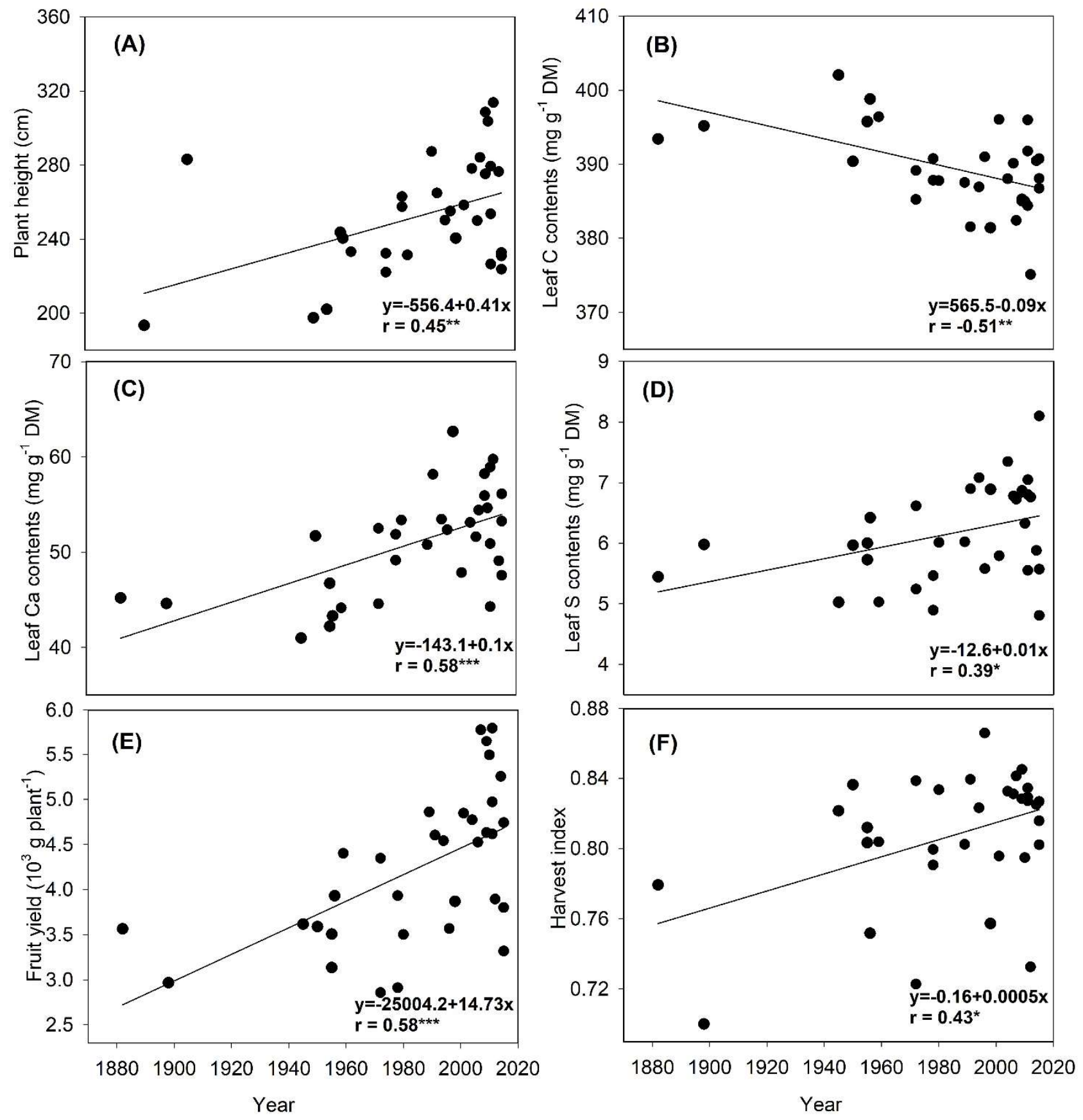

Fig. S2. Performance of 33 salad tomato cultivars in organic low-input production in 2015. Pearson correlations between year of cultivar release with (A) plant height, (B) leaf C content, (C) leaf Ca content, (D) leaf S content, (E) fruit yield, and (F) harvest index. The correlation among cocktail cultivars was not significant. $*, * *$, and $* * *=$ significant at $\mathrm{p}<0.05, \mathrm{p}<0.01$, and $\mathrm{p}<0.001$, respectively 


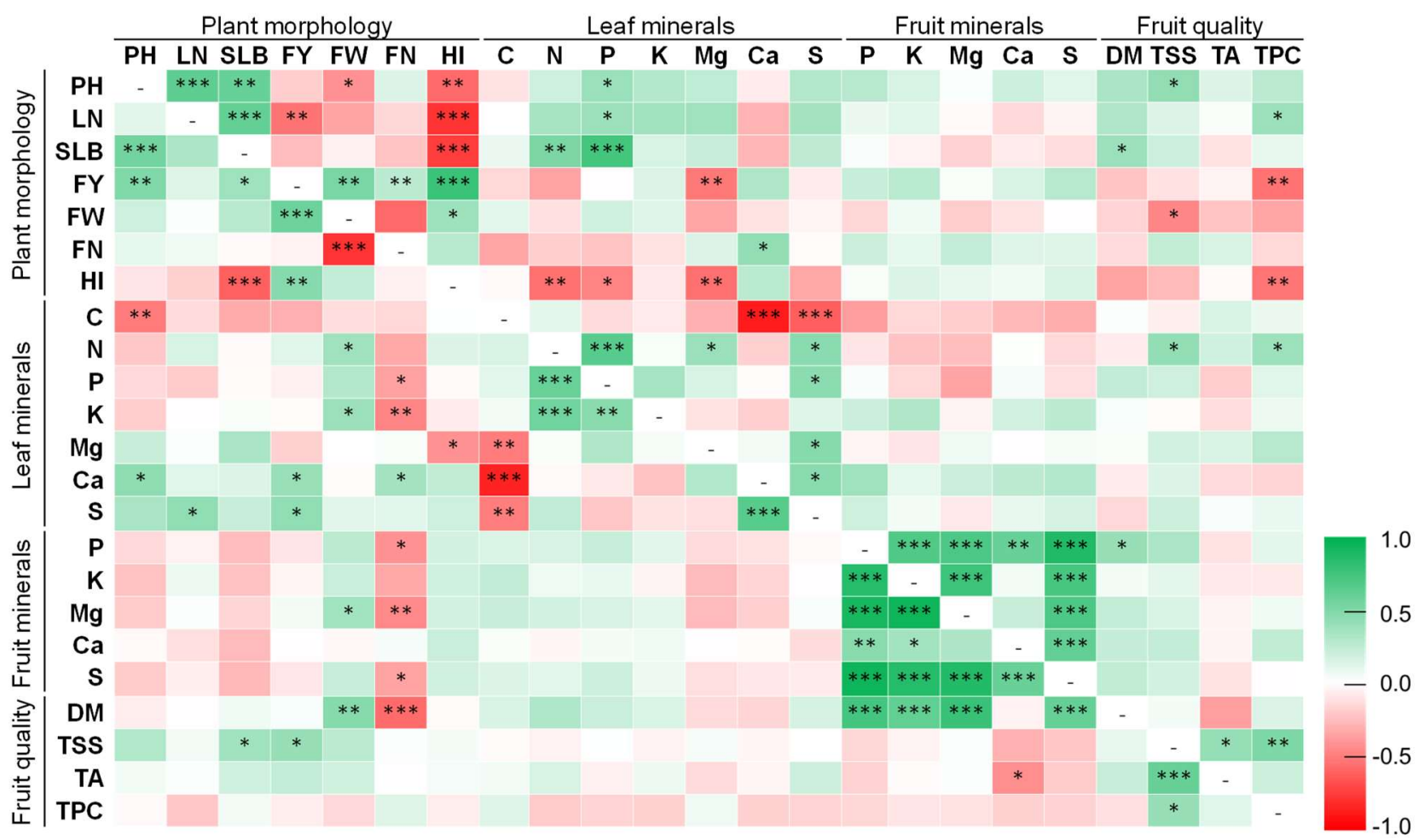

Fig. S3. Correlation among plant morphology and fruit quality traits of salad ( $n=33$, lower diagonal) and cocktail $(n=27$, upper diagonal) tomato cultivars. Color intensity represents the correlation coefficient. $*$, **, and $* * *$ indicate significant correlation at $\mathrm{p}<0.05, \mathrm{p}<0.01$, and $\mathrm{p}<0.001$, respectively. $\mathrm{PH}=$ plant height, $\mathrm{LN}=$ leaf number, $\mathrm{SLB}=$ stem and leaf biomass, $\mathrm{FY}=$ fruit yield, $\mathrm{FN}=$ fruit number, $\mathrm{HI}=$ harvest index, $\mathrm{DM}=$ dry matter, $\mathrm{TSS}=$ total soluble solid; $\mathrm{TA}=$ titratable acidity; $\mathrm{TPC}=$ total phenolic concentration

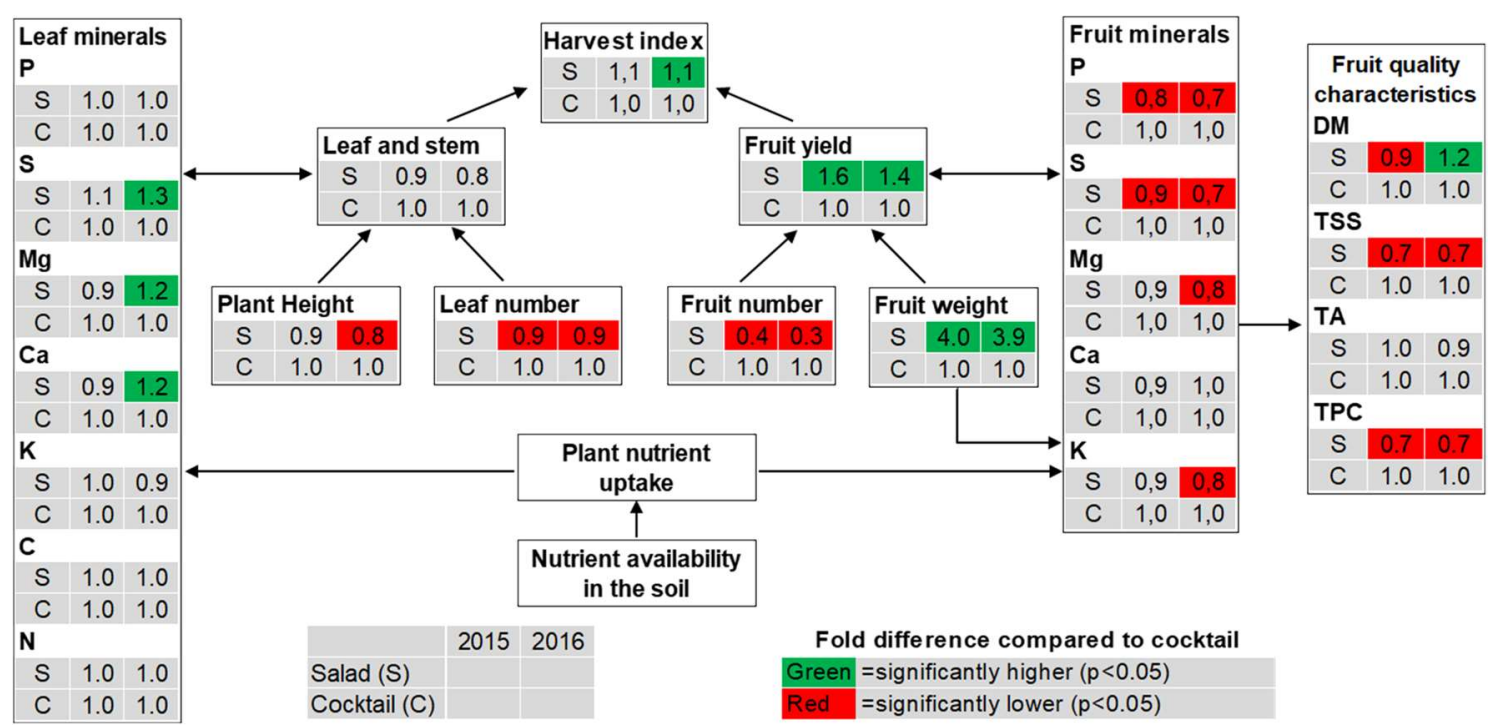

Fig. S4. Summary of plant morphological characteristics and fruit quality of salad $(n=8)$ and cocktail ( $\mathrm{n}=12)$ cultivars grown in 2015 and 2016. The values of cocktail cultivars are set to a factor of 1.0 and the values of salad cultivars are presented as fold differences compared with cocktail cultivars. The significantly higher $(\mathrm{p}<0.05)$ values of salad compared with cocktail cultivars are indicated in green and the significantly lower $(\mathrm{p}<0.05)$ values are indicated in red 
Table S4. Dietary reference intake (DRI) for adult males and females (not pregnant or lactating) aged between 19 and 50 (Institute of Medicine, 2006)

\begin{tabular}{lrrrrr}
\hline $\begin{array}{l}\text { Nutrients } \\
\left(\text { mg day }^{-1}\right)\end{array}$ & Male 19-30 y & Female 19-30 y & Male 31-50 y & Female 31-50 y & Average \\
\hline $\mathrm{Ca} f$ & 1000 & 1000 & 1000 & 1000 & 1000 \\
$\mathrm{Kff}$ & 4700 & 4700 & 4700 & 4700 & 4700 \\
$\mathrm{Mg} f$ & 400 & 310 & 420 & 320 & 363 \\
$\mathrm{Pf}$ & 700 & 700 & 700 & 700 & 700 \\
$\mathrm{Fef}$ & 8 & 18 & 8 & 18 & 13 \\
$\mathrm{Znf}$ & 11 & 8 & 11 & 8 & 9.5 \\
\hline
\end{tabular}

T: RDA Recommended dietary allowance: defined as the average daily dietary intake level sufficient to meet the nutrient requirement of nearly all (97-98\%) healthy individuals in a particular life-stage and gender group (Murphy and Poos, 2002)

Tf: AI Adequate intake: defined as a recommended intake level based on observed or experimentally determined approximations or estimates of nutrient intake by a group (or groups) of healthy people that are assumed to be adequate - used when an RDA cannot be determined (Murphy and Poos, 2002)

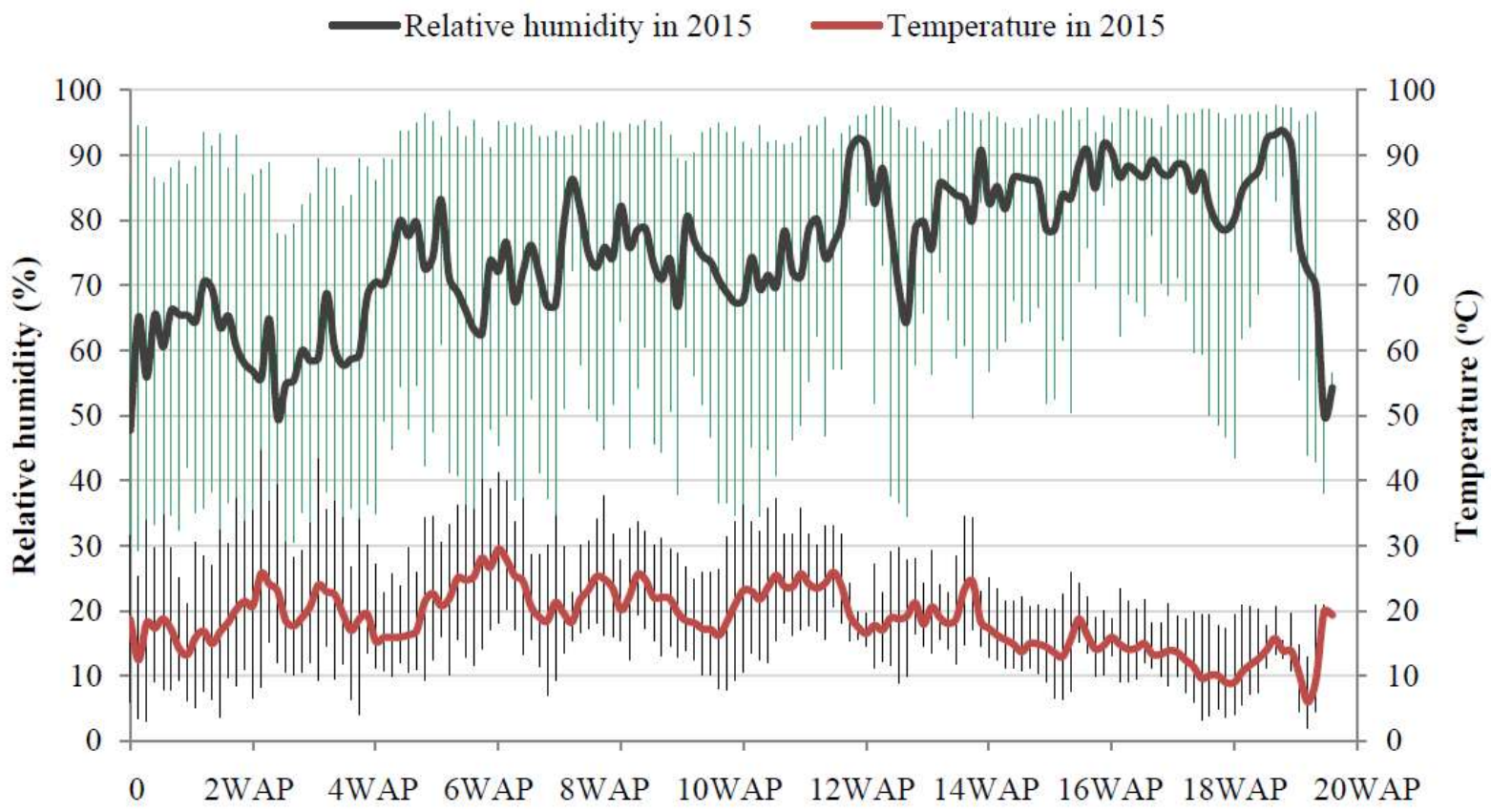

Fig. S5.1 Average daily temperature and relative humidity during the experiment in 2015

Error bars present daily minimum (lower side) and maximum (upper side) of the relative humidity and temperature. Data were recorded by using an EBI 20-TH Data Logger (ebro Electronic GmbH $\&$ Co. KG). The device recorded temperature and relative humidity every 30 minutes; daily mean was derived from 48 data points 


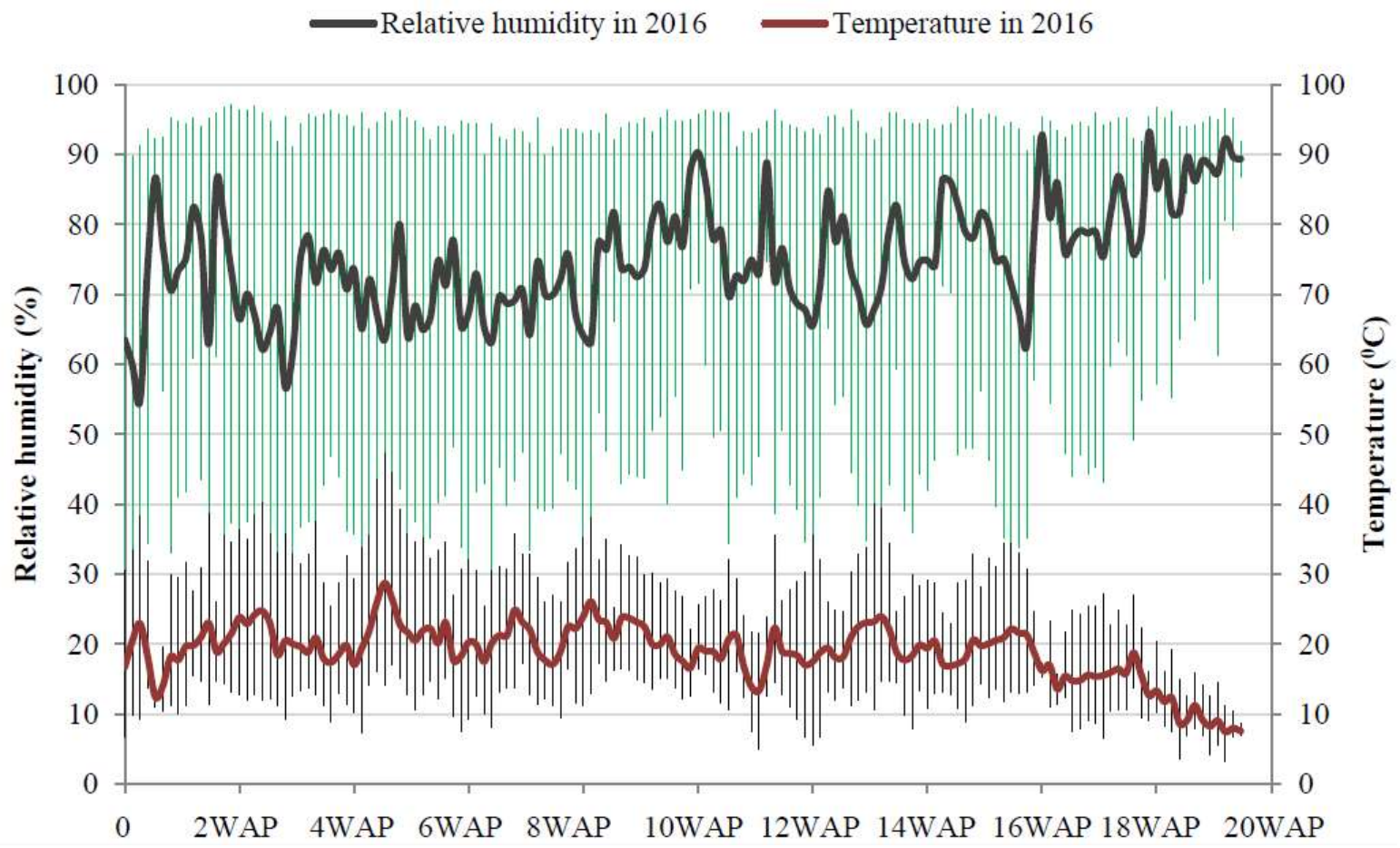

Fig. S5.2 Average daily temperature and relative humidity during the experiment in 2016 Error bars present daily minimum (lower side) and maximum (upper side) of the relative humidity and temperature. Data were recorded by using an EBI 20-TH Data Logger (ebro Electronic GmbH $\&$ Co. KG). The device recorded temperature and relative humidity every 30 minutes; daily mean was derived from 48 data points

\section{Refereces}

Bundessortenamt, 1997. Beschreibende Sortenliste: Fruchtgemüse, Blattgemüse. Landbuch Verlagsgesellschaft mbH, Hannover, Germany.

Dreschflegel, 2005. Saaten und Taten, Witzenhausen, Germany.

European Commission, 2015. Plant variety catalogues \& databases: Vegetable species, $<$ http://ec.europa.eu/food/plant/plant_propagation_material/plant_variety_catalogues_databases/sear $\mathrm{ch} / /$ public/index.cfm?event $=$ SearchForm\&ctl_type $=\mathrm{H}>($ Jun 13, 2016) .

Haage, Schmidt, 1989. Verzeichnis von Blumenzwiebeln und Knollengewächsen für Herbst, Erfurt, Germany.

Institute of Medicine, 2006. DRI, dietary reference intakes: the essential guide to nutrient requirements. National Academies Press, Washington D.C, U.S

Livingston, A.W., Smith, A.F., 1998. Livingston and the tomato. Ohio State University Press, Columbus.

Munro, N., 2014. Heritage seed library: Sowing, growing, sharing. Garden Organic, UK.

Murphy, S.P., Poos, M.I., 2002. Dietary reference intakes: summary of applications in dietary assessment.

Public Health Nutrition 5, 843-849. https://doi.org/10.1079/PHN2002389 
Table S5. Relative concentration of VOCs semiquantified in the 40 tomato cultivars over two harvest dates in 2015 by cultivar

Relative concentration (\%)

\begin{tabular}{|c|c|c|c|c|c|c|c|c|c|c|c|c|}
\hline \multirow[b]{2}{*}{ Cultivar } & \\
\hline & hexanal & $\begin{array}{r}(\mathrm{E})-2- \\
\text { hexenal }\end{array}$ & octanal & $\begin{array}{r}\text { 6-me-5- } \\
\text { heptene-2- } \\
\text { one }\end{array}$ & $\begin{array}{r}1- \\
\text { hexanol }\end{array}$ & $\begin{array}{r}(\mathrm{Z})-3- \\
\text { hexen-1-ol }\end{array}$ & $\begin{array}{r}2 \text {-isobutyl } \\
\text { thiazole }\end{array}$ & $\begin{array}{r}\text { 2-ethyl-1- } \\
\text { hexanol }\end{array}$ & $\begin{array}{l}\text { benzal } \\
\text { dehyde }\end{array}$ & linalool & $\begin{array}{r}\text { methylpta } \\
\text { dione }\end{array}$ & $\begin{array}{r}\beta \text {-cyclo } \\
\text { citral }\end{array}$ \\
\hline Aroma & 27.8 & 10.92 & 3.55 & 19.68 & 2.96 & 3.49 & 12.51 & 0.71 & 0.14 & 2.89 & 0.00 & 1.21 \\
\hline Bonner Beste & 14.2 & 10.69 & 7.70 & 24.16 & 1.92 & 5.41 & 10.91 & 1.53 & 0.15 & 3.13 & 0.00 & 1.45 \\
\hline Cerise gelb & 29.6 & 16.08 & 3.17 & 22.84 & 1.63 & 3.35 & 14.03 & 0.58 & 0.28 & 0.62 & 0.00 & 0.09 \\
\hline Clou & 23.5 & 17.07 & 5.31 & 13.88 & 2.67 & 3.96 & 25.52 & 1.17 & 0.23 & 1.80 & 0.00 & 0.00 \\
\hline Diplom F1 & 24.9 & 4.00 & 6.68 & 19.80 & 3.59 & 4.50 & 14.61 & 0.98 & 0.00 & 3.14 & 0.00 & 1.30 \\
\hline Dorada & 34.4 & 24.90 & 4.61 & 5.29 & 2.44 & 6.30 & 11.51 & 1.17 & 0.26 & 1.58 & 0.00 & 0.00 \\
\hline Dorenia & 34.7 & 7.61 & 4.77 & 21.40 & 1.95 & 2.76 & 10.33 & 0.85 & 0.15 & 2.13 & 0.00 & 0.92 \\
\hline Garance F1 & 33.9 & 7.84 & 2.63 & 24.44 & 1.38 & 1.86 & 12.57 & 0.66 & 0.00 & 1.61 & 0.03 & 0.64 \\
\hline Golden Currant & 27.9 & 7.09 & 2.46 & 14.54 & 5.84 & 7.33 & 17.51 & 0.94 & 1.20 & 1.19 & 0.00 & 0.11 \\
\hline Goldene Königin & 28.7 & 16.24 & 5.01 & 12.03 & 1.92 & 4.09 & 17.24 & 1.17 & 0.39 & 2.72 & 0.00 & 0.00 \\
\hline Golden Pearl F1 & 36.5 & 18.20 & 3.25 & 4.06 & 2.03 & 5.41 & 15.12 & 0.76 & 0.21 & 3.49 & 0.09 & 0.28 \\
\hline Hamlet F1 & 40.6 & 12.47 & 4.51 & 13.92 & 1.32 & 2.04 & 7.07 & 0.77 & 0.06 & 2.13 & 0.00 & 0.81 \\
\hline Haubners Vollendung & 19.6 & 9.29 & 4.38 & 25.25 & 1.66 & 3.43 & 15.08 & 0.65 & 0.00 & 4.50 & 0.00 & 1.30 \\
\hline Hellfrucht & 23.2 & 11.69 & 4.71 & 17.48 & 2.90 & 5.27 & 8.11 & 0.98 & 0.26 & 5.38 & 0.00 & 1.67 \\
\hline Hildares F1 & 22.8 & 10.39 & 3.26 & 19.74 & 2.68 & 4.48 & 9.25 & 1.19 & 0.31 & 5.68 & 0.00 & 1.25 \\
\hline Roi Humbert Jaune & 37.1 & 21.55 & 5.35 & 4.03 & 2.22 & 4.97 & 10.54 & 1.08 & 0.00 & 4.61 & 0.00 & 0.00 \\
\hline König Humbert & 48.5 & 11.19 & 2.83 & 16.10 & 1.20 & 1.47 & 5.48 & 0.44 & 0.22 & 0.89 & 0.02 & 0.94 \\
\hline Lukullus & 25.8 & 5.99 & 6.18 & 18.40 & 3.56 & 5.33 & 14.21 & 1.31 & 0.13 & 3.58 & 0.00 & 1.58 \\
\hline Matina & 28.6 & 11.25 & 4.89 & 18.56 & 2.98 & 3.61 & 12.63 & 0.89 & 0.06 & 2.36 & 0.00 & 1.00 \\
\hline Mecano F1 & 23.8 & 7.92 & 6.90 & 16.87 & 1.53 & 4.09 & 9.43 & 1.01 & 0.38 & 5.30 & 0.00 & 1.78 \\
\hline Moneymaker & 29.3 & 8.13 & 5.74 & 17.61 & 2.60 & 3.44 & 10.86 & 1.39 & 0.00 & 2.40 & 0.00 & 1.34 \\
\hline Nordica F1 & 27.4 & 11.13 & 4.65 & 18.00 & 0.98 & 2.30 & 13.07 & 1.09 & 0.05 & 3.98 & 0.00 & 1.22 \\
\hline Pannovy F1 & 28.5 & 13.81 & 4.45 & 18.84 & 1.89 & 2.78 & 8.79 & 0.73 & 0.34 & 4.06 & 0.00 & 1.03 \\
\hline Phantasia F1 & 20.3 & 11.19 & 7.39 & 14.41 & 1.35 & 6.87 & 8.96 & 2.54 & 0.79 & 4.56 & 0.00 & 1.33 \\
\hline Philovita F1 & 48.1 & 11.72 & 3.16 & 11.93 & 2.46 & 2.70 & 2.55 & 0.43 & 0.12 & 0.51 & 0.00 & 1.29 \\
\hline Black Plum & 45.3 & 8.01 & 4.35 & 15.50 & 2.94 & 2.71 & 8.24 & 0.96 & 0.09 & 1.25 & 0.00 & 0.83 \\
\hline Previa F1 & 26.5 & 12.16 & 5.11 & 18.19 & 1.75 & 3.56 & 9.43 & 1.00 & 0.24 & 2.23 & 0.00 & 1.08 \\
\hline $\begin{array}{l}\text { Quedlinburger Frühe } \\
\text { Liebe }\end{array}$ & 28.1 & 10.09 & 4.08 & 16.74 & 2.42 & 2.84 & 14.06 & 0.56 & 0.26 & 3.95 & 0.16 & 1.03 \\
\hline Rheinlands Ruhm & 24.3 & 9.82 & 5.89 & 16.82 & 2.96 & 4.30 & 10.46 & 1.11 & 0.50 & 6.14 & 0.00 & 1.85 \\
\hline Ricca & 28.3 & 12.89 & 6.22 & 16.69 & 1.68 & 2.96 & 9.47 & 0.91 & 0.18 & 2.65 & 0.15 & 1.52 \\
\hline Rote Murmel & 34.5 & 7.42 & 3.90 & 23.65 & 3.89 & 6.01 & 5.31 & 1.04 & 0.25 & 0.96 & 0.00 & 1.30 \\
\hline Rougella F1 & 38.6 & 13.81 & 4.37 & 16.17 & 1.61 & 2.80 & 3.85 & 0.66 & 0.24 & 2.52 & 0.09 & 0.91 \\
\hline Ruthje & 24.4 & 10.25 & 5.48 & 19.85 & 2.08 & 3.21 & 11.52 & 0.92 & 0.39 & 0.75 & 0.00 & 1.57 \\
\hline Sliwowidnij & 22.7 & 14.42 & 3.60 & 19.67 & 1.68 & 3.86 & 14.08 & 0.83 & 0.15 & 4.75 & 0.00 & 0.00 \\
\hline
\end{tabular}




\begin{tabular}{|c|c|c|c|c|c|c|c|c|c|c|c|c|}
\hline Sparta F1 & 35.4 & 11.74 & 4.05 & 13.32 & 1.71 & 2.41 & 9.57 & 0.67 & 0.05 & 3.75 & 0.00 & 1.08 \\
\hline Tica & 28.3 & 8.60 & 5.59 & 19.40 & 1.73 & 2.77 & 9.86 & 0.80 & 0.17 & 2.02 & 0.00 & 1.35 \\
\hline Trilly F1 & 40.0 & 12.34 & 4.53 & 11.78 & 2.81 & 4.48 & 7.12 & 0.91 & 0.05 & 2.31 & 0.00 & 1.16 \\
\hline Trixi & 28.8 & 15.79 & 5.19 & 18.28 & 2.82 & 5.22 & 3.45 & 0.86 & 0.08 & 1.77 & 0.00 & 2.06 \\
\hline Yellow Submarine & 31.5 & 14.47 & 3.02 & 19.94 & 1.56 & 2.77 & 16.27 & 0.71 & 0.62 & 2.08 & 0.00 & 0.00 \\
\hline Zuckertraube & 22.6 & 15.02 & 6.32 & 17.79 & 2.56 & 5.70 & 2.81 & 1.85 & 0.22 & 2.68 & 0.13 & 2.02 \\
\hline \multicolumn{13}{|l|}{ Statistics } \\
\hline mean & 30.0 & 11.88 & 4.73 & 16.93 & 2.30 & 3.92 & 10.84 & 0.97 & 0.23 & 2.85 & 0.02 & 1.01 \\
\hline HSD & 27.3 & 16.27 & 3.49 & 20.44 & 1.65 & 3.34 & 8.29 & 0.97 & 0.62 & 2.02 & 0.00 & 0.00 \\
\hline Significance & $* * *$ & $* * *$ & $* * *$ & $* * *$ & $* * *$ & $* * *$ & $* * *$ & $* *$ & $* * *$ & $* * *$ & $\mathrm{~ns}$ & $* * *$ \\
\hline
\end{tabular}

Cocktail cultivars are indicated in italics; the others are salad cultivars. Mean values are given for each of the 40 cultivars as mean from fruit sample in 2015.

$\mathrm{CV}$, coefficient of variation; HSD, honestly significant difference at $\mathrm{p} \leq 0.05$; ns, not significant. ${ }^{*} \mathrm{p} \leq 0.05,{ }^{* *} \mathrm{p} \leq 0.01,{ }^{* * *} \mathrm{p} \leq 0.001$

Table S5. Continue

\begin{tabular}{|c|c|c|c|c|c|c|c|c|c|c|c|c|c|}
\hline \multirow[b]{2}{*}{ Cultivar } & \multicolumn{13}{|c|}{ Relative concentration $(\%)$} \\
\hline & $\begin{array}{l}\text { 3- } \\
\text { mebuta } \\
\text { noic acid }\end{array}$ & $\begin{array}{l}\alpha- \\
\text { terpineol }\end{array}$ & $\begin{array}{l}\text { gera } \\
\text { nial }\end{array}$ & $\begin{array}{l}\text { decadi } \\
\text { enal }\end{array}$ & $\begin{array}{l}\boldsymbol{\beta}- \\
\text { damas } \\
\text { cenone }\end{array}$ & $\begin{array}{l}\text { geranyl } \\
\text { acetone }\end{array}$ & $\begin{array}{l}2- \\
\text { mepropa } \\
\text { noic acid }\end{array}$ & $\begin{array}{l}\text { benzyl } \\
\text { alcohol }\end{array}$ & $\begin{array}{l}\text { phenylethyl } \\
\text { alcohol }\end{array}$ & $\begin{array}{l}\beta- \\
\text { ionone }\end{array}$ & $\begin{array}{l}\text { isopropyl } \\
\text { myristate }\end{array}$ & $\begin{array}{l}\text { octanioc } \\
\text { acid }\end{array}$ & $\begin{array}{l}\text { nonanoic } \\
\text { acid }\end{array}$ \\
\hline Aroma & 0.36 & 0.21 & 1.19 & 0.08 & 4.54 & 5.40 & 0.00 & 0.00 & 0.60 & 1.01 & 0.00 & 0.09 & 0.65 \\
\hline Bonner Beste & 0.27 & 0.00 & 3.12 & 0.00 & 2.99 & 7.30 & 0.65 & 0.00 & 0.00 & 1.73 & 0.00 & 0.79 & 1.88 \\
\hline Cerise gelb & 0.83 & 0.11 & 0.00 & 0.00 & 5.82 & 0.20 & 0.00 & 0.00 & 0.47 & 0.11 & 0.00 & 0.13 & 0.07 \\
\hline Clou & 0.59 & 0.00 & 0.00 & 0.00 & 3.18 & 0.75 & 0.18 & 0.00 & 0.08 & 0.08 & 0.00 & 0.06 & 0.00 \\
\hline Diplom F1 & 0.00 & 0.66 & 1.86 & 0.00 & 2.20 & 6.80 & 0.00 & 0.00 & 0.00 & 1.16 & 0.00 & 0.07 & 3.76 \\
\hline Dorada & 0.11 & 0.00 & 0.00 & 0.00 & 5.57 & 0.59 & 0.51 & 0.00 & 0.16 & 0.00 & 0.00 & 0.57 & 0.00 \\
\hline Dorenia & 0.90 & 0.11 & 1.64 & 0.09 & 1.89 & 6.05 & 0.11 & 0.00 & 0.10 & 0.76 & 0.00 & 0.00 & 0.83 \\
\hline Garance F1 & 0.68 & 0.18 & 1.73 & 0.30 & 1.53 & 6.06 & 0.11 & 0.00 & 1.20 & 0.65 & 0.00 & 0.04 & 0.00 \\
\hline Golden Currant & 0.62 & 1.56 & 0.18 & 0.00 & 1.32 & 0.73 & 0.08 & 0.00 & 8.99 & 0.00 & 0.00 & 0.38 & 0.00 \\
\hline Goldene Königin & 0.65 & 0.15 & 0.00 & 0.18 & 4.29 & 0.56 & 0.32 & 0.00 & 0.00 & 0.00 & 0.00 & 0.84 & 3.55 \\
\hline Golden Pearl F1 & 0.31 & 0.00 & 0.00 & 0.00 & 4.94 & 0.16 & 0.67 & 0.10 & 2.94 & 0.00 & 0.00 & 1.00 & 0.47 \\
\hline Hamlet F1 & 0.33 & 0.40 & 1.88 & 0.00 & 2.43 & 7.59 & 0.18 & 0.00 & 0.33 & 0.91 & 0.00 & 0.28 & 0.00 \\
\hline Haubners Vollendung & 0.23 & 0.09 & 1.55 & 0.00 & 4.18 & 6.02 & 0.00 & 0.00 & 0.00 & 1.15 & 0.00 & 0.38 & 1.24 \\
\hline Hellfrucht & 0.33 & 0.34 & 1.73 & 0.00 & 5.80 & 6.19 & 0.30 & 0.00 & 0.00 & 1.49 & 0.00 & 0.20 & 1.92 \\
\hline Hildares F1 & 0.23 & 0.51 & 1.83 & 0.00 & 4.65 & 7.61 & 0.00 & 0.00 & 0.00 & 1.51 & 0.00 & 0.12 & 2.50 \\
\hline Roi Humbert Jaune & 0.40 & 0.21 & 0.00 & 0.00 & 3.88 & 0.80 & 0.41 & 0.00 & 0.00 & 0.00 & 0.00 & 0.28 & 2.55 \\
\hline König Humbert & 1.18 & 0.13 & 1.01 & 0.00 & 2.41 & 4.16 & 0.19 & 0.00 & 0.10 & 0.81 & 0.00 & 0.33 & 0.43 \\
\hline Lukullus & 0.13 & 0.00 & 1.86 & 0.00 & 2.16 & 5.65 & 0.31 & 0.00 & 0.15 & 1.25 & 0.00 & 0.26 & 2.13 \\
\hline
\end{tabular}




\begin{tabular}{|c|c|c|c|c|c|c|c|c|c|c|c|c|c|}
\hline Matina & 0.20 & 0.32 & 1.79 & 0.09 & 3.45 & 5.84 & 0.16 & 0.00 & 0.00 & 1.00 & 0.00 & 0.00 & 0.30 \\
\hline Mecano F1 & 0.25 & 0.83 & 2.70 & 0.00 & 5.37 & 8.96 & 0.08 & 0.00 & 0.11 & 1.90 & 0.00 & 0.83 & 0.00 \\
\hline Moneymaker & 0.14 & 0.34 & 2.59 & 0.00 & 1.52 & 8.13 & 0.18 & 0.00 & 0.00 & 1.39 & 0.00 & 0.18 & 2.77 \\
\hline Nordica F1 & 0.21 & 0.45 & 1.82 & 0.00 & 3.24 & 8.78 & 0.14 & 0.00 & 0.10 & 1.12 & 0.00 & 0.23 & 0.00 \\
\hline Pannovy F1 & 0.67 & 0.36 & 1.45 & 0.00 & 4.80 & 6.44 & 0.00 & 0.00 & 0.00 & 1.03 & 0.00 & 0.00 & 0.00 \\
\hline Phantasia F1 & 0.00 & 0.00 & 1.92 & 0.00 & 7.52 & 8.10 & 0.27 & 0.00 & 0.00 & 1.84 & 0.00 & 0.65 & 0.00 \\
\hline Philovita F1 & 0.57 & 0.16 & 1.80 & 0.07 & 2.17 & 6.27 & 0.19 & 0.00 & 2.43 & 1.08 & 0.00 & 0.34 & 0.00 \\
\hline Black Plum & 0.68 & 0.21 & 1.77 & 0.05 & 0.85 & 4.54 & 0.00 & 0.00 & 0.11 & 0.83 & 0.00 & 0.08 & 0.71 \\
\hline Previa F1 & 0.52 & 0.08 & 2.46 & 0.00 & 2.20 & 9.90 & 0.36 & 0.00 & 1.35 & 1.32 & 0.00 & 0.54 & 0.00 \\
\hline $\begin{array}{l}\text { Quedlinburger Frühe } \\
\text { Liebe }\end{array}$ & 0.08 & 0.15 & 1.17 & 0.00 & 4.97 & 6.33 & 0.24 & 0.43 & 0.94 & 0.89 & 0.00 & 0.13 & 0.34 \\
\hline Rheinlands Ruhm & 0.11 & 0.11 & 1.62 & 0.00 & 4.05 & 6.94 & 0.11 & 0.00 & 0.00 & 1.41 & 0.00 & 0.28 & 1.20 \\
\hline Ricca & 0.13 & 0.77 & 1.93 & 0.00 & 3.82 & 7.07 & 0.19 & 0.00 & 0.50 & 1.48 & 0.00 & 0.18 & 0.34 \\
\hline Rote Murmel & 0.93 & 1.28 & 1.23 & 0.00 & 1.74 & 3.84 & 0.00 & 0.42 & 1.08 & 1.01 & 0.00 & 0.27 & 0.00 \\
\hline Rougella F1 & 0.50 & 0.26 & 1.63 & 0.00 & 2.99 & 6.86 & 0.05 & 0.00 & 0.77 & 0.99 & 0.00 & 0.23 & 0.04 \\
\hline Ruthje & 0.39 & 0.29 & 3.34 & 0.00 & 1.09 & 9.26 & 0.51 & 0.22 & 2.25 & 1.73 & 0.00 & 0.48 & 0.00 \\
\hline Sliwowidnij & 0.47 & 0.13 & 0.00 & 0.00 & 12.20 & 0.23 & 0.51 & 0.00 & 0.00 & 0.00 & 0.00 & 0.31 & 0.45 \\
\hline Sparta F1 & 0.26 & 0.37 & 1.33 & 0.00 & 4.08 & 7.53 & 0.40 & 0.00 & 0.31 & 1.07 & 0.06 & 0.13 & 0.71 \\
\hline Tica & 0.55 & 0.58 & 2.97 & 0.10 & 1.89 & 9.35 & 0.35 & 0.00 & 0.99 & 1.66 & 0.00 & 0.69 & 0.27 \\
\hline Trilly F1 & 0.49 & 0.00 & 1.38 & 0.13 & 4.01 & 3.94 & 0.11 & 0.00 & 1.53 & 0.81 & 0.00 & 0.15 & 0.00 \\
\hline Trixi & 0.19 & 0.12 & 1.38 & 0.00 & 4.67 & 5.46 & 0.29 & 0.43 & 1.35 & 1.78 & 0.00 & 0.00 & 0.00 \\
\hline Yellow Submarine & 1.01 & 0.09 & 0.00 & 0.00 & 3.24 & 0.36 & 0.14 & 0.00 & 0.55 & 0.00 & 0.00 & 0.57 & 1.09 \\
\hline Zuckertraube & 0.00 & 0.00 & 2.18 & 0.00 & 6.28 & 5.69 & 0.43 & 1.70 & 2.23 & 1.80 & 0.00 & 0.00 & 0.00 \\
\hline \multicolumn{14}{|l|}{ Statistics } \\
\hline mean & 0.41 & 0.29 & 1.45 & 0.03 & 3.75 & 5.31 & 0.22 & 0.08 & 0.79 & 0.97 & 0.00 & 0.30 & 0.76 \\
\hline HSD & 0.00 & 0.00 & 0.00 & 0.00 & 4.19 & 0.37 & 0.19 & 0.00 & 0.93 & 0.00 & 0.00 & 0.00 & 0.00 \\
\hline Significance & $* * *$ & $\mathrm{~ns}$ & $* * *$ & $* *$ & $* * *$ & $* * *$ & $\mathrm{~ns}$ & $* * *$ & $* * *$ & $* * *$ & $\mathrm{~ns}$ & $* * *$ & $* * *$ \\
\hline
\end{tabular}

Cocktail cultivars are indicated in italics; the others are salad cultivars. Mean values are given for each of the 40 cultivars as mean from fruit sample in 2015.

$\mathrm{CV}$, coefficient of variation; HSD, honestly significant difference at $\mathrm{p} \leq 0.05$; ns, not significant. ${ }^{\mathrm{p}} \leq 0.05, * * \mathrm{p} \leq 0.01, * * * \mathrm{p} \leq 0.001$

Table S6. Instrumental parameters of the 20 tomato cultivars over two harvest dates and two years, $\mathrm{n}=240$

\begin{tabular}{|c|c|c|c|c|c|c|c|}
\hline \multirow[b]{2}{*}{ Cultivar } & \multicolumn{7}{|c|}{ Concentration/values (mean \pm SD) } \\
\hline & TSS ( $\circ$ Brix) & TA (\%) & $\mathbf{L}^{*}$ & $a^{*}$ & $\mathbf{b}^{*}$ & $\mathrm{C}^{*}$ & $\mathbf{h}^{\circ}$ \\
\hline Goldita & $7.38 \pm 0.88$ & $0.45 \pm 0.11$ & $56.71 \pm 2.27$ & $7.48 \pm 1.47$ & $32.04 \pm 4.51$ & $35.25 \pm 7.53$ & $77.28 \pm 3.15$ \\
\hline Supersweet $100 \mathrm{~F} 1$ & $8.61 \pm 1.10$ & $0.46 \pm 0.11$ & $49.64 \pm 0.81$ & $16.99 \pm 2.20$ & $20.72 \pm 2.15$ & $29.13 \pm 7.53$ & $52.29 \pm 7.42$ \\
\hline Resi & $7.07 \pm 0.50$ & $0.42 \pm 0.08$ & $51.08 \pm 1.89$ & $18.74 \pm 3.44$ & $20.97 \pm 2.42$ & $30.61 \pm 7.49$ & $50.00 \pm 8.63$ \\
\hline Bartelly F1 & $7.68 \pm 0.62$ & $0.38 \pm 0.08$ & $49.47 \pm 0.50$ & $14.36 \pm 1.48$ & $19.61 \pm 1.33$ & $26.78 \pm 8.02$ & $55.34 \pm 7.20$ \\
\hline Benarys Gartenfreude & $8.38 \pm 0.59$ & $0.46 \pm 0.08$ & $49.76 \pm 0.51$ & $14.15 \pm 2.19$ & $19.54 \pm 1.52$ & $26.61 \pm 8.00$ & $55.83 \pm 7.49$ \\
\hline
\end{tabular}




\begin{tabular}{|c|c|c|c|c|c|c|c|}
\hline Primavera & $5.97 \pm 0.86$ & $0.31 \pm 0.07$ & $49.57 \pm 0.67$ & $12.72 \pm 1.63$ & $20.11 \pm 1.46$ & $26.28 \pm 8.13$ & $59.17 \pm 6.43$ \\
\hline Black Cherry & $7.17 \pm 0.51$ & $0.42 \pm 0.11$ & $47.89 \pm 0.90$ & $4.51 \pm 1.51$ & $9.60 \pm 0.60$ & $14.06 \pm 11.16$ & $66.52 \pm 9.40$ \\
\hline Sakura F1 & $7.94 \pm 0.51$ & $0.45 \pm 0.10$ & $49.40 \pm 0.99$ & $13.92 \pm 1.60$ & $20.78 \pm 1.34$ & $27.41 \pm 7.88$ & $57.48 \pm 6.77$ \\
\hline Primabella & $7.05 \pm 0.66$ & $0.44 \pm 0.10$ & $50.86 \pm 1.56$ & $19.73 \pm 1.47$ & $22.52 \pm 1.55$ & $32.08 \pm 7.62$ & $50.29 \pm 6.03$ \\
\hline TasteryF 1 & $6.81 \pm 0.62$ & $0.31 \pm 0.08$ & $51.52 \pm 0.89$ & $12.39 \pm 1.50$ & $22.30 \pm 1.29$ & $27.90 \pm 8.19$ & $62.43 \pm 5.00$ \\
\hline Annamay F1 & $6.48 \pm 0.75$ & $0.41 \pm 0.10$ & $50.92 \pm 0.47$ & $17.25 \pm 2.24$ & $22.17 \pm 1.86$ & $30.45 \pm 7.59$ & $53.76 \pm 7.28$ \\
\hline Amoroso F1 & $6.43 \pm 0.72$ & $0.39 \pm 0.09$ & $49.79 \pm 1.25$ & $13.70 \pm 2.00$ & $20.08 \pm 1.05$ & $26.70 \pm 8.34$ & $57.54 \pm 6.49$ \\
\hline Campari F1 & $6.19 \pm 0.47$ & $0.40 \pm 0.10$ & $50.25 \pm 1.39$ & $17.08 \pm 1.27$ & $22.58 \pm 1.02$ & $30.49 \pm 7.62$ & $54.76 \pm 5.58$ \\
\hline Auriga & $5.39 \pm 0.55$ & $0.44 \pm 0.10$ & $61.37 \pm 1.36$ & $13.08 \pm 1.95$ & $42.19 \pm 3.64$ & $45.93 \pm 6.32$ & $73.24 \pm 2.87$ \\
\hline Harzfeuer F1 & $5.57 \pm 0.55$ & $0.35 \pm 0.08$ & $50.64 \pm 1.31$ & $18.92 \pm 3.06$ & $23.56 \pm 2.74$ & $32.45 \pm 7.38$ & $52.99 \pm 6.41$ \\
\hline Roterno F1 & $4.69 \pm 0.46$ & $0.30 \pm 0.07$ & $53.02 \pm 0.60$ & $20.76 \pm 1.84$ & $26.08 \pm 2.61$ & $35.41 \pm 7.22$ & $52.92 \pm 5.80$ \\
\hline Lyterno F1 & $4.75 \pm 0.42$ & $0.29 \pm 0.06$ & $52.89 \pm 0.79$ & $18.71 \pm 1.96$ & $23.95 \pm 2.63$ & $32.61 \pm 7.92$ & $53.68 \pm 5.80$ \\
\hline Bocati F1 & $4.86 \pm 1.09$ & $0.31 \pm 0.07$ & $53.22 \pm 0.97$ & $23.01 \pm 2.28$ & $26.56 \pm 2.47$ & $37.10 \pm 7.27$ & $50.55 \pm 5.45$ \\
\hline Cappricia F1 & $4.39 \pm 0.45$ & $0.27 \pm 0.05$ & $53.24 \pm 0.83$ & $20.76 \pm 2.45$ & $26.23 \pm 2.89$ & $35.46 \pm 7.77$ & $53.03 \pm 5.27$ \\
\hline Green Zebra & $5.01 \pm 0.64$ & $0.50 \pm 0.15$ & $59.56 \pm 2.26$ & $-10.59 \pm 1.85$ & $36.59 \pm 2.80$ & $40.25 \pm 7.25$ & $105.73 \pm 3.39$ \\
\hline Overall mean \pm SD & $6.40 \pm 1.41$ & $0.39 \pm 0.11$ & $52.01 \pm 3.58$ & $14.49 \pm 7.33$ & $23.86 \pm 7.00$ & $31.11 \pm 9.84$ & $59.55 \pm 13.87$ \\
\hline CV (\%) & 10.54 & 23.80 & 2.35 & 14.20 & 9.61 & 25.25 & 10.58 \\
\hline HSD & 0.97 & 0.13 & 1.77 & 2.95 & 3.32 & 11.37 & 9.14 \\
\hline \multicolumn{8}{|l|}{ Year } \\
\hline 2015 & $6.01 \pm 1.31$ & $0.34 \pm 0.10$ & $52.15 \pm 3.98$ & $15.53 \pm 7.35$ & $24.45 \pm 7.52$ & $30.00 \pm 7.40$ & $56.87 \pm 13.34$ \\
\hline 2016 & $6.78 \pm 1.40$ & $0.43 \pm 0.10$ & $51.87 \pm 3.15$ & $13.46 \pm 7.20$ & $23.27 \pm 6.42$ & $32.21 \pm 11.71$ & $62.21 \pm 13.92$ \\
\hline \multicolumn{8}{|l|}{ Source of variation } \\
\hline Cultivar, C & $* * *$ & $* * *$ & $* * *$ & $* * *$ & $* * *$ & $* * *$ & ** \\
\hline Harvest, $\mathrm{H}$ & $* *$ & $* * *$ & $* * *$ & $* *$ & $* * *$ & $* * *$ & $* *$ \\
\hline year, Y & $* * *$ & $* * *$ & $* *$ & $* * *$ & $* * *$ & $*$ & $* *$ \\
\hline $\mathrm{C} \times \mathrm{H}$ & $* *$ & $* * *$ & $* *$ & $* * *$ & $* * *$ & ns & he \\
\hline $\mathrm{C} \times \mathrm{Y}$ & $* *$ & $* *$ & $* * *$ & $* * *$ & $* * *$ & ns & \\
\hline $\mathrm{C} \times \mathrm{H} \times \mathrm{Y}$ & ns & ns & $* *$ & $* * *$ & $* * *$ & ns & \\
\hline
\end{tabular}

The cultivars are arranged in ascending order according to their average single fruit weight; cocktail cultivars are indicated in italics; the others are salad cultivars. Mean values are given for each of the 20 cultivars as mean from both years and from each year \pm SD (standard deviation). TSS (total soluble solid); TA (titratable acid); color component: L*: lightness; $\mathrm{a}^{*}$ : red (+)/green $(-)$; $\mathrm{b}^{*}$ : yellow $(+) / \mathrm{blue}(-)$; $\mathrm{C}^{*}$ : chroma; h० (hue angle). CV, coefficient of variation; HSD, honestly significant difference at $\mathrm{P} \leq 0.05 ;$ ns, not significant. $* \mathrm{P} \leq 0.05,{ }^{*} * \mathrm{P} \leq 0.01,{ }^{*} * \mathrm{P} \leq 0.001$ 
Table S7. Breeder's sensory test of the 20 tomato cultivars over two harvest dates in 2015 by cultivar, $n=120$

\begin{tabular}{|c|c|c|c|c|c|c|c|}
\hline \multirow[t]{3}{*}{ Cultivar } & \multicolumn{7}{|c|}{ Breeder's sensory score $^{\mathrm{a}}($ mean \pm SD) } \\
\hline & \multirow{2}{*}{$\begin{array}{r}\text { Fruit } \\
\text { firmness }\end{array}$} & \multicolumn{3}{|c|}{ Skin } & \multicolumn{3}{|c|}{ Tomato } \\
\hline & & Juiciness & firmness & Sweetness & Sourness & typical-aroma & Acceptability \\
\hline Goldita & $3.83 \pm 0.89$ & $6.19 \pm 0.64$ & $6.58 \pm 0.44$ & $7.14 \pm 0.70$ & $6.11 \pm 0.27$ & $7.39 \pm 0.60$ & $7.33 \pm 0.60$ \\
\hline Supersweet $100 \mathrm{~F} 1$ & $3.67 \pm 0.94$ & $6.72 \pm 0.68$ & $6.08 \pm 0.71$ & $7.39 \pm 0.66$ & $5.86 \pm 0.52$ & $7.36 \pm 0.54$ & $7.39 \pm 0.61$ \\
\hline Resi & $2.81 \pm 1.00$ & $6.81 \pm 0.45$ & $6.47 \pm 0.79$ & $6.31 \pm 0.68$ & $6.00 \pm 0.41$ & $7.53 \pm 0.50$ & $5.92 \pm 0.65$ \\
\hline Bartelly F1 & $3.83 \pm 0.94$ & $5.47 \pm 0.99$ & $4.92 \pm 0.61$ & $6.92 \pm 0.48$ & $5.08 \pm 0.49$ & $6.67 \pm 0.69$ & $6.33 \pm 0.89$ \\
\hline Benarys Gartenfreude & $4.78 \pm 1.34$ & $5.00 \pm 0.52$ & $7.33 \pm 0.52$ & $7.03 \pm 0.78$ & $5.44 \pm 0.58$ & $6.56 \pm 0.69$ & $5.47 \pm 1.00$ \\
\hline Primavera & $3.92 \pm 0.42$ & $6.22 \pm 0.58$ & $5.33 \pm 0.77$ & $5.25 \pm 0.84$ & $5.25 \pm 0.67$ & $5.00 \pm 0.79$ & $4.56 \pm 1.00$ \\
\hline Black Cherry & $3.19 \pm 0.64$ & $6.56 \pm 0.47$ & $6.94 \pm 0.43$ & $6.75 \pm 0.44$ & $6.64 \pm 0.32$ & $7.69 \pm 0.31$ & $7.28 \pm 1.20$ \\
\hline SakuraF1 & $5.81 \pm 0.31$ & $6.44 \pm 0.33$ & $6.08 \pm 0.42$ & $7.50 \pm 0.45$ & $5.89 \pm 0.72$ & $7.19 \pm 0.48$ & $7.36 \pm 0.27$ \\
\hline Primabella & $6.06 \pm 0.46$ & $5.42 \pm 1.03$ & $5.67 \pm 0.24$ & $5.61 \pm 0.70$ & $6.19 \pm 1.13$ & $5.75 \pm 1.10$ & $5.11 \pm 1.00$ \\
\hline Tastery F1 & $8.08 \pm 0.35$ & $5.47 \pm 0.82$ & $5.00 \pm 1.07$ & $6.61 \pm 0.75$ & $4.19 \pm 1.04$ & $4.33 \pm 0.89$ & $5.00 \pm 0.82$ \\
\hline Annamay F1 & $5.89 \pm 0.98$ & $5.53 \pm 0.34$ & $4.67 \pm 0.81$ & $6.31 \pm 0.34$ & $5.33 \pm 0.94$ & $6.03 \pm 0.51$ & $6.33 \pm 0.61$ \\
\hline Amoroso F1 & $6.50 \pm 0.45$ & $5.75 \pm 0.33$ & $4.06 \pm 0.68$ & $5.86 \pm 0.52$ & $5.25 \pm 0.65$ & $5.33 \pm 0.79$ & $5.53 \pm 0.57$ \\
\hline Campari F1 & $4.58 \pm 0.57$ & $5.08 \pm 0.70$ & $5.78 \pm 0.74$ & $6.33 \pm 0.84$ & $5.00 \pm 0.67$ & $6.17 \pm 0.80$ & $6.17 \pm 0.68$ \\
\hline Auriga & $3.39 \pm 1.90$ & $5.28 \pm 2.62$ & $5.44 \pm 2.74$ & $4.50 \pm 2.28$ & $5.75 \pm 2.88$ & $5.58 \pm 2.76$ & $5.07 \pm 2.84$ \\
\hline Harzfeuer F1 & $4.44 \pm 0.91$ & $5.56 \pm 1.04$ & $6.31 \pm 0.75$ & $5.19 \pm 1.04$ & $4.78 \pm 0.94$ & $5.00 \pm 1.10$ & $4.28 \pm 1.06$ \\
\hline Roterno F1 & $6.17 \pm 0.77$ & $5.17 \pm 0.80$ & $3.56 \pm 0.83$ & $3.56 \pm 0.66$ & $3.19 \pm 0.56$ & $3.08 \pm 0.36$ & $2.64 \pm 0.58$ \\
\hline Lyterno F1 & $6.94 \pm 0.86$ & $4.97 \pm 0.48$ & $4.94 \pm 0.74$ & $3.28 \pm 0.65$ & $4.94 \pm 1.18$ & $3.44 \pm 0.58$ & $3.11 \pm 0.81$ \\
\hline Bocati F1 & $5.72 \pm 1.16$ & $5.28 \pm 0.43$ & $3.53 \pm 0.92$ & $2.75 \pm 0.36$ & $4.42 \pm 1.13$ & $2.86 \pm 0.80$ & $2.44 \pm 0.40$ \\
\hline Cappricia F1 & $6.81 \pm 0.76$ & $5.08 \pm 0.59$ & $3.83 \pm 0.69$ & $2.39 \pm 0.25$ & $3.61 \pm 1.18$ & $2.08 \pm 0.65$ & $1.94 \pm 0.57$ \\
\hline Green Zebra & $2.67 \pm 0.38$ & $6.89 \pm 0.54$ & $5.03 \pm 0.97$ & $4.94 \pm 0.56$ & $7.28 \pm 0.71$ & $6.75 \pm 0.36$ & $6.17 \pm 0.55$ \\
\hline mean $\pm \mathrm{SD}$ & $4.95 \pm 1.72$ & $5.74 \pm 1.02$ & $5.38 \pm 1.38$ & $5.58 \pm 1.71$ & $5.31 \pm 1.33$ & $5.59 \pm 1.85$ & $5.27 \pm 1.87$ \\
\hline $\mathrm{CV}(\%)$ & 17.89 & 15.13 & 17.34 & 14.51 & 18.99 & 16.41 & 17.92 \\
\hline HSD & 1.86 & 1.82 & 1.96 & 1.70 & 2.12 & 1.93 & 1.98 \\
\hline \multicolumn{8}{|l|}{ Source of variation } \\
\hline Cultivar, C & $* * *$ & $* * *$ & $* * *$ & $* * *$ & $* * *$ & $* * *$ & $* * *$ \\
\hline Harvest, H & ns & $*$ & ns & $* * *$ & $* * *$ & $* * *$ & $*$ \\
\hline $\mathrm{C} \times \mathrm{H}$ & $* *$ & $*$ & ns & ns & ns & ns & ns \\
\hline
\end{tabular}

The cultivars are arranged in ascending order according to their average single fruit weight; cocktail cultivars are indicated in italics; the others are salad cultivars. ${ }^{a}$ The breeder's sensory scoring was based on a 9-point scale where $1=$ minimum intensity and $9=$ maximum intensity; mean values are given for each of the 20 cultivars as mean from both years and from each year \pm SD (standard deviation). CV, coefficient of variation; HSD, honestly significant difference at $\mathrm{P} \leq 0.05$; ns, not significant. $* \mathrm{P} \leq 0.05, * * \mathrm{P} \leq 0.01, * * * \mathrm{P} \leq 0.001$ 
Table S8. Panel sensory test of the 20 tomato cultivars over two harvest dates in 2016 by cultivar, $n=120$

\begin{tabular}{|c|c|c|c|c|c|c|c|}
\hline \multirow[t]{3}{*}{ Cultivar } & \multicolumn{7}{|c|}{ Panel sensory score ${ }^{a}($ mean \pm SD) } \\
\hline & Fruit & & Skin & & & Tomato & \\
\hline & firmness & Juiciness & firmness & Sweetness & Sourness & typical-aroma & Acceptability \\
\hline Goldita & $28.37 \pm 4.25$ & $60.74 \pm 3.48$ & $58.58 \pm 2.86$ & $45.79 \pm 4.62$ & $49.80 \pm 4.76$ & $56.69 \pm 3.90$ & $48.17 \pm 8.86$ \\
\hline Supersweet $100 \mathrm{~F} 1$ & $29.44 \pm 8.04$ & $58.78 \pm 4.31$ & $54.32 \pm 4.36$ & $52.21 \pm 7.02$ & $45.40 \pm 3.96$ & $58.19 \pm 2.30$ & $56.08 \pm 3.22$ \\
\hline Resi & $30.71 \pm 4.43$ & $65.70 \pm 3.49$ & $53.77 \pm 4.34$ & $41.77 \pm 5.46$ & $48.51 \pm 5.61$ & $54.67 \pm 3.14$ & $45.08 \pm 4.71$ \\
\hline Bartelly F1 & $32.41 \pm 2.40$ & $57.51 \pm 3.92$ & $45.81 \pm 3.92$ & $48.36 \pm 4.17$ & $39.88 \pm 6.04$ & $57.47 \pm 3.73$ & $53.78 \pm 4.22$ \\
\hline Benarys Gartenfreude & $45.54 \pm 4.09$ & $58.79 \pm 5.96$ & $58.62 \pm 3.92$ & $45.08 \pm 3.05$ & $48.19 \pm 3.03$ & $52.09 \pm 1.80$ & $41.58 \pm 5.91$ \\
\hline Primavera & $26.09 \pm 3.29$ & $68.26 \pm 3.82$ & $50.12 \pm 4.60$ & $39.62 \pm 3.93$ & $37.31 \pm 4.73$ & $43.27 \pm 2.55$ & $33.38 \pm 3.59$ \\
\hline Black Cherry & $32.95 \pm 6.98$ & $64.76 \pm 3.18$ & $52.10 \pm 3.20$ & $40.38 \pm 4.08$ & $55.00 \pm 4.48$ & $55.68 \pm 3.66$ & $50.98 \pm 5.97$ \\
\hline SakuraF1 & $42.46 \pm 6.05$ & $61.37 \pm 1.89$ & $49.65 \pm 5.14$ & $46.42 \pm 4.89$ & $48.66 \pm 5.82$ & $57.65 \pm 2.30$ & $56.87 \pm 3.91$ \\
\hline Primabella & $50.04 \pm 7.07$ & $63.79 \pm 2.85$ & $43.62 \pm 1.97$ & $36.07 \pm 4.85$ & $51.29 \pm 5.40$ & $50.52 \pm 5.35$ & $43.84 \pm 5.00$ \\
\hline Tastery F1 & $78.76 \pm 2.98$ & $59.98 \pm 4.05$ & $43.30 \pm 1.70$ & $49.13 \pm 3.90$ & $28.04 \pm 2.46$ & $40.53 \pm 2.47$ & $45.12 \pm 2.91$ \\
\hline Annamay F1 & $54.85 \pm 5.36$ & $60.57 \pm 3.36$ & $45.93 \pm 3.40$ & $39.50 \pm 4.98$ & $46.92 \pm 6.07$ & $52.80 \pm 6.17$ & $49.38 \pm 7.96$ \\
\hline Amoroso F1 & $54.92 \pm 3.70$ & $60.32 \pm 2.15$ & $39.10 \pm 2.55$ & $44.28 \pm 6.21$ & $39.60 \pm 5.85$ & $50.79 \pm 3.08$ & $51.89 \pm 6.55$ \\
\hline Campari F1 & $42.86 \pm 2.27$ & $59.87 \pm 3.08$ & $45.37 \pm 2.54$ & $35.23 \pm 3.78$ & $43.44 \pm 3.23$ & $46.48 \pm 3.50$ & $44.27 \pm 3.47$ \\
\hline Auriga & $29.00 \pm 3.48$ & $64.08 \pm 2.34$ & $56.66 \pm 3.96$ & $30.83 \pm 4.41$ & $56.78 \pm 2.40$ & $45.06 \pm 5.83$ & $33.23 \pm 9.14$ \\
\hline Harzfeuer F1 & $32.88 \pm 6.72$ & $58.00 \pm 4.97$ & $50.77 \pm 5.31$ & $29.80 \pm 6.76$ & $36.91 \pm 2.47$ & $38.86 \pm 6.25$ & $26.40 \pm 9.07$ \\
\hline Roterno F1 & $58.57 \pm 4.87$ & $61.06 \pm 2.78$ & $34.35 \pm 3.86$ & $20.79 \pm 4.10$ & $25.85 \pm 2.73$ & $28.41 \pm 4.08$ & $25.43 \pm 4.62$ \\
\hline Lyterno F1 & $63.35 \pm 4.40$ & $58.33 \pm 3.68$ & $38.94 \pm 3.83$ & $20.73 \pm 3.10$ & $32.25 \pm 3.05$ & $32.77 \pm 1.74$ & $27.78 \pm 2.89$ \\
\hline Bocati F1 & $56.76 \pm 3.28$ & $61.48 \pm 3.20$ & $37.80 \pm 4.78$ & $20.69 \pm 4.88$ & $30.63 \pm 2.18$ & $29.64 \pm 3.90$ & $23.63 \pm 5.17$ \\
\hline Cappricia F1 & $62.50 \pm 1.88$ & $56.80 \pm 0.93$ & $35.48 \pm 3.47$ & $17.62 \pm 2.34$ & $32.26 \pm 3.08$ & $26.10 \pm 4.65$ & $22.52 \pm 3.75$ \\
\hline Green Zebra & $26.08 \pm 4.95$ & $72.46 \pm 3.62$ & $41.52 \pm 5.29$ & $29.58 \pm 1.57$ & $61.22 \pm 9.97$ & $53.94 \pm 3.86$ & $47.13 \pm 2.90$ \\
\hline mean $\pm \mathrm{SD}$ & $43.93 \pm 15.63$ & $61.63 \pm 4.99$ & $46.79 \pm 8.20$ & $36.69 \pm 11.24$ & $42.90 \pm 10.67$ & $46.58 \pm 10.95$ & $41.33 \pm 12.26$ \\
\hline CV (\%) & 10.99 & 5.71 & 8.31 & 12.53 & 11.07 & 8.48 & 13.51 \\
\hline HSD & 10.14 & 7.38 & 8.16 & 9.65 & 9.97 & 8.28 & 11.72 \\
\hline \multicolumn{8}{|l|}{ Source of variation } \\
\hline Cultivar, C & $* * *$ & $* * *$ & $* * *$ & $* * *$ & $* * *$ & $* * *$ & $* * *$ \\
\hline Harvest, $\mathrm{H}$ & $* *$ & ns & $* * *$ & ns & $* * *$ & ns & ns \\
\hline $\mathrm{C} \times \mathrm{H}$ & $\mathrm{ns}$ & $*$ & ns & ns & $* *$ & $* *$ & * \\
\hline
\end{tabular}

The cultivars are arranged in ascending order according to their average single fruit weight; cocktail cultivars are indicated in italics; the others are salad cultivars. ${ }^{a}$ the panel was rated based on a 0 to 100 sensory perceptible scale $(0=$ not perceptible and $100=$ highly perceptible). Mean values are given for each of the 20 cultivars as mean from both years and from each year \pm SD (standard deviation). $\mathrm{CV}$, coefficient of variation; HSD, honestly significant difference at $\mathrm{P} \leq 0.05 ; \mathrm{ns}$, not significant. $\mathrm{P} \leq 0.05, * * \mathrm{P} \leq 0.01, * * * \mathrm{P} \leq 0.001$ 
Table S9. Correlation coefficients, between and within, VOCs in the 20 cultivars over two harvest dates and two years, $n=240$

\begin{tabular}{|c|c|c|c|c|c|c|c|c|c|}
\hline VOCs & $\begin{array}{r}(E)-2- \\
\text { hexenal }\end{array}$ & octanal & $\begin{array}{r}\text { 6-methyl-5- } \\
\text { hepten-2-one }\end{array}$ & 1-hexanol & $\begin{array}{r}(Z)-3- \\
\text { hexen-1-ol }\end{array}$ & $\begin{array}{l}\text { 6-methyl-5- } \\
\text { hepten-2-ol }\end{array}$ & $\begin{array}{r}\text { 2-ethyl-1- } \\
\text { hexanol }\end{array}$ & benzaldehyde & $\beta$-cyclocitral \\
\hline (E)-2-hexenal & 1.00 & & & & & & & & \\
\hline octanal & -0.06 & 1.00 & & & & & & & \\
\hline 6-methyl-5-hepten-2-one & -0.22 & -0.03 & 1.00 & & & & & & \\
\hline 1-hexanol & 0.03 & 0.01 & 0.06 & 1.00 & & & & & \\
\hline (Z)-3-hexen1-ol & 0.39 & 0.30 & 0.00 & $0.69 * *$ & 1.00 & & & & \\
\hline 6-methyl-5-hepten-2-ol & -0.40 & 0.19 & -0.18 & -0.44 & $-0.50^{*}$ & 1.00 & & & \\
\hline 2-ethyl-1-hexanol & 0.22 & $0.69 * *$ & $-0.45^{*}$ & 0.00 & 0.27 & -0.04 & 1.00 & & \\
\hline benzaldehyde & 0.12 & -0.10 & 0.08 & -0.12 & -0.08 & -0.10 & -0.24 & 1.00 & \\
\hline$\beta$-cyclocitral & 0.19 & 0.05 & -0.34 & 0.03 & 0.42 & -0.32 & 0.20 & 0.40 & 1.00 \\
\hline 3-methyl-butanoic acid & -0.23 & $-0.57 * *$ & 0.22 & -0.17 & $-0.45^{*}$ & 0.09 & $-0.66^{* *}$ & 0.38 & 0.04 \\
\hline geranial & -0.34 & $0.62 * *$ & 0.07 & -0.27 & -0.12 & $0.59 * *$ & 0.21 & -0.20 & -0.21 \\
\hline methyl salicylate & -0.07 & 0.00 & -0.28 & 0.09 & 0.09 & 0.01 & 0.15 & -0.10 & 0.06 \\
\hline geranial & 0.04 & 0.28 & -0.18 & 0.11 & 0.25 & 0.12 & 0.43 & -0.37 & -0.17 \\
\hline 2-methyl-propanoic acid & 0.26 & 0.34 & $-0.54 *$ & -0.14 & 0.15 & -0.14 & $0.55^{*}$ & 0.42 & $0.63 * *$ \\
\hline benzyl alcohol & $0.53 *$ & 0.02 & -0.10 & 0.07 & 0.30 & -0.17 & 0.25 & -0.14 & -0.10 \\
\hline phenylethyl alcohol & $0.62 * *$ & 0.06 & -0.05 & -0.16 & 0.25 & -0.22 & 0.16 & -0.02 & -0.07 \\
\hline$\beta$-ionone & 0.13 & 0.16 & -0.38 & 0.05 & $0.45^{*}$ & -0.30 & 0.32 & 0.31 & $0.98^{* *}$ \\
\hline eugenol & -0.16 & 0.10 & $-0.53 *$ & -0.15 & -0.14 & 0.26 & 0.16 & -0.05 & 0.07 \\
\hline farnesyl acetone & 0.10 & -0.22 & 0.01 & 0.07 & 0.36 & -0.20 & -0.21 & 0.33 & $0.71 * *$ \\
\hline octanoic acid & 0.17 & 0.34 & 0.12 & -0.19 & 0.16 & 0.04 & 0.01 & $0.72 * *$ & $0.47^{*}$ \\
\hline nonanoic acid & 0.07 & $-0.62 *$ & -0.10 & -0.03 & -0.14 & 0.06 & $-0.45^{*}$ & 0.37 & 0.12 \\
\hline
\end{tabular}

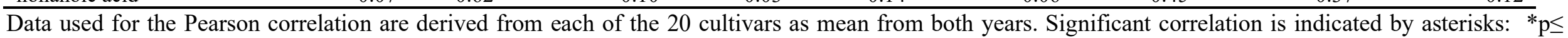

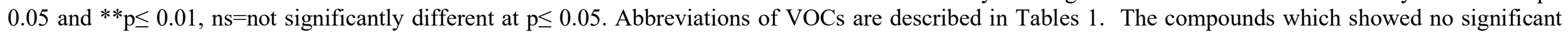
correlations with other VOCs were not included in the Pearson correlation table 
Table S9. Continue

\begin{tabular}{|c|c|c|c|c|c|c|c|c|c|c|}
\hline VOCs & $\begin{array}{r}\text { 3-methyl- } \\
\text { butanoic acid }\end{array}$ & geranial & $\begin{array}{r}\text { methyl } \\
\text { salicylate }\end{array}$ & geranial & $\begin{array}{r}\text { 2-methyl- } \\
\text { propanoic acid }\end{array}$ & benzyl alcohol & $\begin{array}{r}\text { phenylethyl } \\
\text { alcohol }\end{array}$ & $\beta$-ionone & eugenol & $\begin{array}{r}\text { farnesyl } \\
\text { acetone } \\
\end{array}$ \\
\hline 3-methyl-butanoic acid & 1.00 & & & & & & & & & \\
\hline geranial & -0.22 & 1.00 & & & & & & & & \\
\hline methyl salicylate & -0.08 & 0.19 & 1.00 & & & & & & & \\
\hline geranial & $-0.50^{*}$ & -0.01 & -0.03 & 1.00 & & & & & & \\
\hline 2-methyl-propanoic acid & -0.29 & -0.03 & 0.16 & -0.05 & 1.00 & & & & & \\
\hline benzyl alcohol & -0.39 & -0.30 & -0.28 & $0.73 * *$ & 0.07 & 1.00 & & & & \\
\hline phenylethyl alcohol & -0.41 & -0.20 & -0.29 & $0.54 *$ & 0.05 & $0.83 * *$ & 1.00 & & & \\
\hline$\beta$-ionone & -0.09 & -0.11 & 0.11 & -0.07 & $0.65 * *$ & -0.09 & -0.07 & 1.00 & & \\
\hline eugenol & -0.10 & 0.31 & $0.71 * *$ & -0.11 & 0.28 & -0.44 & -0.27 & 0.15 & 1.00 & \\
\hline farnesyl acetone & 0.29 & -0.29 & -0.12 & 0.10 & 0.10 & 0.16 & 0.10 & $0.65 * *$ & -0.29 & 1.00 \\
\hline octanoic acid & 0.11 & 0.19 & -0.21 & -0.27 & $0.51 *$ & -0.12 & 0.04 & 0.41 & -0.11 & 0.36 \\
\hline nonanoic acid & $0.56^{* *}$ & -0.42 & 0.39 & -0.26 & -0.07 & -0.27 & -0.24 & 0.01 & 0.32 & 0.24 \\
\hline
\end{tabular}

Data used for the Pearson correlation are derived from each of the 20 cultivars as mean from both years. Significant correlation is indicated by asterisks: ${ }^{*} \mathrm{p} \leq$ 0.05 and ${ }^{* *} p \leq 0.01$, ns $=$ not significantly different at $p \leq 0.05$. The VOCs which showed no significant correlations with other VOCs were not included in the Pearson correlation table 
Table S10. Correlation coefficients between and within VOCs, instrumental and sensory traits in the 20 cultivars over two harvest dates and two years

VOCs Instrumental parameters

\begin{tabular}{|c|c|c|c|c|c|c|c|c|c|c|c|c|c|c|}
\hline & & & & & & & & \\
\hline & TSS & TA & $\mathrm{L}^{*}$ & $a^{*}$ & $b^{*}$ & $\mathrm{C}^{*}$ & $\mathrm{~h}^{\circ}$ & $\begin{array}{l}\text { Fruit } \\
\text { firmness }\end{array}$ & Juiciness & $\begin{array}{l}\text { Skin } \\
\text { firmness }\end{array}$ & $\begin{array}{l}\text { Sweetnes } \\
\text { S }\end{array}$ & Sourness & $\begin{array}{l}\text { Tomato } \\
\text { typical- } \\
\text { aroma }\end{array}$ & $\begin{array}{l}\text { Accept } \\
\text { ability }\end{array}$ \\
\hline (E)-2-hexenal & $0.59 * *$ & $0.54^{*}$ & -0.10 & -0.33 & -0.03 & -0.18 & 0.23 & $-0.49^{*}$ & 0.12 & $0.48^{*}$ & $0.64 * *$ & $0.50^{*}$ & $0.67^{* *}$ & $0.69 * *$ \\
\hline octanal & 0.00 & $-0.45^{*}$ & -0.35 & 0.23 & -0.32 & -0.33 & -0.30 & 0.34 & $-0.50 *$ & -0.04 & 0.11 & $-0.51 *$ & -0.22 & -0.07 \\
\hline 1-hexanol & 0.31 & 0.22 & -0.19 & -0.12 & -0.20 & -0.29 & 0.02 & $-0.49 *$ & 0.38 & $0.65 * *$ & 0.39 & 0.26 & 0.33 & 0.12 \\
\hline (Z)-3-hexen1-ol & $0.54 *$ & 0.27 & -0.15 & 0.04 & -0.08 & -0.17 & -0.09 & -0.39 & 0.00 & $0.80 * *$ & $0.58 * *$ & 0.20 & 0.37 & 0.26 \\
\hline 2-isobutylthiazole & $-0.68 * *$ & -0.41 & 0.16 & 0.31 & 0.22 & 0.37 & -0.17 & 0.34 & -0.03 & $-0.61 * *$ & $-0.69 * *$ & -0.31 & $-0.55^{*}$ & $-0.49 *$ \\
\hline 6-methyl-5-hepten-2-ol & $-0.52 *$ & $-0.56^{*}$ & -0.11 & $0.51 *$ & -0.12 & 0.07 & -0.42 & 0.44 & $-0.45^{*}$ & $0.52 *$ & $-0.69 * *$ & $-0.48^{*}$ & $-0.64 * *$ & $-0.59 * *$ \\
\hline 3-methyl-butanoic acid & $-0.45^{*}$ & 0.13 & 0.44 & -0.09 & 0.39 & $0.47 *$ & 0.21 & -0.25 & 0.36 & -0.18 & $-0.50^{*}$ & 0.28 & -0.15 & -0.29 \\
\hline geranial & -0.08 & $-0.60 * *$ & $-0.53 *$ & $0.58 * *$ & $0.51^{*}$ & -0.34 & $-0.66 * *$ & $0.63 * *$ & $-0.67 * *$ & -0.30 & -0.19 & $-0.68 * *$ & $-0.47 *$ & -0.35 \\
\hline citral & $0.64 * *$ & 0.08 & $-0.67 * *$ & 0.34 & $-0.60 * *$ & $-0.53 *$ & $-0.54^{*}$ & -0.11 & -0.25 & 0.35 & $0.55^{*}$ & -0.07 & 0.37 & 0.35 \\
\hline benzyl alcohol & $0.51 *$ & 0.40 & 0.10 & -0.24 & 0.08 & -0.05 & 0.24 & -0.43 & -0.06 & $0.49 *$ & $0.49 *$ & 0.29 & $0.52 *$ & $0.49 *$ \\
\hline phenylethyl alcohol & $0.63 * *$ & 0.41 & -0.10 & -0.04 & -0.03 & -0.09 & 0.00 & -0.27 & -0.25 & 0.31 & $0.6^{* *}$ & 0.20 & $0.56^{* *}$ & $0.63 * *$ \\
\hline eugenol & -0.24 & -0.41 & -0.10 & 0.28 & -0.07 & 0.01 & -0.24 & $0.55^{*}$ & -0.21 & -0.39 & -0.15 & -0.40 & -0.36 & -0.22 \\
\hline farnesyl acetone & 0.01 & 0.21 & $0.51 *$ & 0.18 & $0.55^{*}$ & $0.53 *$ & 0.02 & -0.27 & -0.13 & 0.42 & -0.07 & 0.25 & -0.01 & -0.16 \\
\hline nonanoic acid & -0.35 & 0.25 & $0.5^{*}$ & -0.16 & $0.54^{*}$ & $0.57 * *$ & 0.33 & -0.22 & 0.33 & -0.06 & -0.37 & 0.33 & -0.11 & -0.24 \\
\hline
\end{tabular}

Data used for the Pearson correlation are derived from each of the 20 cultivars as mean from both years. Significant correlation is indicated by asterisks: ${ }^{*} \mathrm{p} \leq$

0.05 and ${ }^{* *} p \leq 0.01$, ns $=$ not significantly different at $\mathrm{p} \leq 0.05$. VOCs: volatile organic compounds; TSS (total soluble solid); TA (titratable acid); color attributes: color parameters: $L^{*}$ : lightness coordinate; $a^{*}$ : red $(+) /$ green $(-)$; $b^{*}$ : yellow $(+) / b l u e ~(-) ; C^{*}$ : chroma; h॰ (hue angle). The compounds which showed no significant correlations with other attributes were not included in the Pearson correlation table 
Table S11. Result of Principal component analysis (PCA) on the VOCs, instrumental and sensory traits of each of the 20 cultivars as mean from both years showing the scores on the significant principal component (PC)

\begin{tabular}{lrrrr}
\hline Cultivar & PC 1 & \multicolumn{1}{c}{ PC 2 } & \multicolumn{1}{c}{ PC 3 } & \multicolumn{1}{c}{ PC 4 } \\
\hline Goldita & $\mathbf{- 4 . 7 1 2 0 8}$ & 1.18978 & 1.48795 & -2.24906 \\
Supersweet 100 F1 & $\mathbf{- 4 . 7 6 6 4 2}$ & -0.27465 & 2.63385 & 2.89370 \\
Resi & -2.18701 & 0.11594 & $\mathbf{- 3 . 8 7 9 9 4}$ & 1.70876 \\
Bartelly F1 & -2.41541 & -0.91176 & 0.58109 & 0.45502 \\
Benarys Gartenfreude & -3.66397 & -1.80679 & -1.88391 & 2.37462 \\
Primavera & -1.81006 & -1.59013 & 0.64042 & -2.24474 \\
Black Cherry & -2.74993 & -1.12863 & -1.41632 & -1.05258 \\
SakuraF1 & -2.96401 & 0.32036 & 1.27924 & 0.91447 \\
Primabella & -0.22770 & -0.00075 & -2.97668 & -1.95256 \\
TasteryF1 & 0.36356 & -3.75713 & 2.15633 & $\mathbf{- 5 . 1 2 2 5 5}$ \\
Annamay F1 & -0.83434 & -1.07934 & -0.78042 & 0.87639 \\
Amoroso F1 & -0.79199 & -1.15137 & 0.82433 & 0.37389 \\
Campari F1 & 1.42009 & -0.63559 & 0.67651 & 1.15320 \\
Auriga & 1.52762 & $\mathbf{7 . 9 6 7 6 6}$ & $\mathbf{4 . 5 8 9 2 0}$ & 0.13958 \\
Harzfeuer F1 & 2.46159 & -0.09306 & 0.51408 & 1.16976 \\
Roterno F1 & $\mathbf{5 . 3 2 6 5 7}$ & -1.20887 & -1.51708 & 0.84413 \\
Lyterno F1 & $\mathbf{5 . 0 5 1 5 4}$ & -1.97738 & 2.15305 & 1.19421 \\
Bocati F1 & $\mathbf{5 . 1 2 7 7 8}$ & -0.36653 & -1.49632 & -0.77666 \\
Cappricia F1 & $\mathbf{5 . 3 1 8 2 6}$ & -0.98659 & 0.56130 & 0.83882 \\
Green Zebra & 0.52592 & $\mathbf{7 . 3 7 4 8 3}$ & $\mathbf{- 4 . 1 4 6 6 8}$ & -1.53840 \\
Total variance (\%) & 23.94 & 17.26 & 10.92 & 7.86 \\
\hline Data used for PCA & are & derived for & each & \\
\hline
\end{tabular}

Data used for PCA are derived for each of the 20 cultivars as mean from both years. The percentage variance accounted for by each principal component (PC). Tomato cultivars in each principal component, in proportion to the magnitude of their variation value (bold numeric), are independent from the tomato cultivars in the other principal component. Tomato cultivars in the same principal component are related to each other, according to positive and negative variation

Table S12. Loading scores for principal component analysis of volatiles of 20 tomato cultivars

\begin{tabular}{lrrrr}
\hline \multirow{2}{*}{ VOCs } & \multicolumn{4}{c}{ Principal component $\mathbf{( P C )}$} \\
\cline { 2 - 5 } & \multicolumn{1}{c}{ PC 1 } & PC 2 & PC 3 & PC 4 \\
\hline hexanal & 0.01 & -0.26 & -0.47 & $\mathbf{- 0 . 5 3}$ \\
mebuOAc & -0.15 & 0.03 & -0.40 & 0.22 \\
hexenal & $\mathbf{- 0 . 6 3}$ & 0.25 & 0.35 & -0.06 \\
octanal & 0.05 & -0.56 & $\mathbf{0 . 5 6}$ & 0.11 \\
meheptone & -0.11 & 0.12 & -0.38 & $\mathbf{0 . 6 4}$ \\
hexanol & -0.49 & -0.04 & -0.17 & -0.14 \\
hexenol & $\mathbf{- 0 . 6 0}$ & -0.05 & 0.43 & 0.00 \\
isobut & $\mathbf{0 . 7 4}$ & 0.08 & -0.05 & 0.12 \\
meheptenol & $\mathbf{0 . 6 9}$ & -0.32 & -0.03 & 0.18 \\
ethexanol & -0.05 & -0.33 & $\mathbf{0 . 6 1}$ & -0.49 \\
benzald & 0.19 & $\mathbf{0 . 5 1}$ & 0.30 & 0.36 \\
linalool & 0.28 & 0.20 & 0.34 & 0.33 \\
meheptdione & 0.13 & -0.05 & -0.05 & 0.21 \\
cyclocit & 0.05 & 0.35 & $\mathbf{0 . 7 0}$ & -0.05 \\
mebutacid & 0.38 & $\mathbf{0 . 5 9}$ & -0.45 & 0.25 \\
terpineol & -0.10 & -0.07 & 0.04 & 0.13 \\
geranial & 0.37 & -0.75 & 0.13 & 0.28 \\
citral & -0.53 & -0.55 & 0.00 & 0.39 \\
deca & -0.29 & -0.18 & -0.17 & 0.31 \\
meOSal & 0.26 & -0.15 & 0.03 & $\mathbf{- 0 . 5 6}$ \\
damasc & 0.00 & $\mathbf{0 . 5 7}$ & 0.33 & 0.23 \\
gera & -0.21 & -0.16 & 0.28 & -0.25 \\
mepropacid & 0.04 & 0.11 & $\mathbf{0 . 7 5}$ & -0.31 \\
benzylalc & $\mathbf{0 . 5 9}$ & 0.12 & 0.29 & -0.06 \\
& & & &
\end{tabular}




\begin{tabular}{lrrrr} 
phenylet & $\mathbf{- 0 . 5 9}$ & 0.00 & 0.34 & 0.11 \\
ionone & 0.06 & 0.21 & $\mathbf{0 . 7 4}$ & -0.13 \\
eugenol & 0.42 & -0.30 & 0.08 & -0.48 \\
farnesylac & -0.03 & $\mathbf{0 . 5 1}$ & 0.42 & 0.26 \\
octacid & 0.11 & 0.20 & 0.57 & $\mathbf{0 . 5 5}$ \\
nonacid & 0.31 & $\mathbf{0 . 6 3}$ & -0.21 & -0.17 \\
TSS & $\mathbf{- 0 . 9 1}$ & -0.22 & 0.03 & 0.12 \\
TA & -0.70 & $\mathbf{0 . 5 6}$ & -0.20 & 0.15 \\
L* & 0.30 & $\mathbf{0 . 8 2}$ & 0.13 & -0.22 \\
a* & 0.37 & -0.53 & 0.19 & 0.38 \\
b $^{*}$ & 0.32 & $\mathbf{0 . 7 9}$ & 0.20 & -0.14 \\
C* & 0.49 & $\mathbf{0 . 6 7}$ & 0.12 & 0.01 \\
h & -0.16 & $\mathbf{0 . 7 2}$ & -0.09 & -0.41 \\
fruit firmness & 0.55 & -0.56 & 0.09 & -0.19 \\
juiceness & -0.24 & $\mathbf{0 . 5 5}$ & -0.46 & -0.36 \\
skin firmness & -0.77 & 0.21 & 0.16 & 0.13 \\
sweet & $\mathbf{- 0 . 9 2}$ & -0.17 & 0.14 & -0.08 \\
sour & -0.60 & $\mathbf{0 . 6 6}$ & -0.22 & 0.05 \\
aroma & $\mathbf{- 0 . 9 2}$ & 0.22 & -0.11 & 0.07 \\
accept & $\mathbf{- 0 . 8 5}$ & 0.08 & 0.01 & -0.02 \\
Cocktail cultivar (fruit type) & -0.84 & -0.37 & -0.06 & -0.17 \\
Salad cultivar (fruit type) & 0.84 & 0.37 & 0.06 & 0.17 \\
\hline Total variance (\%) & 23.94 & 17.26 & 10.92 & 7.86 \\
\hline
\end{tabular}

The percentage variance accounted for by each principal component (PC). The variables in each principal component, in proportion to the magnitude of their variation value (bold numeric), are independent from the variables in the other principal component. Variables in the same principal component are related to each other, according to positive and negative variation 